\title{
CATálogo de CARTAS NÁUticas DE LOS OCÉANOS Y COSTAS DE COLOMBIA
}

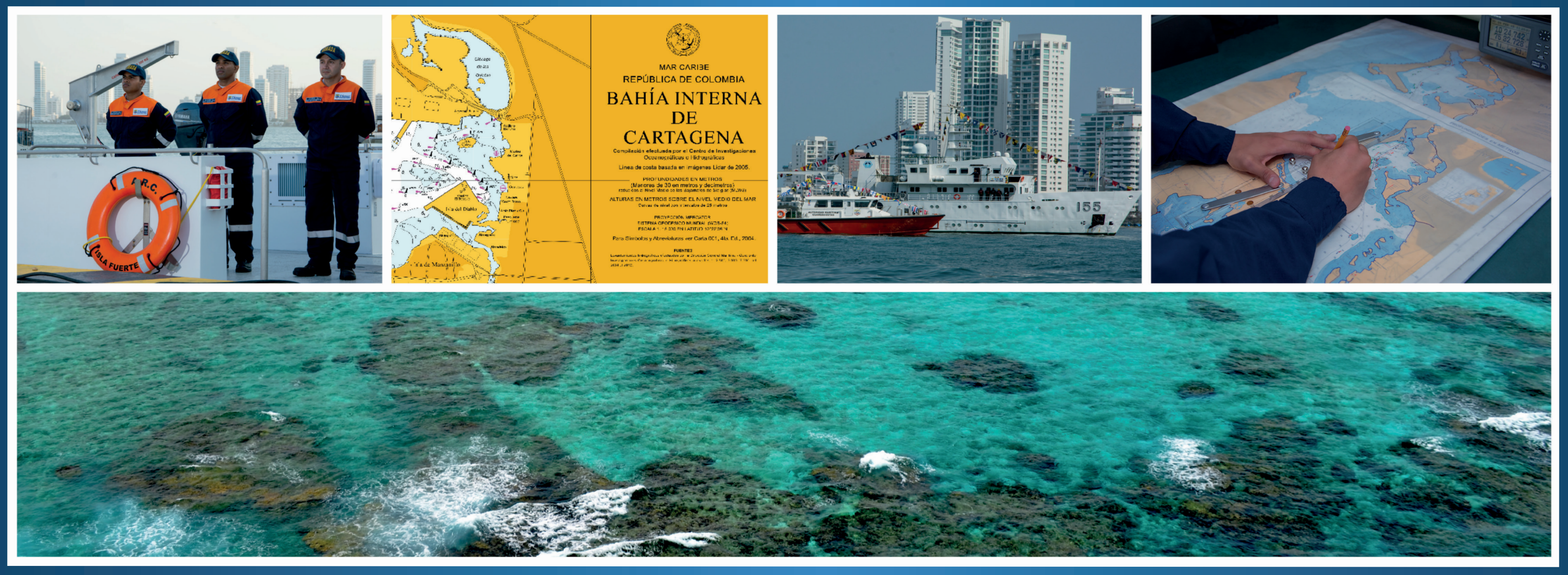

(3) Dlmar (0)=

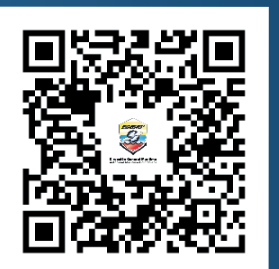




\title{
Catálogo de CARTAS Náuticas
}

\author{
de Los OCÉanos y COSTAS de Colombia
}




\section{CATÁlOgO dE LAS CARTAS NÁUtiCAS dE LOS OCÉANOS Y COSTAS DE COLOMBIA}

Vicealmirante Pablo Emilio Romero Rojas

Director General Marítimo

Capitán de Navío Esteban Uribe Alzate

Coordinador General Dimar

Capitán de Navío Alex Fernando Ferrero Ronquillo

Director Centro de Investigaciones Oceanográficas e Hidrográficas del Caribe (Dimar-ClOH)

AUTORES

Capitán de Corbeta Gustavo Adolfo Gutiérrez Leones

Jefe Área de Hidrografía CIOH-Servicio Hidrográfico Nacional (SHN)

Suboficial Jefe Carlos Alberto Zúñiga Guzmán

Responsable Sección Náutica CIOH-SHN

Suboficial Segundo Juan David Ortiz Buitrago

Jefe Grupo de Actualización Cartográfica y Avisos a los Navegantes CIOH-SHN

Suboficial Jefe Rafael Orozco

Jefe Sección de Levantamientos ClOH-SHN

Olga Bonfante Lozada

Jefe Sección Cartografía CIOH-SHN

Mario José Tapias Avilez

Cartógrafo CIOH-SHN

Ludis Castro Buendía

Cartógrafa ClOH-SHN

Lorena Bonfante Lozada

Cartógrafa ClOH-SHN

David Fernández

Cartógrafo ClOH-SHN
Wilmer Díaz Padilla

Responsable Mapoteca CIOH-SHN

Concepto Gráfico y Diseño

Carlos Alberto Giraldo Lipeda

Ingeniero de Sistemas Sección Náutica CIOH-SHN

Revisión TéCNICA

Capitán de Corbeta Javier Enrique Gómez Torres

Hidrógrafo Categoría A

Jefe Técnico (RA) Dagoberto Uriel David Viteri

Hidrógrafo Clase B OHI FIG/AC

\section{Coordinación Editorial}

Angélica María Castrillón Gálvez

Editora de Publicaciones Dim

Gina Alexandra Bustos Luna

Corresponsal del Caribe ClOH-Dimar

Fotografía

Archivo Fotográfico Dimar

EDITORIAL

Dimar

Edición Quinta

IMPRESIÓN

JCP Impresores S.A.S

ISBN Impreso: 978-958-58978-3-0

ISBN e-book: 978-958-58978-4-7

CATÁLOGO DE LAS CARTAS NÁUTICAS DE LOS OCÉANOS Y COSTAS DE COLOMBIA es una publicación de Dimar está bajo una licencia de Creative Commons Reconocimiento-No Comercial-Compartir Igual 4.0 Internacional.

\section{CITAR ESTA OBRA COMO:}

Dimar-CIOH-SHN. (2016). Catálogo deCartas Náuticas de losOcéanos yCostas deColombia (5a edición) (Formatos impreso y digital). Dirección General Marítima-Centro de Investigaciones

Oceanográficas e Hidrográficas del Caribe-Servicio Hidrográfico Nacional. Bogotá, D.C., Colombia: editorial Dimar.

EL CATÁLOGO DE LASCARTAS NÁUTICAS DE LOS OCÉANOS Y COSTAS DE COLOMBIA es una publicación en Hidrografía, dirigida a la comunidad científica, técnica, la academia del ámbito global y, de manera especial, a los navegantes y al gremio marítimo. Realizada por Dimar-CIOH-SHN. Su edición cuenta con el ISBN 978-958-58978-3-0 para formato impreso y el ISBN 978-958-58978-4-7 para e-book, que permite la visualización de la cartografía yáutica colombina oficial de manera previa a su adquisición. Este producto intelectual está protegido por el Copyrigth O y cuenta con una política de acceso abierto para su consulta sus condiciones de uso y distribución están definidas por el licenciamiento Creative Commons@.

\section{ADVERTENCIAS}

1. Las cartas presentadas en esta publicación no son aptas para la navegación.

2. La escala indicada en las imágenes corresponden a la original de las cartas. 


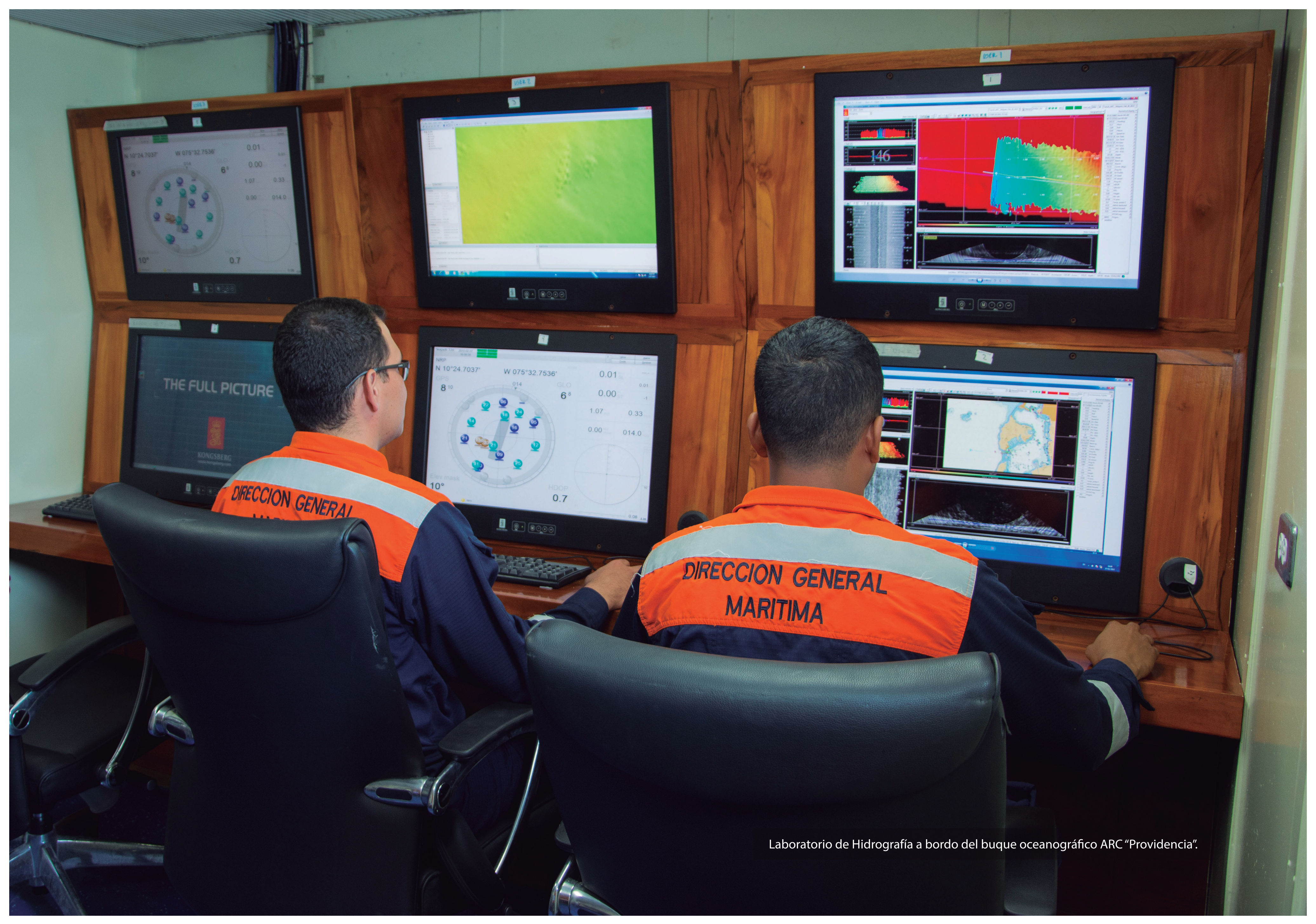




\section{Registro de Correcciones de Avisos Publicados que Afectan el Catálogo}
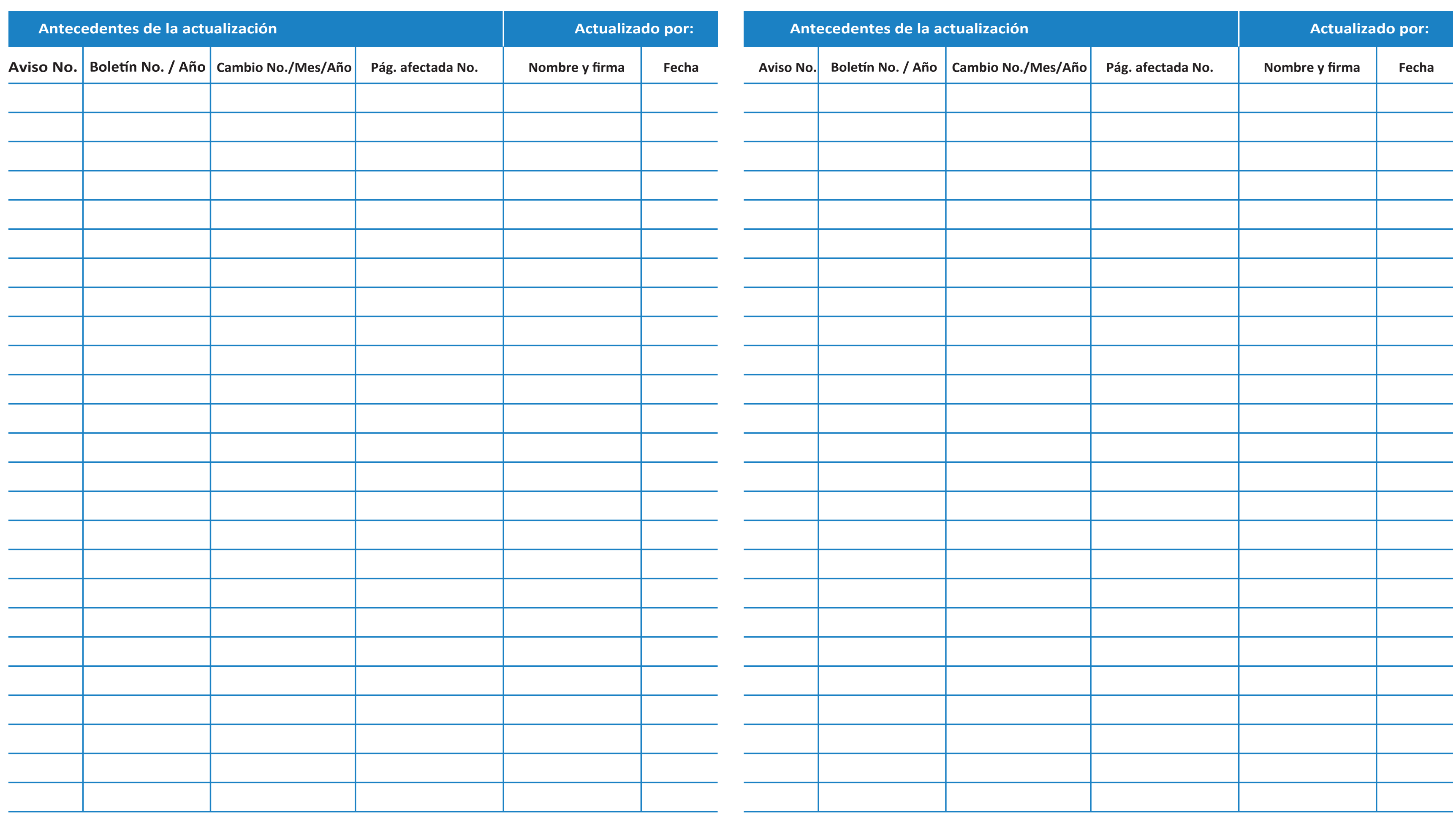

Dimar

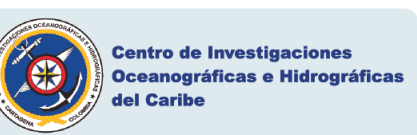




\section{Registro de Correcciones de Avisos Publicados que Afectan el Catálogo}
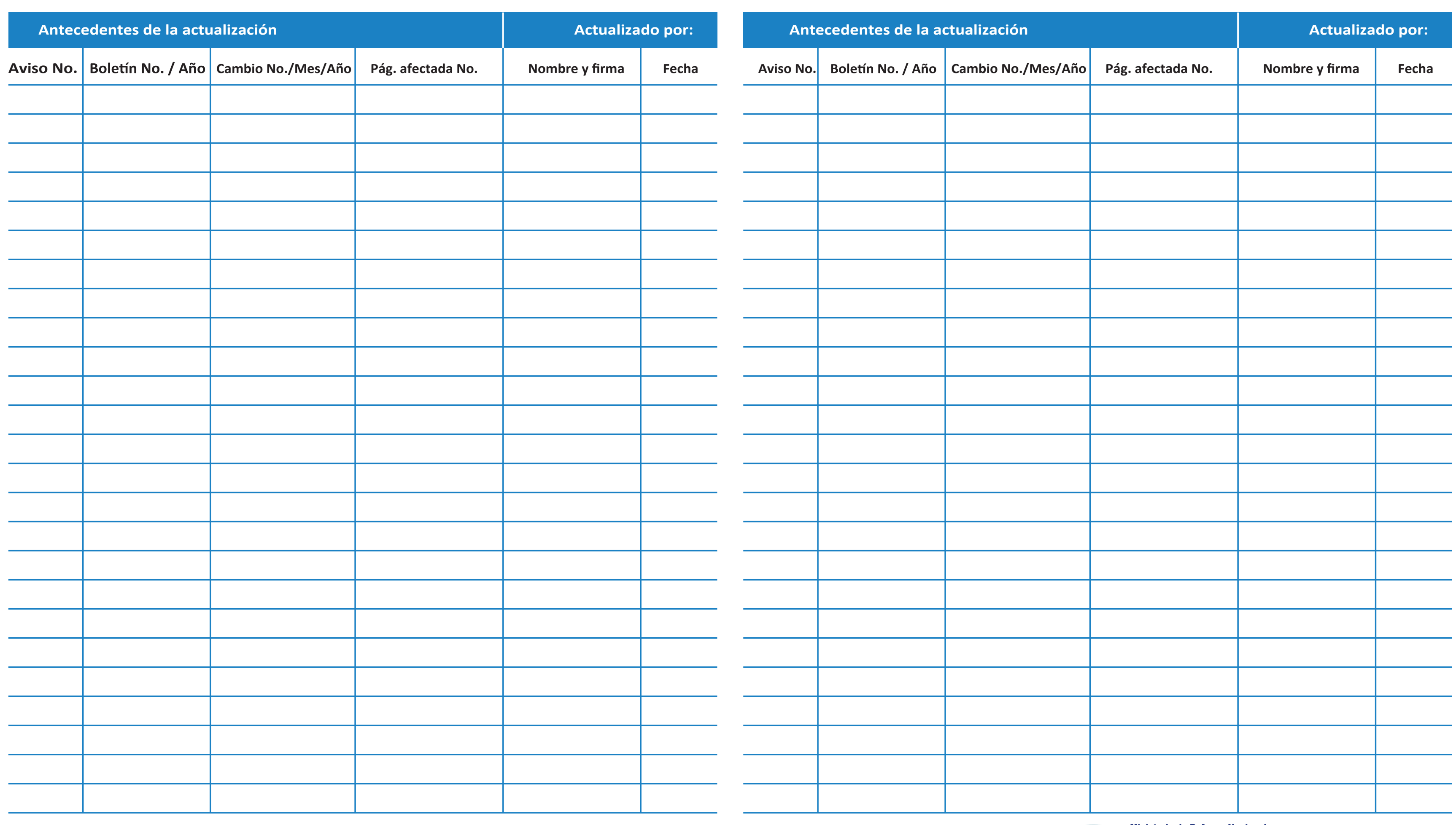

(1) 


\section{ÍNDICE GENERAL}

Prefacio

Índice de Cartas Náuticas

Lista de Figuras / Lista de Tablas

Dirección General Marítima (Dimar) Reseña Histórica ..................................................................

Centro de Investigaciones Oceanográficas e Hidrográficas del Caribe $(\mathrm{CIOH})$ Reseña Histórica ................................. Introducción.

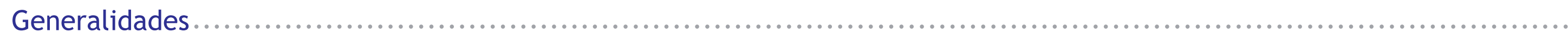

Esquema Cartográfico de las Cartas Náuticas de Papel ....

Esquema Cartográfico Náutico Nacional.

Clasificación Internacional de las Cartas Náuticas....

Corrección y Actualizaciones de las Cartas Náuticas .......

¿Cómo adquirir las cartas náuticas?

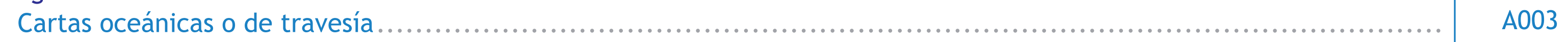

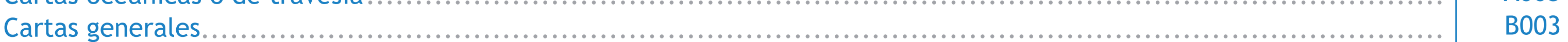

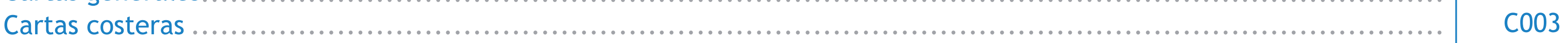

Cartas aproximación (acceso a puerto, aguas costeras congestionadas o tortuosas)...................................... D003

Cartas de puerto (puertos, bahías, fondeaderos, estrechos) .......................................................... E003

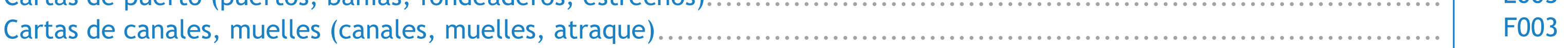

Cartografía Océano Pacífico Colombiano

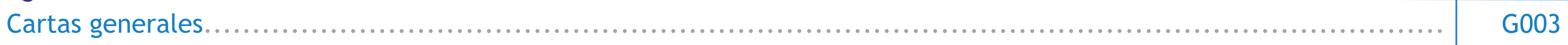

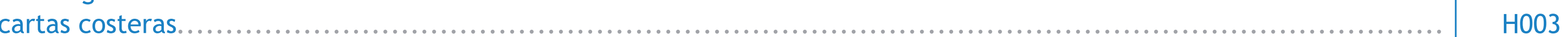

cartas aproximación (acceso a puerto, aguas costeras congestionadas o tortuosas) ....................................... 1003

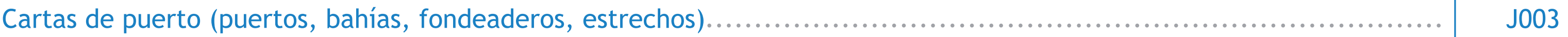

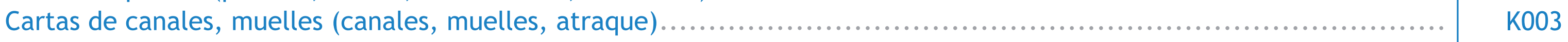

Cartografía Temática

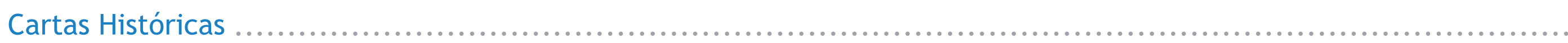

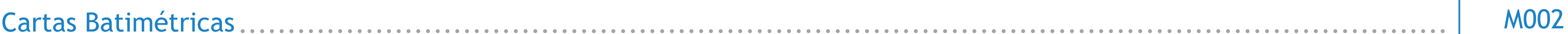

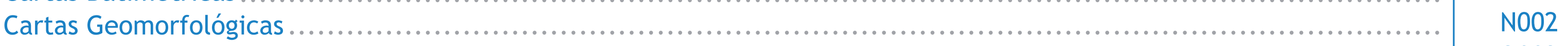

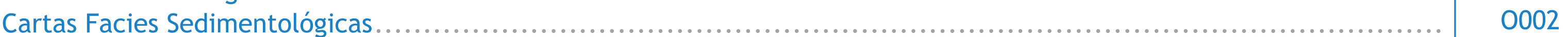

Referencias Bibliográficas 


\section{Prefacio}

I Centro de Investigaciones Oceanográficas e Hidrográficas del Caribe $(\mathrm{ClOH})$, dependencia de la Dirección General Marítima (Dimar), fue creado mediante la Resolución No. 238 del 9 de julio de 1975, convirtiéndose en la principal institución del Ministerio de Defensa Nacional para la generación de conocimiento en materia oceanográfica, hidrográfica, de protección del medio marino y el manejo integrado de zonas costeras en el Caribe colombiano.

Desde antes de su fundación, en 1971, ya contaba con sus primeras ediciones de cartas náuticas publicadas; teniendo para comienzos de 2016 un total de 127 nuevas ediciones y 246 actualizaciones, entre ellas oceánicas, generales, costeras, de aproximación, puertos, canales y temáticas, que abarcan todo el territorio nacional.

El Centro de Investigaciones también edita y actualiza con la frecuencia necesaria publicaciones náuticas, de relevante interés para los navegantes y el gremio marítimo, denominadas: 'Lista de Luces de las Costas y Áreas Insulares del Caribe y Pacifico Colombianos", 'Carta 001. Símbolos, Abreviaturas y Términos Usados en las Cartas Náuticas Colombianas', 'Derrotero de las Costas, Áreas Insulares del Caribe y Pacífico Colombiano' y el presente Catálogo de Cartas Náuticas.

En esta ocasión, el CIOH entrega una nueva versión del 'CATÁLOGO DE CARTAS NáUTICAS DE LOS OCÉANOS Y COSTAS DE COLOMBIA' que compila la totalidad de la cartografía vigente y suministra al usuario un medio dinámico y práctico para la búsqueda las cartas náuticas que requiere para la navegación dentro de los espacios marítimos jurisdiccionales del país. Adicionalmente, incluye consultada y descargada para imprimir fácilmente las páginas afectadas por actualizaciones, y de acuerdo con las necesidades de cada usuario.

Dimar, a través del $\mathrm{ClOH}$, tiene como objetivo mantener todas las cartas actualizadas en el menor tiempo posible, invitando a los usuarios y/o navegantes a consultar las afectaciones de las cartas náuticas por medio de las actualizaciones que se realizan diariamente a través de los 'Avisos a los Navegantes', en el enlace de su sitio electrónico: https://www.cioh.org.co/index.php/avisos-a-los-navegantes.html

Se invita a todos nuestros usuarios a enviar sugerencias, observaciones y recomendaciones acerca de esta publicación al correo electrónico: nautica@dimar.mil.co. Todos sus aportes se constituyen en una valiosa contribución para mejorar los productos y servicios que ofrece el Servicio Hidrografico Nacional ( $\mathrm{SHN}$ ), cuyo norte es garantizar la seguridad de la navegación, desarrollo marítimo, costero y fluvial de Colombia, así como también coadyuvar al seguimiento y control de la soberanía nacional.

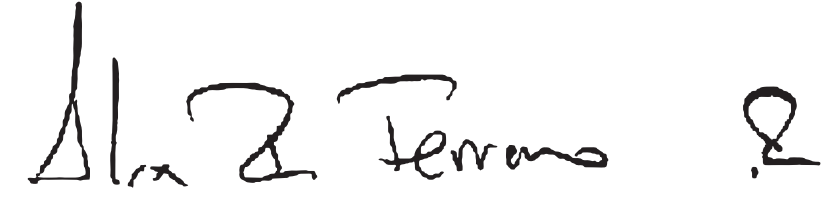

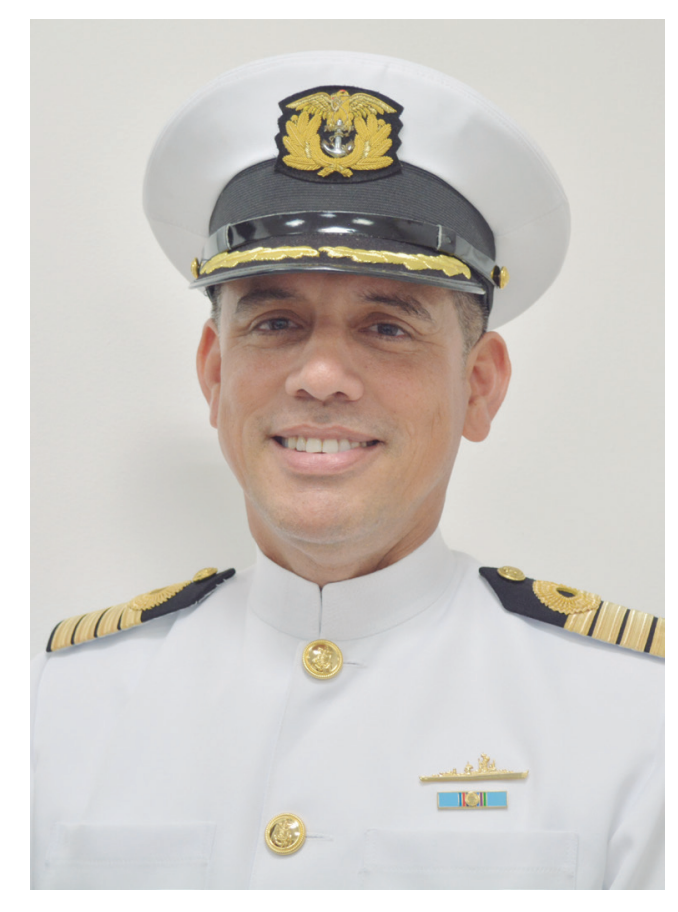

Capitán de Navío Alex Fernando Ferrero Ronquillo 
Mar Caribe Colombiano

\section{Índice de Cartas NÁuticas}

Cartas oceánicas o de travesía(escalas 1:2.000.001 y menores)

\begin{tabular}{|c|c|c|c|c|c|}
\hline No. Carta & Nombre & Escala & Edición & Año & Pág. \\
\hline 007 & El Gran Caribe & $1: 3.000 .000$ & 5 & 2013 & A003 \\
\hline No. Carta & Nombre & Escala & Edición & Año & Pág. \\
\hline 004 & Archipiélago de San Andrés y Providencia & $1: 600.000$ & 2 & 2000 & B003 \\
\hline 005 & Carta General del Caribe Colombiano & $1: 1.500 .000$ & 4 & 2011 & B004 \\
\hline 008 INT 4025 & Cabo Gracias a Dios a Santa Marta & $1: 1.000 .000$ & 2 & 2013 & B005 \\
\hline 020 INT 4126 & Pedro Bank a Isla Cayos de Quitasueño & $1: 400.000$ & 1 & 2006 & B006 \\
\hline 021 INT 4124 & Cabo Gracias a Dios a Isla de San Andrés & $1: 400.000$ & 1 & 2006 & B007 \\
\hline 022 INT 4122 & Isla de San Andrés a Golfo de los Mosquitos & $1: 400.000$ & 1 & 2006 & B008 \\
\hline 023 INT 4120 & Golfo de los Mosquitos a Punta Mosquito & 1:400.000 & 1 & 2006 & B009 \\
\hline 028 & Barranquilla a Punta Espada & $1: 500.000$ & 3 & 2013 & B010 \\
\hline 029 & Golfo de Urabá a Barranquilla & $1: 500.000$ & 3 & 2013 & B011 \\
\hline
\end{tabular}

Cartas costeras (escalas 1:350.000 - 1:75.001)

\begin{tabular}{|cllccc|c|}
\hline No. Carta & Nombre & Escala & Edición & Año \\
\hline 402 & Punta Gallinas a Cabo Chichibacoa & $1: 100.000$ & 1 & 2009 & C003 \\
\hline 403 & Cabo de la Vela a Punta Gallinas & $1: 100.000$ & 1 & 2015 & C004 \\
\hline 404 & Punta la Vela a Cabo de la Vela & $1: 100.000$ & 1 & 2009 & C005 \\
\hline 406 & Santa Marta a Cabo San Agustín & $1: 100.000$ & 3 & 2011 & C006 \\
\hline 407 & Puerto Colombia a Santa Marta & $1: 100.000$ & 2 & 1999 & C007 \\
\hline 408 & Punta Canoas a Puerto Colombia & $1: 100.000$ & 1 & 1999 & C008 \\
\hline 409 & Bajo Tortuguilla a Punta Canoas & $1: 100.000$ & 2 & 2004 & C009 \\
\hline 410 & Isla Fuerte a Punta Comisario & $1: 100.000$ & 3 & 2013 & C010 \\
\hline 411 & Punta Gigantón a Isla Fuerte & $1: 100.000$ & 2 & 2004 & C011 \\
\hline 412 & Golfo de Urabá & $1: 100.000$ & 3 & 2009 & C012 \\
\hline 413 & Cabo Tiburón a Punta Gigantón & $1: 100.000$ & 1 & 1999 & C013 \\
\hline 416 & Isla Cayos de Quitasueño & $1: 100.000$ & 1 & 2000 & C014 \\
\hline
\end{tabular}




\section{Mar Caribe Colombiano}

Cartas de aproximación (acceso a puerto, aguas costeras congestionadas o tortuosas) - (escalas 1:75.000 - 1:30.001)

\begin{tabular}{|l|l|ccc|c|c|}
\hline No. Carta & \multicolumn{1}{c|}{ Nombre } & Escala & Edición & Año & Pág. \\
\hline 206 & Bajo Alicia & $1: 50.000$ & 2 & 2003 & D003 \\
\hline 259 & Archipiélago de San Bernardo & $1: 35.000$ & 1 & 1999 & D004 \\
\hline 603 & Aproximación a Bahía Portete & $1: 50.000$ & 4 & 2015 & D005 \\
\hline 605 & Aproximación a Manaure & $1: 50.000$ & 1 & 2009 & D006 \\
\hline 606 & Aproximación a Riohacha & $1: 50.000$ & 1 & 2003 & D007 \\
\hline 608 & Aproximación a Puerto Brisa & $1: 50.000$ & 1 & 2014 & D008 \\
\hline 612 & Aproximación a Barranquilla & $1: 50.000$ & 3 & 2014 & D009 \\
\hline 618 & Golfo de Morrosquillo & $1: 50.000$ & 3 & 2012 & D010 \\
\hline 625 & Bahía Colombia & $1: 35.000$ & 4 & 2013 & D011 \\
\hline 613 & Galerazamba a Punta Morro Hermoso & $1: 50.000$ & 2 & 2016 & D012 \\
\hline
\end{tabular}

Cartas de puerto (puertos, bahías, fondeaderos, estrechos) - (escalas 1:30.000 -1:12.501)

\begin{tabular}{|c|c|c|c|c|c|}
\hline No. Carta & Nombre & Escala & Edición & Año & Pág. \\
\hline 201 & Isla de San Andrés & $1: 25.000$ & 3 & 2008 & E003 \\
\hline 203 & Cayo Alburquerque & 1:20.000 & 2 & 2003 & E004 \\
\hline 204 & Cayo East Southeast (Este Sudeste) & $1: 20.000$ & 2 & 2003 & E005 \\
\hline 208 & Cayo Serranilla & $1: 25.000$ & 2 & 2003 & E006 \\
\hline 211 & Isla Cayos de Roncador & $1: 20.000$ & 3 & 2003 & E007 \\
\hline 213 & Cayo Serrana & 1:20.000 & 2 & 2003 & E008 \\
\hline 215 & Cayo Quitasueño & $1: 25.000$ & 1 & 2000 & E009 \\
\hline 218 & Isla de Providencia & $1: 20.000$ & 3 & 2016 & E010 \\
\hline 222 & Aproximación a Puerto López & $1: 25.000$ & 1 & 2008 & E011 \\
\hline 227 & Bahía Honda & $1: 20.000$ & 1 & 1997 & E012 \\
\hline 229 & Bahía Portete & $1: 25.000$ & 4 & 2015 & E013 \\
\hline 231 & Cabo de la Vela & $1: 25.000$ & 1 & 2000 & E014 \\
\hline 244 & Bahía de Taganga a Punta Barro Blanco & $1: 25.000$ & 3 & 2011 & E015 \\
\hline 245 & Ciénaga & $1: 25.000$ & 2 & 2013 & E016 \\
\hline 246 & Puerto Zúñiga & $1: 20.000$ & 1 & 2014 & E017 \\
\hline 253 & Río Magdalena (Bocas de Ceniza-Puente Laureano Gómez) & 1:15.000 & 6 & 2016 & E018 \\
\hline
\end{tabular}




\section{Ínolce de Cartas Náuticas}

\section{Mar Caribe Colombiano}

Cartas de puerto (puertos, bahías, fondeaderos, estrechos) - (escalas 1:30.000 -1:12.501)

\begin{tabular}{|ll|ccc|c|c|}
\hline No. Carta & \multicolumn{1}{c}{ Nombre } & Escala & Edición & Año & Pág. \\
\hline 255 & Archipiélago Islas del Rosario & $1: 25.000$ & 2 & 2010 & E019 \\
\hline 261 & Bahía de Cartagena & $1: 25.000$ & 8 & 2011 & E020 \\
\hline 262 & Bahía de Cartagena (Sector A, B, C) & $1: 15.000$ & 3 & 2016 & E021 \\
265 & Aproximación a Coveñas y Santiago de Tolú & $1: 30.000$ & 2 & 2016 & E022 \\
\hline 266 & Boca de Tinajones a Bahía de Cispatá & $1: 30.000$ & 1 & 2005 & E023 \\
\hline 267 & Isla Fuerte & $1: 15.000$ & 1 & 2003 & E024 \\
\hline 279 & Acandí & $1: 25.000$ & 1 & 2000 & E025 \\
\hline 280 & Cabo Tiburón a Isla Terrón de Azúcar & $1: 25.000$ & 2 & 2010 & E026 \\
\hline
\end{tabular}

Cartas de canales (canales, muelles, atraque) - (escalas 1:12.500 y mayores)

\begin{tabular}{|l|l|ccc|c|}
\hline No. Carta & \multicolumn{1}{c|}{ Nombre } & Escala & Edición & Año & Pág. \\
\hline 880 & Puerto de San Andrés & $1: 7.500$ & 1 & 2016 & F003 \\
\hline 202 & Rada el Cove & $1: 5.000$ & 3 & 2010 & F004 \\
\hline 804 & Bahía de Santa Marta & $1: 10.000$ & 4 & 2015 & F005 \\
808 & Puerto Brisa & $1: 10.000$ & 1 & 2014 & F006 \\
\hline 833 & Bahía de Cartagena (canal de acceso) & $1: 5.000$ & 5 & 2015 & F007 \\
885 & Bahía de Santa Catalina & $1: 5.000$ & 1 & 2016 & F008 \\
\hline 848 & Santiago de Tolú & $1: 10.000$ & 1 & 2013 & F009 \\
822 & Ensenada Trebal (Puerto Velero) & $1: 10.000$ & 1 & 2016 & F010 \\
\hline
\end{tabular}




\section{Ínolce de Cartas Náuticas}

\section{OCÉano PacíFlo COLOMBIANO}

Cartas generales (escalas 1:2.000.000 -1:350.001)

\begin{tabular}{|c|c|c|c|c|c|}
\hline No. Carta & Nombre & Escala & Edición & Año & Pág. \\
\hline 003 INT 6000 & Bahía de Panamá a Cabo San Francisco & $1: 1.200 .000$ & 4 & 2011 & G003 \\
\hline 030 INT 6100 & Canal de Panamá al Golfo de Cupica & $1: 500.000$ & 2 & 2004 & G004 \\
\hline 031 INT 6105 & Golfo de Cupica a Bahía de Buenaventura & $1: 500.000$ & 3 & 2009 & G005 \\
\hline 032 INT 6110 & Bahía de Buenaventura a Bahía Ancón de Sardinas & $1: 500.000$ & 3 & 2009 & G006 \\
\hline \multicolumn{6}{|c|}{ Cartas costeras (escalas 1:350.000 - 1:75.001) } \\
\hline No. Carta & Nombre & Escala & Edición & Año & Pág. \\
\hline 302 & Golfo de Tribugá & $1: 100.000$ & 1 & 2010 & H003 \\
\hline 303 & Nuquí a Punta Catripe & $1: 100.000$ & 1 & 2010 & H004 \\
\hline 306 & Río San Juan a Boca Yurumanguí & $1: 100.000$ & 1 & 1998 & H005 \\
\hline 308 & Punta Coco a Isla Barrera & $1: 100.000$ & 1 & 2013 & HOO6 \\
\hline 310 & Punta Isla Cascajal a Río Mataje & $1: 100.000$ & 2 & 2013 & H007 \\
\hline
\end{tabular}

Cartas de aproximación (acceso a puerto, aguas costeras congestionadas o tortuosas) - (escalas 1:75.000-1:30.001)

\begin{tabular}{|c|c|c|c|c|c|}
\hline No. Carta & Nombre & Escala & Edición & Año & Pág. \\
\hline 514 & Isla Carauma a Punta Mulatos & $1: 50.000$ & 1 & 2005 & 1003 \\
\hline 515 & Punta Mulatos a Pasacaballos & $1: 50.000$ & 1 & 2005 & 1004 \\
\hline 520 & Isla Gorgona & $1: 50.000$ & 1 & 2003 & 1005 \\
\hline 521 & Isla Malpelo & $1: 50.000$ & 1 & 2005 & 1006 \\
\hline
\end{tabular}




\section{Ínolce de Cartas Náuticas}

\section{OCÉANO PaĆ́FICO Colombiano}

Cartas de puerto (puertos, bahías, fondeaderos, estrechos) - (escalas 1:30.000 -1:12.501)

\begin{tabular}{|c|c|c|c|c|c|}
\hline No. Carta & Nombre & Escala & Edición & Año & Pág. \\
\hline 101 & Aproximación a Tumaco & $1: 25.000$ & 4 & 2009 & J003 \\
\hline 103 & Isla Mono a Juradó & $1: 25.000$ & 1 & 2008 & J004 \\
\hline 107 & Bahías de Cupica y Chirichirí & $1: 30.000$ & 1 & 1998 & J005 \\
\hline 109 & Aproximación a Bahía Solano & $1: 25.000$ & 1 & 2008 & J006 \\
\hline 135 & Bocana Iscuandé & $1: 25.000$ & 1 & 2005 & J007 \\
\hline 136 & Bocana de Amarales & $1: 25.000$ & 1 & 2005 & J008 \\
\hline 137 & Boca de Sanquianga & $1: 25.000$ & 1 & 2006 & J009 \\
\hline 145 & Cabo Manglares & $1: 25.000$ & 1 & 2005 & J010 \\
\hline 150 & Bahía Málaga & $1: 25.000$ & 5 & 2013 & J011 \\
\hline 154 & Bahía de Buenaventura (bahía externa) & $1: 25.000$ & 1 & 2016 & J012 \\
\hline 155 & Bahía de Buenaventura (bahía interna) & 1:25.000 & 1 & 2016 & J013 \\
\hline
\end{tabular}

Cartas de canales (canales, muelles, atraque) - (escalas 1:12.500 y mayores)

\begin{tabular}{|c|c|c|c|c|c|}
\hline No. Carta & Nombre & Escala & Edición & Año & Pág. \\
\hline 770 & Puerto de Tumaco & 1:10.000 & 5 & 2016 & K003 \\
\hline 116 & Bahía Interior de Solano & 1:10.000 & 2 & 2008 & K004 \\
\hline 740 & Guapi & $1: 10.000$ & 1 & 2010 & K005 \\
\hline
\end{tabular}




\section{CaRTAS Temáticas}

\section{Ínoice de Cartas Náuticas}

Cartas históricas

\begin{tabular}{|c|c|c|c|c|c|}
\hline No. Carta & Nombre & & Edición & Año & Pág. \\
\hline 1010 & \multicolumn{2}{|l|}{ Carta Histórica Naval de la Bahía de Cartagena de Indias } & 1 & 2000 & L002 \\
\hline \multicolumn{6}{|c|}{ Cartas batimétricas (escalas 1:100.000 - 1:1.000.000) } \\
\hline No. Carta & Nombre & Escala & Edición & Año & Pág. \\
\hline 1601 & Caribe Suroccidental Sector Oeste & $1: 1.000 .000$ & 1 & 2000 & M002 \\
\hline 1621 & Barranquilla a Riohacha & $1: 250.000$ & 1 & 1998 & M003 \\
\hline 1622 & Abanico del Magdalena & $1: 250.000$ & 1 & 1999 & M004 \\
\hline 1623 & Talud Caribaná Sector Suroeste & $1: 250.000$ & 1 & 1999 & M005 \\
\hline 1624 & Islas de San Andrés y Providencia & $1: 200.000$ & 1 & 1998 & M006 \\
\hline 1625 & Bancos de Quitasueño y Serrana & $1: 250.000$ & 1 & 1999 & M007 \\
\hline 1626 & Banco Serranilla-Bajo Nuevo & $1: 250.000$ & 1 & 1999 & M008 \\
\hline 1649 & Punta Barú a Punta Canoas & $1: 100.000$ & 1 & 1998 & M009 \\
\hline 1701 & Océano Pacífico Colombiano & $1: 1.000 .000$ & 1 & 1999 & M010 \\
\hline
\end{tabular}

Cartas geomorfológicas (escalas 1:50.000)

\begin{tabular}{c|l|c|ccc|c|c|}
\hline \multirow{2}{*}{$\begin{array}{c}\text { No. Carta } \\
1416\end{array}$} & Nombre & Escala & Edición & Año & Pág. \\
\hline 1417 & Cerro Furú-Galerazamba & $1: 50.000$ & 1 & 1997 & N002 \\
\hline
\end{tabular}

Cartas facies sedimentológicas (escalas 1:300.000)

\begin{tabular}{c|l|c|ccc} 
No. Carta & \multicolumn{1}{c|}{ Nombre } & Escala & Edición & Año & Pág. \\
\hline 2634 & Dibulla-Castilletes & $1: 300.000$ & 2 & 1999 & 0002 \\
2728 & Cabo Corrientes a Boca de Cajambre & $1: 300.000$ & 2 & 1999 & 0003 \\
\hline
\end{tabular}




\section{LISTA DE FIGURAS / LISTA DE TABLAS}

\section{LISTA DE FIEURAS}

\begin{tabular}{|lll|}
\hline Figura 1. & Esquema general de cartas oceánicas mar Caribe. & Pág. \\
\hline Figura 2. & Esquema de cartas generales mar Caribe. & $\mathrm{B} 002$ \\
\hline Figura 3. & Esquema de cartas costeras mar Caribe. & $\mathrm{C002}$ \\
\hline Figura 4. & Esquema de cartas de aproximación mar Caribe. & $\mathrm{D} 002$ \\
\hline Figura 5. & Esquema de cartas de puerto mar Caribe. & $\mathrm{E} 002$ \\
\hline Figura 6. & Esquema de cartas de canales mar Caribe. & $\mathrm{F} 002$ \\
\hline Figura 7. & Esquema de cartas generales océano Pacífico. & $\mathrm{G002}$ \\
\hline Figura 8. & Esquema de cartas costeras océano Pacífico. & $\mathrm{H} 002$ \\
\hline Figura 9. & Esquema de cartas de aproximación océano Pacífico. & 1002 \\
\hline Figura 10. & Esquema de cartas de puertos océano Pacífico. & $\mathrm{J} 002$ \\
\hline Figura 11. & Esquema de cartas de canales océano Pacífico. & $\mathrm{K} 002$ \\
\hline
\end{tabular}

\section{LISTA DE TABLAS}

Tabla 1. Esquema Cartográfico mar Caribe.

Tabla 2. Esquema Cartográfico océano Pacífico. 26

Tabla 3. Numeración de las cartas náuticas por departamentos. 27

Tabla 4. Cartas náuticas disponibles. $\quad 27$

Tabla 5. Clasificación de las cartas náuticas según su escala. 28

Tabla 6. Clasificación de las cartas náuticas según su edición. 28

Tabla 7. Clasificación de las cartas náuticas según su objetivo. 28

Tabla A1. Carta oceánica mar Caribe. $\quad$ A001

Tabla B1. Cartas generales mar Caribe. $\quad B 001$

Tabla C1. Cartas costeras mar Caribe. $\quad$ C001

Tabla D1. Cartas de aproximación mar Caribe. D001

Tabla E1. Cartas de puerto mar Caribe. $\quad$ E001

Tabla F1. Cartas de canales mar Caribe. $\quad F 001$

Tabla G1. Cartas generales océano Pacífico. $\quad$ G001

Tabla H1. Cartas costeras océano Pacífico. $\quad H 001$

Tabla I1. Cartas de aproximación océano Pacífico. 1001

Tabla J1. Cartas de puerto océano Pacífico. J001

Tabla K1. Cartas de canales océano Pacífico. $\quad$ K001

Tabla L1. Carta histórica. $\quad$ L001

Tabla M1. Cartas batimétricas. $\quad$ M001

Tabla N1. Cartas geomorfológicas. $\quad$ N001

Tabla 01. Cartas facies sedimentológicas. $\quad 0001$ 


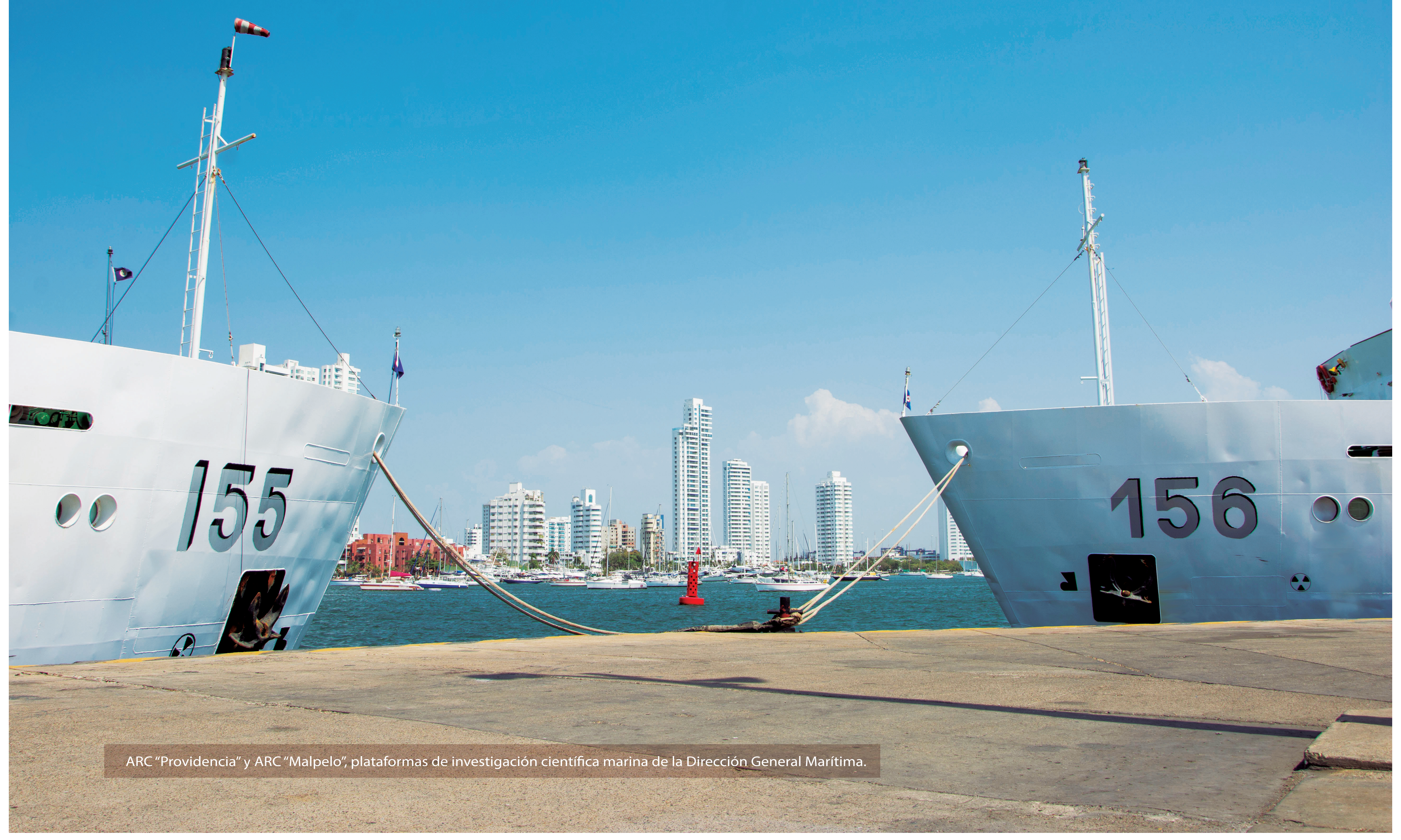




\section{DIRECCIÓN GENERAL MARÍTIMA (DIMAR) RESEÑA HISTÓRICA}

nte la escasez de medios de transporte nacionales, altos fletes y pagos en moneda extranjera, a finales de los años 20 del siglo XX surge en Colombia la necesidad de contar con una marina mercante propia que ayudara a prome

En tal sentido, se empieza a desarrollar una creciente labor normativa, la cual ha evolucionado hacia lo que hoy es la Dirección General Marítima: Autoridad Marítima Colombiana (Dimar).

Para 1931 se promulga la Ley 30, primera norma referente al transporte marítimo. Esta autoriza al Gobierno a fomentar, por medio de contratos, la formación, organizacion y desarrollo de una 'compañía nacional de marina mercante', así como la creación de una 'sección o departamento de la marina', dirigida por oficiales navales colombianos.

Con el Decreto No:120 de 1951 se asignan a la Armada Nacional de Colombia (ARC) las funciones de reconocimiento, clasificación y registro de embarcaciones. Además, se le navales, una sección es prestar un mejor servicio al sector marítimo y contribuir al fortalecimiento económico del país.

Posteriormente, el 3 de diciembre de 1952 se expide el Decreto 3183, mediante el cual se establece la Dirección de Marina Mercante Colombiana, dependiente del Comando de la Armada Nacional y cuyos objetivos son la dirección de la marina mercante, la investigación, la regulación y el control del transporte marítimo y los puertos del país. Para 1971 esta Dirección es reestructurada a través del Decreto Ley 2349, por el cual surge la Dirección General Marítima y Portuaria (Dimar). Una nueva reorganización surge en 1984, en los niveles normativo, práctico y técnico, a través del conocido Decreto Ley 2324.

En el año de 1991, el Gobierno Nacional determina el carácter especial de los puertos en Colombia al privatizarlos. De esta manera se expide la Ley 1 de 1991, la cua establece el Estatuto General de Puertos del Pais, dándose desde este momento una propias de Dimar en las áreas jurisdiccionales marítimas colombianas. Dichas áreas comprenden las aguas interiores, incluyendo canales intercostales y de tráfico marítimo: todos aquellos sistemas marinos y fluviomarinos; mar territorial, zona contigua, zona económica exclusiva, lecho y subsuelo marinos, aguas suprayacentes; litorales, incluyendo playas y terrenos de bajamar; puertos del pais situados en su jurisdicción; islas, islotes y cayos; al igual que aquellas embarcaciones que realizan tráfico 政 esté y que porte la bandera nacional.

Posteriormente, teniendo en cuenta aspectos como la modernización del Estado y sus desafíos para hacer frente a las necesidades de los usuarios nacionales, as como la importancia de trascender las fronteras nacionales, se expidió el Decreto 156 estableciendo que es una dependencia del Ministerio la naturaleza juridica de Dimar, reitera, aclara y modifica algunas de las funciones de Dimar y establece la estructura actual que le permite cumplir su misión.

Se hace perentorio señalar que dicho decreto es el instrumento legal que reafirma que la Autoridad Maritima Nacional es la entidad que representa a la Nacion en los foros y conferencias maritimas internacionales, como tambien la entidad que asesora al Gobierno Nacional en todo lo relacionado con el conocimiento y acción acerca de los instrumentos interr 


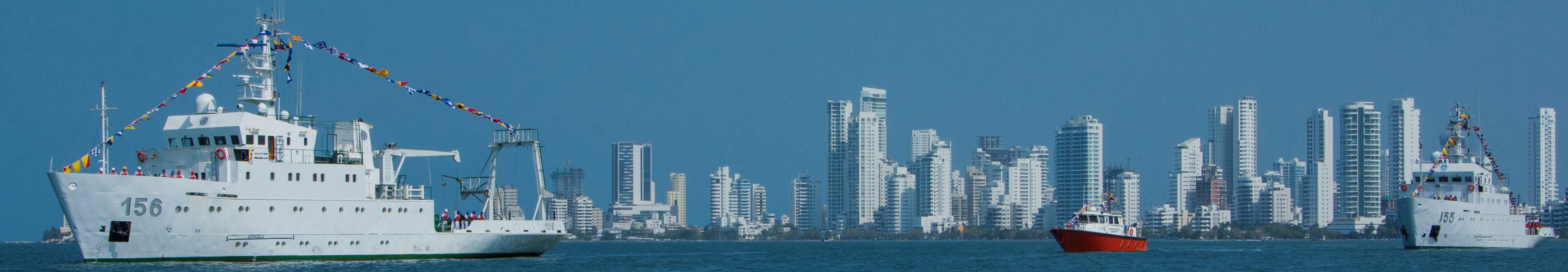




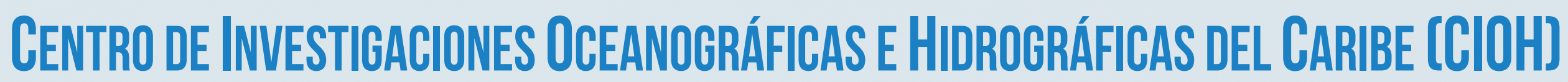 RESEÑA HISTÓRICA}

a investigación hidrográfica en Colombia tuvo su inicio en julio de 1947, cuando se estableció un convenio cooperativo entre el Ministerio de Defensa Armada Nacional, y el Departamento de Defensa de los Estados Unidos, representado por la Oficina Oceanográfica Naval (Navoceano).

En 1968 se creó la División de Hidrografía de la Dirección General de la Marina Mercante, contando con el buque ARC "Quindio", adaptado para realizar diferentes estudios hidrográficos en aguas jurisdiccionales colombianas. Igualmente, se coordino con la Universidad Nacional de Colombia (UNAL) para que ingenieros civiles y estudiantes se vincularan activamente, con el fin de realizar el primer levantamiento hidrográfico en el Pacifico colombiano. Este levantamiento se realizo a bordo del buque an primera edición 1971.

Los primeros oficiales y suboficiales colombianos especialistas en Hidrografía se capacitaron en el exterior, principalmente en Brasil, España y Estados Unidos; permitiendo el logro del conocimiento técnico para formar personal nacional en la especialidad, hasta consolidar una identidad propia.

Para 1972 se publicaron las cartas náuticas 'COL 100 Puerto Interior de Tumaco', 'COL 200 Puerto Interior de San Andrés', 'COL 201 Isla de San Andrés' y la 'COL 261 Bahía de Cartagena'.

Con la implementación del Plan de Desarrollo de Ciencias y Tecnologías del Mar, en 1979, se trastadó al Centro de Investigaciones Oceanográticas é Hidrográticas de incorporan a la Armada Nacional de Colombia (ARC) los buques oceanográficos ARC "Malpelo" y ARC "Providencia", utilizados para realizar levantamientos hidrográficos en el territorio marítimo nacional.

En 1981 se llevó a cabo el primer curso de Hidrografía Básica en la Escuela Naval de Suboficiales de Barranquilla (ENSB), formandose asi una nueva especialidad en la ARC, denominada "Ciencias del Mar', dirigida al desarrollo de todas las labores de 1998, Colombia se convierte en el país miembro No. 67 de la Organización
Hidrográfica Internacional $(\mathrm{OHI})$, con sede en Mónaco, máxima autoridad que establece las especificaciones hidrograficas y cartograficas internacionales. De esta de Investigaciones Oceanográficas de Hidrográficas del Caribe (CIOH), al usuario final la elaboración y suministro de productos que cumplen con los máximos estándares internacionales en materia hidrográfica.

Durante el presente milenio Dimar- $\mathrm{ClOH}$ inició la producción de cartas

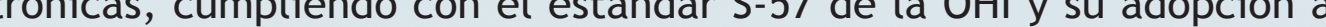
S-100. Se adquirió la lancha hidrográfica ARC "Isla Barú”, equipada con sistema de
levantamiento multihaz, con ecosonda de alta frecuencia y demás periféricos.

En 2014 se instalaron a bordo de las plataformas oceanográficos ARC "Malpelo" y ARC "Providencia" dos sistemas multhaz, integrados por un conjunto marítima tales como: sistemas GNSS, con precisión submetrica que asegura la calidad en el posicionamiento de la información colectada; ecosondas multihaz, con resolución de $1^{\circ} \times 1^{\circ}$ en el ARC "Providencia" y $2^{\circ} \times 2^{\circ}$ en el ARC "Malpelo", las cuales permiten obtener una cobertura total del fondo, una alta resolución en lo que respecta a la detección de rasgos y con un alcance de hasta $7000 \mathrm{~m}$, así mismo permite colectar datos de retrodispersion acústica para el análisis y caracterización del fondo marino, y la colección de datos de la columna de agua. Dimar-CIOH cuenta con una ecosonda monohaz de doble frecuencia y un sistema de Sub Bottom Profilers para identificar y caracterizar las capas de sedimentos o rocas en el subsuelo.

Con estos sistemas, el SHN, que opera desde el $\mathrm{ClOH}$, se ubica a la vanguardia en la recoleccion y presentación de información nautica, altgurand que los puertos colombianos cuenten con cartografía y publicaciones de alta calidad de impulsar el desarrollo de los intereses maritimos colombianos.

El recurso humano es el bien más valioso con el que dispone Dimar- $\mathrm{ClOH}$ y nacionales e internacionales en virtud a la calidad de sus productos. 


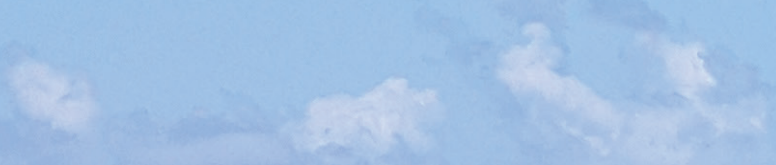

\section{the}

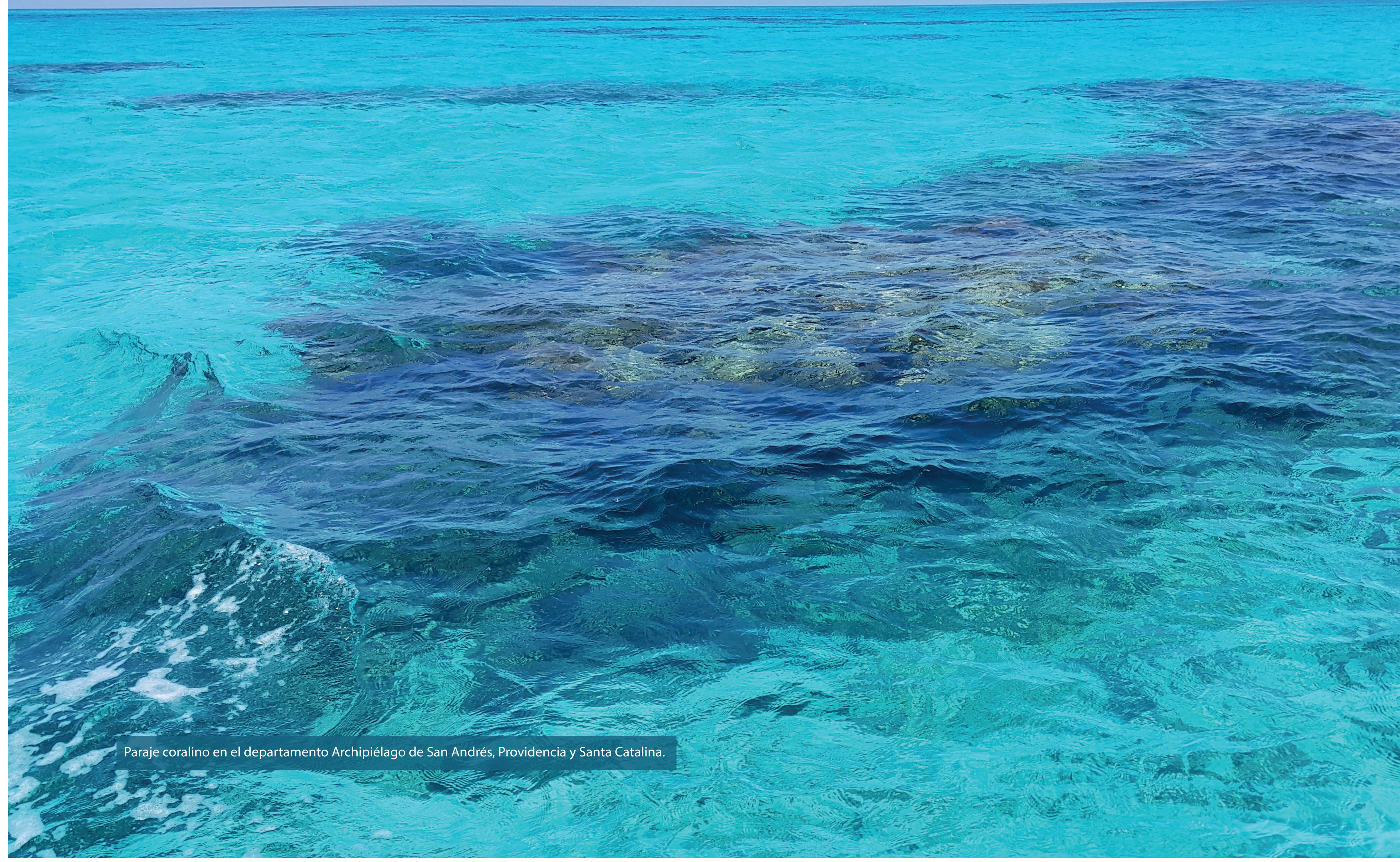




\section{INTRODUCCIÓN}

s importante recordar el significado de la Hidrografía, su importancia en el ámbito mundial y el rol que desempeña en el marco de mundial y el rol que deser

De acuerdo con la OHI, la Hidrografía se define como "Rama de la ciencia aplicada que tiene por objeto la medición y descripción de las características físicas de la porcion navegable de la superficie de la Tierra y areas costeras adyacentes, esencialmente, con vista a facilitar la Navegación" (OHI, Diccionario Hidrográfico S-32, 1996).

Hoy el $\mathrm{ClOH}$ entrega al gremio marítimo y a los navegantes en general el 'CATÁLOGO DE LAS CARTAS NÁUTICAS DE LOS OCÉANOS Y COSTAS DE COLOMBIA' publicación que suple el servicio informativo y de consulta que por cuatro ediciones cumplio el 'Atlas Cartográfico de los Océanos y Costas de Colombia' (Publicacion No. 3007, Cuarta Edicion 2012). Siendo el mismo objetivo de facilitar al usuario toda la información de la cartografía náutica nacional, de una manera más dinámica de las áreas de interés y claridad al momento de elegir la carta náutica que se requiere para el tráfico ingreso a un área marítima en particular.

En Colombia pocas son las publicaciones que permiten apreciar y tener una visión clara y completa de la geomorfología submarina, accidentes hidrográficos, conformación de la línea de costa, límites marítimos, islas, islotes, cayos, bajos, áreas coralinas, clasificación de sedimentos y toponimia, entre otros; que ofrezca una perspectiva general de la riqueza natural, turística, cultural, ubicación de canales navegables y puertos enmarcados en la jurisdicción nacional.

El conocimiento de las características geográficas, geologicas y geofisicas del fondo marino y el litoral, asi como de otras caracteristicas oceanograficas son el producto de los estudios propios de la Hidrografia y la Oceanografía. Como nación soberana, Colombia elabora y ámbitos marítimo y fluvial, desde el SHN del CIOH-Dimar.

$\mathrm{El} \mathrm{ClOH}$ tiene la responsabilidad de recolectar, procesar y poner a disposicion de la comunidad maritima nacional e internacional, información que contribuya al desarrollo de los espacios marítimos del país, tendiente a garantizar fundamentalmente la seguridad en la navegacion y salvaguardar la vida humana en el mar; requisitos indispensables para promover el comercio maritimo, el turismo, los deportes náuticos, la explotación de los recursos naturales y la investigación científica marina, entre otras actividades relativas a la actividad marítima. 


\section{GENERALIDADES}

a Hidrografía y la Cartografía son ciencias de suma importancia que contribuyen

al desarrollo marítimo del país. Su evolución y tecnificación, así como la

incorporación de los sistemas de información cada vez más avanzados, han perfeccionado la producción cartográfica, generando mayor volumen de datos, precisión y exactitud; factores que hacen necesaria la actualización y reestructuración permanente del Esquema Cartográfico Náutico Nacional (ECNN).

Desde la década de los 70 Dimar realiza esta labor en forma sistemática organizada, con la elaboración de cartas nauticas de papel en forma tradicional; lo cua permitió la proyección y reconocimiento del Servicio Hidrográfico Nacional (SHN) de Colombia. A la fecha se han experimentado cambios importantes en cuanto al manejo y organización de la información, principalmente, en la presentación e integración de los datos, como consecuencia de los avances tecnológicos en los sistemas de navegación y posicionamiento.

Con la aparición de los Sistemas de Información Geográfica (SIG) el SHN incrementa el promedio anual de producción de cartas náuticas, ampliando el futuro de la Cartografía Electrónica, servicio cartográfico que en la actualidad se utiliza masivamente en la navegación. Esta se elabora soportada en estándares internacionales definidos por la OH y aceptados por la comunidad hidrográfica internacional.
En Colombia la elaboración del primer ECNN tuvo lugar en 1976, documento revisado actualizado en 1998, adaptado a los requerimientos del momento histórico. Dicho Esquema, muy visionario y exigente, presentaba un total de 233 cartas náuticas, las cuales cubrían el territorio marítimo nacional en sus diferentes escalas, ajustadas y modificadas de acuerdo a las necesidades y prioridades de las circunstancias de la época. Sin embargo, debido a la gran cantidad de cartas náuticas, batimétricas, temáticas y especiales proyectadas para su realización, sólo se logró completar al $33 \%$ de avance de lo planeado.

Para la actualización del presente ECNN fueron atendidas las prioridades nacionales de desarrollo, defensa y seguridad; reduciéndose a 102 cartas náuticas las 233 proyectadas a finales de los años 90 . Así desde 2010 se cuenta con la aprobación del
Esquema que señala una nueva organización y redistribución de las áreas marinas, coherente a las responsabilidades de Dimar en el cumplimiento de su Misión; bajo los criterios de eficiencia y teniendo en cuenta la estandarización de las cartas de papel como respaldo a las cartas electrónicas; evitando así tener duplicidad de cartas con el mismo propósito de navegación en un mismo sector.

El ECNN vigente se encuentra en actualización con el fin de fortalecer y cubrir con las necesidades requeridas por el gremio marítimo.

\section{Competencias asociadas a la Hidrografía}

La Hidrografía como ciencia cobra relevancia por la variedad de competencias asociadas a ella. Según el Manual de Hidrografía (OHI, Manual de Hidrográfia C-13 (Correcciones a abril de 2010), 2005) dicha competencias son:
(1) Transporte marítimo
Administración de las zonas costeras 


\section{GeNERALIDADES}

\section{Carta Náutica}

Para definir el concepto de 'carta náutica' se toma como referencia la Regla 2 del Capítulo V "Seguridad de la Navegación - versión enmendada en el 2000" del Convenio Internacional para la Seguridad de la Vida humana en la Mar de 1974 (OMI, SOLAS, 1974) la cual establece: “Una carta náutica o publicación náutica, es un mapa o especialmente recopilada, de la cual se obtiene dicho mapa o libro, publicado oficialmente por un Gobierno o bajo su autoridad un Servicio Hidrográfico autorizado o cualquier autra institución estatal pertinente y que está diseñada para cubrir las necesidades de la navegación maritima." para cubrir las necesidades de la navegación marítima."

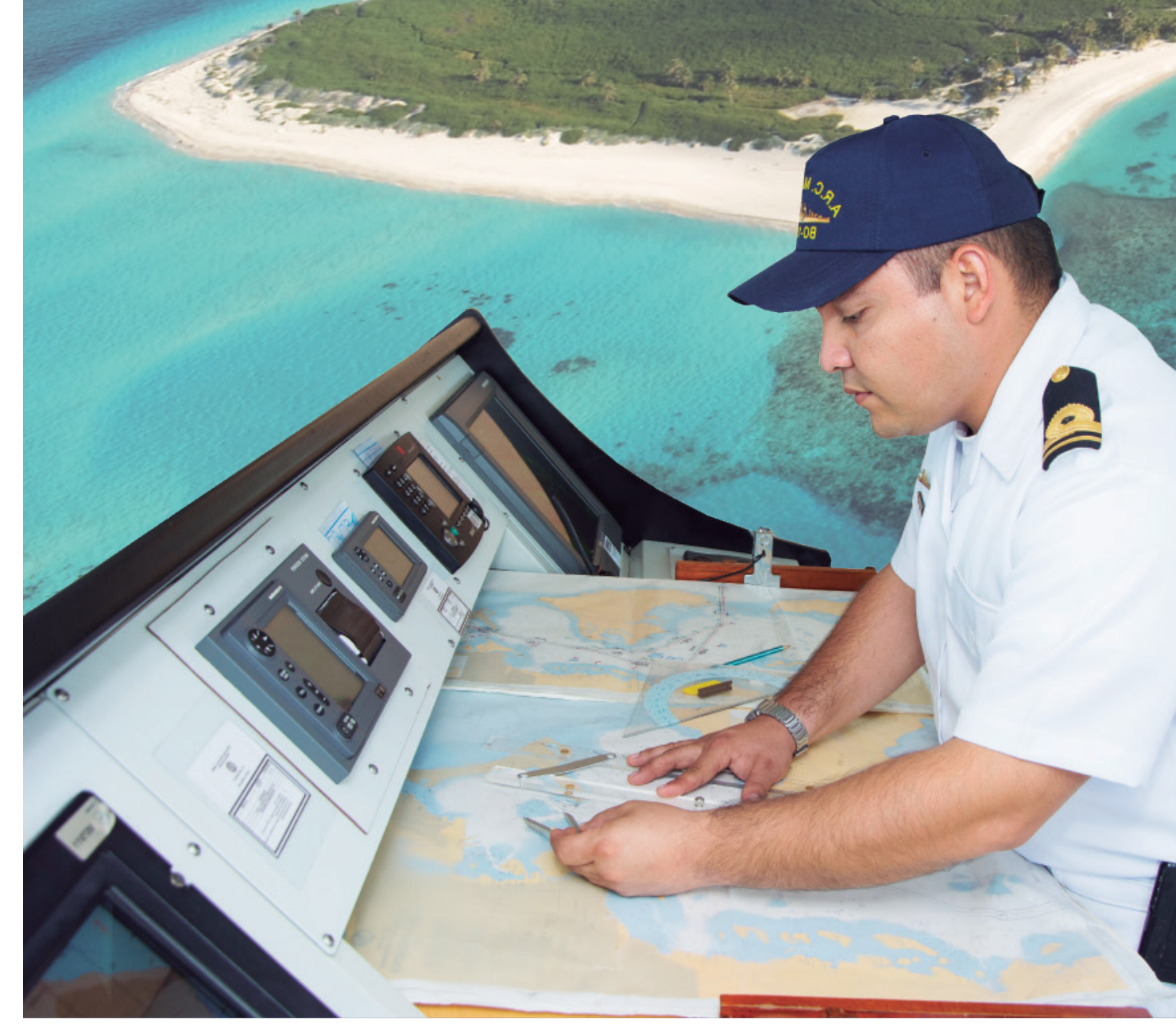

Las cartas náuticas están destinadas a satisfacer principalmente las siguientes necesidades:

Ayuda, información y seguridad a la navegación.

(iv) Protección y gestión del medio ambiente.

Control eficaz del tráfico marítimo.

(1) Navegación por rutas comerciales.

(1) Exploración y explotación de recursos marinos.

Administración costera

(7) Navegación e información de rutas turísticas.

Actividades deportivas

Bivulgación de información náutica que contribuya a la difusión de los intereses marítimos de la Nación.

(1) Utilización como información base de estudios científicos y técnicos de desarrollo nacional e internacional.

(1) Base de difusión de materias de índole educacional.

*i) Infraestructura de datos espaciales nacionales.

Prevención y atención de desastres.

Soberanía nacional.

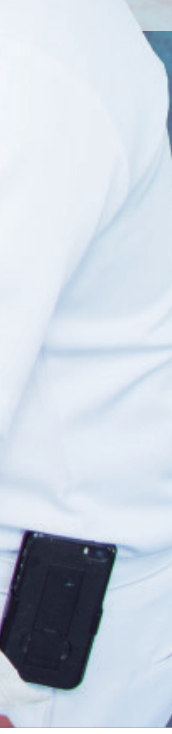

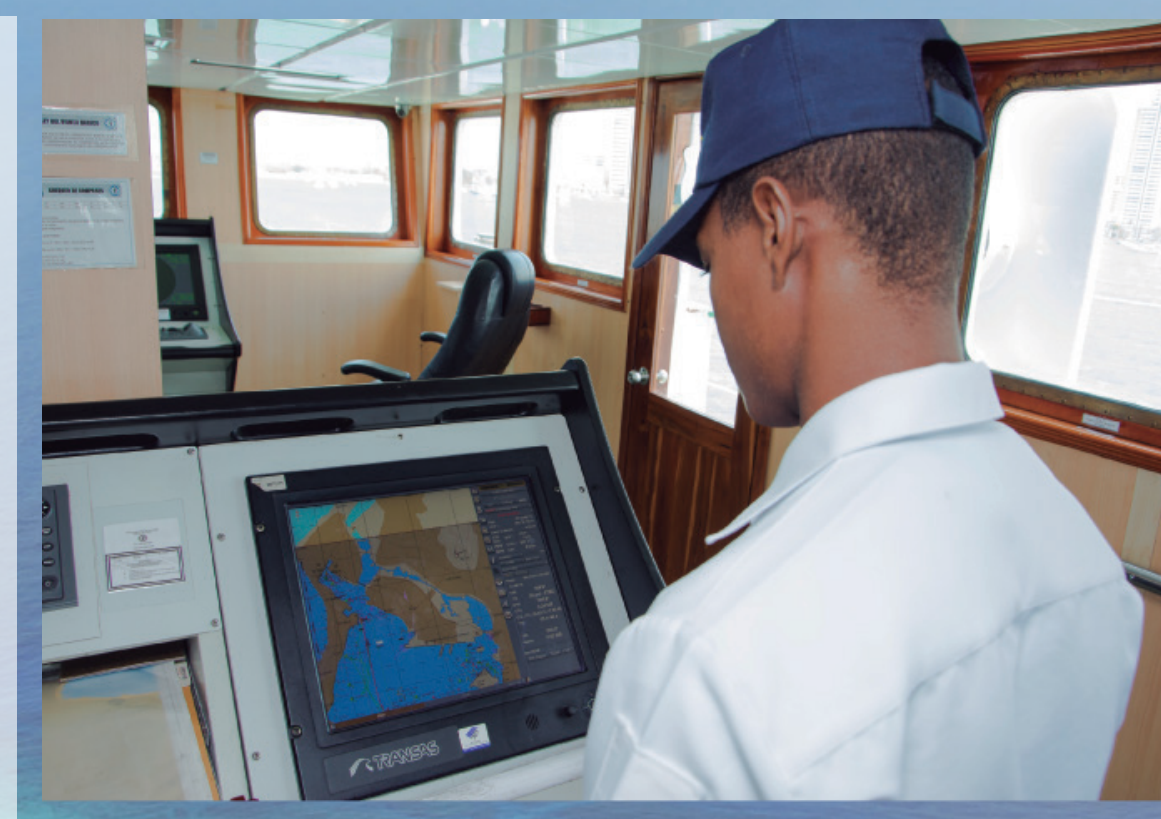

Carta Náutica Electrónica (CNE)

La Organización Marítima Internacional (OMI) y la $\mathrm{OHI}$ promueven el desarrollo del sistema de navegación con carta electrónica, con el fin de incrementar la seguridad en la navegación y para esto han estandarizado la especicican sean cumplidas por los diferentes servicios hidrográficos del conversión de las cartas de papel a formato S-57.

La Dirección General Marítima es la encargada de la publicación de las cartas náuticas electrónicas (CNE) oficiales a través del Servicio Hidrográfico, que cubren los principales puertos y áreas específicas del Caribe y Pacífico colombiano, con diferentes propósitos de navegación.

La distribución de las celdas electrónicas se realiza través del Centro Internacional de Cartas Náuticas Electrónicas (IC-ENC, por sus siglas en inglés), quienes se encargan de la distribución comercial por medio de los vendedores de valor agregado (VAR).

Catálogo de Cartas Náuticas de COLOMBia Dimar-CIOH Pág. 025 


\section{Esquema Cartográfico de las Cartas Náuticas de Papel}

La cartografía básica es el conjunto técnico de los procesos necesarios para representar a escala la forma y localización de la superficie terrestre a través de observaciones, cálculos geodésicos, mediciones topográficas del terreno y su representación en papel y electrónica.

En el ECNN se presentan en forma detallada los números, nombres, escalas y limites de las cartas, con sus respetivas gráficas de ubicación, las cuales se muestran al final de cada serie para una comprensión más fácil del esquema. Esta clasificación fue realizada de acuerdo con los reglamentos de la $\mathrm{OHI}$ para cartas internacionales (INT) y especificaciones cartográficas de la $\mathrm{OHI}(\mathrm{OHI}$, Reglamento de la $\mathrm{OHI}$ para Cartas Internacionales y Especificaciones Cartográficas de OHI S-4, 2016).

La actualización del ECNN se realizó con base en el mismo marco teórico del plan anterior, reduciéndose aproximadamente en un 55 \% la cantidad de cartas, sin omitir el cubrimiento del espacio marítimo nacional. Para la determinación de los límites geográficos de las cartas náuticas se utilizó como referencia el sistema geodésico mundial WGS-84, proyección Mercator. El diseño y las dimensiones no exceden el tamaño del papel máximo recomendado para las cartas náuticas A0 $(119 \mathrm{~cm} \times 84 \mathrm{~cm})$.

La numeración de las cartas náuticas está distribuida de Este $(\mathrm{E})$ a Oeste (W) para el Mar Caribe, y de Norte $(\mathrm{N})$ a Sur (S) para el océano Pacífico. Para efectos de su enumeración según su objetivo, se subdividen en tres grupos así:

Primer dígito cero: oceánicas y generales del Caribe y el Pacífico.

Primer dígito par: mar Caribe colombiano.

Primer dígito impar: océano Pacífico colombiano.

En algunos casos se presentan excepciones a la regla, éstas corresponden a las cartas ya publicadas. La información de los datos de cada carta como: el nombre, el número, la escala y límites internos pueden ser modificados de acuerdo a los requerimientos y necesidades de la Nación.

\section{GENERALIDADES}

\section{Mar Caribe}

\begin{tabular}{|c|c|c|}
\hline Primer digito & Uso & Escala \\
\hline Cero $(0)$ & $\begin{array}{l}\text { Cartas oceánicas o de travesía } \\
\text { Cartas generales }\end{array}$ & $\begin{array}{l}1: 2.000 .001 \text { y menores } \\
1: 2.000 .000-1: 350.001\end{array}$ \\
\hline Cuatro (4) & Cartas costeras & $1: 350.000-1: 75.001$ \\
\hline Seis $(6)$ & $\begin{array}{l}\text { Cartas de aproximación } \\
\text { (acceso a puerto, aguas costeras) }\end{array}$ & $1: 75.000-1: 30.001$ \\
\hline Dos (2) & $\begin{array}{l}\text { Cartas de puerto } \\
\text { (puertos, bahias, fondeaderos, } \\
\text { estrechos) }\end{array}$ & $1: 30.000-1: 12.501$ \\
\hline Ocho (8) & $\begin{array}{l}\text { Cartas de canales, muelles } \\
\text { (canales, muelles, atraque) }\end{array}$ & $1: 12.500$ y mayores \\
\hline
\end{tabular}

\section{Océano Pacífico}

Tabla 2. Esquema cartográfico océano Pacífico.

\begin{tabular}{lll}
\hline Primer dígito & \multicolumn{1}{c|}{ Uso } & \multicolumn{1}{c}{ Escala } \\
\hline Cero (0) & Cartas generales & $1: 2.000 .000-1: 350.001$ \\
\hline Tres (3) & Cartas costeras & $1: 350.000-1: 75.001$ \\
\hline Cinco (5) & $\begin{array}{l}\text { Cartas de aproximación } \\
\text { (acceso a puerto, aguas, costeras) }\end{array}$ & $1: 75.000-1: 30.001$ \\
Uno (1) & $\begin{array}{l}\text { Cartas de puerto } \\
\text { (puertos, bahias, fondeaderos, } \\
\text { estrechos) }\end{array}$ & $1: 30.000-1: 12.501$ \\
Siete (7) & $\begin{array}{l}\text { Cartas de canales, muelles } \\
\text { (canales, muelles, atraque) }\end{array}$ & $1: 12.500$ y mayores \\
\hline
\end{tabular}




\section{GENERALIDADES}

\section{Esquema Cartográfico Náutico Nacional}

La numeración por departamentos para las cartas a escalas 1:12.500 y mayores será así: Tabla 3. Numeración de las cartas náuticas por departamentos.

\begin{tabular}{|c|c|}
\hline \multicolumn{2}{|c|}{ Mar Caribe } \\
\hline La Guajira & $800-809$ \\
\hline Magdalena & $810-819$ \\
\hline Atlántico & $820-829$ \\
\hline Bolívar & $830-839$ \\
\hline Sucre & $840-849$ \\
\hline Córdoba & $850-859$ \\
\hline Antioquia & $860-869$ \\
\hline Chocó & $870-879$ \\
\hline $\begin{array}{l}\text { Archipiélago } \\
\text { de San Andrés y } \\
\text { Providencia }\end{array}$ & $880-889$ \\
\hline
\end{tabular}

\begin{tabular}{|l|l|}
\hline \multicolumn{2}{|c|}{ Océano Pacífico } \\
\hline Chocó & $700-719$ \\
\hline Valle del Cauca & $720-739$ \\
\hline Cauca & $\mathbf{7 4 0}-759$ \\
\hline Nariño & $\mathbf{7 6 0}-779$ \\
\hline
\end{tabular}

Cartas náuticas que se encuentran actualmente disponibles: Tabla 4. Cartas náuticas disponibles.

\begin{tabular}{l|ccc}
$\begin{array}{c}\text { Según su } \\
\text { Objetivo }\end{array}$ & $\begin{array}{r}\text { Caribe } \\
\text { Total }\end{array}$ & $\begin{array}{c}\text { Pacífico } \\
\text { Total }\end{array}$ & $\begin{array}{c}\text { Cartas } \\
\text { Total }\end{array}$ \\
\hline Oceánicas & 1 & - & 1 \\
\hline Generales & 9 & 4 & 13 \\
Costeras & 12 & 5 & 17 \\
Aproximación & 10 & 4 & 14 \\
\hline Puerto & 24 & 11 & 35 \\
\hline Canales o muelles & 8 & 3 & 11 \\
\hline \multicolumn{1}{r}{ Total Cartas } & 64 & 27 & 91 \\
\hline
\end{tabular}




\section{Clasificación Internacional de las Cartas Náuticas}

\section{GENERALIDADES}

Las especificaciones internacionales de la OHI (OHI, Reglamento de la OHI para Cartas Internacionales y Especificaciones Cartográficas de OHI S-4, 2016) y el ECNN (Dimar - $\mathrm{CIOH}, 2010$ ) clasifican las cartas náuticas como a continuación se indica:

\section{Según su escala}

Tabla 5. Clasificación de las cartas náuticas según su escala. Escala Pequeña

Cartas oceánicas o de travesía

Cartas generale

Cartas costeras

$1: 2.000 .000-1: 350.000$

$1: 350.000-1: 75.000$

Escala Grande

Cartas de aproximación

$1: 75.000-1: 30.000$

Bahías, fondeaderos, puerto,

Mayores que 1:30.000

canales estrechos

Escalas muy grandes

Según su edición

Tabla 6. Clasificación de las cartas náuticas según su edición.

Tabla 6. Clasificación de las cartas náuticas

Primera publicación de una carta que cubre un área no cartografiada anteriormente a la escala indicada, o cubre un área de cualquier existente.

\section{Nueva Edición (NE)}

Es una nueva edición de una carta náutica que ha sido afectada por modificaciones esenciales a la navegación que por lo general se ha obtenido a partir de información recibida recientemente.

$$
\text { Nueva Edición Limitada (LNE) }
$$

Debería prepararse sólo cuando exista información que se necesite incluir en una carta rápidamente, pero que no pueda ser promulgada por el Grupo de Avisos a los Navegantes (GAN) o en un aviso gráfico, debido a la extensión geográfica o a la complejidad de la información, o cuando haya otros motivos para producir una NE en muy poco tiempo.

$$
\text { Reimpresión }
$$

Nueva impresión de la edición vigente de una carta, a la cual se le han incluido todos los avisos a los navegantes que la afe, a la cual se le han pueden ser incorporadas también modificaciones de formato.

\section{Según su objetivo}

Tabla 7. Clasificación de las cartas náuticas según su objetivo. Oceánica o de Travesía

Satisfacen la navegación oceánica, para viajes prolongados en altamar entre puertos distantes; se usan, generalmente, en lugares donde no se alcanza a ver la costa.

\begin{tabular}{|c|c|}
\hline \multicolumn{2}{|c|}{ Generales } \\
\hline $\begin{array}{l}\text { Utilizadas para la navegación a lo } \\
\text { largo de la costa, entre puertos } \\
\text { costeros distantes, con frecuencia la } \\
\text { costa no está a la vista. }\end{array}$ & $1: 2.000 .000-1: 350.001$ \\
\hline \multicolumn{2}{|c|}{ Costeras } \\
\hline $\begin{array}{l}\text { Permiten desarrollar la navegación } \\
\text { costera en donde la posición de los } \\
\text { buques puede determinarse utilizando } \\
\text { ayudas a la navegación y puntos } \\
\text { conspicuos en la costa como referencia. }\end{array}$ & $1: 350.001-1: 75.001$ \\
\hline \multicolumn{2}{|c|}{ De Aproximación o Acceso a Puerto } \\
\hline $\begin{array}{l}\text { Permiten desarrollar la navegación } \\
\text { costera y aproximarse a los puertos, } \\
\text { ríos y canales del litoral (acceso a } \\
\text { puerto, aguas costeras congestionadas } \\
\text { o tortuosas). }\end{array}$ & $1: 75.000-1: 30.001$ \\
\hline \multicolumn{2}{|c|}{ De Puertos o de Fondeaderos } \\
\hline $\begin{array}{l}\text { Diseñadas para recalar a puerto y } \\
\text { zonas de fondeo dentro de un área } \\
\text { relativamente pequeña (puertos, } \\
\text { bahías, fondeaderos, estrechos). En } \\
\text { estas cartas se pueden utilizar las } \\
\text { instalaciones portuarias y zarpar de } \\
\text { allí con seguridad. }\end{array}$ & $1: 30.000-1: 12.501$ \\
\hline \multicolumn{2}{|c|}{ De Canales, Muelles y Atraque } \\
\hline $\begin{array}{l}\text { Se utilizan para maniobras de navegación } \\
\text { de gran precisión, debido a la } \\
\text { complejidad del área a navegar. }\end{array}$ & 1: 12.500 y mayores \\
\hline
\end{tabular}

$1: 2.000 .001$ y menores

Catálogo de Cartas Náuticas de Colombia Dimar-CiOH Pág. 028 


\section{GENERALIDADES}

\section{Corrección y Actualizaciones de las Cartas Náuticas}

La carta náutica constituye uno de los elementos más importantes que emplea el navegante para la determinación de rumbos, distancias, situaciones, etc., siendo fundamental el mantener la cartografía siempre actualizada y en condiciones de uso inmediato. Las correcciones y actualizaciones a las cartas náuticas se grafican de acuerdo con la publicación 'Carta 001. Símbolos, Abreviaturas y Términos Usados en las Cartas Náuticas Colombianas'. Para esto e navegante tendrá especial cuidado de no obstruir otras informaciones que figuren en la carta.

La actualización de las cartas náuticas deben ser corregidas y actualizadas por los navegantes, de acuerdo a la publicación de los avisos a los navegantes que realiza el $\mathrm{ClOH}$ de forma permanente a través de su sitio electrónico realiza el $\mathrm{ClOH}$ de forma permanente a traves de su sitio electronico WWw.cioh.org.CO, donde se dan a conocer las novedades inherentes a la actividad
marítima. De igual forma, los usuarios pueden enviar adiciones y comentarios al $\mathrm{CIOH}$ al correo electrónico nautica@dimar.mil.co o a través de la APP 'Gente de Mar'.

Avisos a los navegantes

Un aviso a los navegantes es un reporte oficial de datos para suministrar información de utilidad relacionada con las modificaciones en las ayudas a la navegación, los peligros para la misma, nuevos sondajes de importancia y todo lo que permita brindar seguridad en la navegacion y actualizacion de las publicaciones náuticas y cartográficas. Los avisos a los navegantes pueden ser de carácter general $(G)$, temporal $(T)$ o permanente $(P)$. Únicamente puede ser emitido por la Sección de Náutica del SHN.

Avisos permanentes (P)

Informan un cambio permanente en las cartas o publicaciones afectadas, causadas por modificaciones en las estructuras y características, supresión definitiva, reubicación, adición de nuevas ayudas y cambios en el fondo marino o la línea de costa.
Avisos temporales $(\mathrm{T})$

Informan novedades o alteraciones de naturaleza transitoria que se presentan físicamente en las ayudas en la navegación y demás novedades que afecten la seguridad marítima.

Avisos generales $(G)$

Comunican a los navegantes toda información o instrucción que por su naturaleza no altera un documento y advierten anticipadamente acontecimientos, de cualquier tipo, que van a producirse en la comunidad marítima específicamente y que generalmente no implican correcciones a las cartas y publicaciones náuticas. También se utilizan para suministrar información de manera local o jurisdiccional de un puerto o área específica.

\section{¿Cómo adquirir las cartas náuticas?}

En esta ocasión el $\mathrm{CIOH}$ entrega una nueva edición del CATÁLOGO DE LAS CARTAS NÁUTICAS DE LOS OCÉANOS Y COSTAS DE COLOMBIA, el cual compila las cartas que se encuentran vigentes y que a su vez brindan al usuario una manera más dinámica y práctica de encontrar las cartas náuticas que requiere para navegar de manera segura.

La lista completa de cartas y publicaciones náuticas se encuentra disponible en la tienda virtual de Dimar: http://tienda.dimar.mil.co. En este portal podrá comprar todas las cartas y publicaciones náuticas oficiales de Colombia, actualizadas con la última información suministrada por el SHN del CIOH-Dimar. 


\section{AGRADECIMIENTOS}

ant

(4) $\frac{14}{11}+\frac{1}{4}$

\section{.}
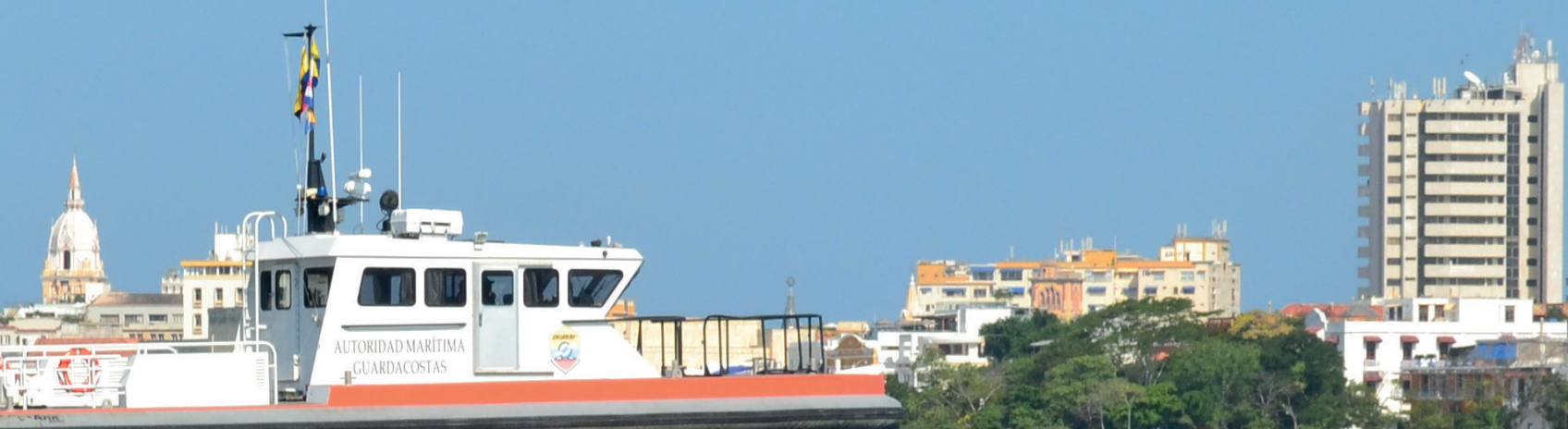

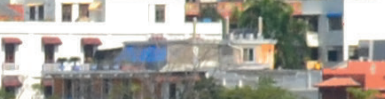
B.mintos 14

El Servicio Hidrográfico Nacional expresa sinceros agradecimientos a todos los funcionarios que hicieron realidad esta edición del CATÁlogo de CARTAS NÁUticAS de los OCÉANOS Y COSTAS DE COLOMBIA

A la Dirección General Marítima, especialmente al Centro de Investigaciones Oceanográficas e Hidrográficas del $\mathrm{Caribe}(\mathrm{ClOH})$ y al señor Capitán de Corbeta Gustavo Adolfo Gutiérrez Leones, Responsable del Área de Hidrografía CIOH - Servicio Hidrográfico Nacional.

A todo el personal que integra la Sección de Náutica, al Suboficial Jefe Carlos Alberto Zúñiga Guzmán, Responsable Sección Náutica; al Suboficial Segundo Juan David Ortiz Buitrago, Responsable de los Avisos a los Navegantes y Actualización Cartográfica, por sus amables sugerencias, comentarios, recomendaciones y disposición a colaborar permanentemente.

A la señora Profesional de Defensa Angélica María Castrillón Gálvez, editora del Área de Comunicaciones Estratégicas de Dimar, por sus aportes y acompañamiento en el proceso de edición e impresión de esta publicación.

\section{¡A todos gracias!}




\section{CARTOGRAFÍA MAR CARIBE COLOMBIANO}

(3) $\overline{\mathrm{Dlmar}}$

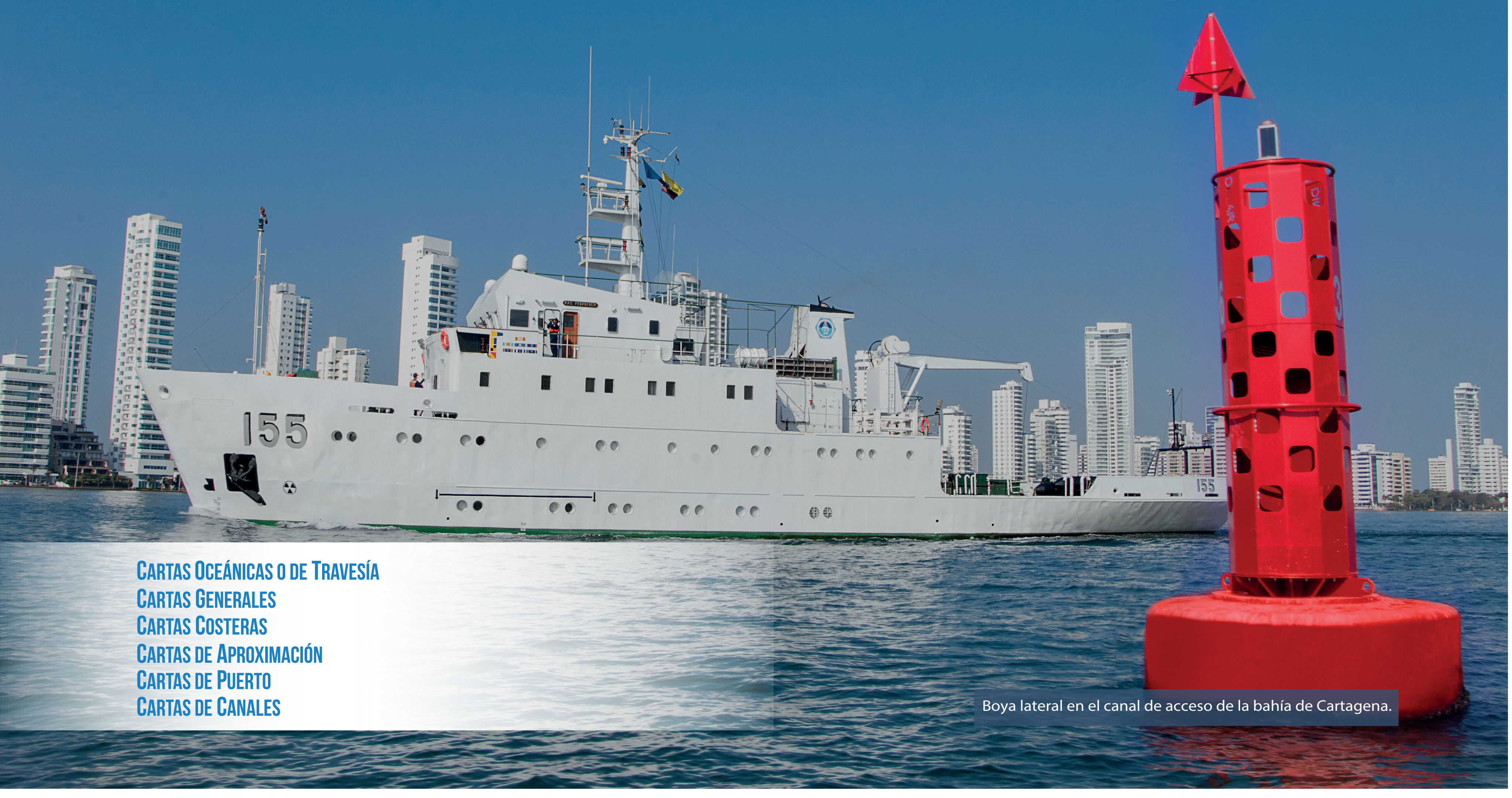




\section{CARTAS OCEÁNICAS / MAR CARIBE}

Cartas oceánicas o de travesía(escalas 1:2.000.001 y menores)

Tabla A1. Carta oceánica mar Caribe.

\begin{tabular}{c|c} 
No. Carta & \\
007 & El Gran Caribe
\end{tabular}

Nombre

Escala

1:3.000.000

\begin{tabular}{c|c|c}
\hline Edición & Año & Pág. \\
\hline 5 & 2013 & A003 \\
\hline
\end{tabular}

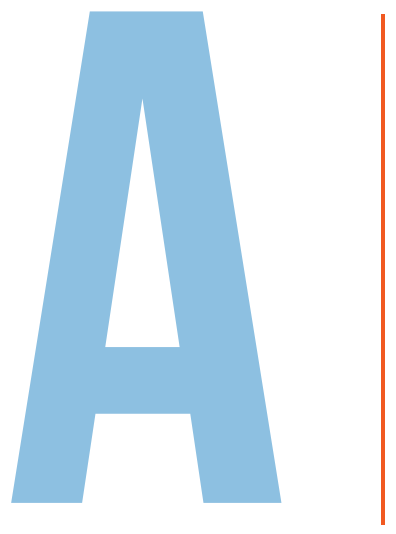




\section{CARTAS OCEÁNICAS / MAR CARIBE}

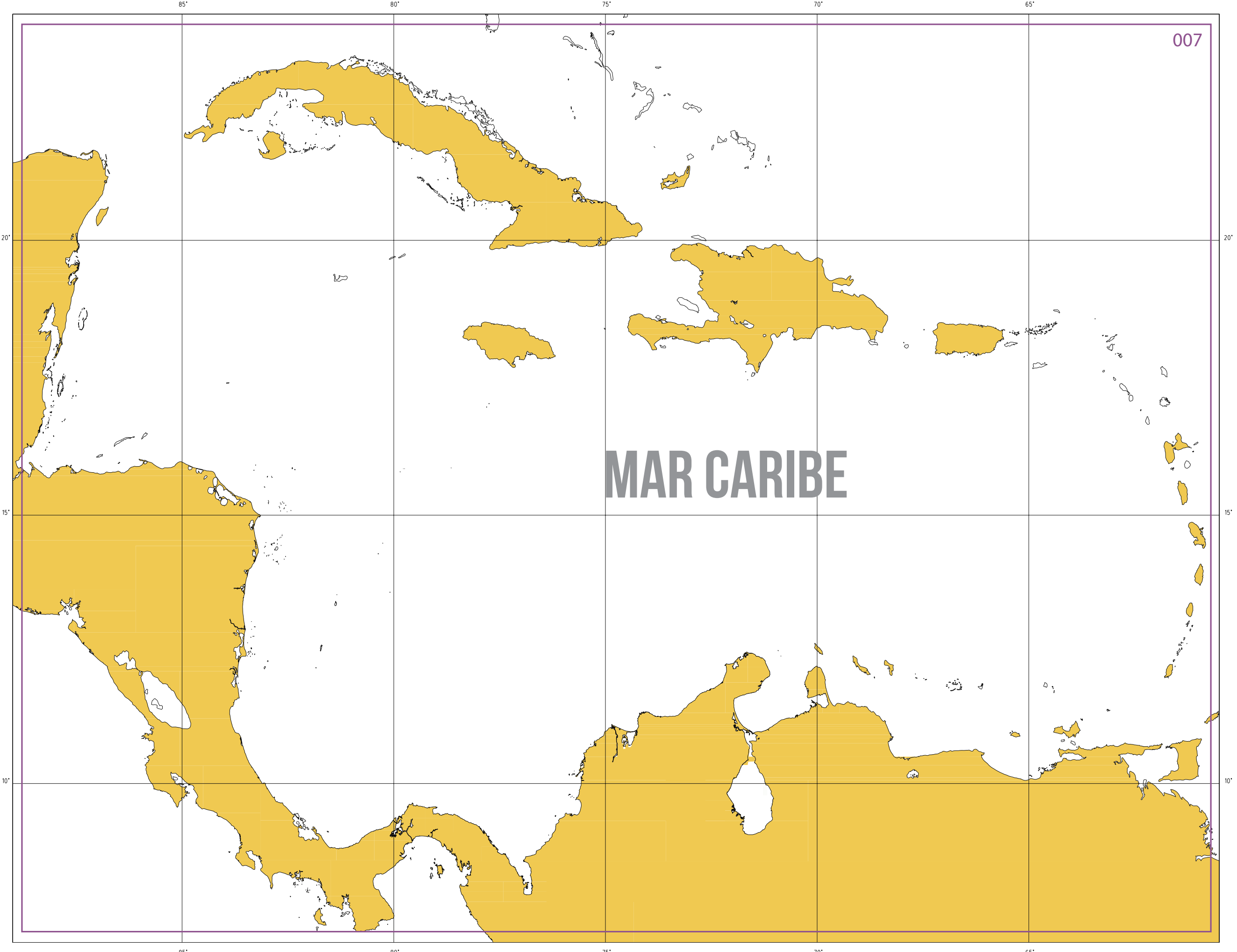

Figura 1. Esquema general de cartas oceánicas mar Caribe. 


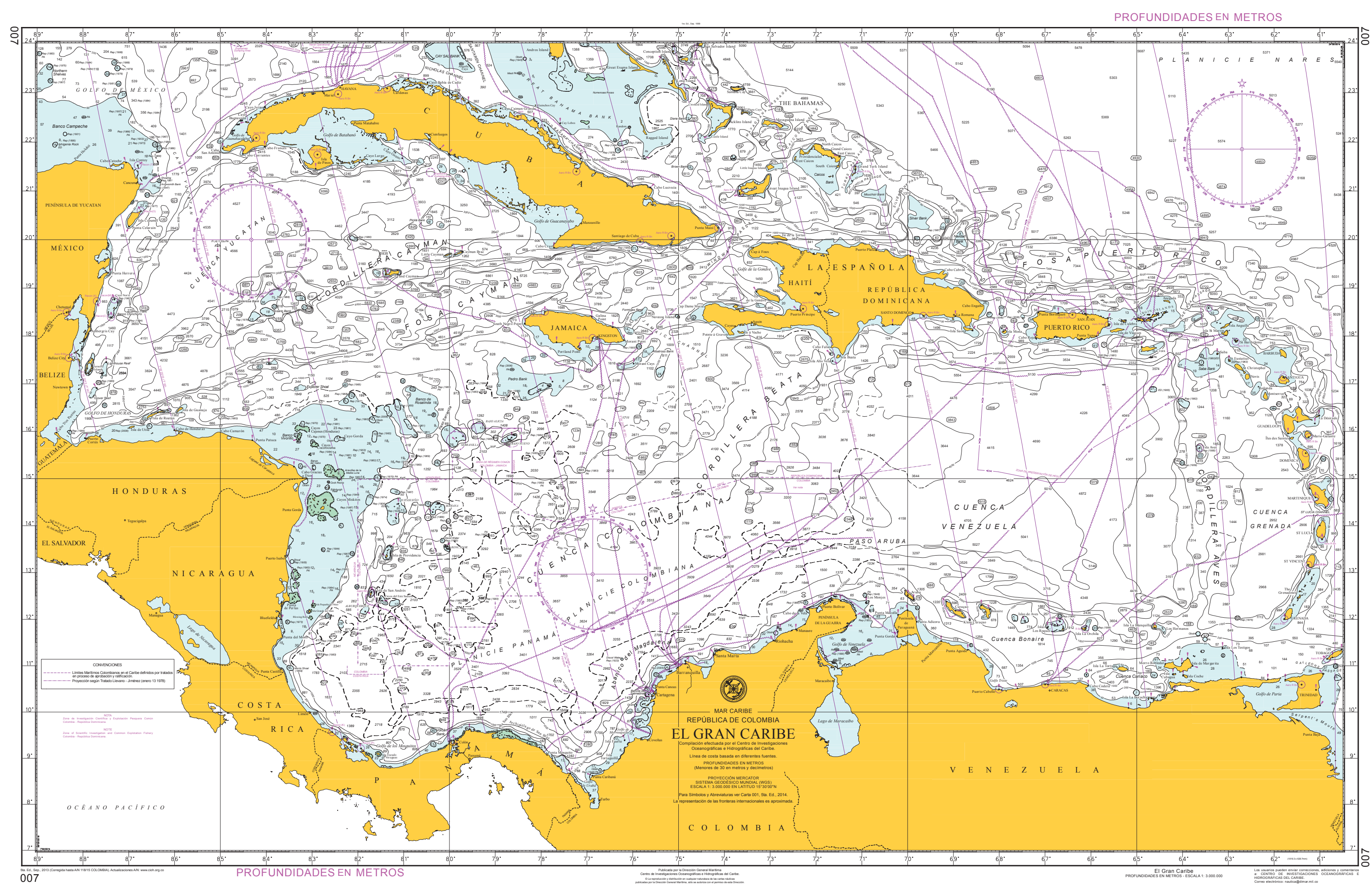

(5) Dlmar (6)= 
Cartas generales (escalas 1:2.000.000 - 1:350.001)

Tabla B1. Cartas generales mar Caribe.

\begin{tabular}{|c|l|c|c|c|c|}
\hline No. Carta & \multicolumn{1}{c}{ Nombre } & Escala & Edición & Año & Pág. \\
\hline 004 & Archipiélago de San Andrés y Providencia & $1: 600.000$ & 2 & 2000 & B003 \\
\hline 005 & Carta General del Caribe Colombiano & $1: 1.500 .000$ & 4 & 2011 & B004 \\
\hline 008 INT 4025 & Cabo Gracias a Dios a Santa Marta & $1: 1.000 .000$ & 2 & 2013 & B005 \\
\hline 020 INT 4126 & Pedro Bank a Isla Cayos de Quitasueño & $1: 400.000$ & 1 & 2006 & B006 \\
\hline 021 INT 4124 & Cabo Gracias a Dios a Isla de San Andrés & $1: 400.000$ & 1 & 2006 & B007 \\
\hline 022 INT 4122 & Isla de San Andrés a Golfo de los Mosquitos & $1: 400.000$ & 1 & 2006 & B008 \\
\hline 023 INT 4120 & Golfo de los Mosquitos a Punta Mosquito & $1: 400.000$ & 1 & 2006 & B009 \\
\hline 028 & Barranquilla a Punta Espada & $1: 500.000$ & 3 & 2013 & B010 \\
\hline 029 & Golfo de Urabá a Barranquilla & $1: 500.000$ & 3 & 2013 & B011 \\
\hline
\end{tabular}

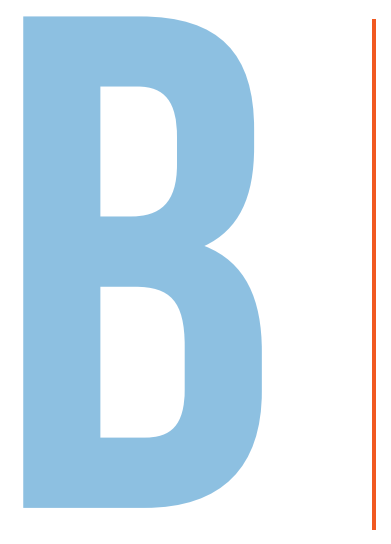




\section{CARTAS GenERALES / MAR CARIBE}

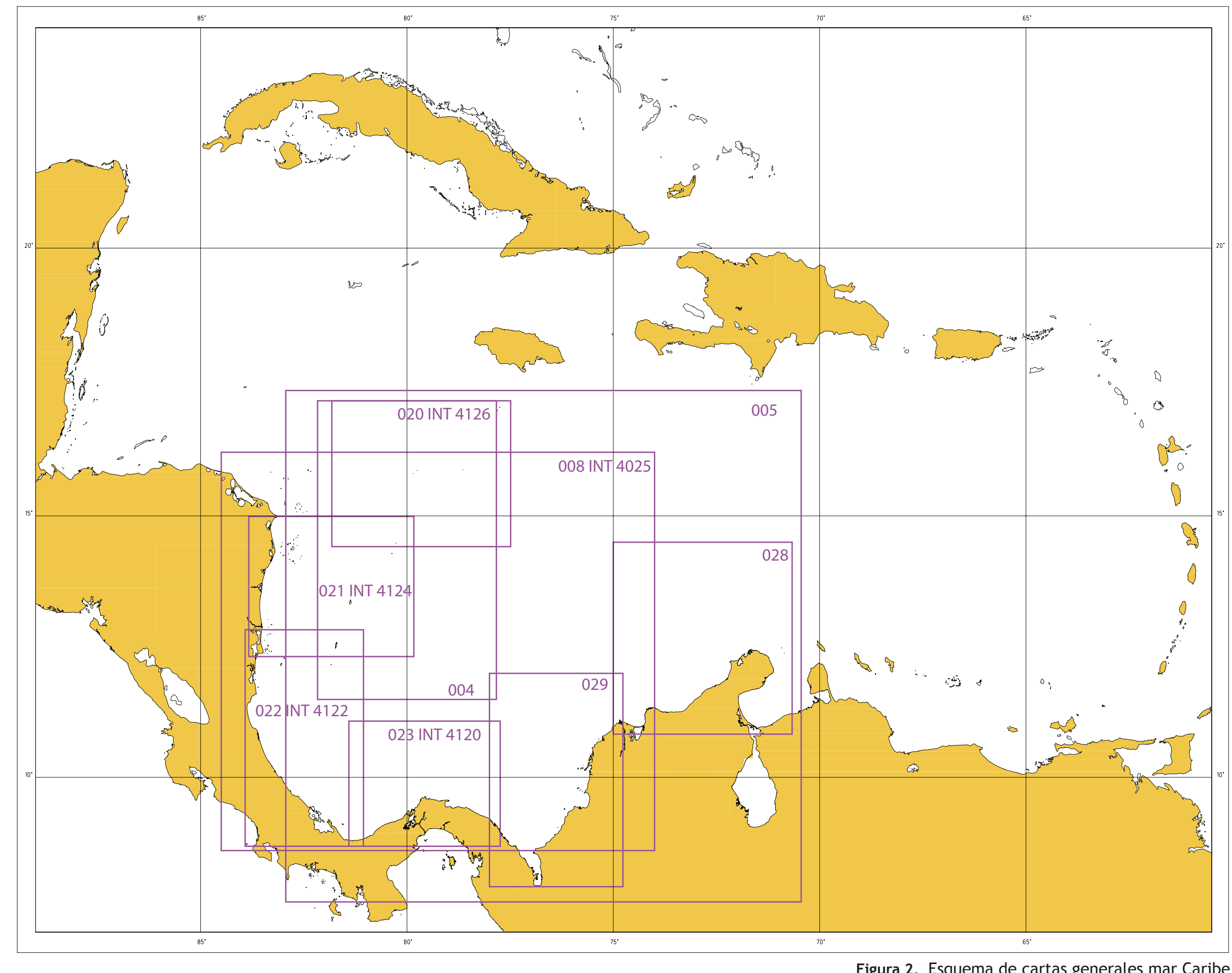

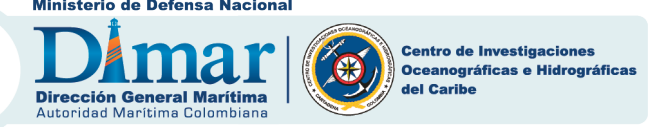




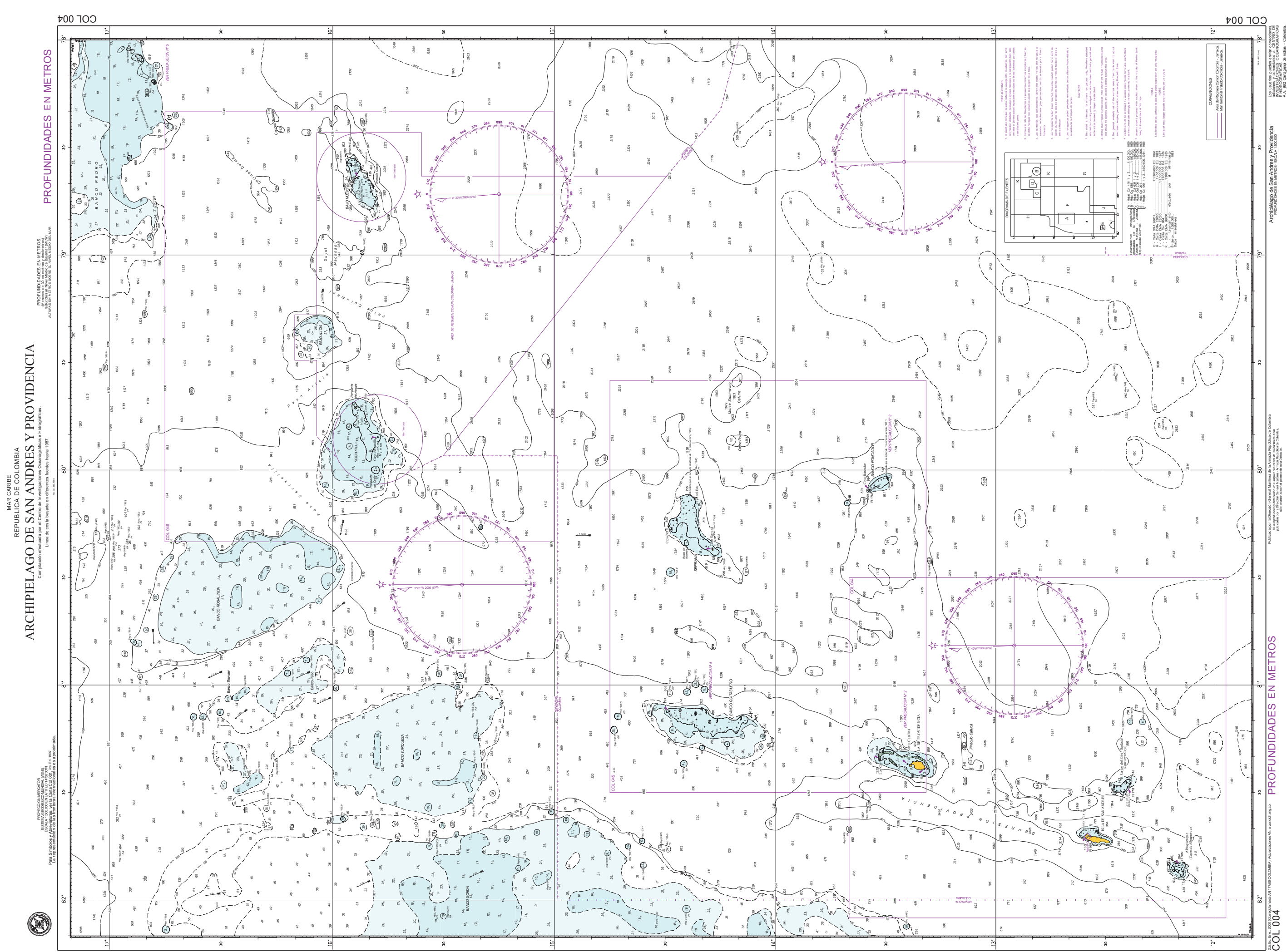




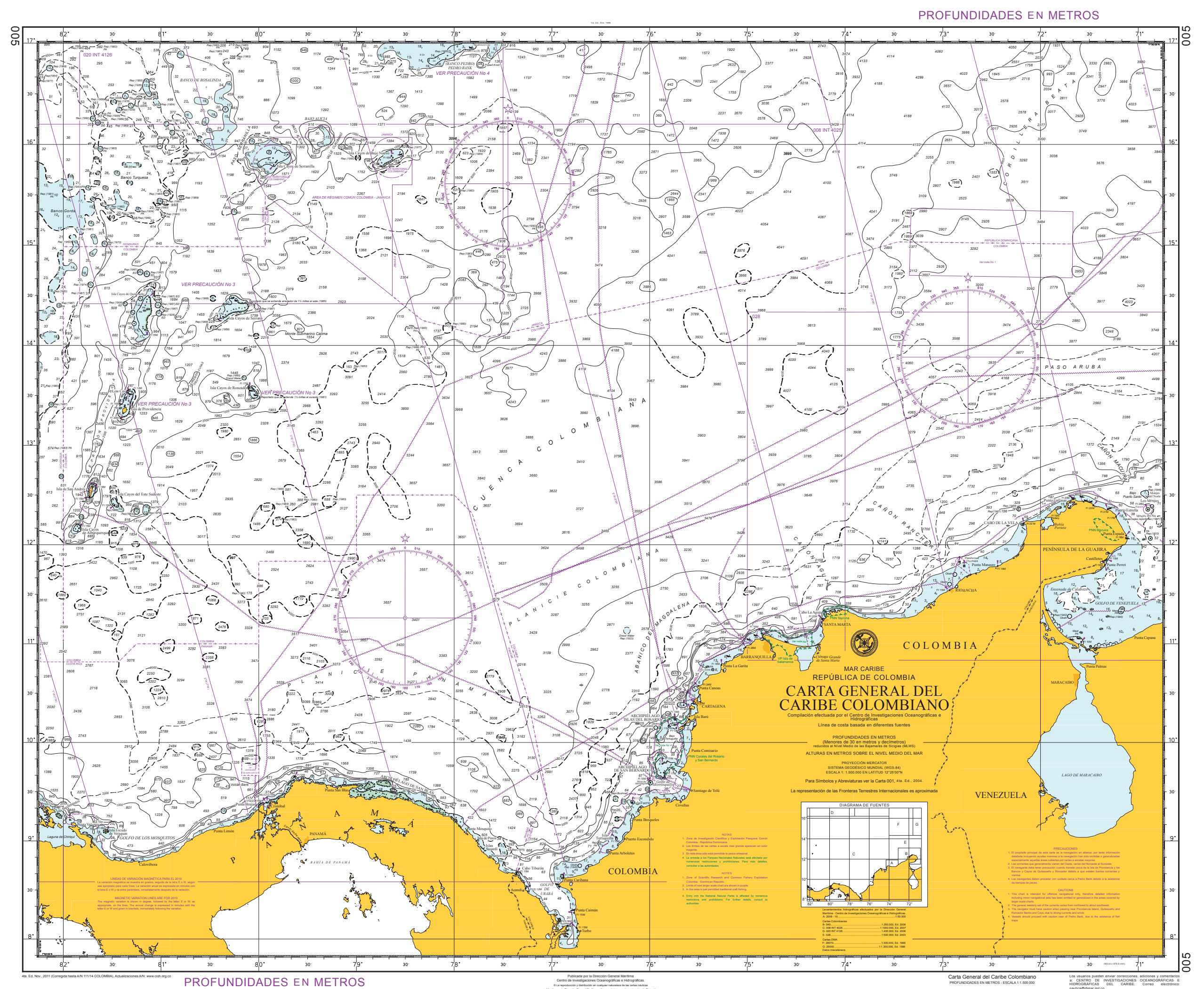

Dimar (c) = 


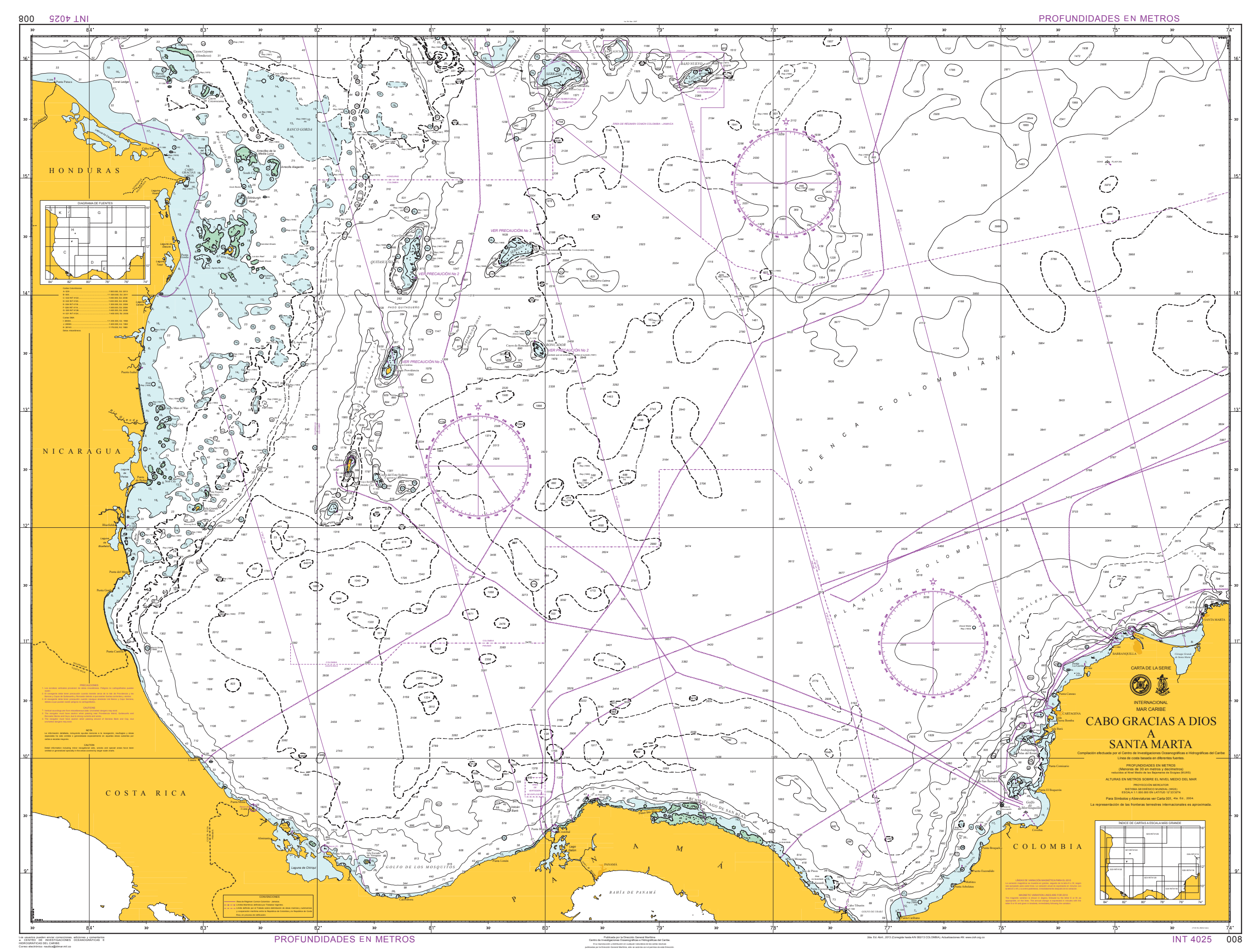




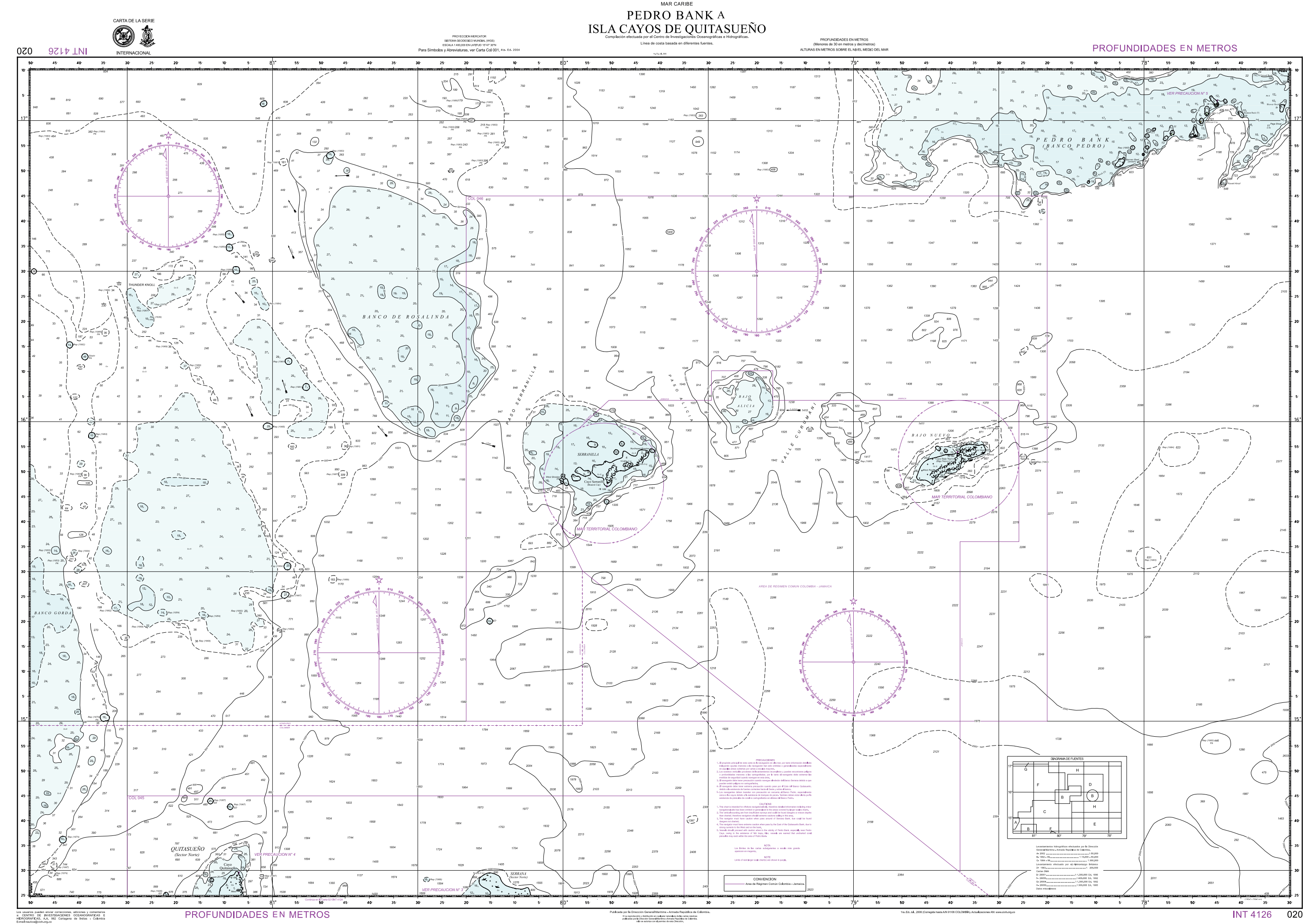




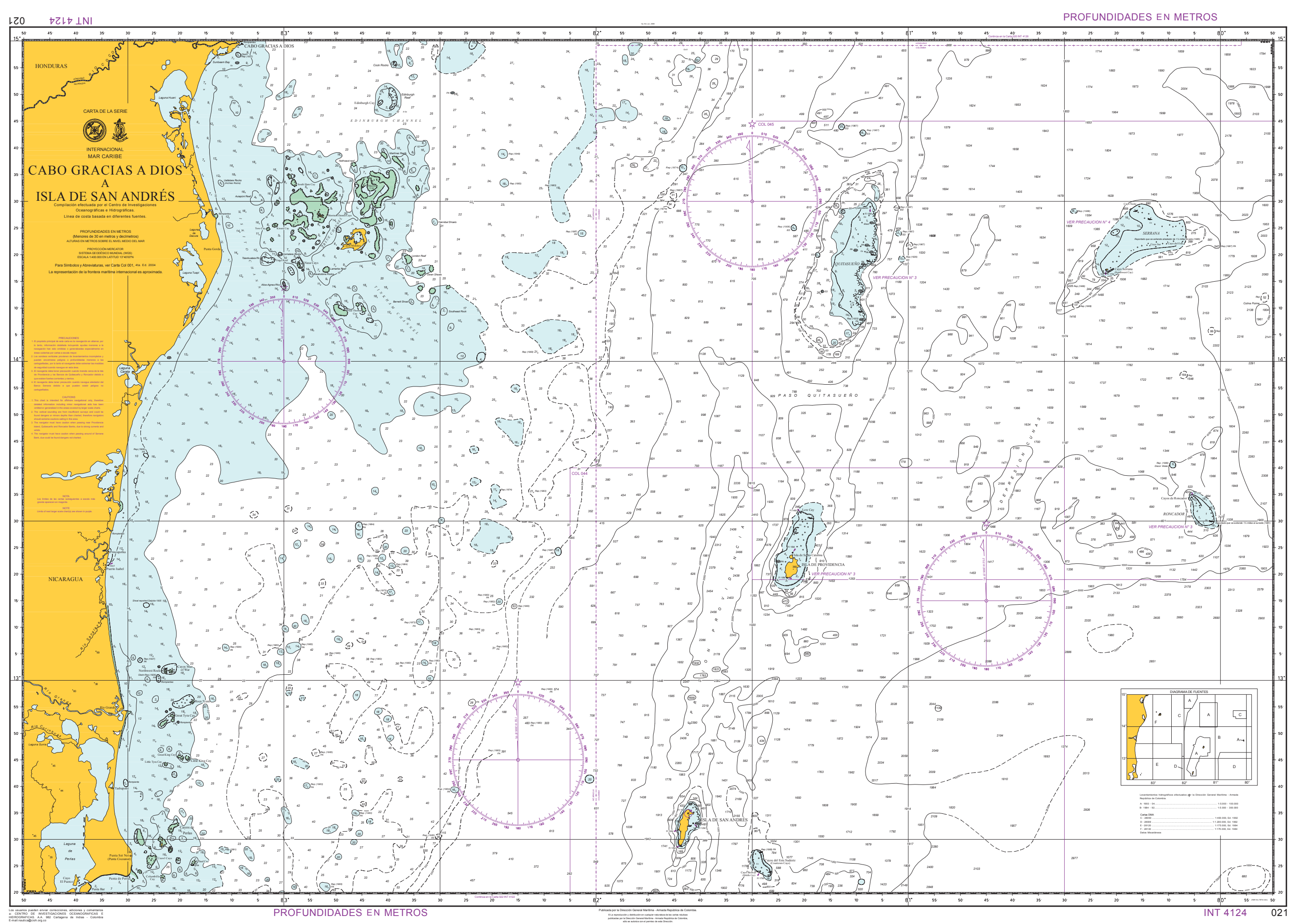




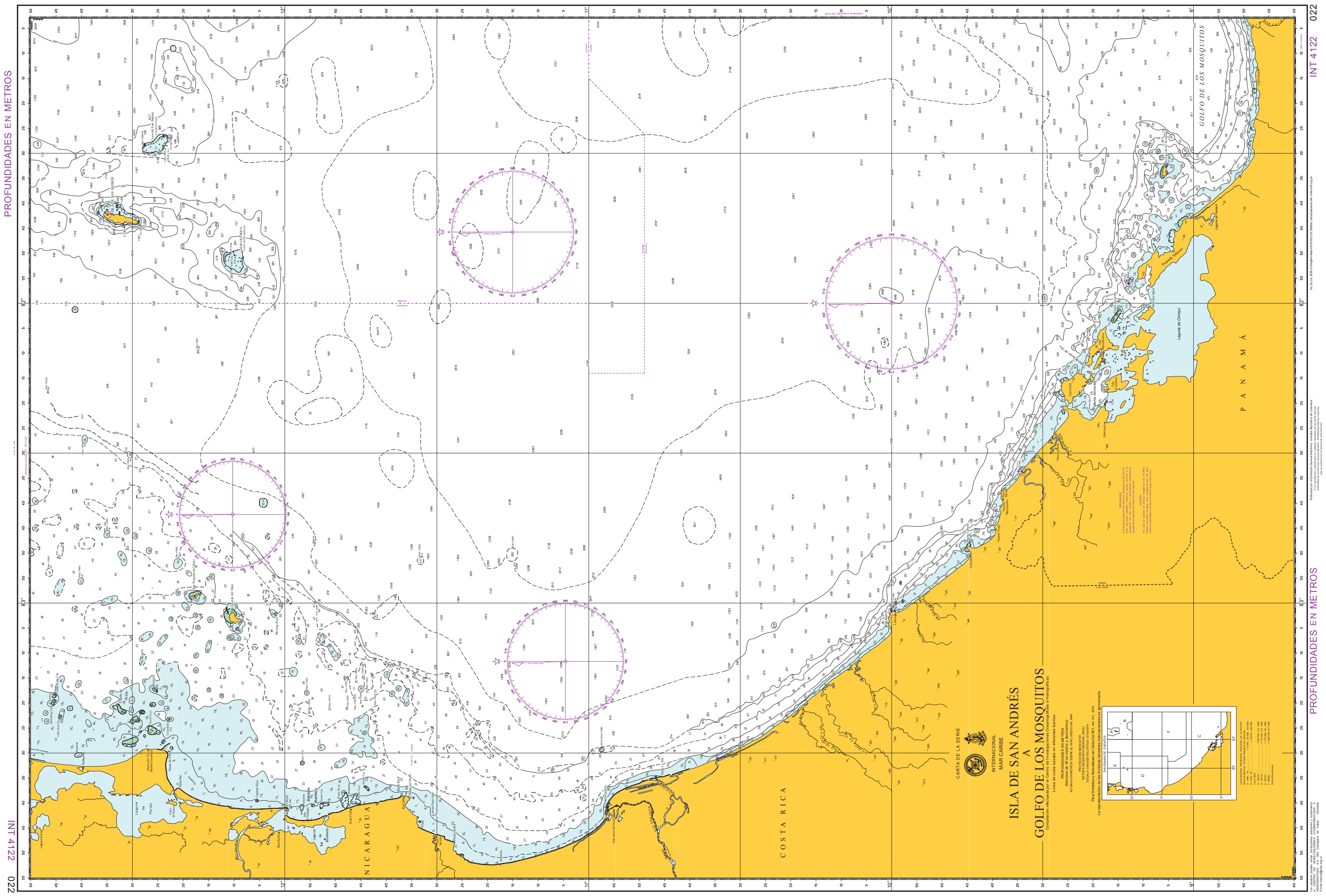

(3) Dlmar $(0)=$ 


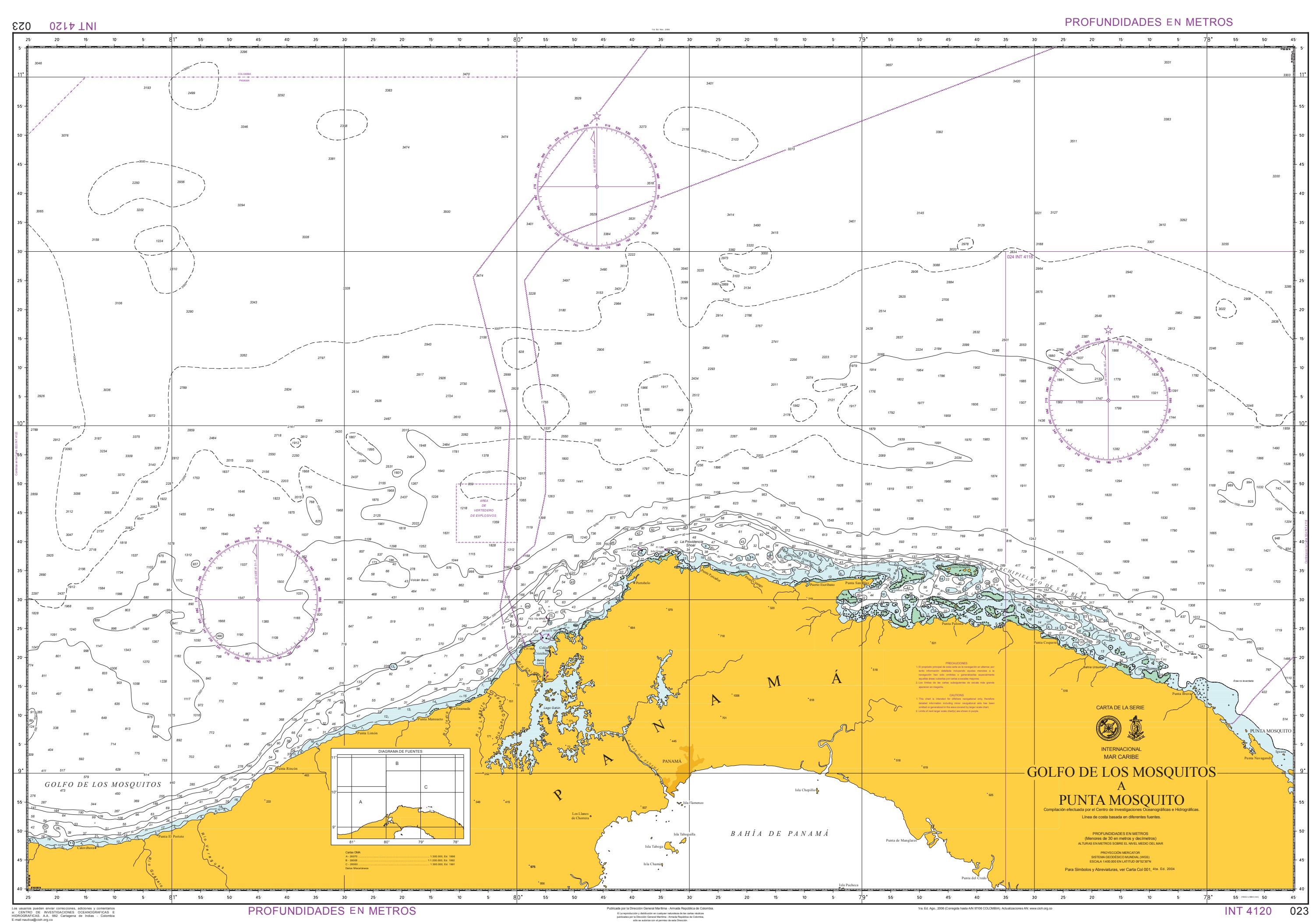




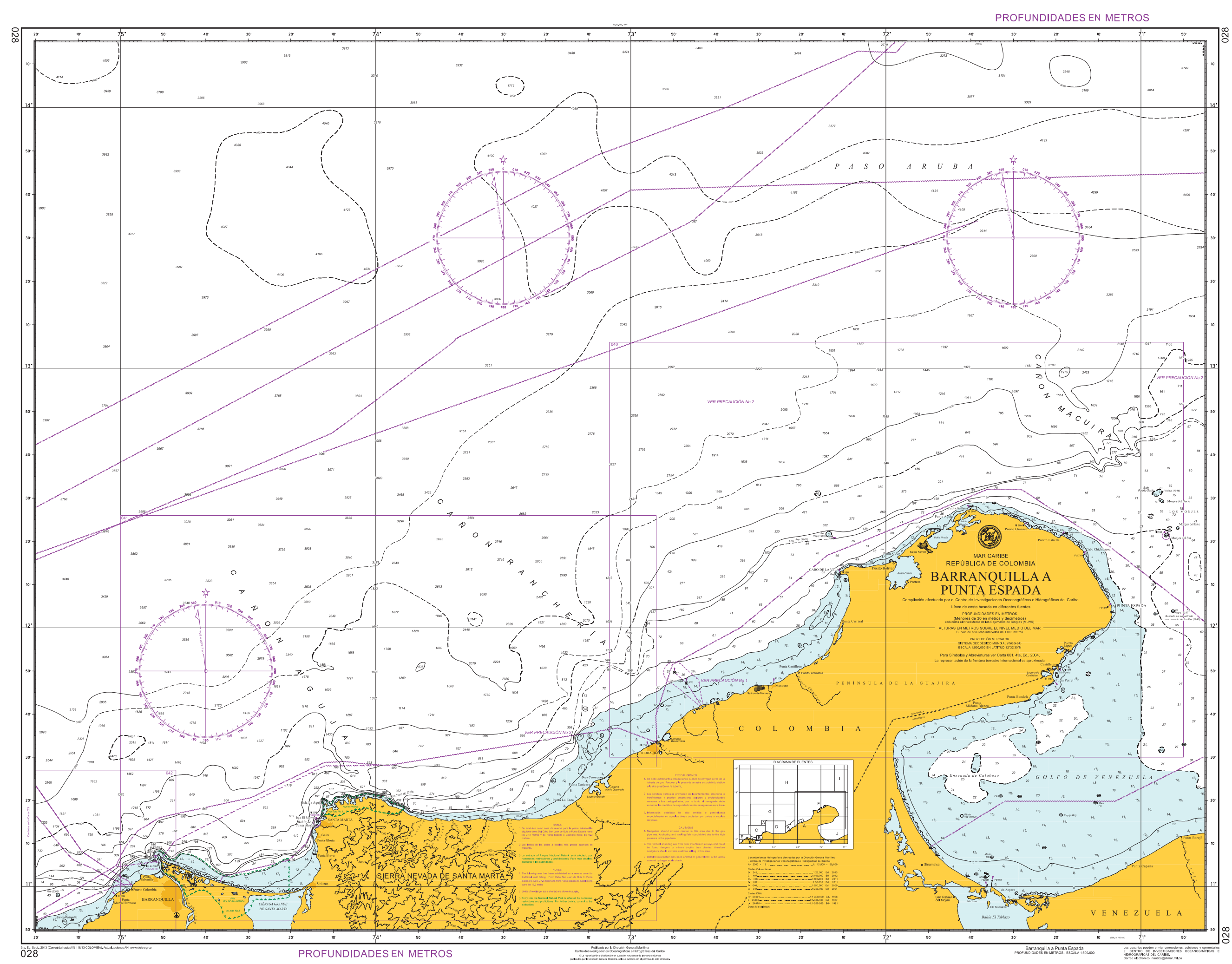

Dimar $(0)=$ 


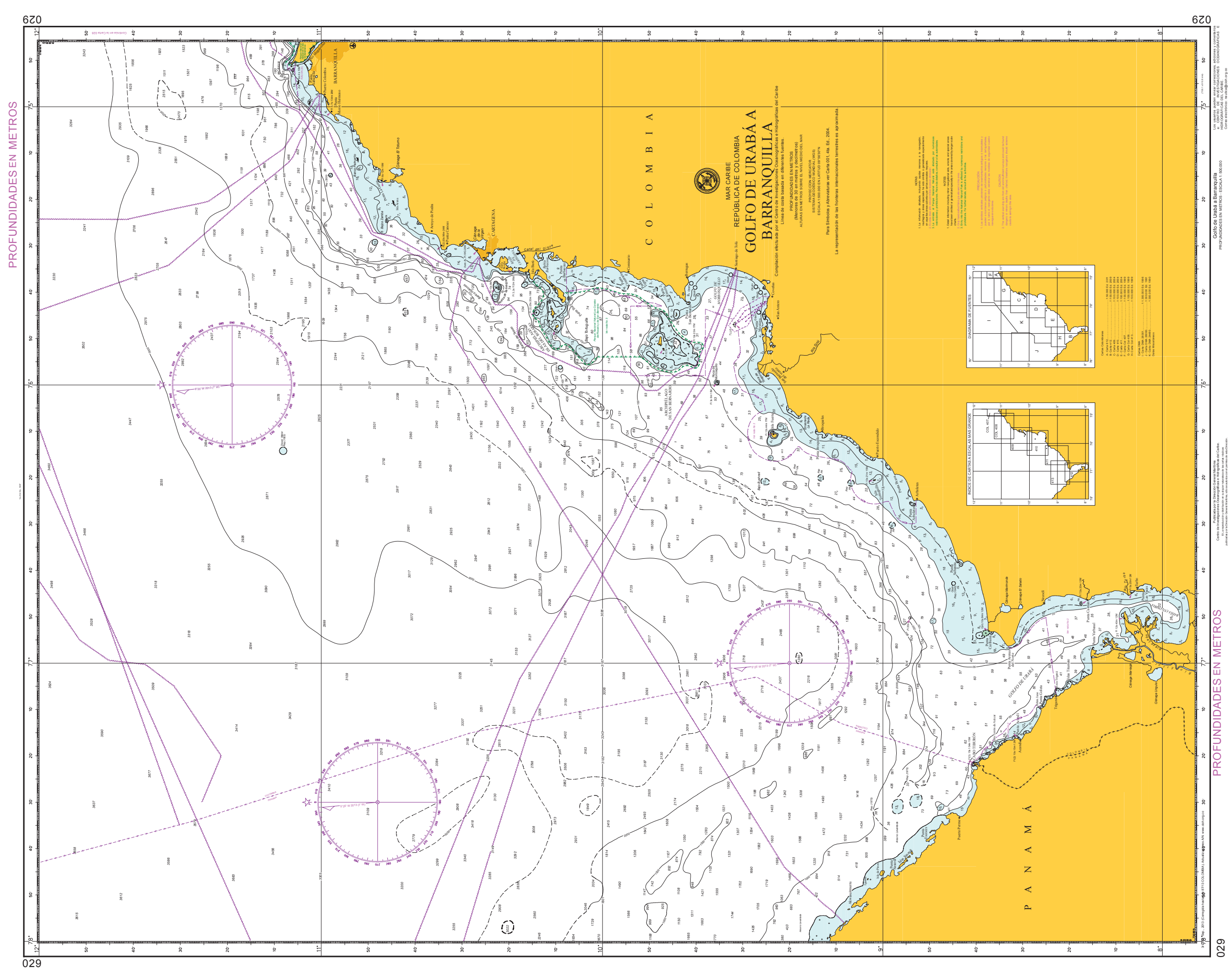




\section{CARTAS CosterAS / MAR CARIBE}

Cartas costeras (escalas 1:350.000 - 1:75.001)

Tabla C1. Cartas costeras mar Caribe.

\begin{tabular}{|c|c|c|c|c|c|}
\hline No. Carta & Nombre & Escala & Edición & Año & Pág. \\
\hline 402 & Punta Gallinas a Cabo Chichibacoa & 1:100.000 & 1 & 2009 & $\mathrm{co03}$ \\
\hline 403 & Cabo de la Vela a Punta Gallinas & 1:100.000 & 1 & 2015 & C004 \\
\hline 404 & Punta la Vela a Cabo de la Vela & 1:100.000 & 1 & 2009 & C005 \\
\hline 406 & Santa Marta a Cabo San Agustín & 1:100.000 & 3 & 2011 & C006 \\
\hline 407 & Puerto Colombia a Santa Marta & 1:100.000 & 2 & 1999 & C007 \\
\hline 408 & Punta Canoas a Puerto Colombia & 1:100.000 & 1 & 1999 & $\mathrm{C} 008$ \\
\hline 409 & Bajo Tortuguilla a Punta Canoas & $1: 100.000$ & 2 & 2004 & C009 \\
\hline 410 & Isla Fuerte a Punta Comisario & 1:100.000 & 3 & 2013 & C010 \\
\hline 411 & Punta Gigantón a Isla Fuerte & $1: 100.000$ & 2 & 2004 & C011 \\
\hline 412 & Golfo de Urabá & 1:100.000 & 3 & 2009 & $\mathrm{C} 012$ \\
\hline 413 & Cabo Tiburón a Punta Gigantón & 1:100.000 & 1 & 1999 & C013 \\
\hline 416 & Isla Cayos de Quitasueño & 1:100.000 & 1 & 2000 & C014 \\
\hline
\end{tabular}

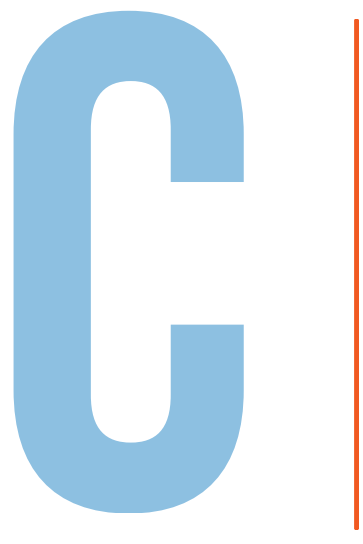




\section{CARTAS COSTERAS / MAR CARIBE}

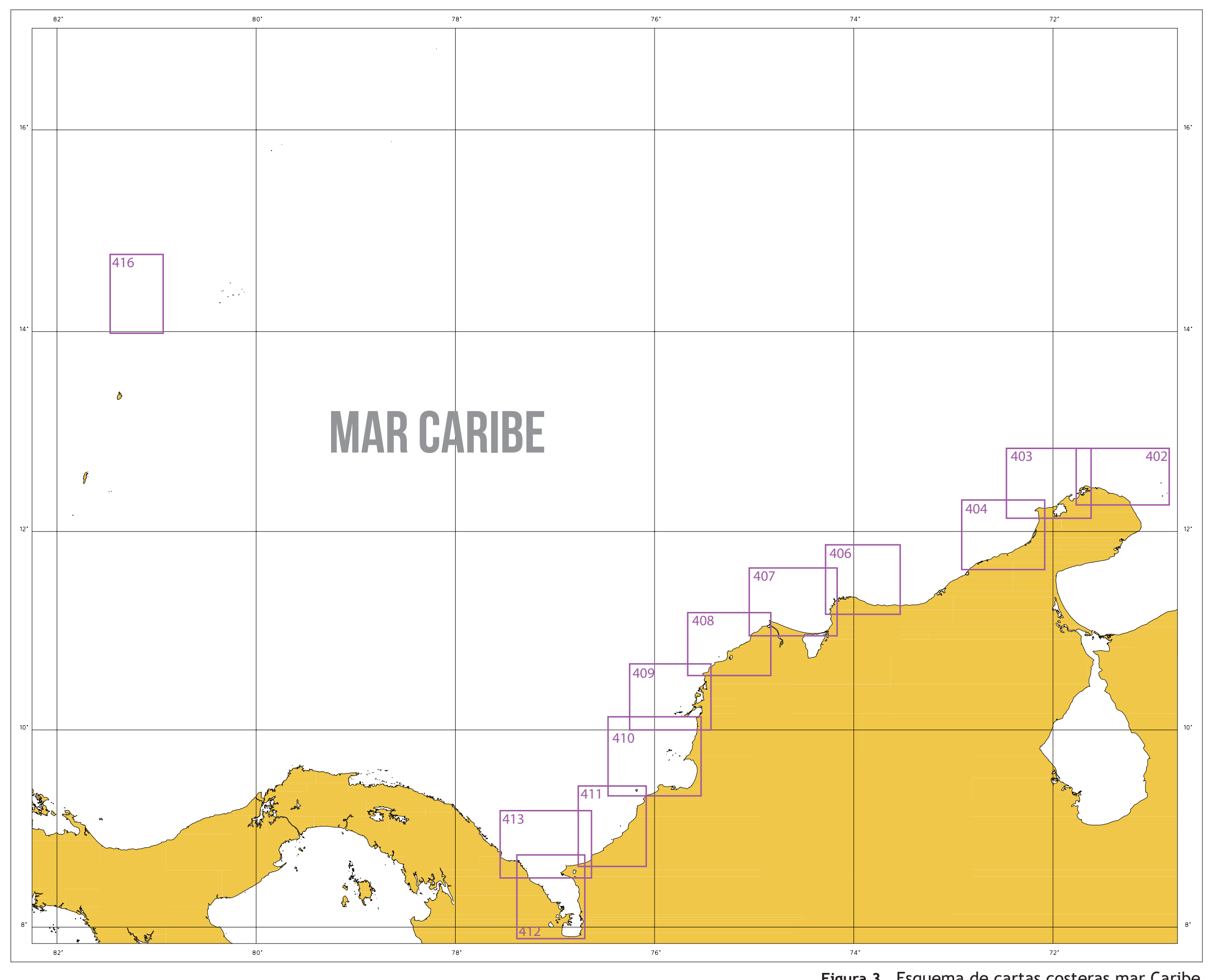




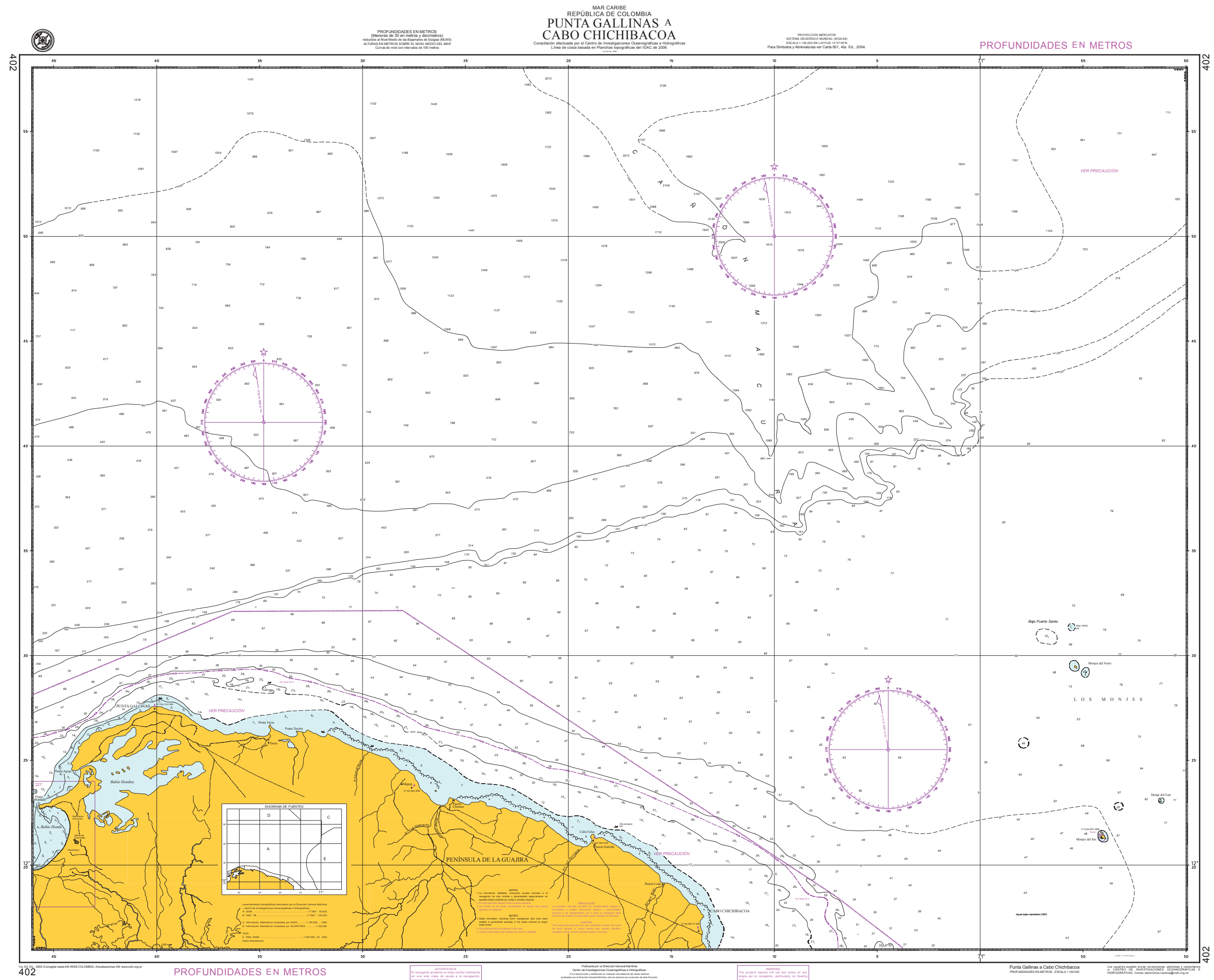

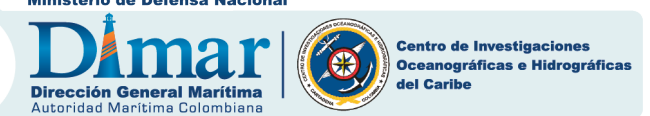




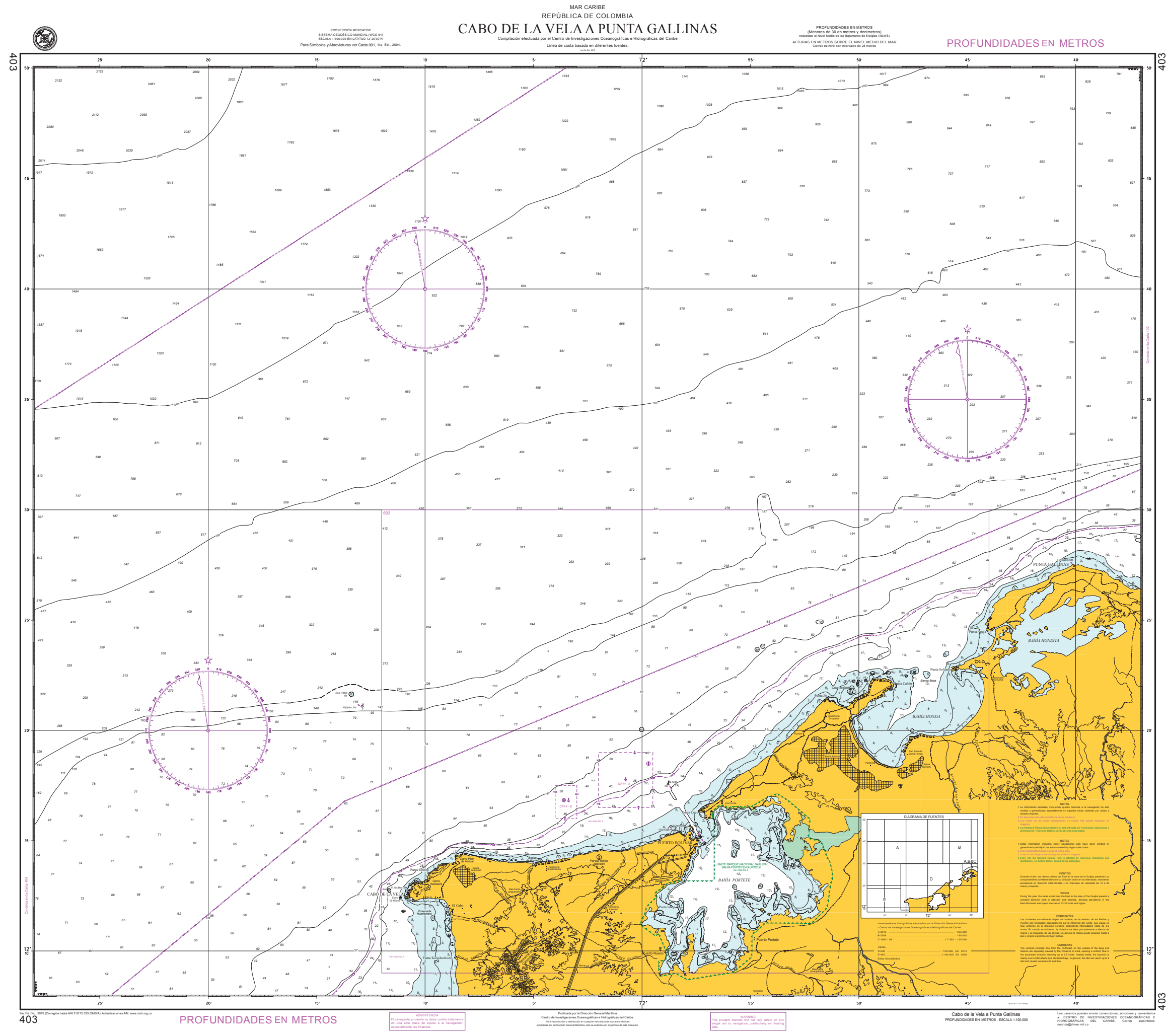




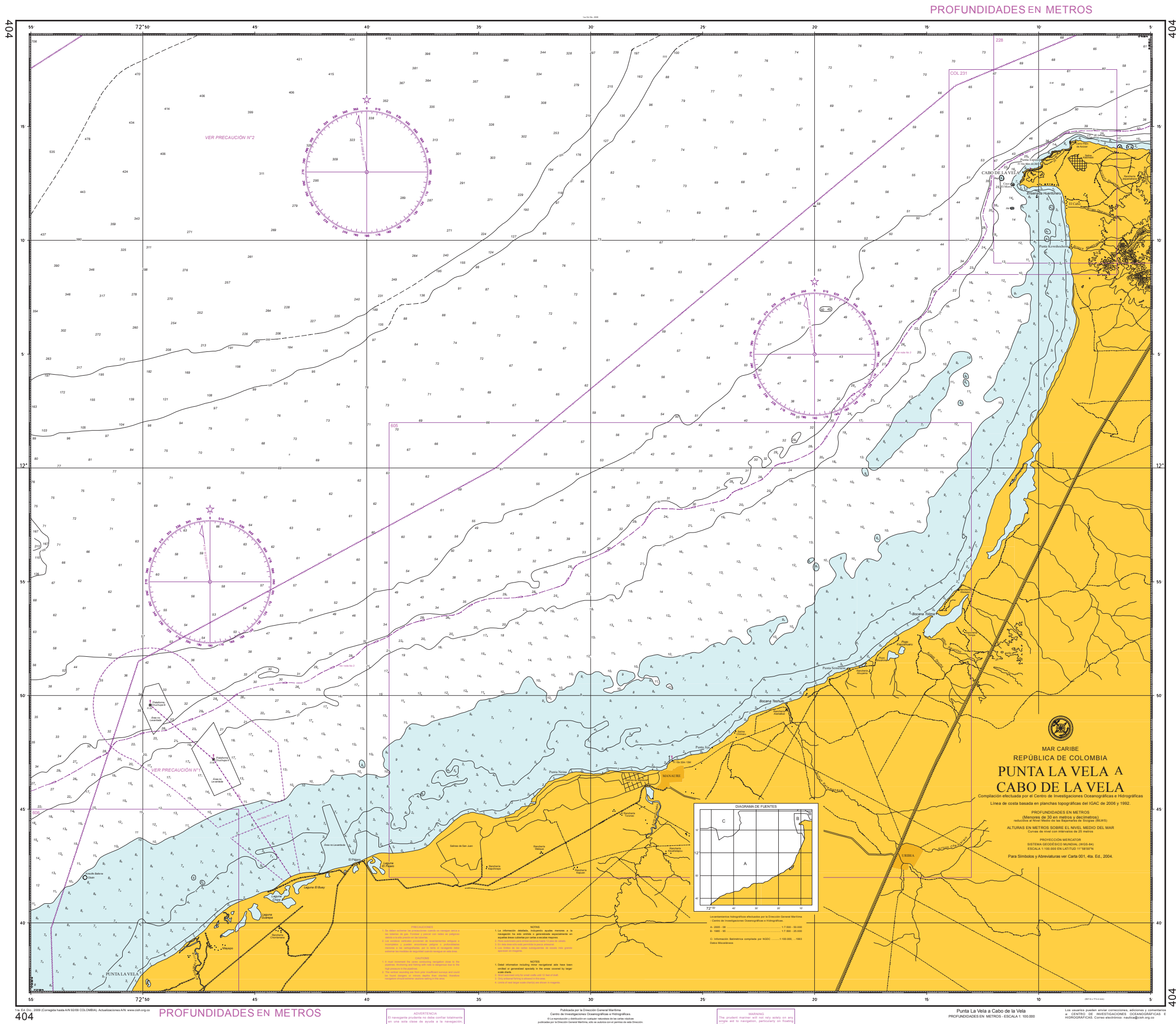

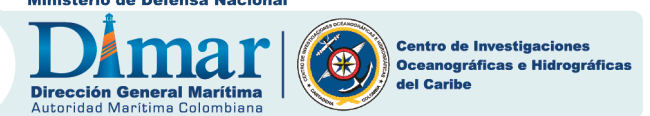




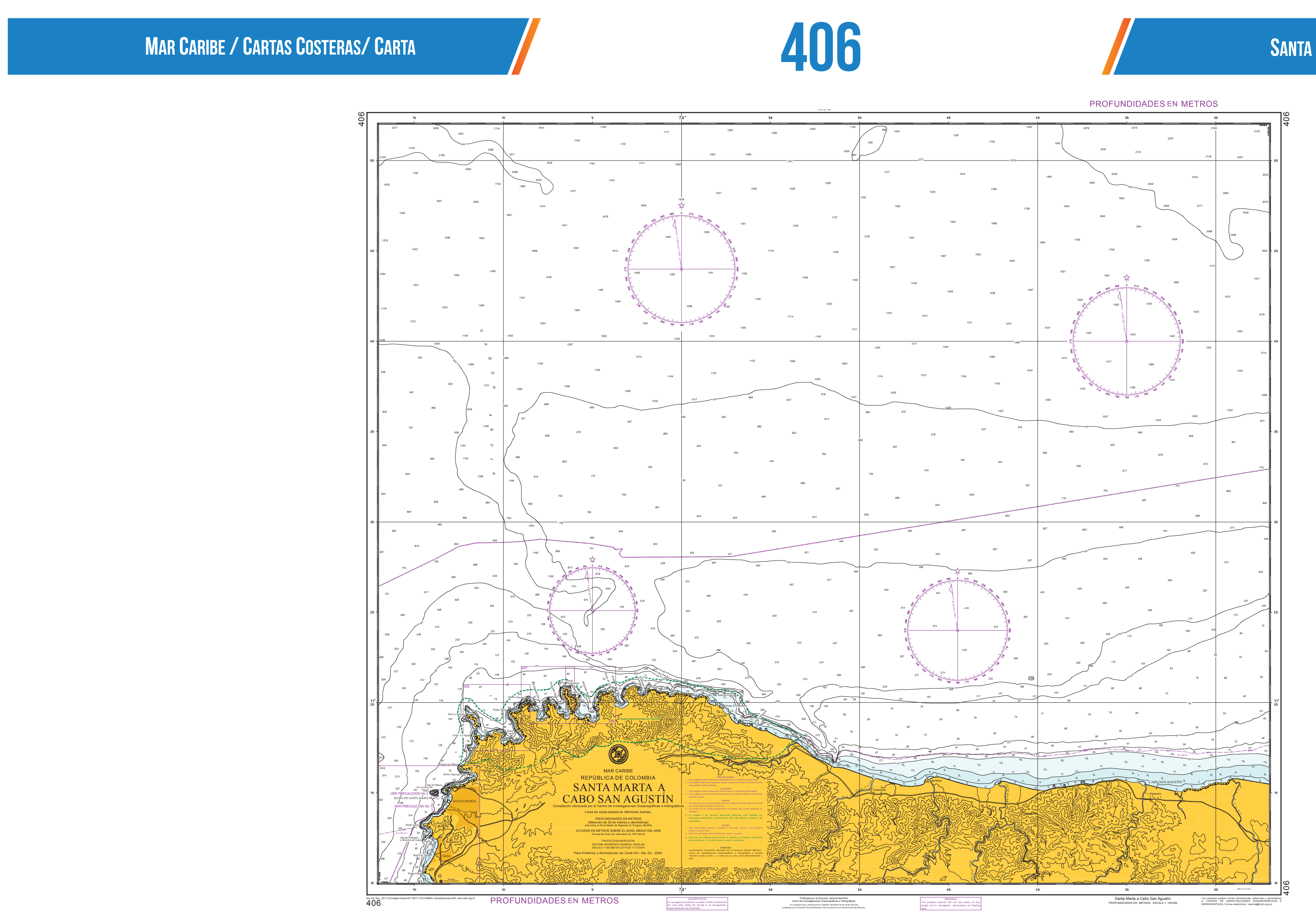

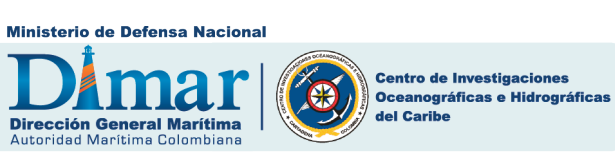

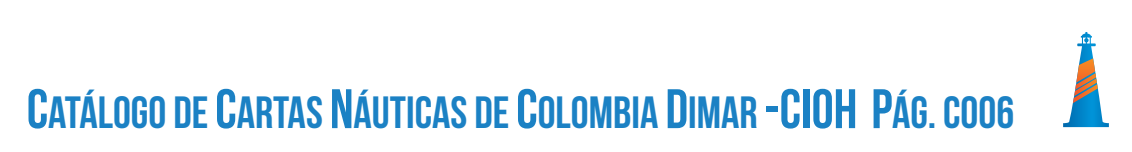




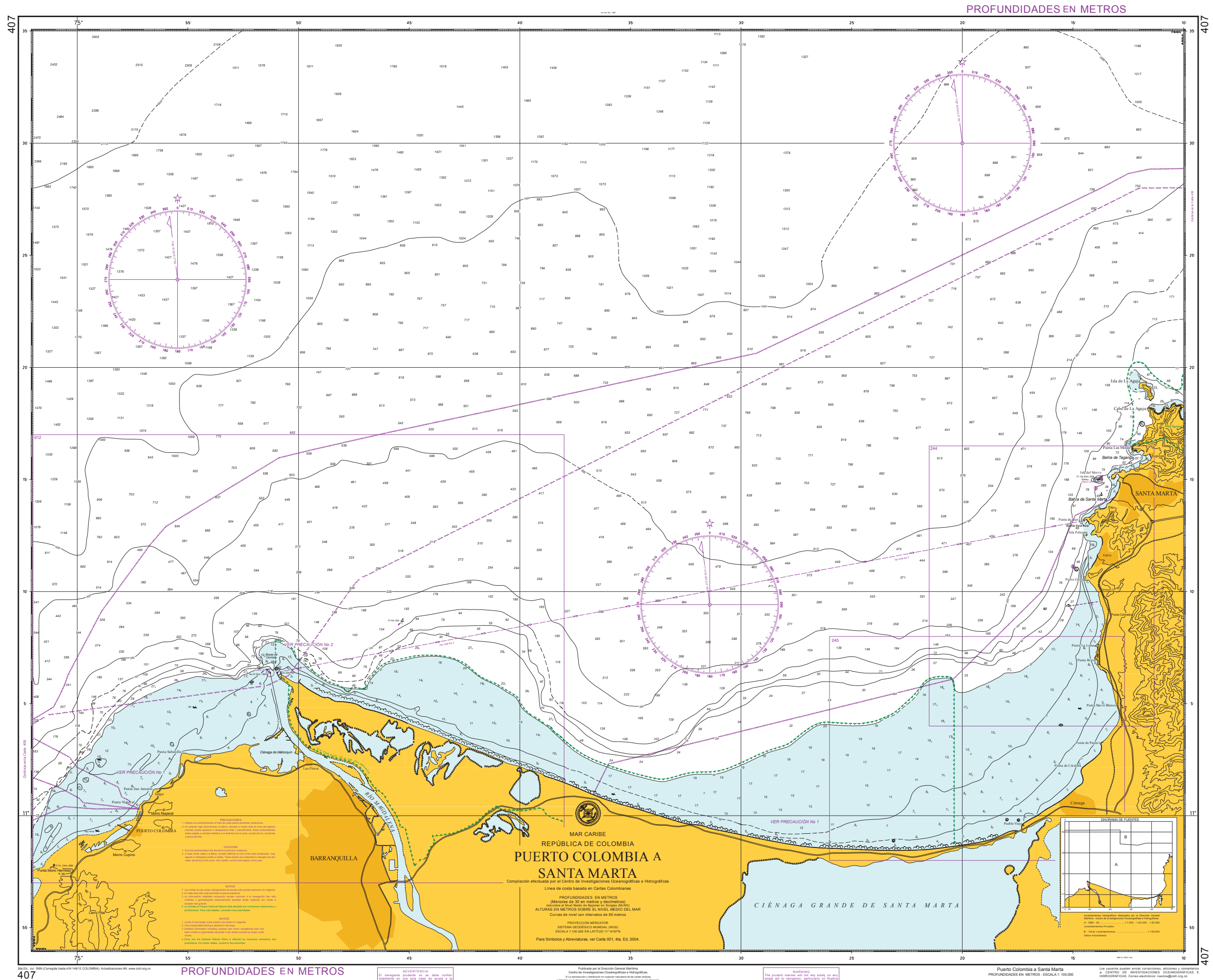

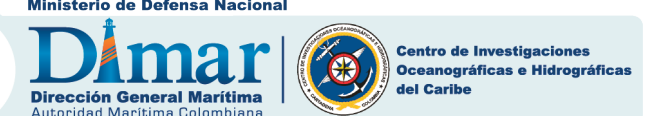




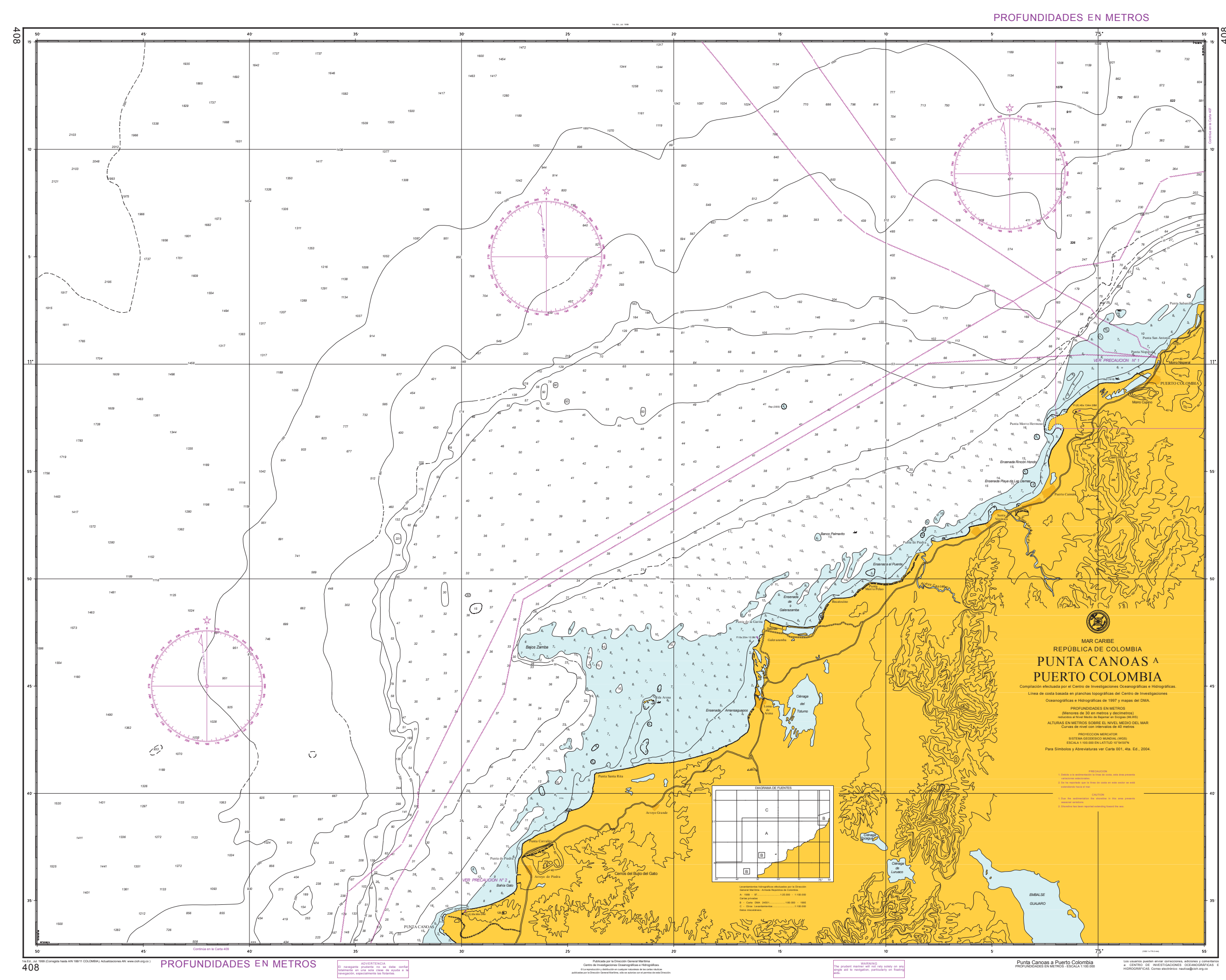




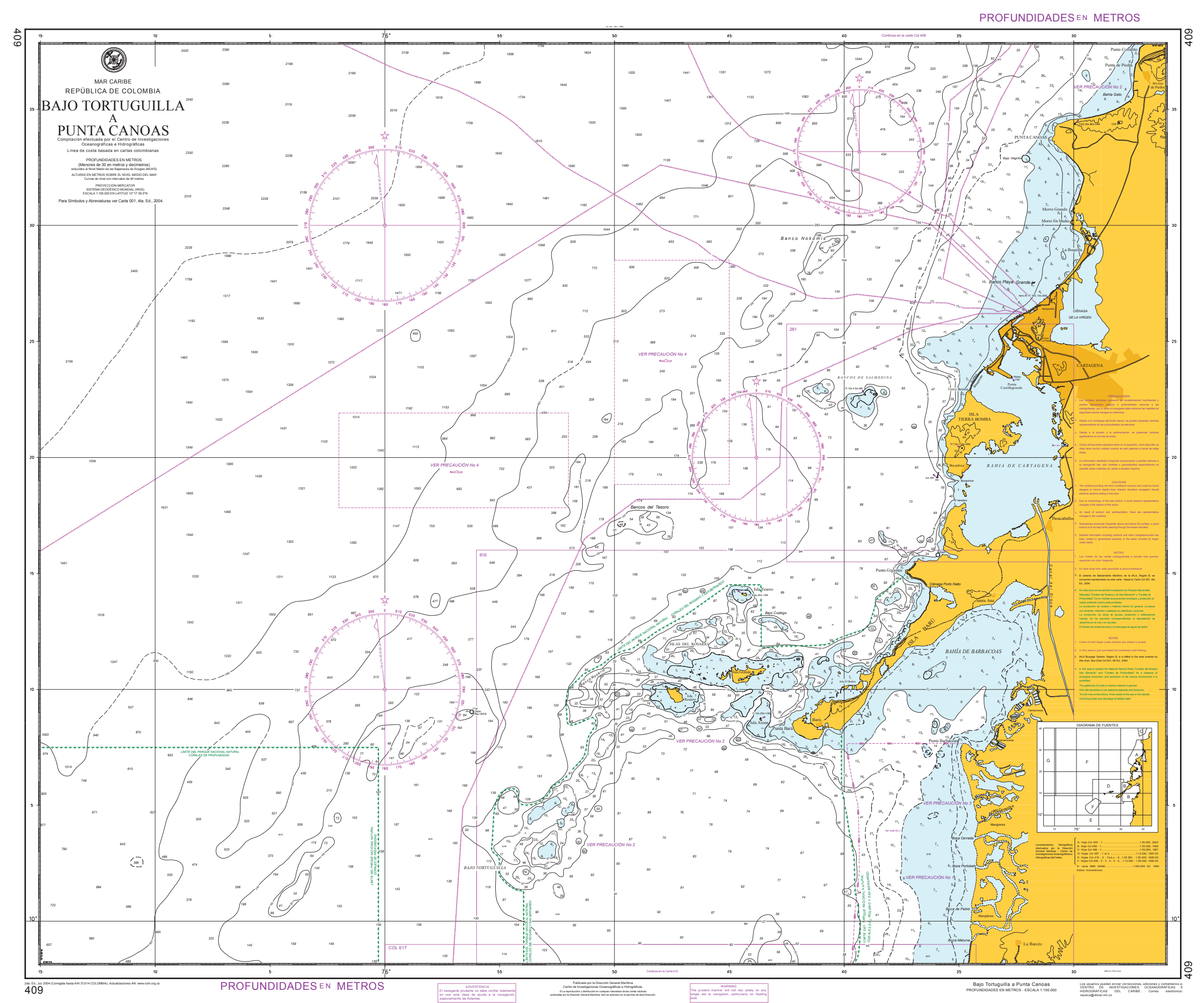




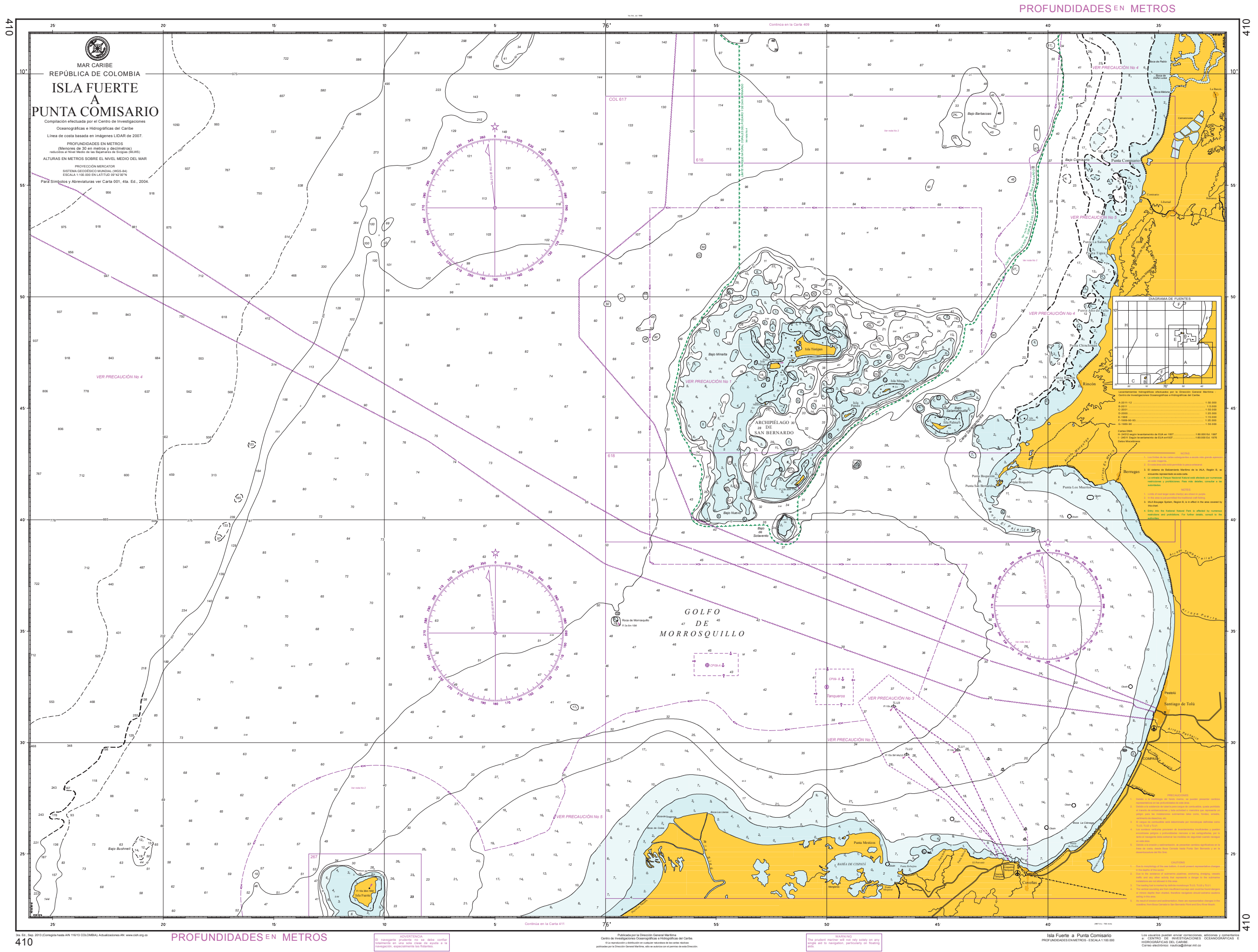

\section{Dimar}




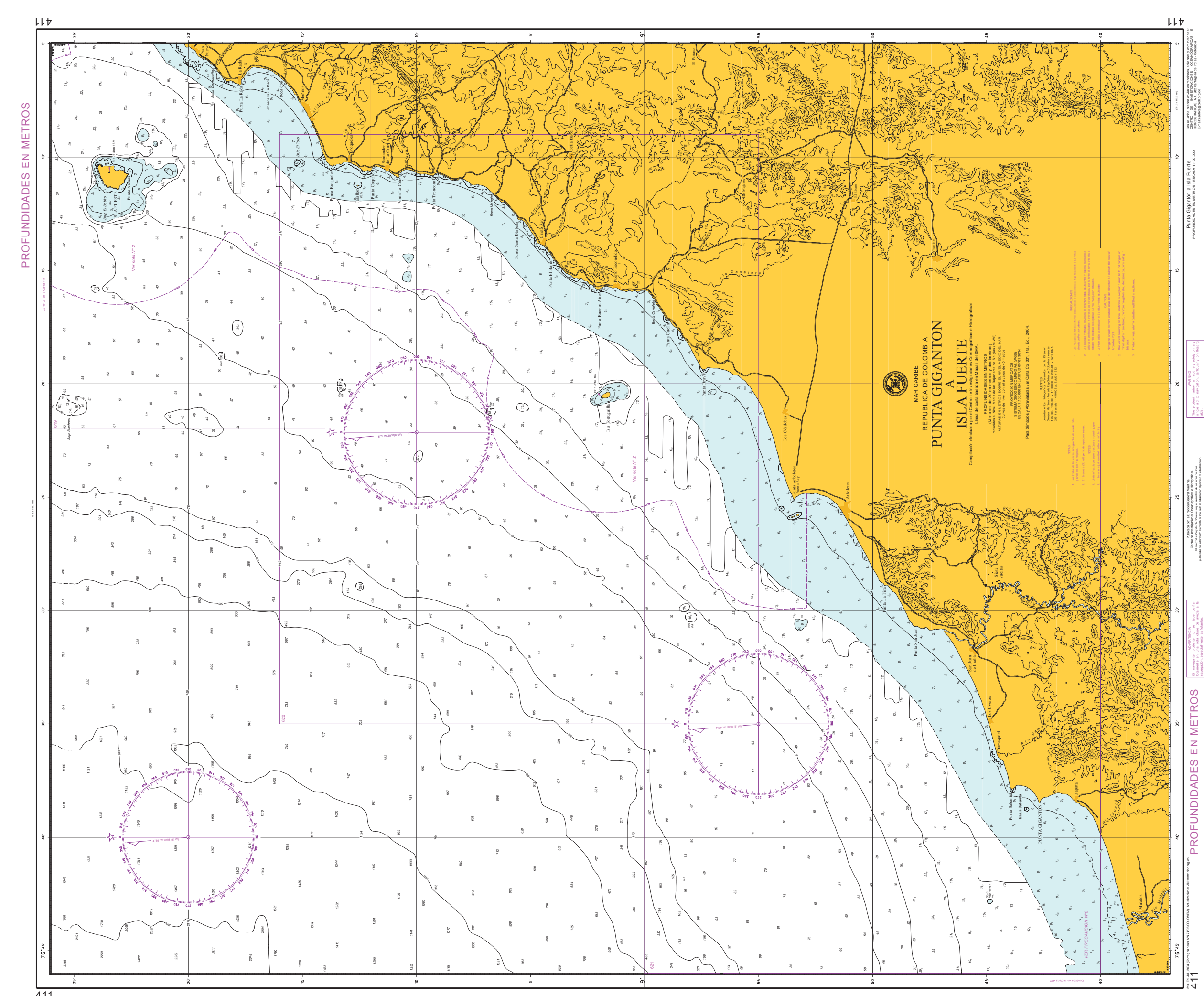




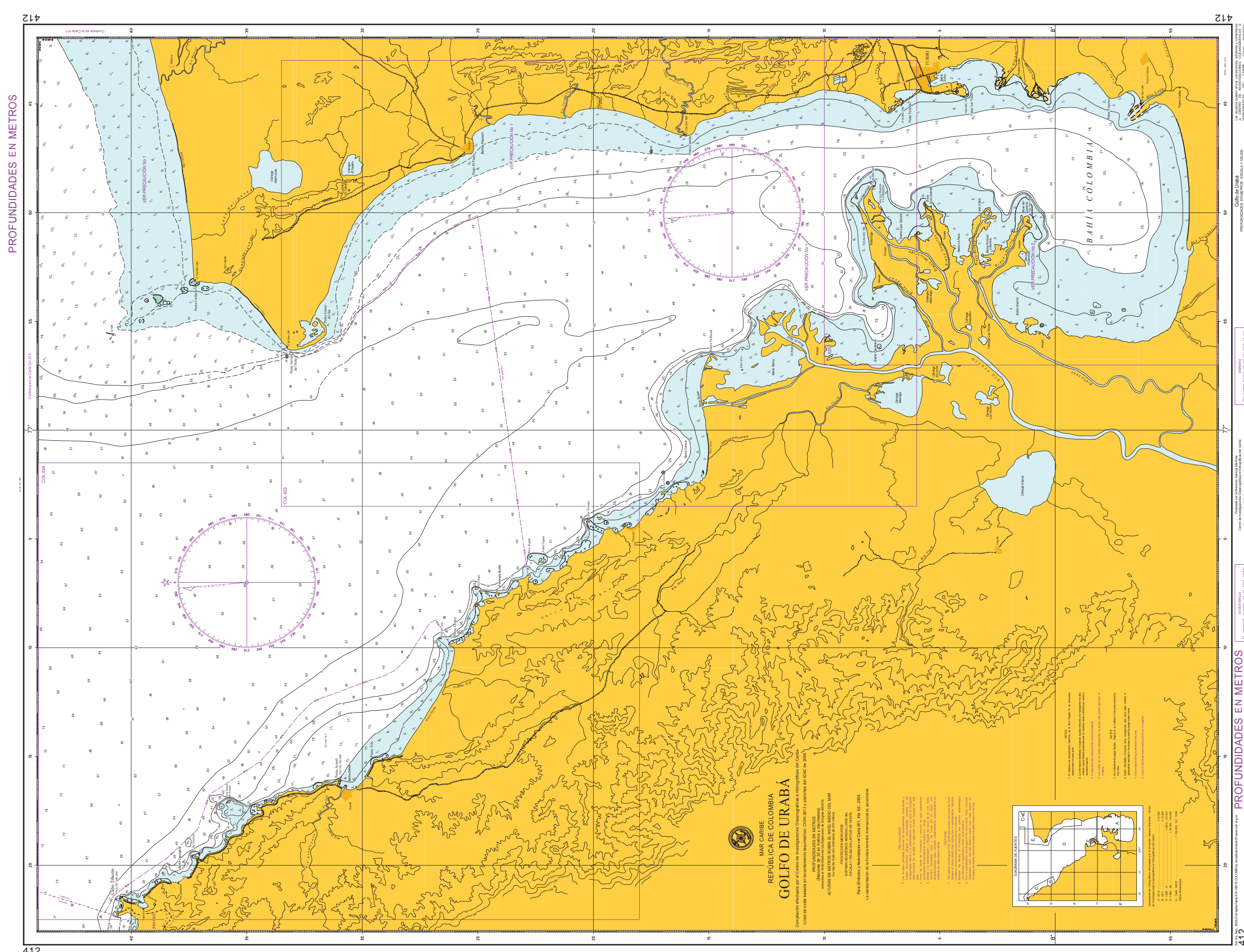




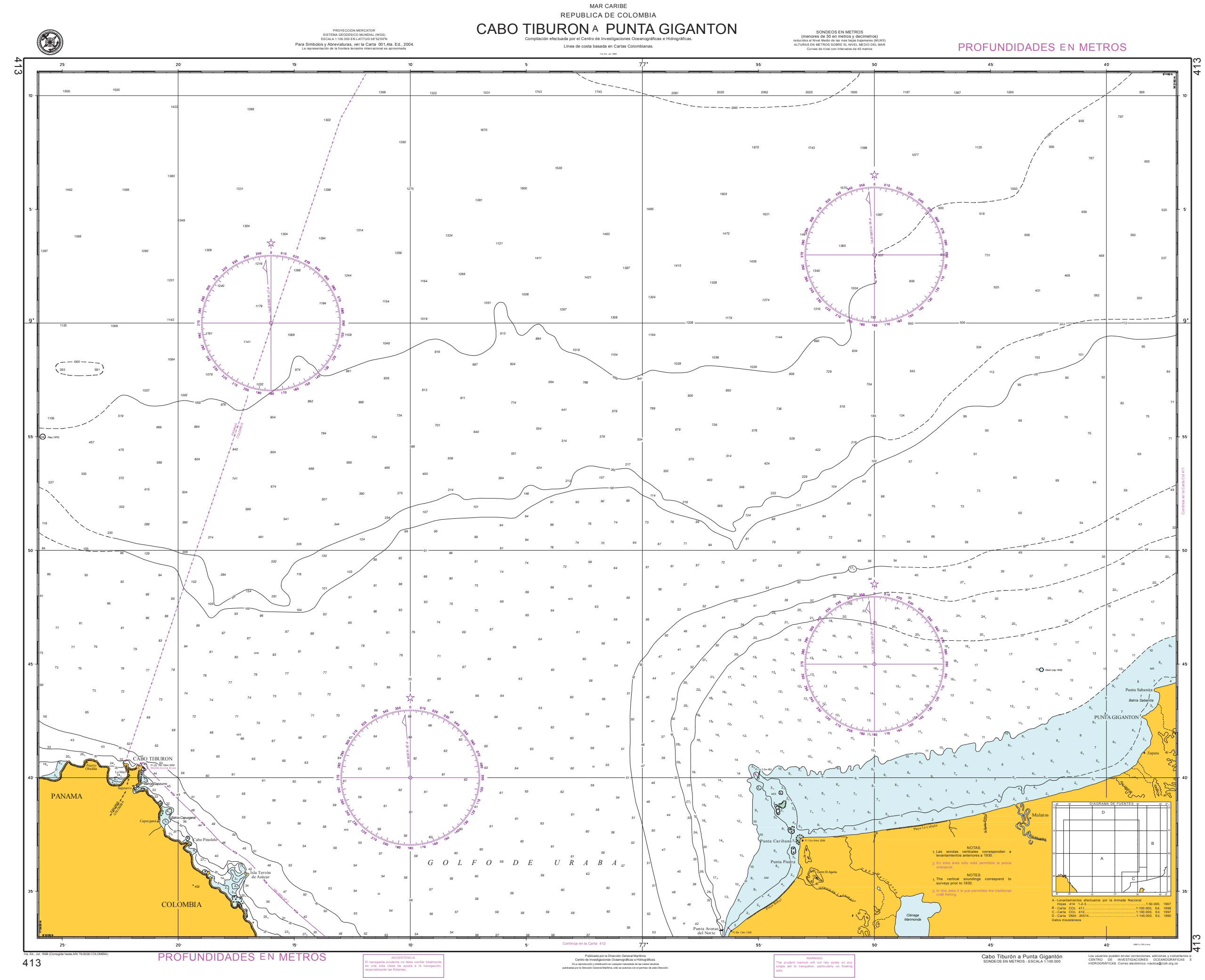

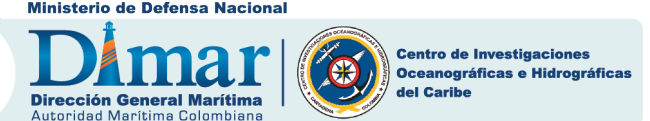




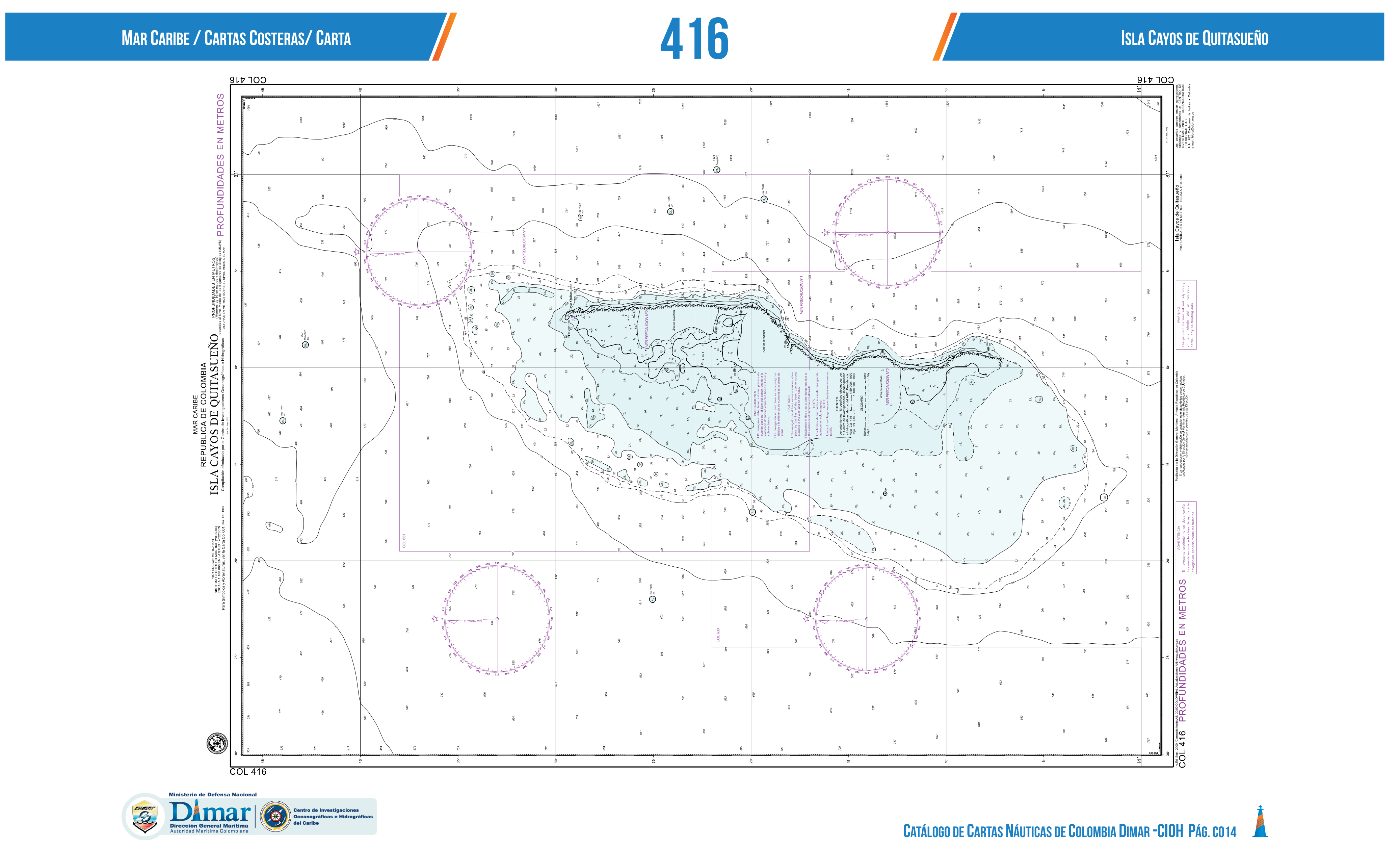


Cartas de aproximación (acceso a puerto, aguas costeras congestionadas o tortuosas) - (escalas 1:75.000 - 1:30.001) Tabla D1. Cartas de aproximación mar Caribe.

\begin{tabular}{|c|c|c|c|c|c|}
\hline No. Carta & Nombre & Escala & Edición & Año & Pág. \\
\hline 206 & Bajo Alicia & $1: 50.000$ & 2 & 2003 & D003 \\
\hline 259 & Archipiélago de San Bernardo & $1: 35.000$ & 1 & 1999 & D004 \\
\hline 603 & Aproximación a Bahía Portete & $1: 50.000$ & 4 & 2015 & D005 \\
\hline 605 & Aproximación a Manaure & $1: 50.000$ & 1 & 2009 & D006 \\
\hline 606 & Aproximación a Riohacha & $1: 50.000$ & 1 & 2003 & D007 \\
\hline 608 & Aproximación a Puerto Brisa & $1: 50.000$ & 1 & 2014 & D008 \\
\hline 612 & Aproximación a Barranquilla & $1: 50.000$ & 3 & 2014 & D009 \\
\hline 618 & Golfo de Morrosquillo & $1: 50.000$ & 3 & 2012 & D010 \\
\hline 625 & Bahía Colombia & $1: 35.000$ & 4 & 2013 & D011 \\
\hline 613 & Galerazamba a Punta Morro Hermoso & $1: 50.000$ & 2 & 2016 & D012 \\
\hline
\end{tabular}

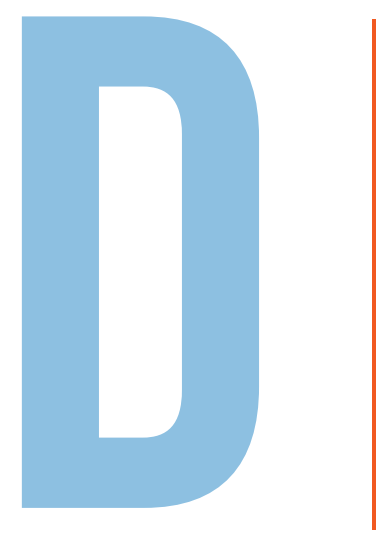




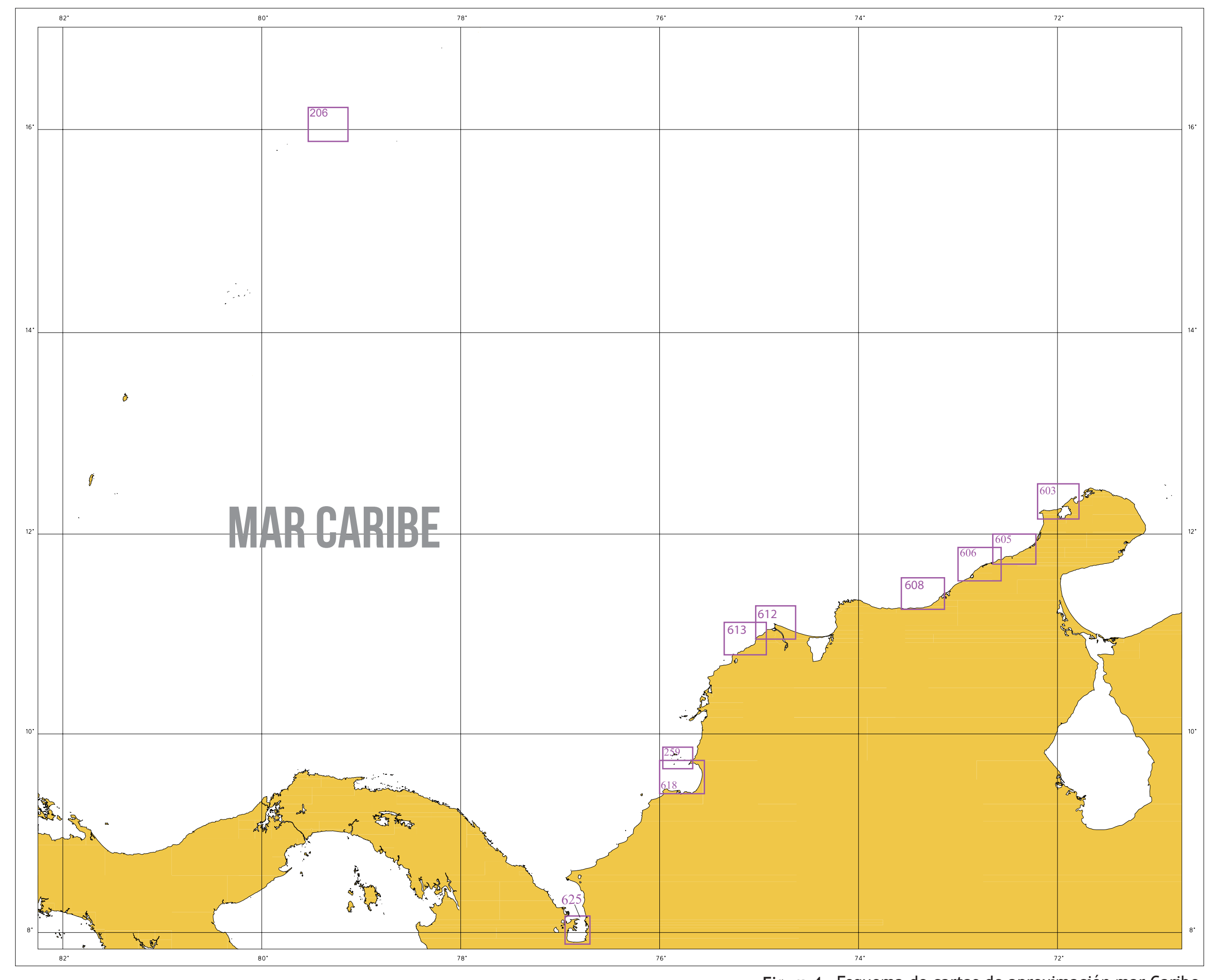

Figura 4. Esquema de cartas de aproximación mar Caribe 
Mar CarlBe / Cartas de Aproximací́N/ Garta

206

BAJO ALICHA

(2)

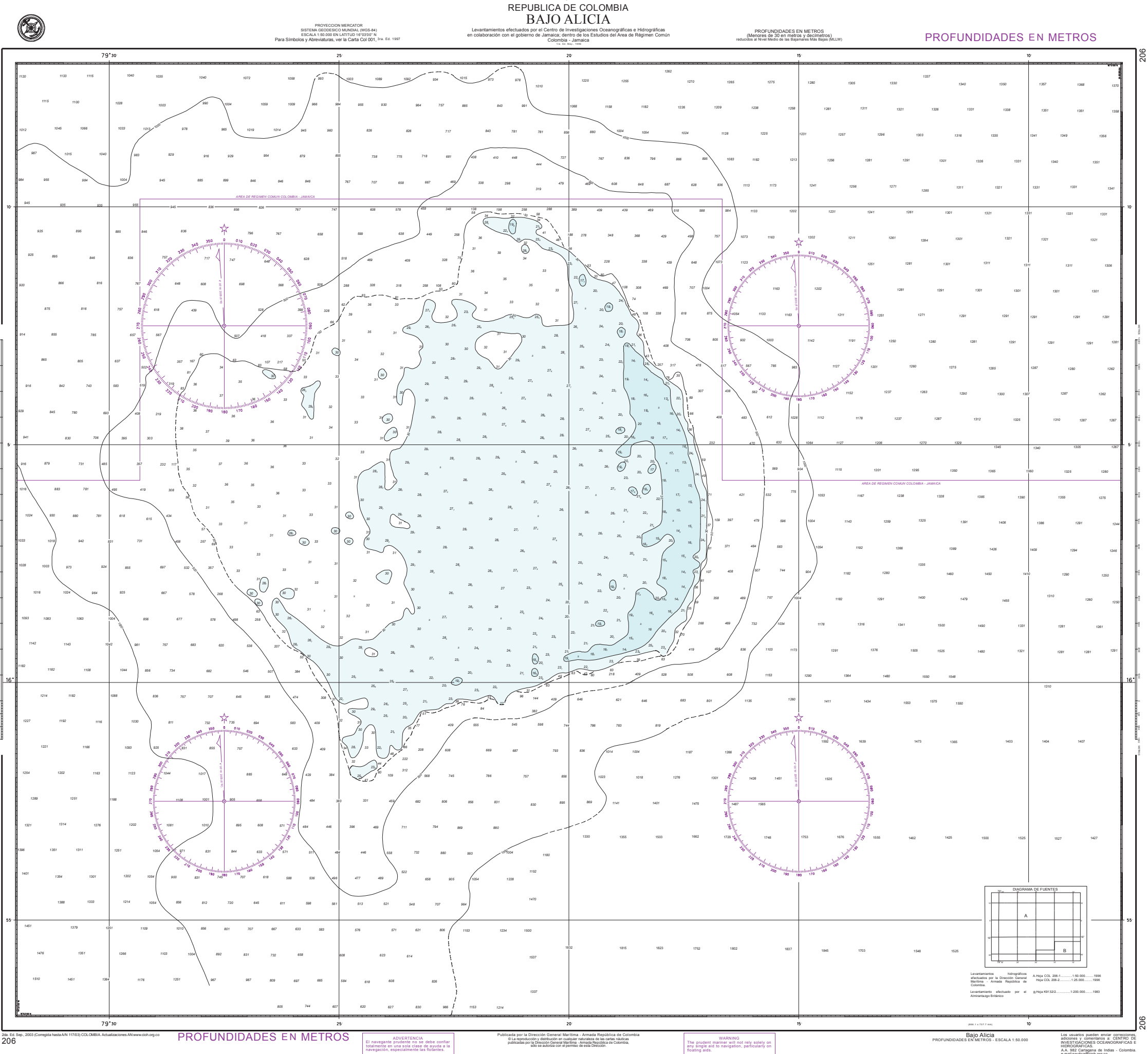

Dilmar

Catálogo de Cartas Náuticas de Colombia Dimar -Cloh Pág.ooo3 


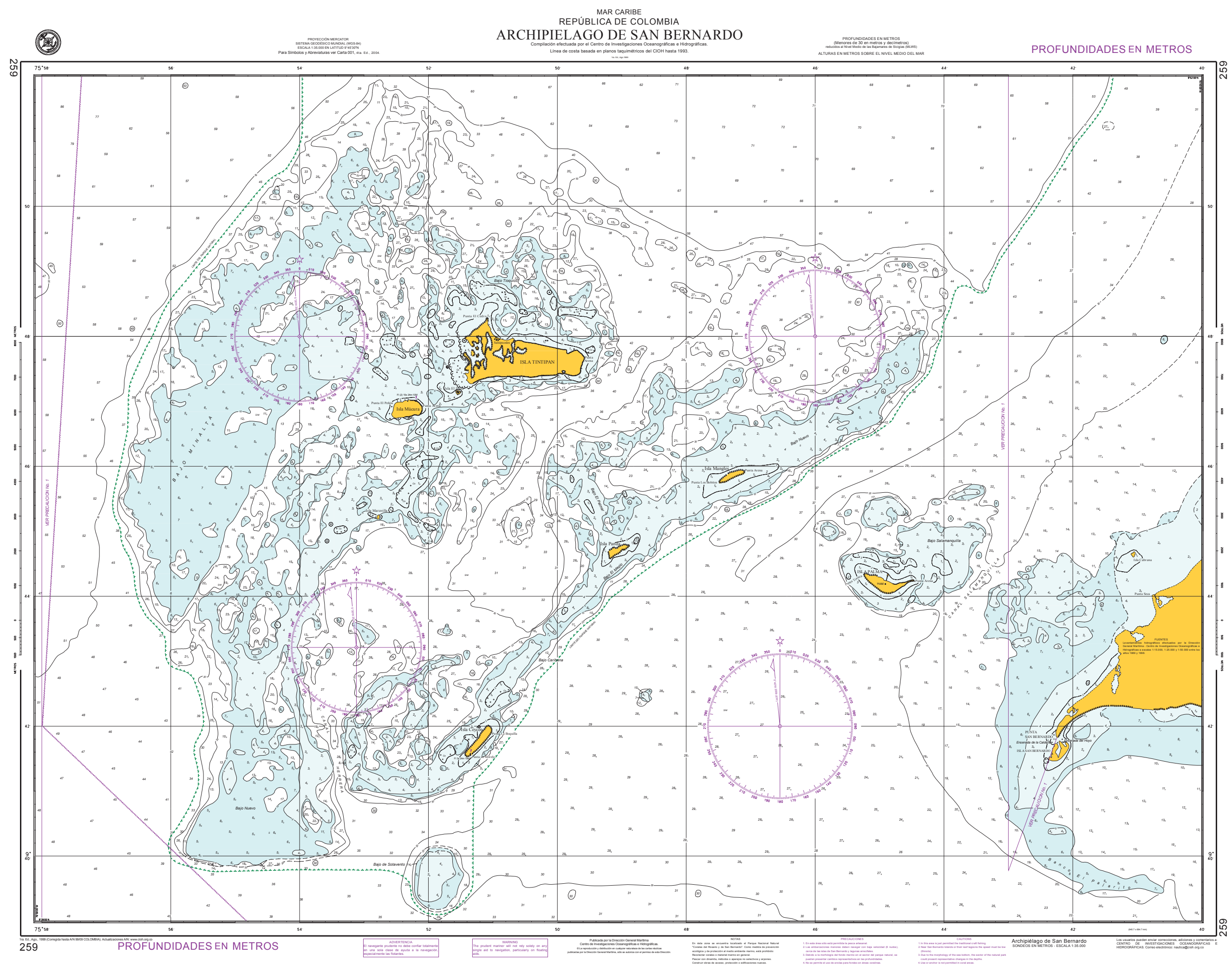

\section{Dimar.}




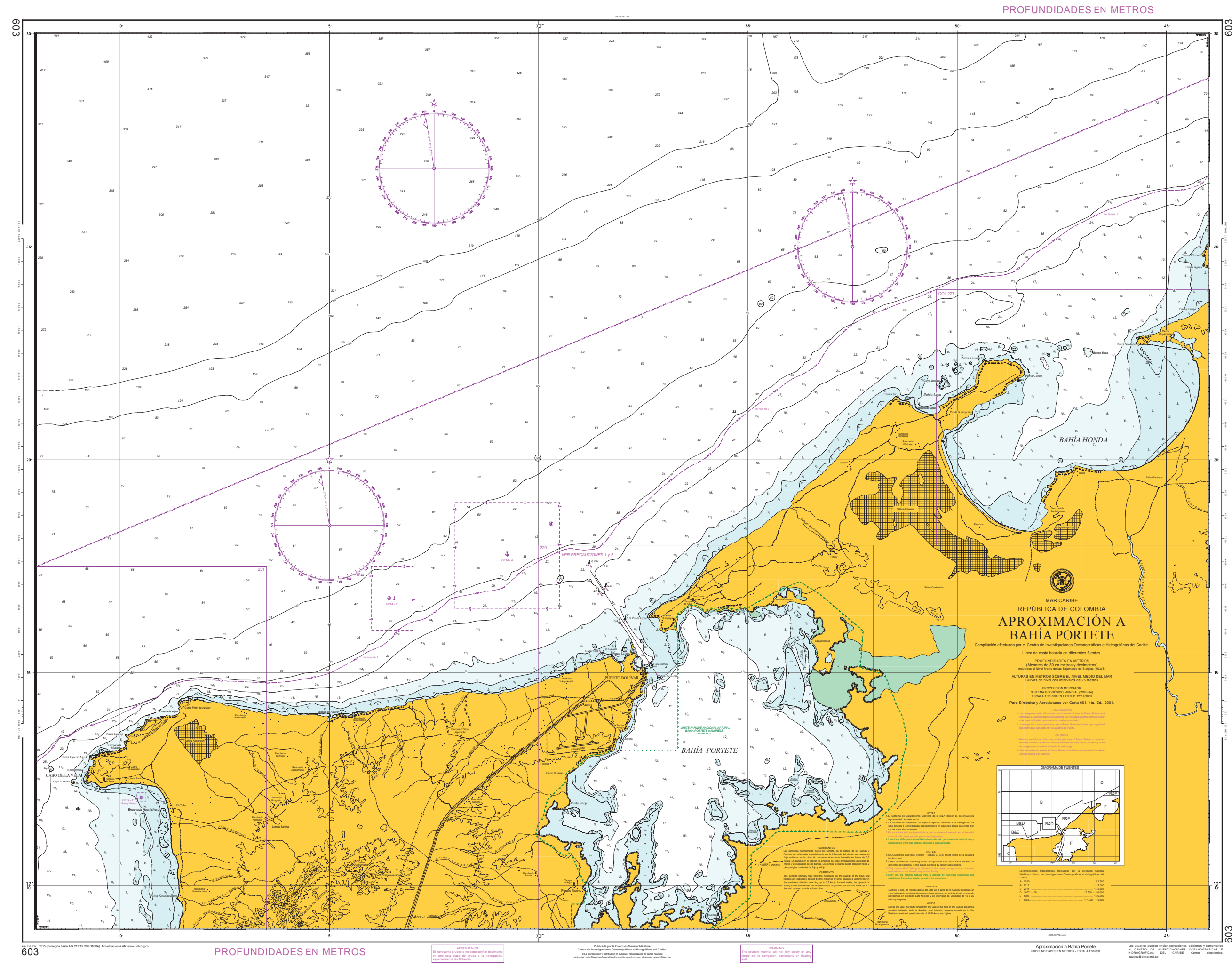

Dimar (c) = 


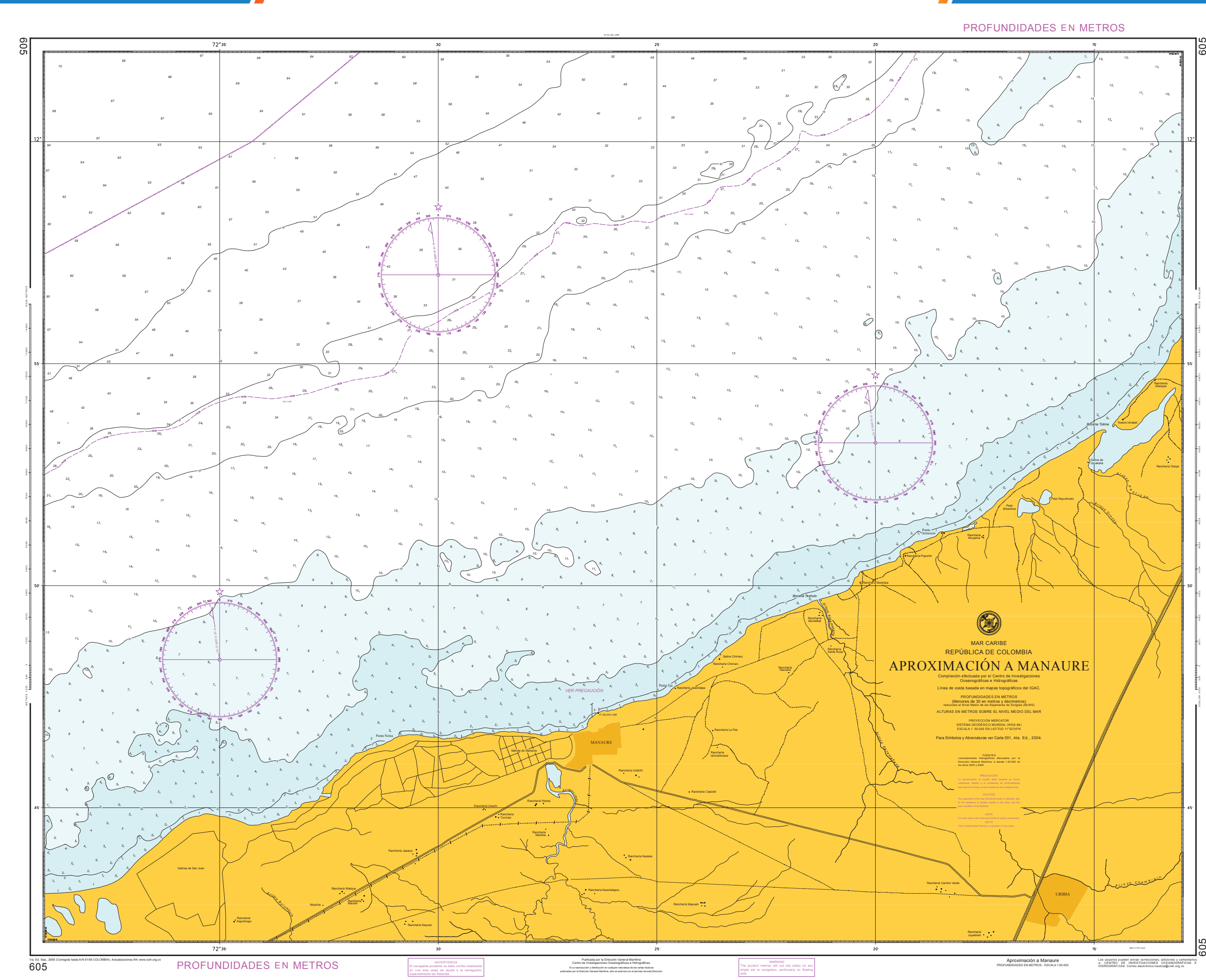

Dimar (c) = 


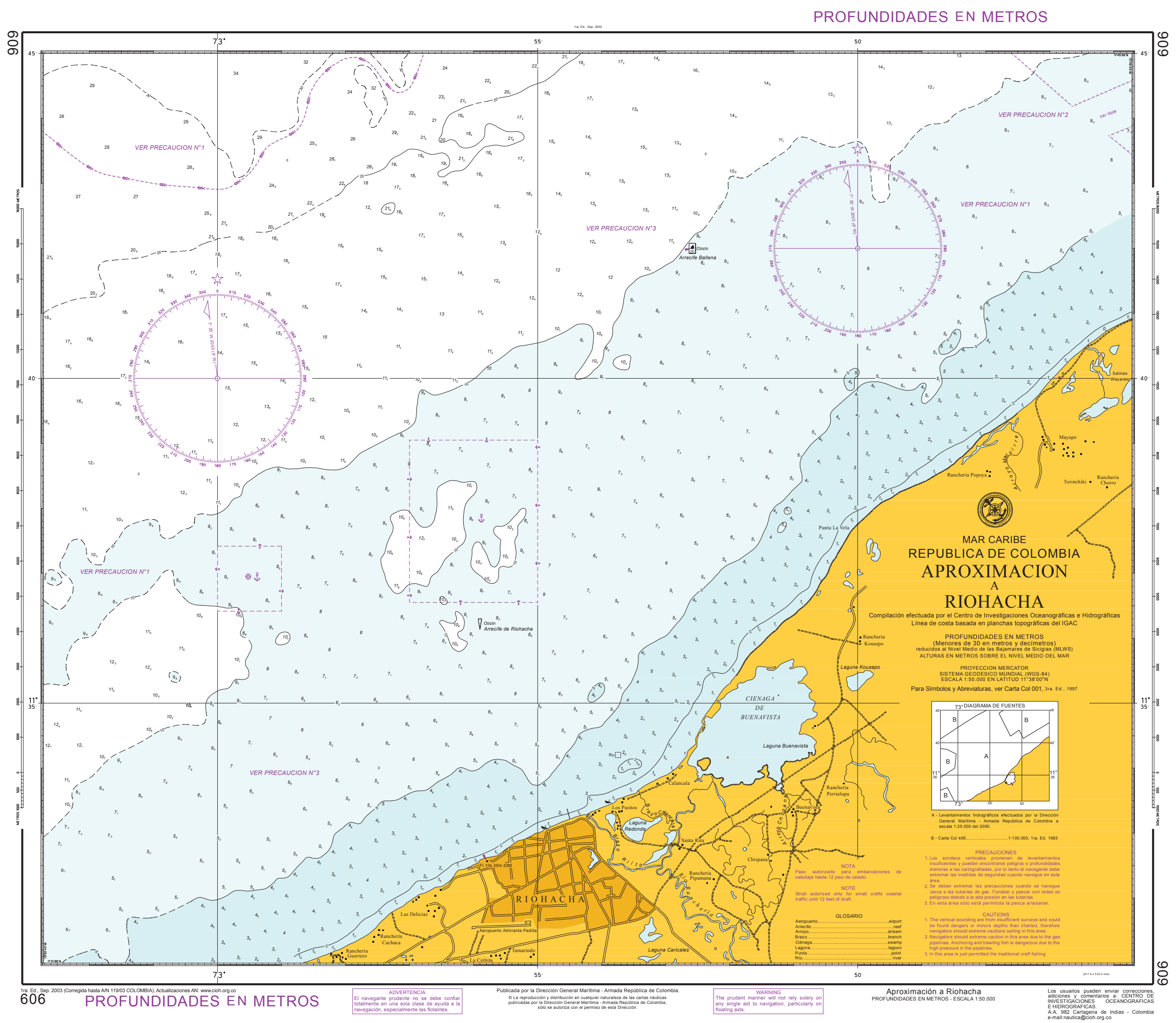




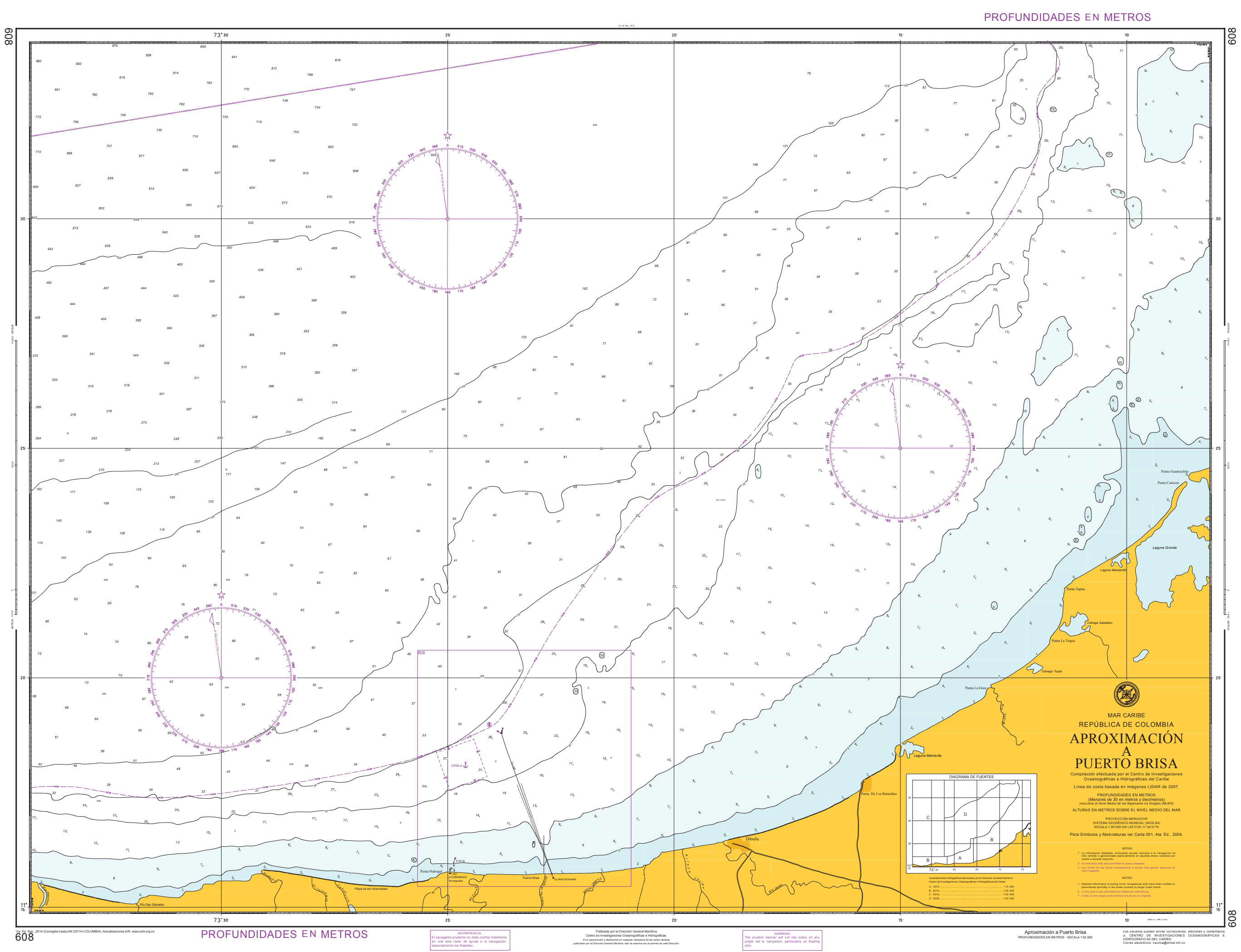

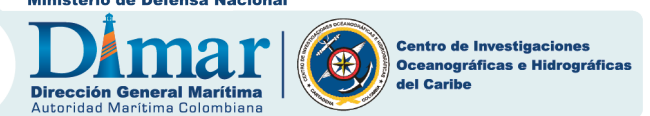




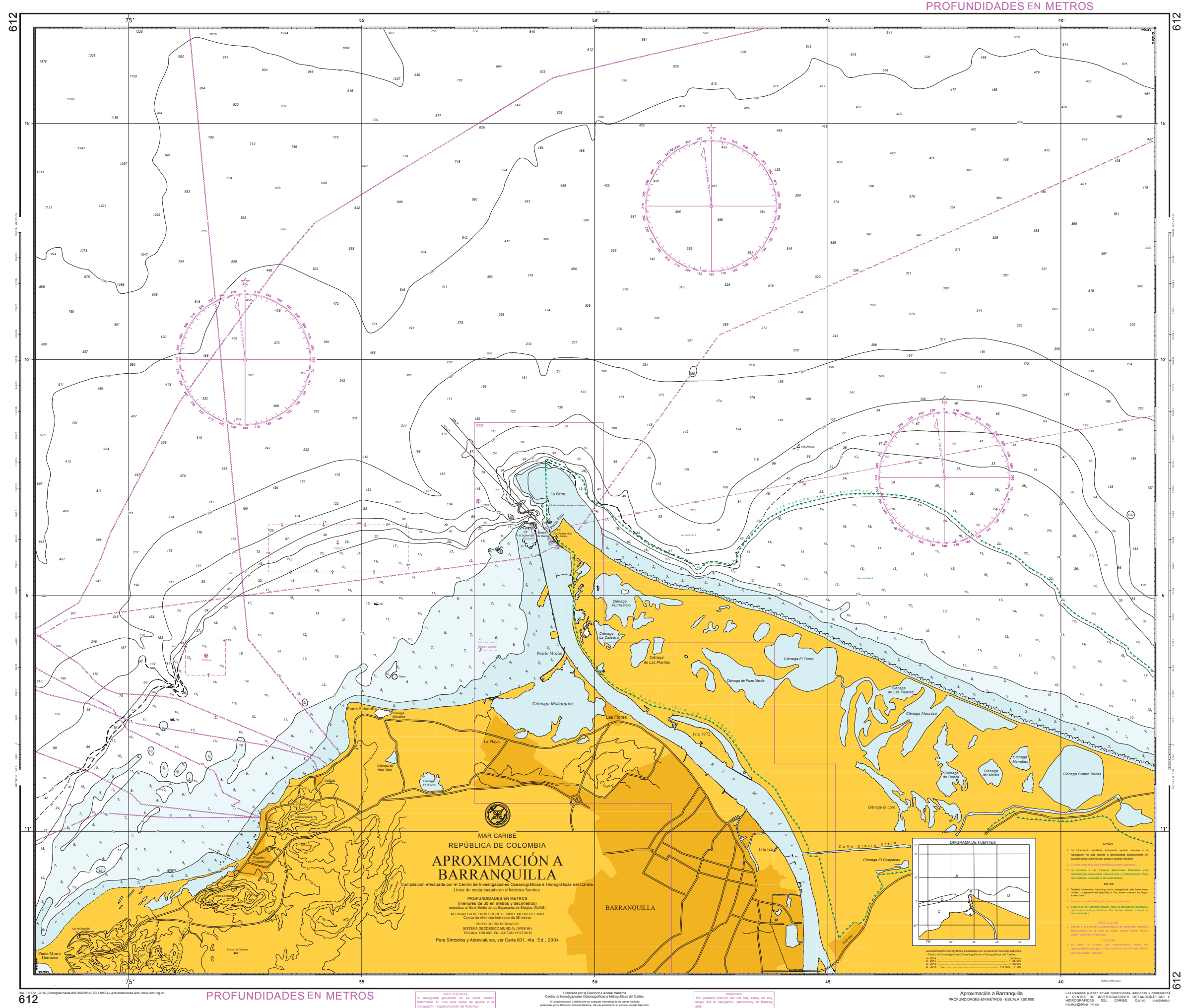

\section{D}




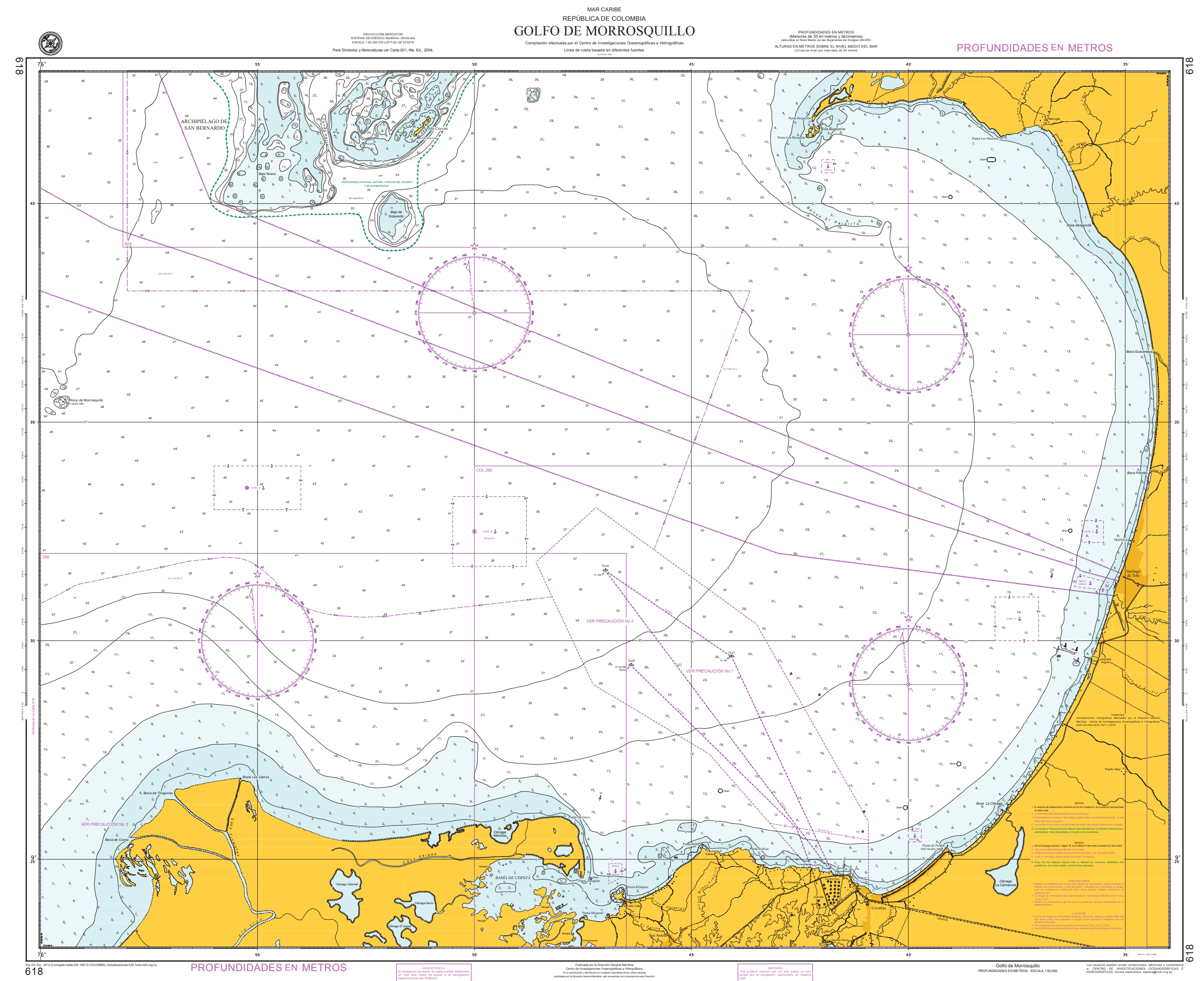




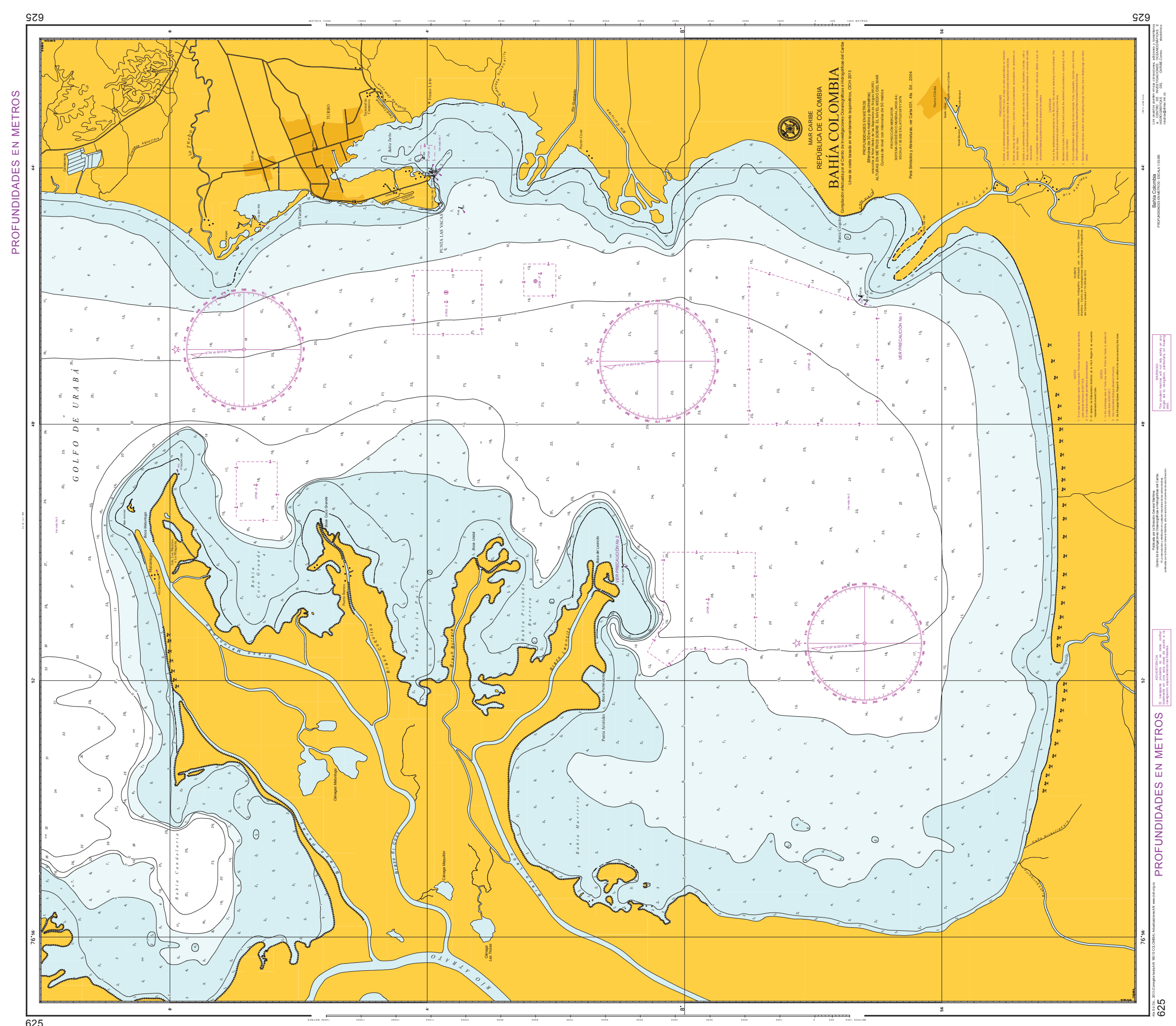




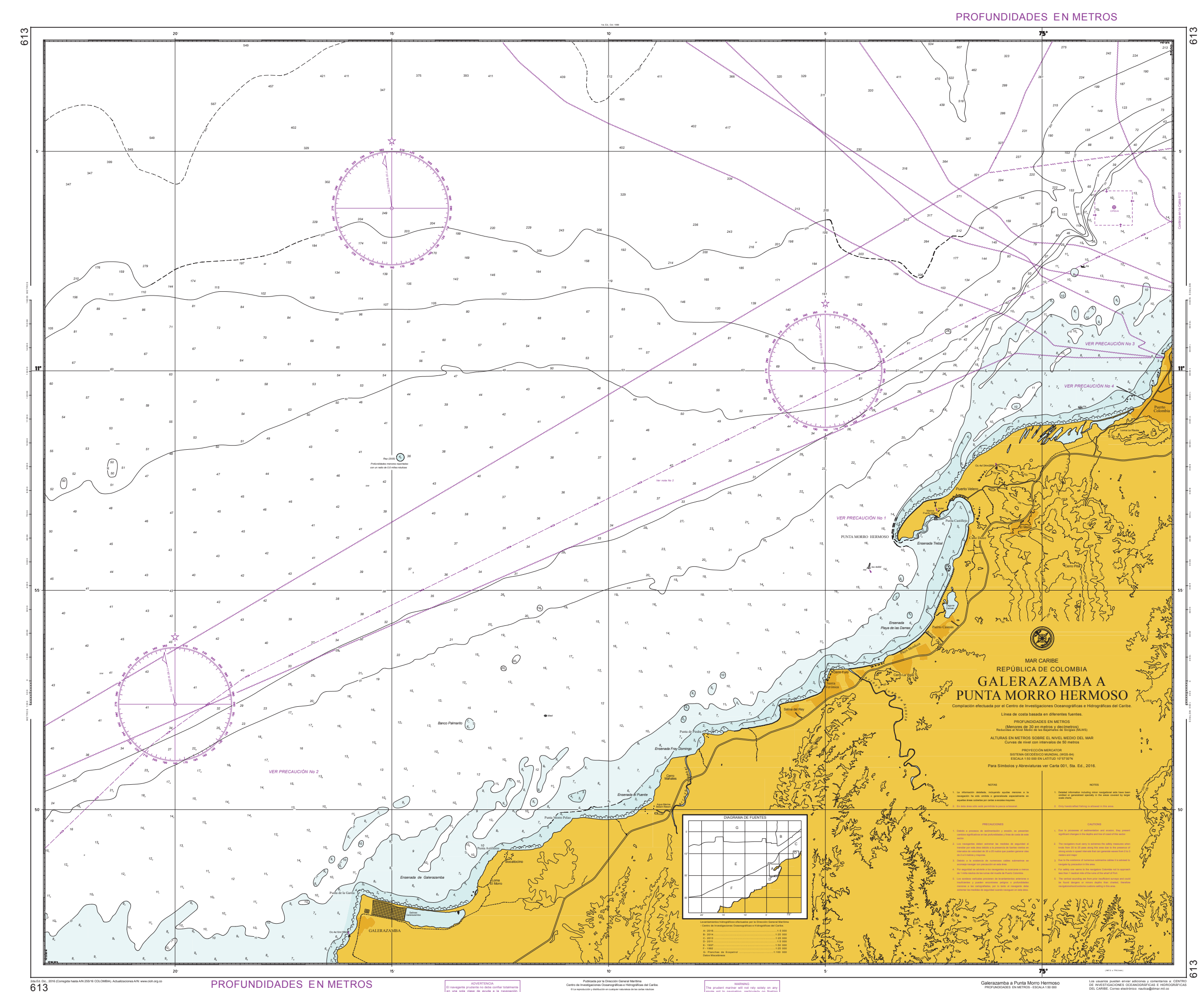

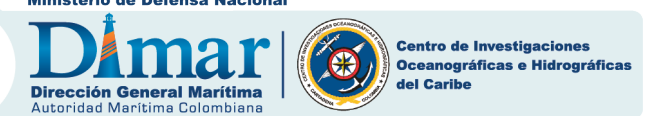




\section{CARTAS DE PUERTO / MAR CARIBE}

Cartas de puerto (puertos, bahías, fondeaderos, estrechos) - (escalas 1:30.000 -1:12.501) Tabla E1. Cartas de puerto mar Caribe.

\begin{tabular}{|c|c|c|c|c|c|}
\hline No. Carta & Nombre & Escala & Edición & Año & Pág. \\
\hline 201 & Isla de San Andrés & 1:25.000 & 3 & 2008 & E003 \\
\hline 203 & Cayo Alburquerque & $1: 20.000$ & 2 & 2003 & E004 \\
\hline 204 & Cayo East Southeast (Este Sudeste) & $1: 20.000$ & 2 & 2003 & E005 \\
\hline 208 & Cayo Serranilla & $1: 25.000$ & 2 & 2003 & E006 \\
\hline 211 & Isla Cayos de Roncador & $1: 20.000$ & 3 & 2003 & E007 \\
\hline 213 & Cayo Serrana & $1: 20.000$ & 2 & 2003 & E008 \\
\hline 215 & Cayo Quitasueño & 1:25.000 & 1 & 2000 & E009 \\
\hline 218 & Isla de Providencia & $1: 20.000$ & 3 & 2016 & E010 \\
\hline 222 & Aproximación a Puerto López & $1: 25.000$ & 1 & 2008 & E011 \\
\hline 227 & Bahía Honda & $1: 20.000$ & 1 & 1997 & E012 \\
\hline 229 & Bahía Portete & $1: 25.000$ & 4 & 2015 & E013 \\
\hline 231 & Cabo de la Vela & $1: 25.000$ & 1 & 2000 & E014 \\
\hline 244 & Bahía de Taganga a Punta Barro Blanco & $1: 25.000$ & 3 & 2011 & E015 \\
\hline 245 & Ciénaga & $1: 25.000$ & 2 & 2013 & E016 \\
\hline 246 & Puerto Zúñiga & $1: 20.000$ & 1 & 2014 & E017 \\
\hline 253 & Río Magdalena (Bocas de Ceniza-Puente Laureano Gómez) & 1:15.000 & 6 & 2016 & E018 \\
\hline 255 & Archipiélago Islas del Rosario & $1: 25.000$ & 2 & 2010 & E019 \\
\hline 261 & Bahía de Cartagena & 1:25.000 & 8 & 2011 & E020 \\
\hline 262 & Bahía de Cartagena (Sector A, B, C) & 1:15.000 & 3 & 2016 & E021 \\
\hline 265 & Aproximación a Coveñas y Santiago de Tolú & $1: 30.000$ & 2 & 2016 & E022 \\
\hline 266 & Boca de Tinajones a Bahía de Cispatá & $1: 30.000$ & 1 & 2005 & E023 \\
\hline 267 & Isla Fuerte & 1:15.000 & 1 & 2003 & E024 \\
\hline 279 & Acandí & 1:25.000 & 1 & 2000 & E025 \\
\hline 280 & Cabo Tiburón a Isla Terrón de Azúcar & $1: 25.000$ & 2 & 2010 & E026 \\
\hline
\end{tabular}




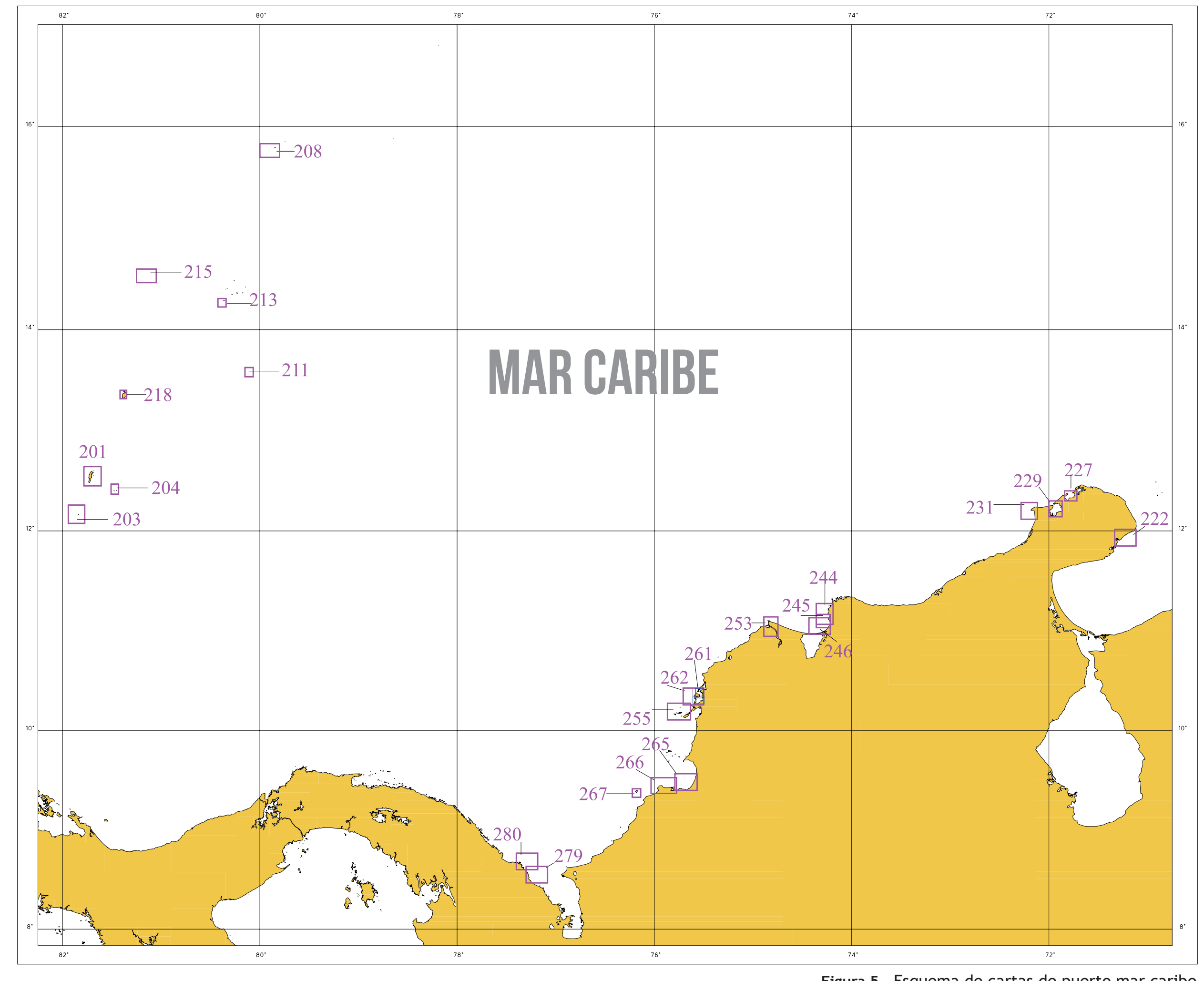

Figura 5. Esquema de cartas de puerto mar caribe. 


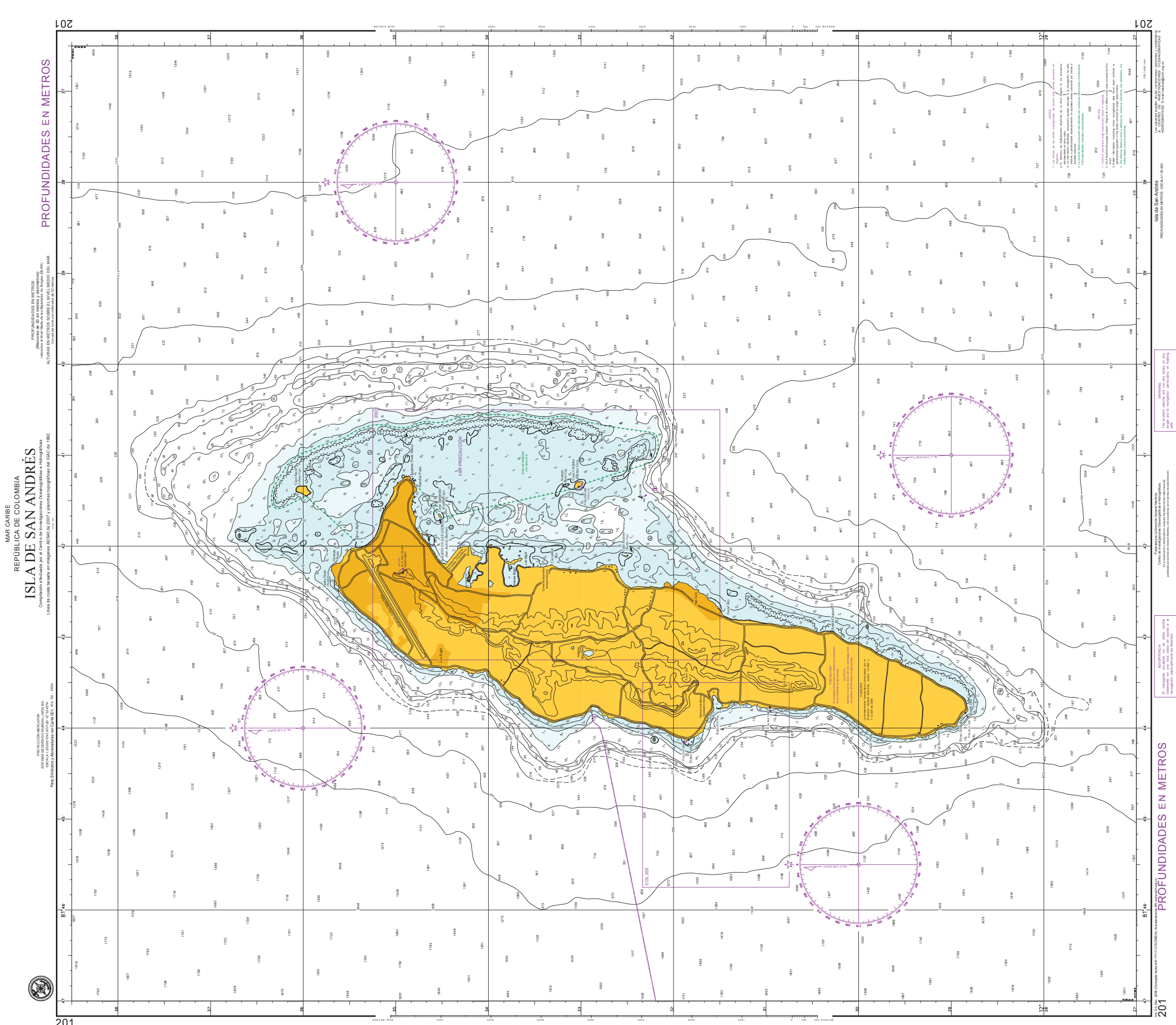




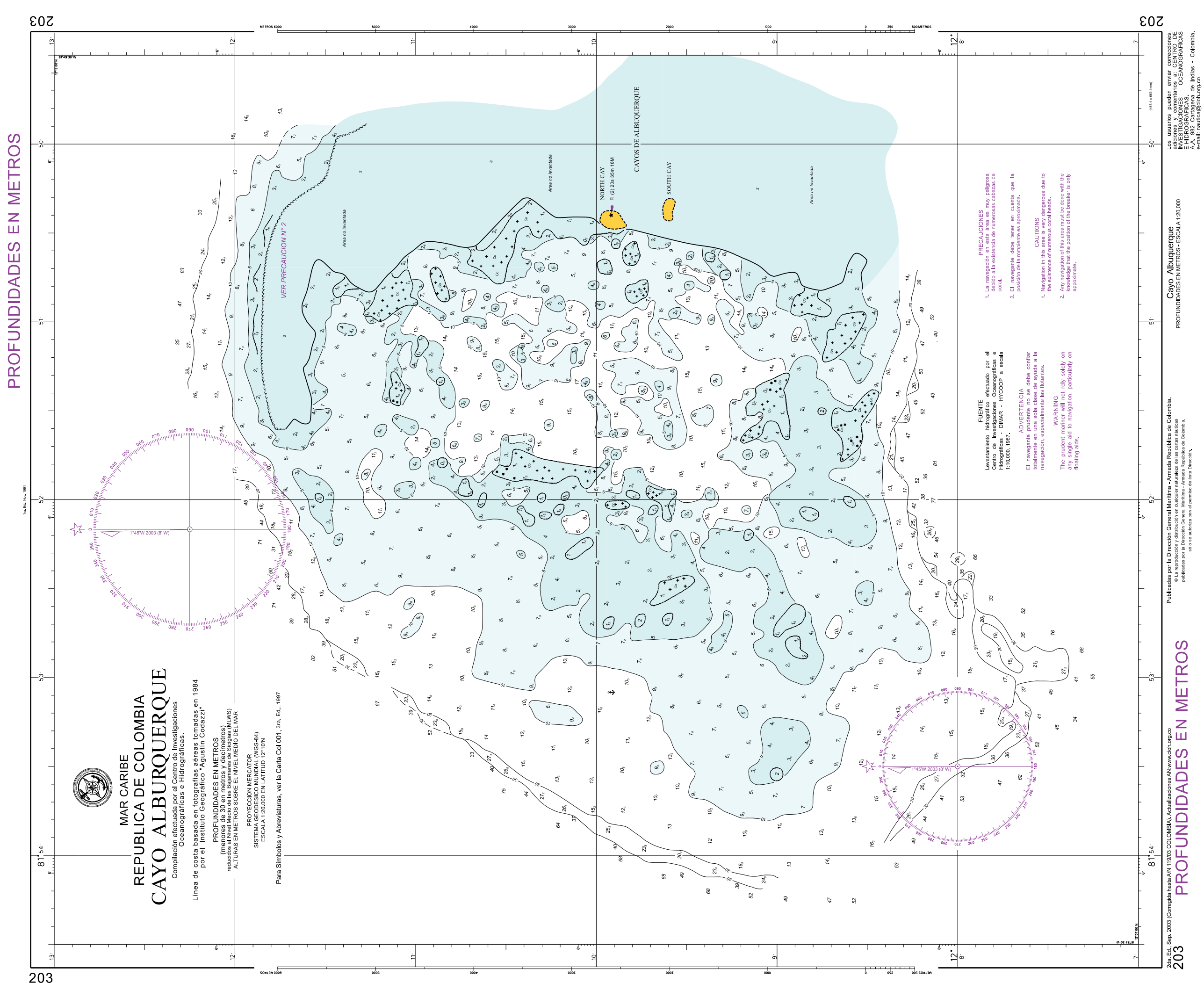




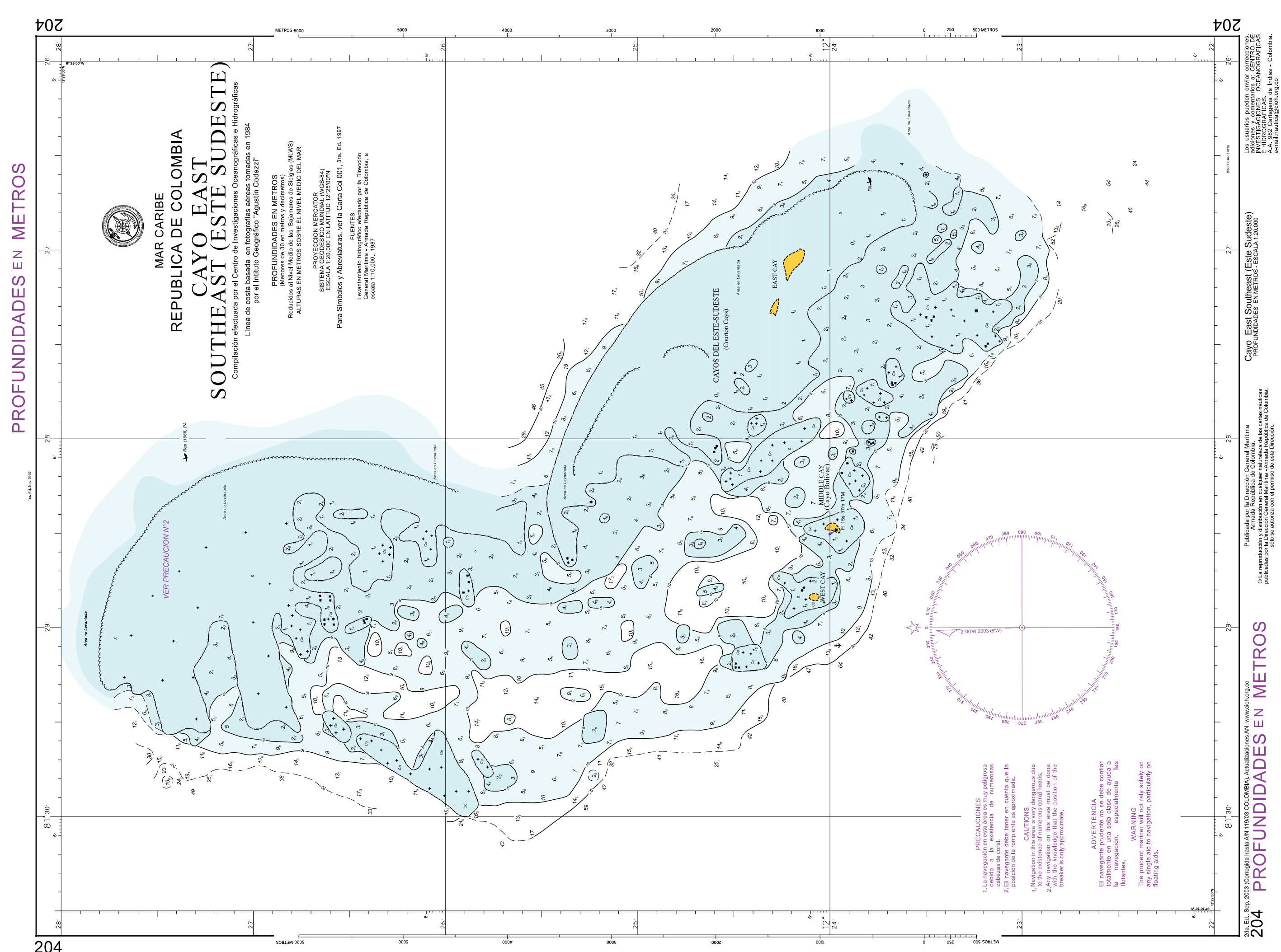




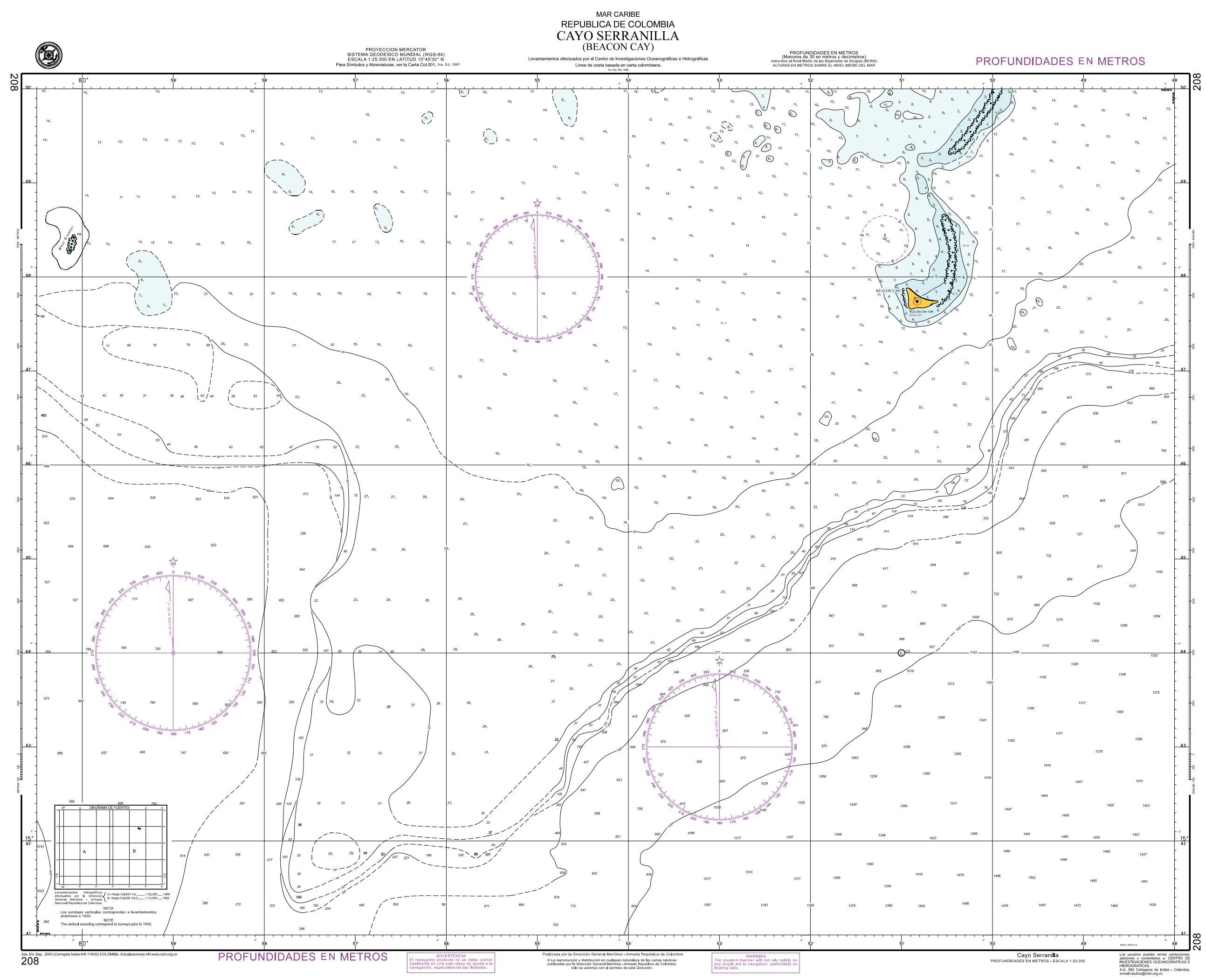

\section{Dlmar $(6)=$}




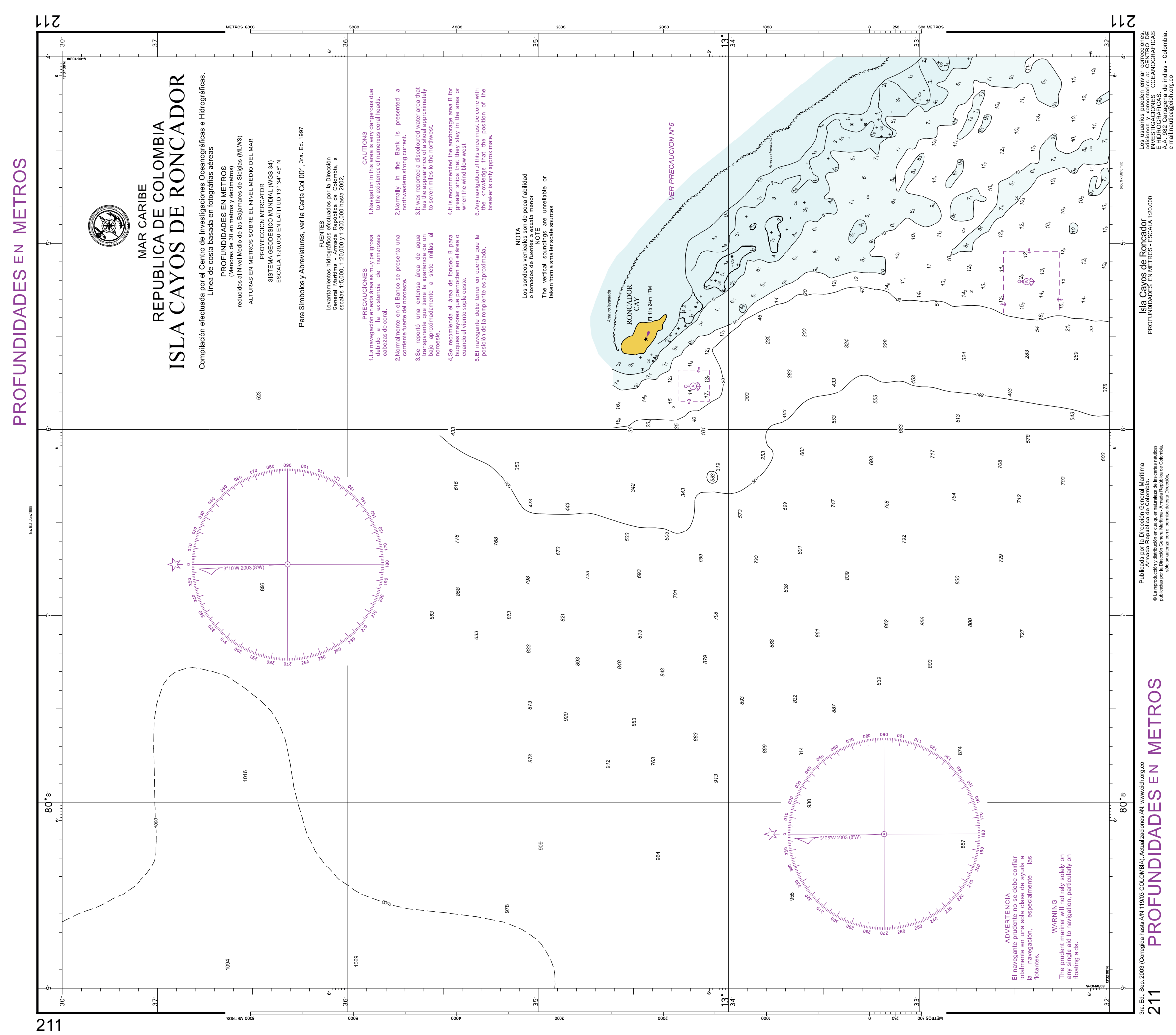




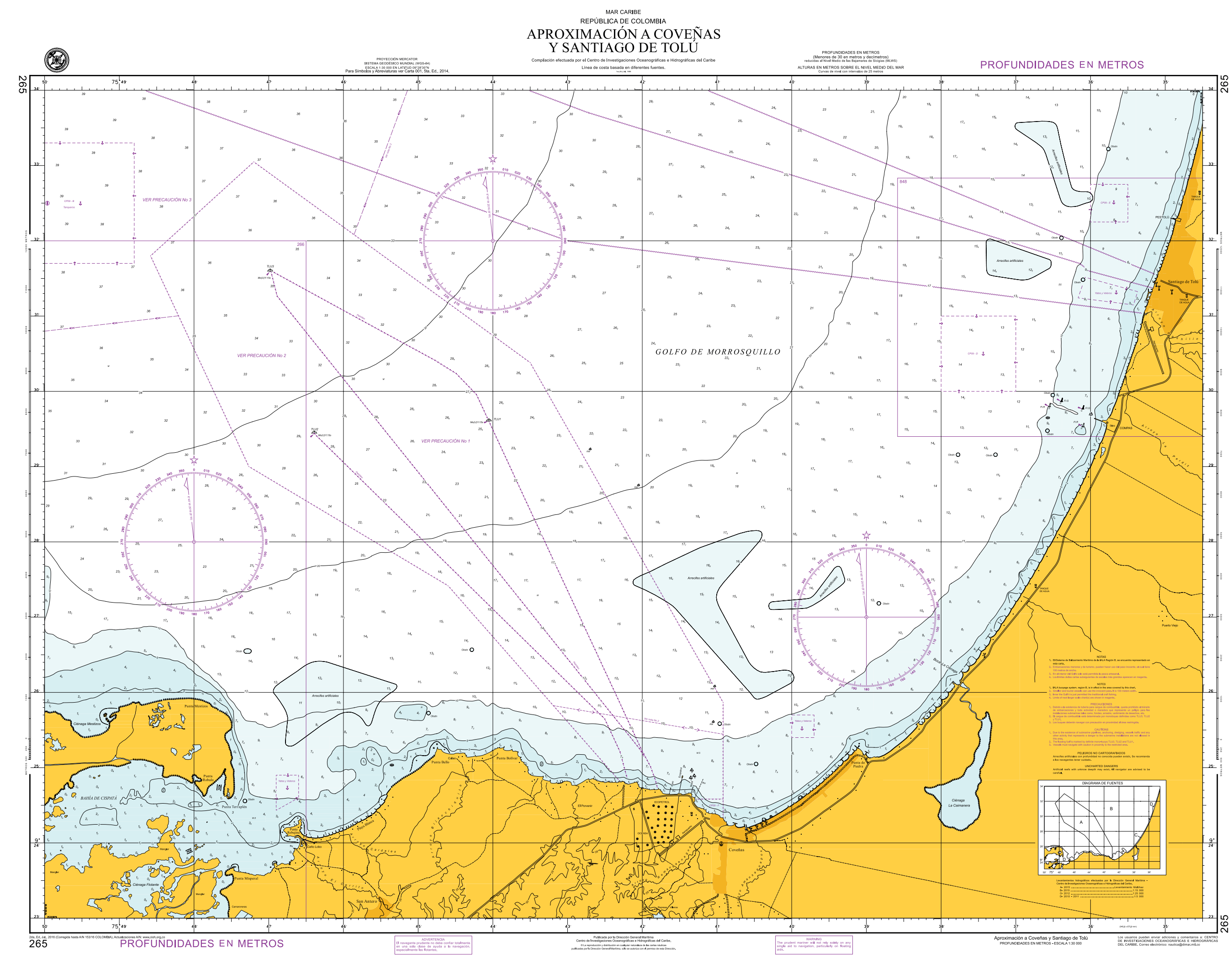

\section{Dimar.}




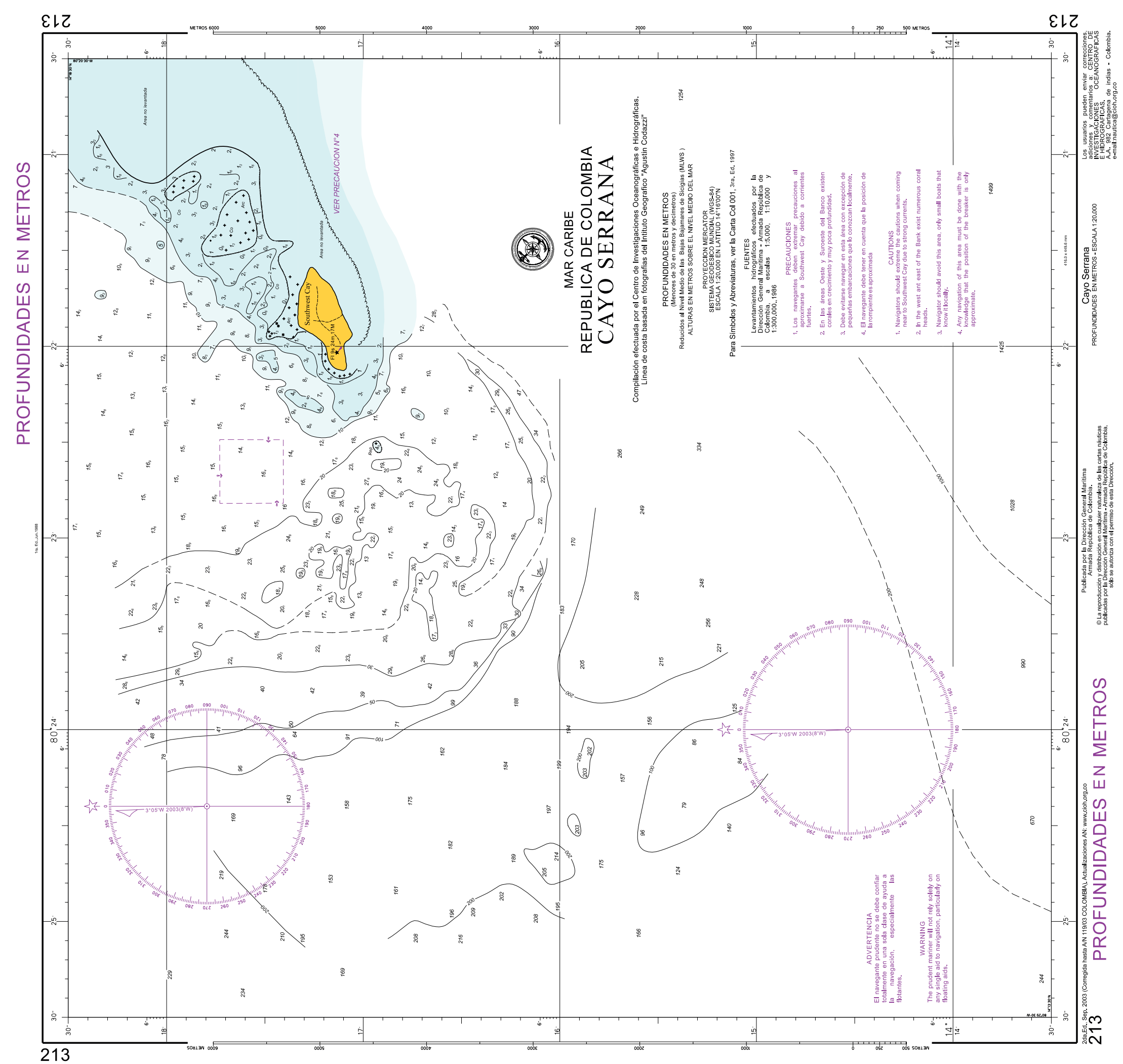




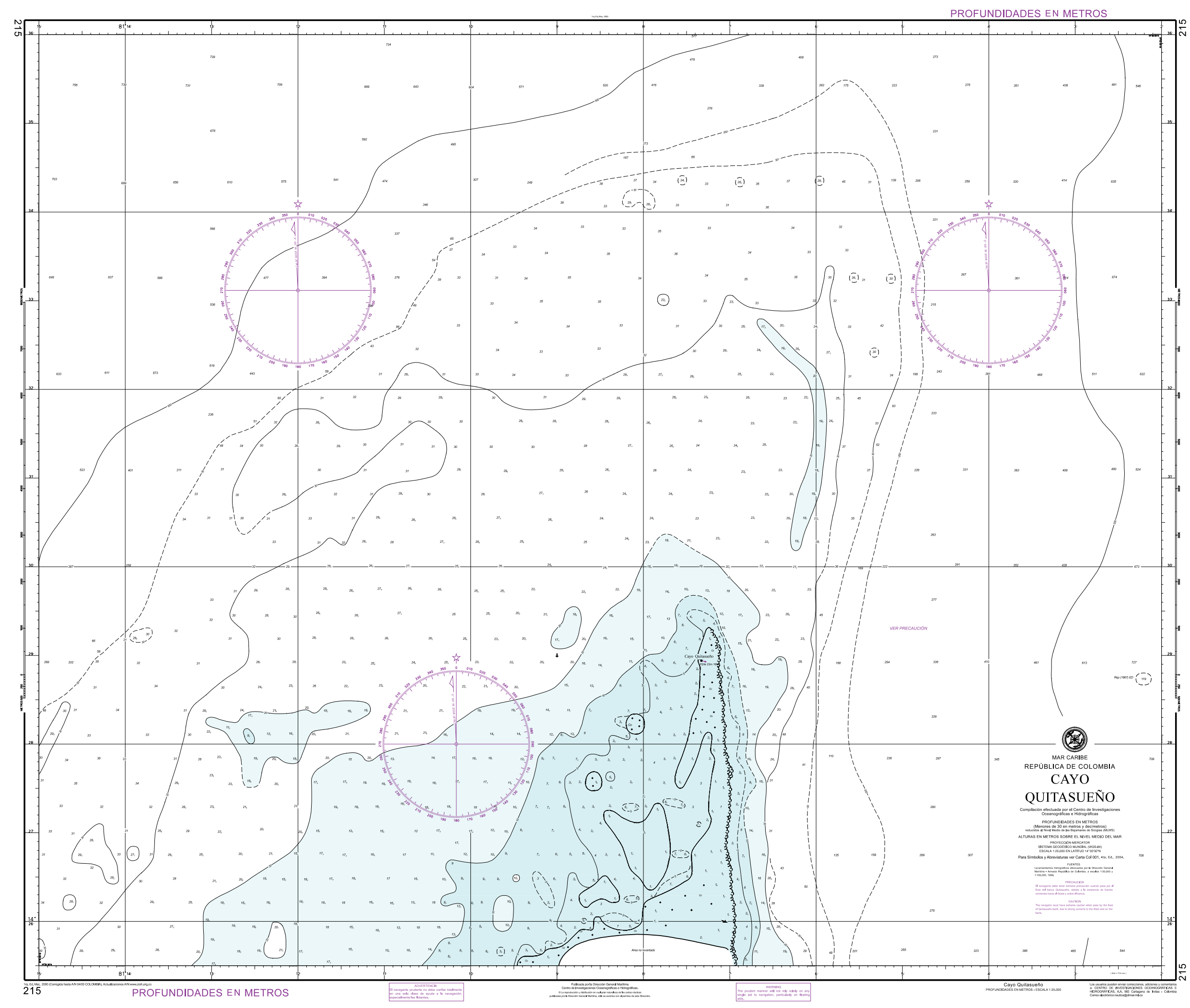

\section{Dimar.}




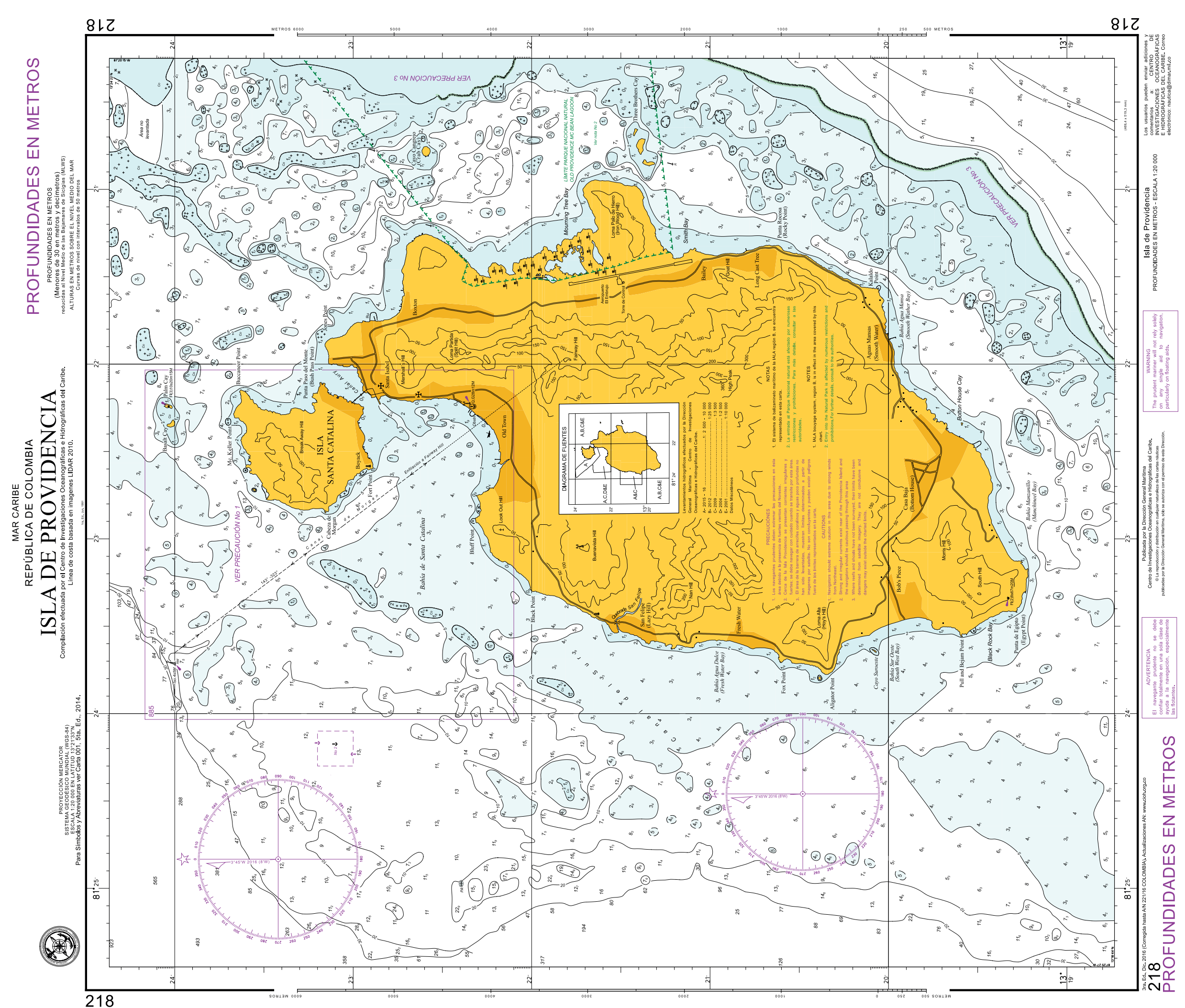




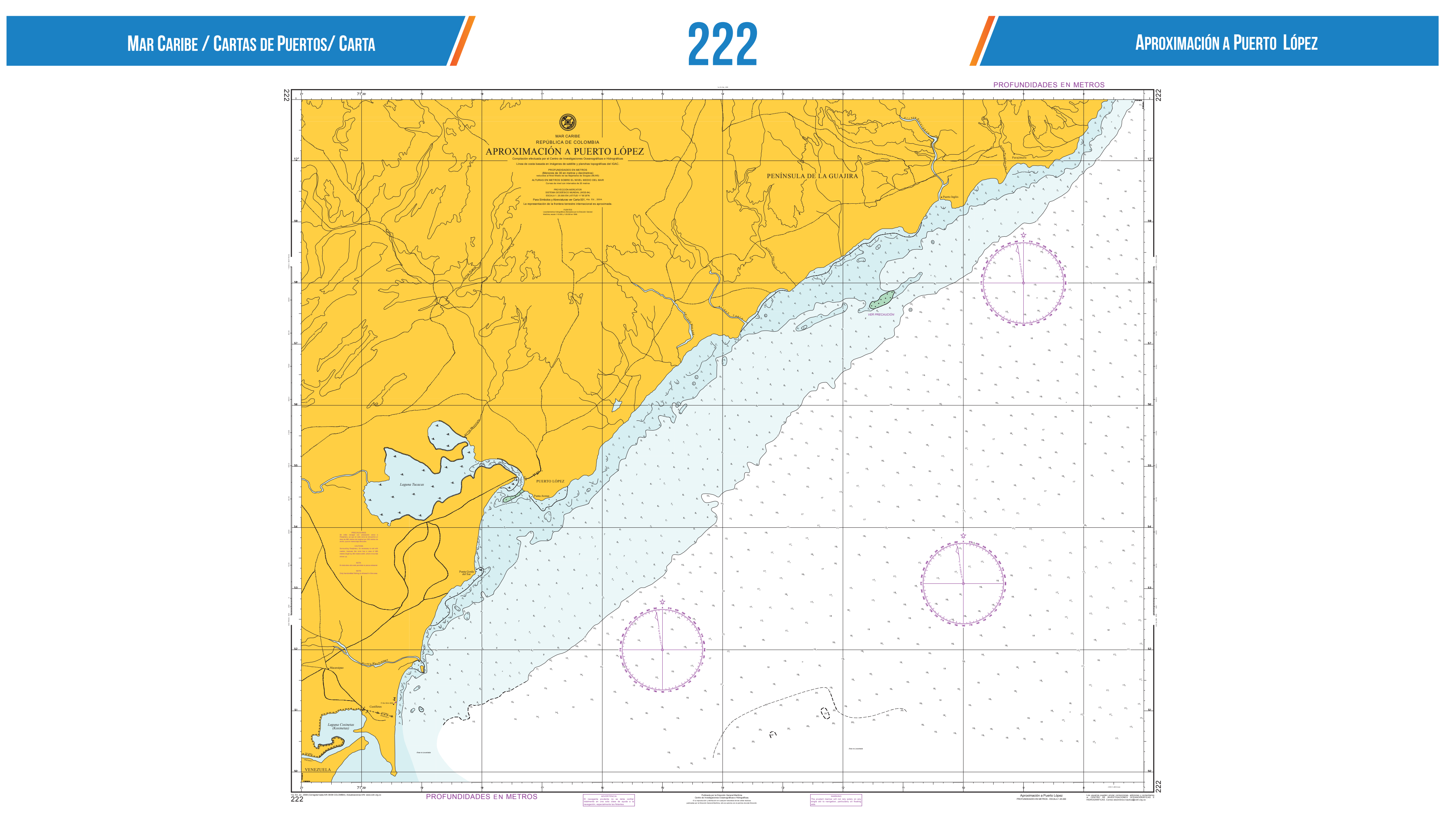

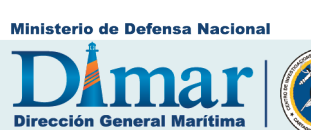
Catálogo de Cartas Náuticas de Colombia Dimar-Cloh Pág.ev11 


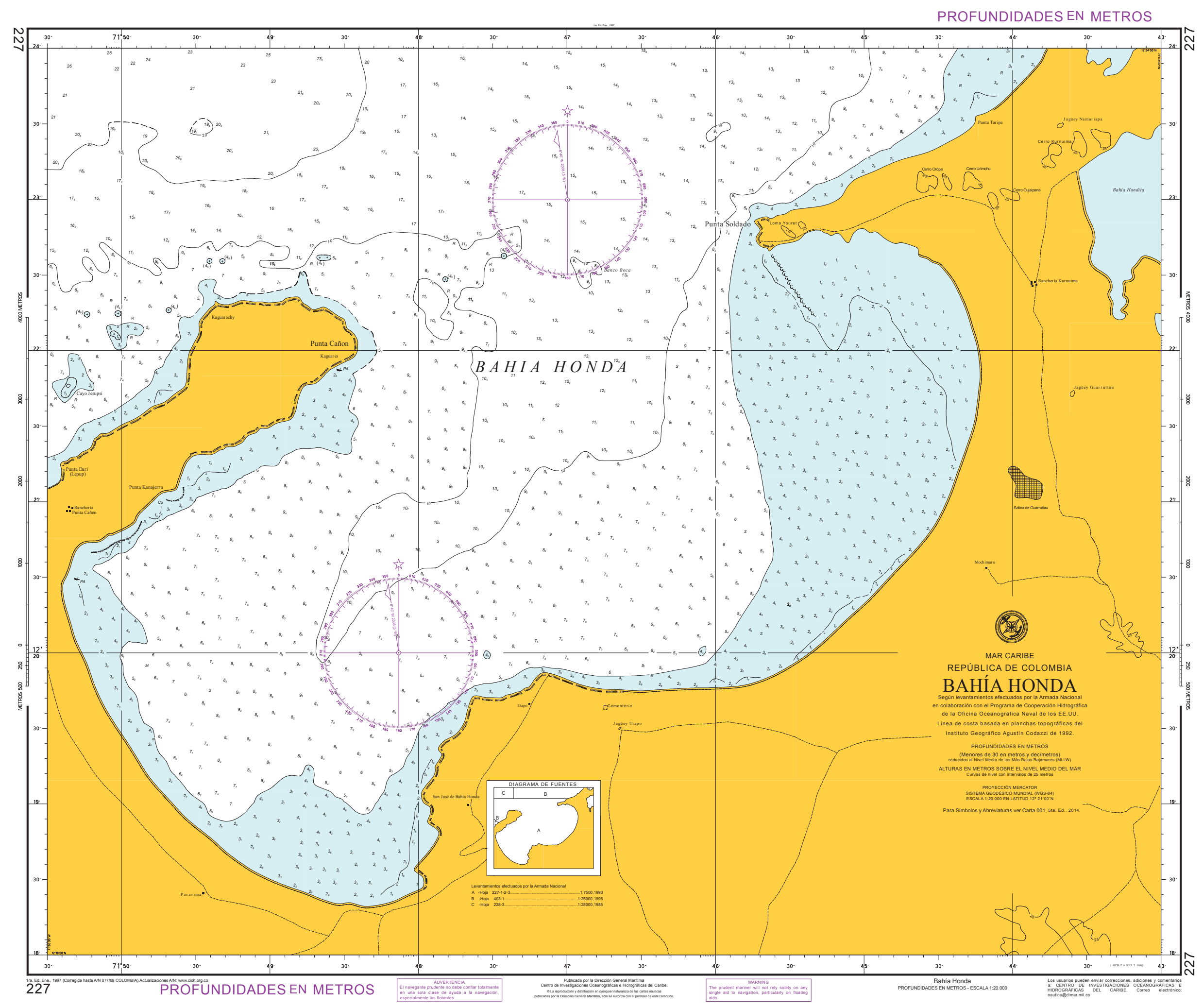

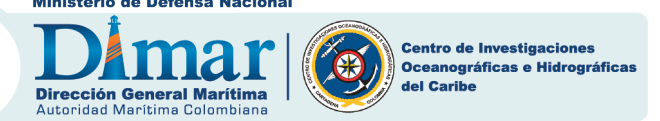




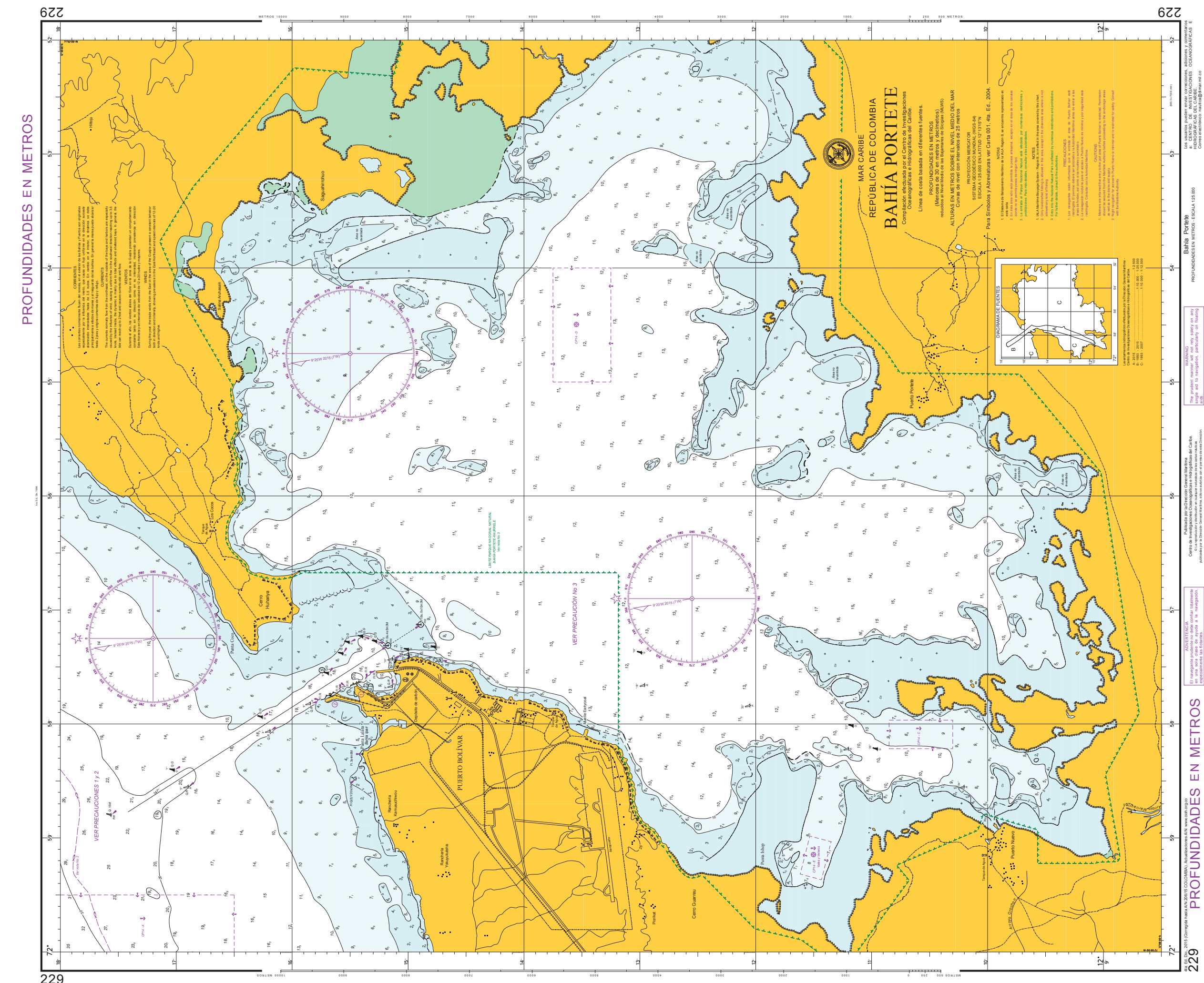


Mar Caribe / Cartas de Puertos/ Carta

231

CABO DE LA VeLA

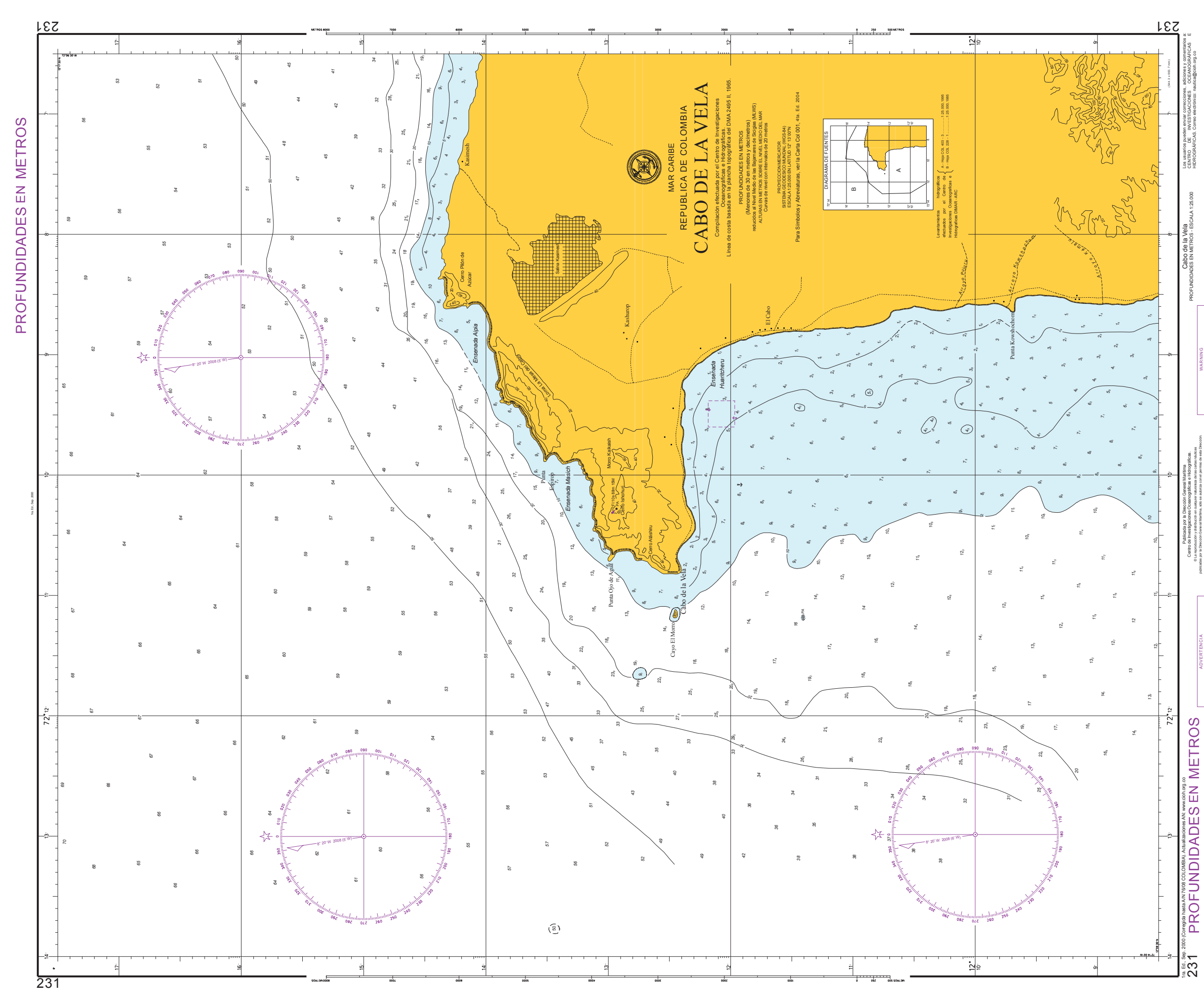

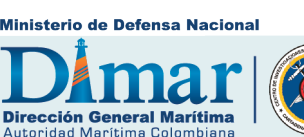

Catálogo de Cabtas Náuticas de Colombia Dimar-Cloh Pág.E014 


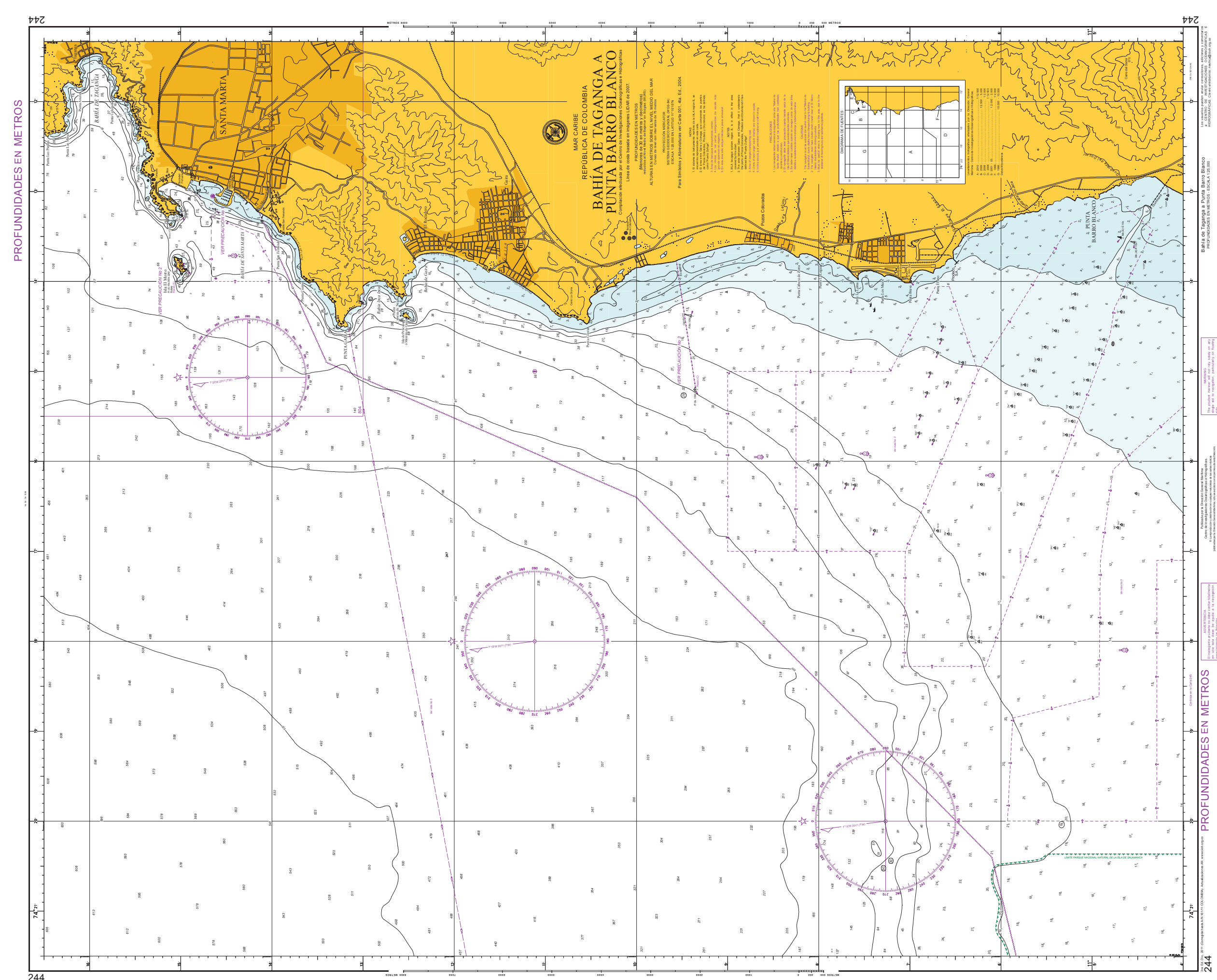




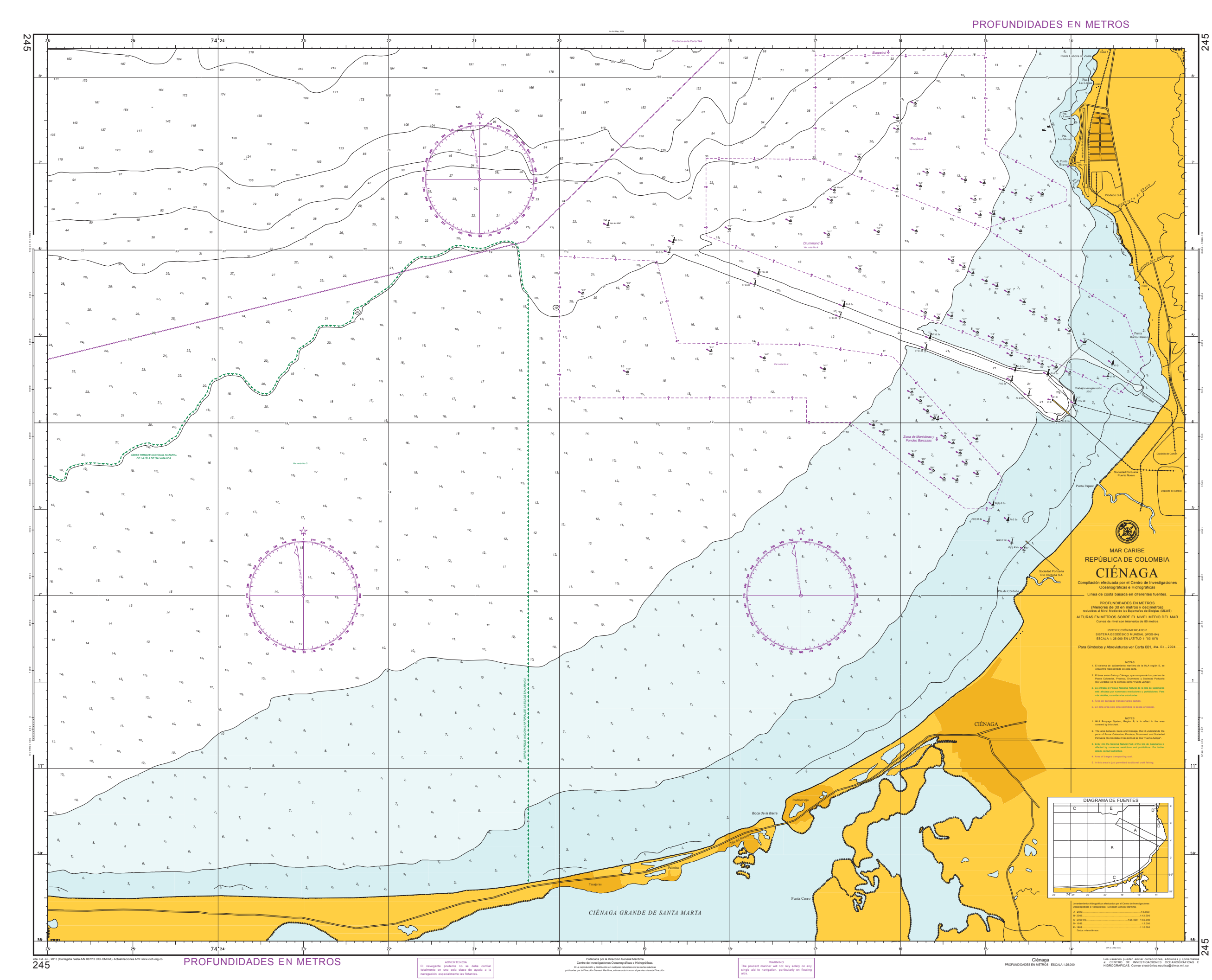




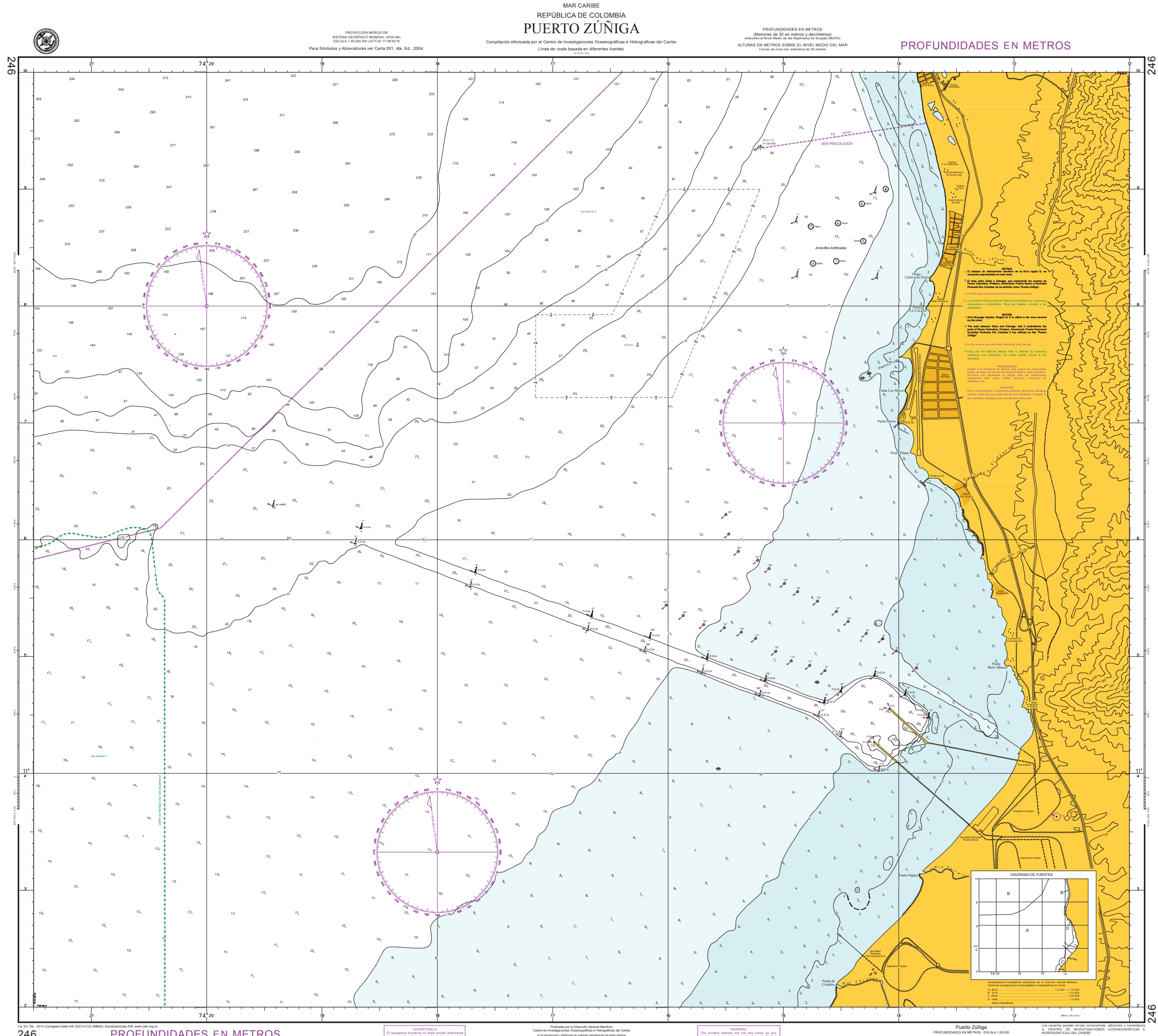




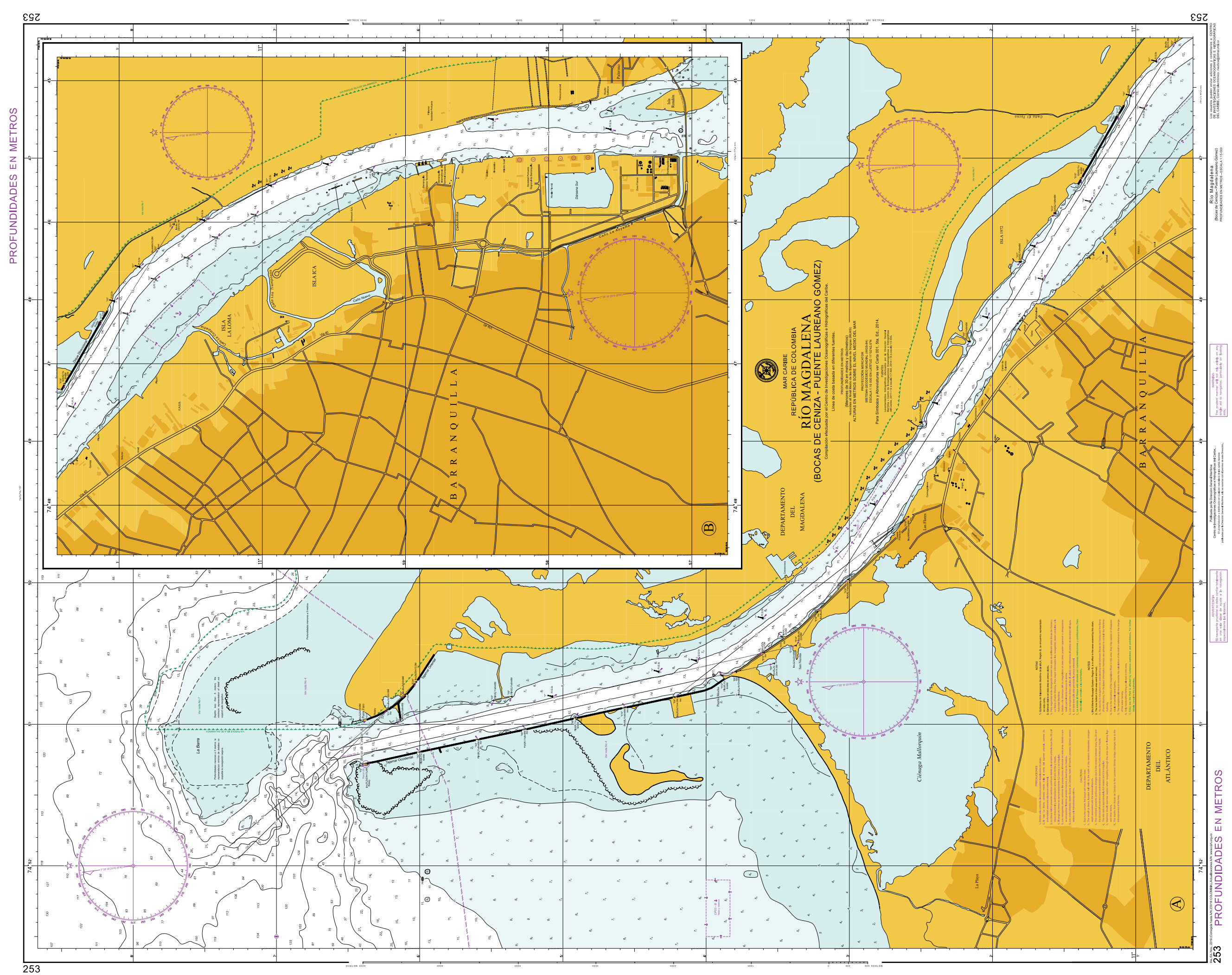




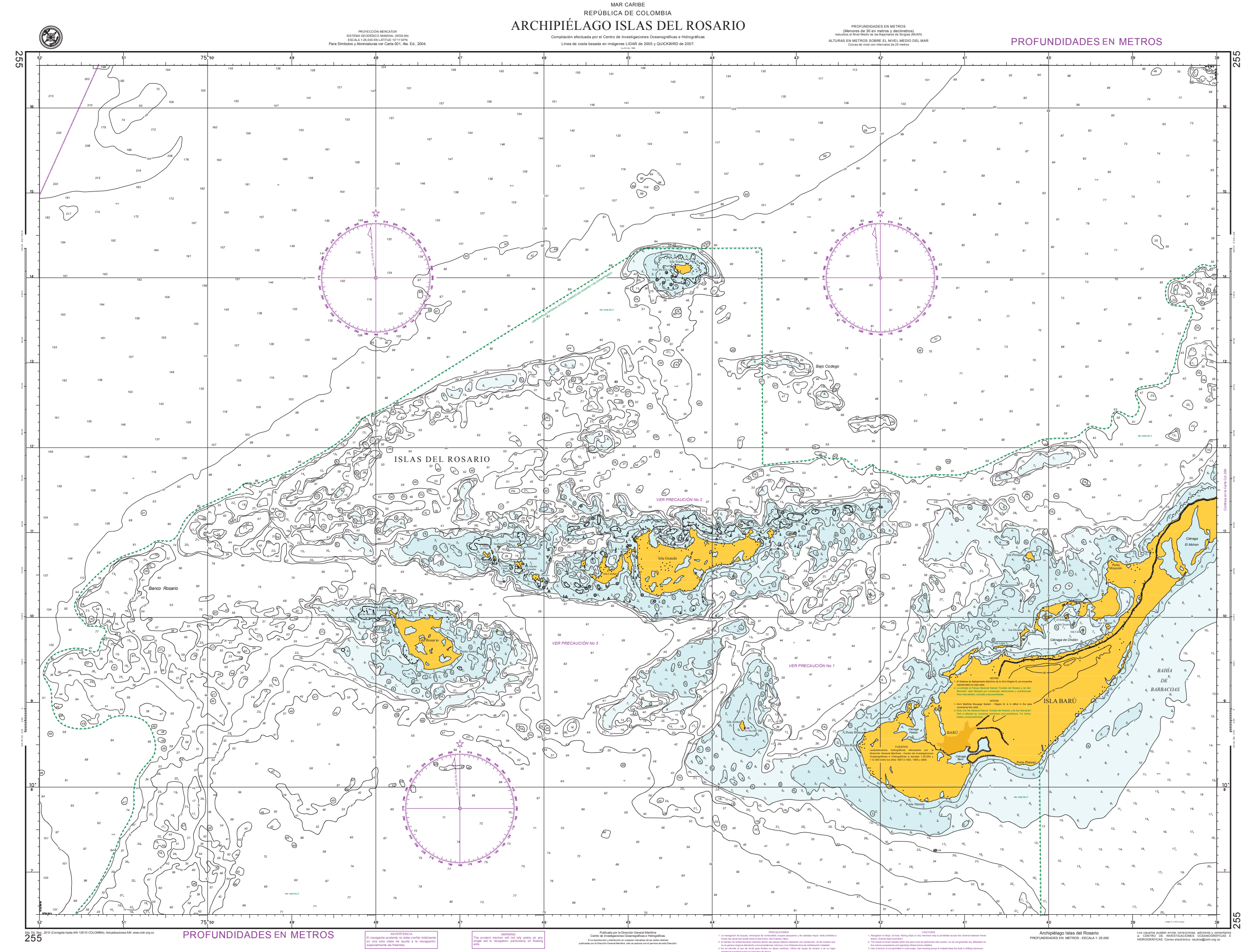




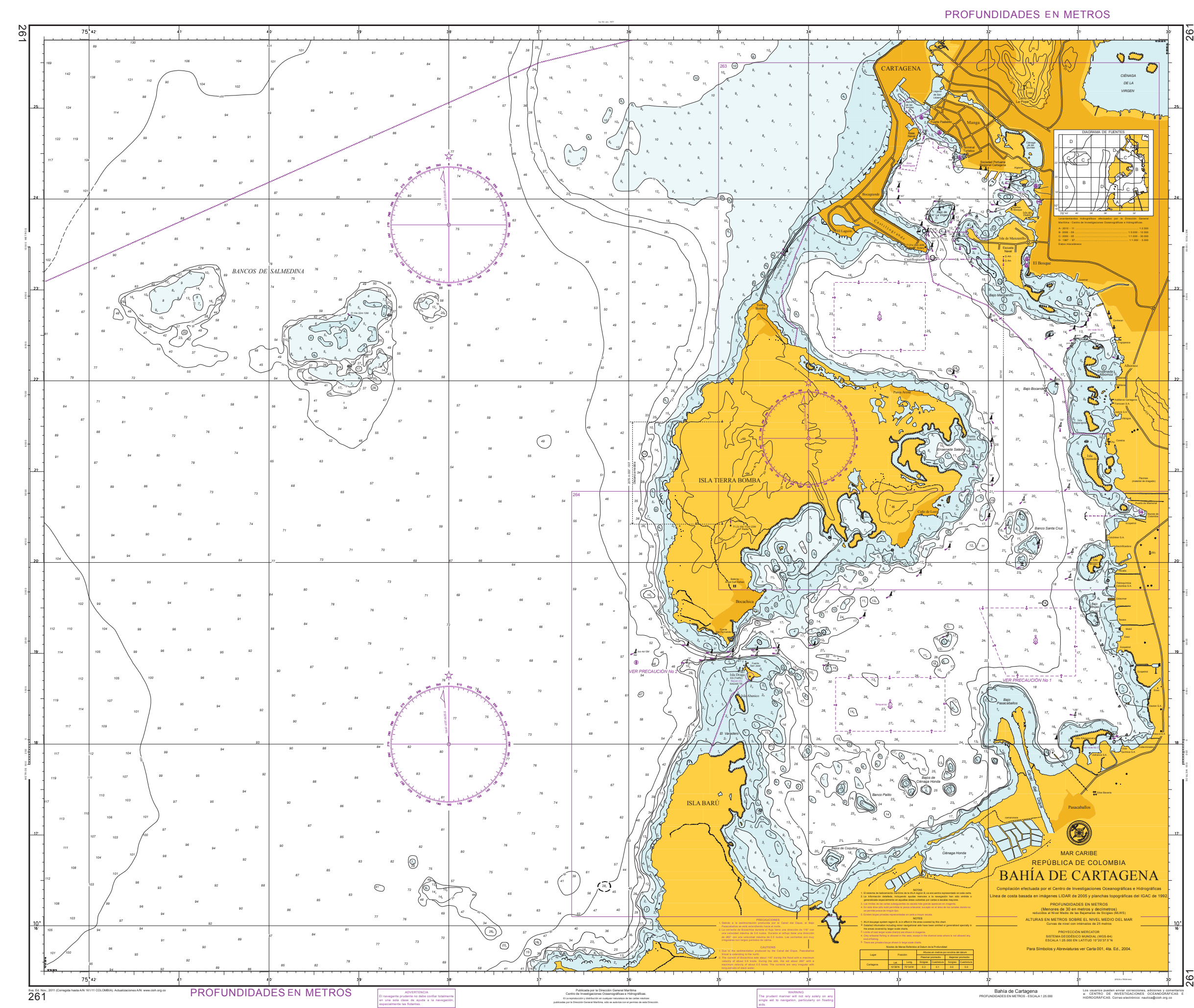




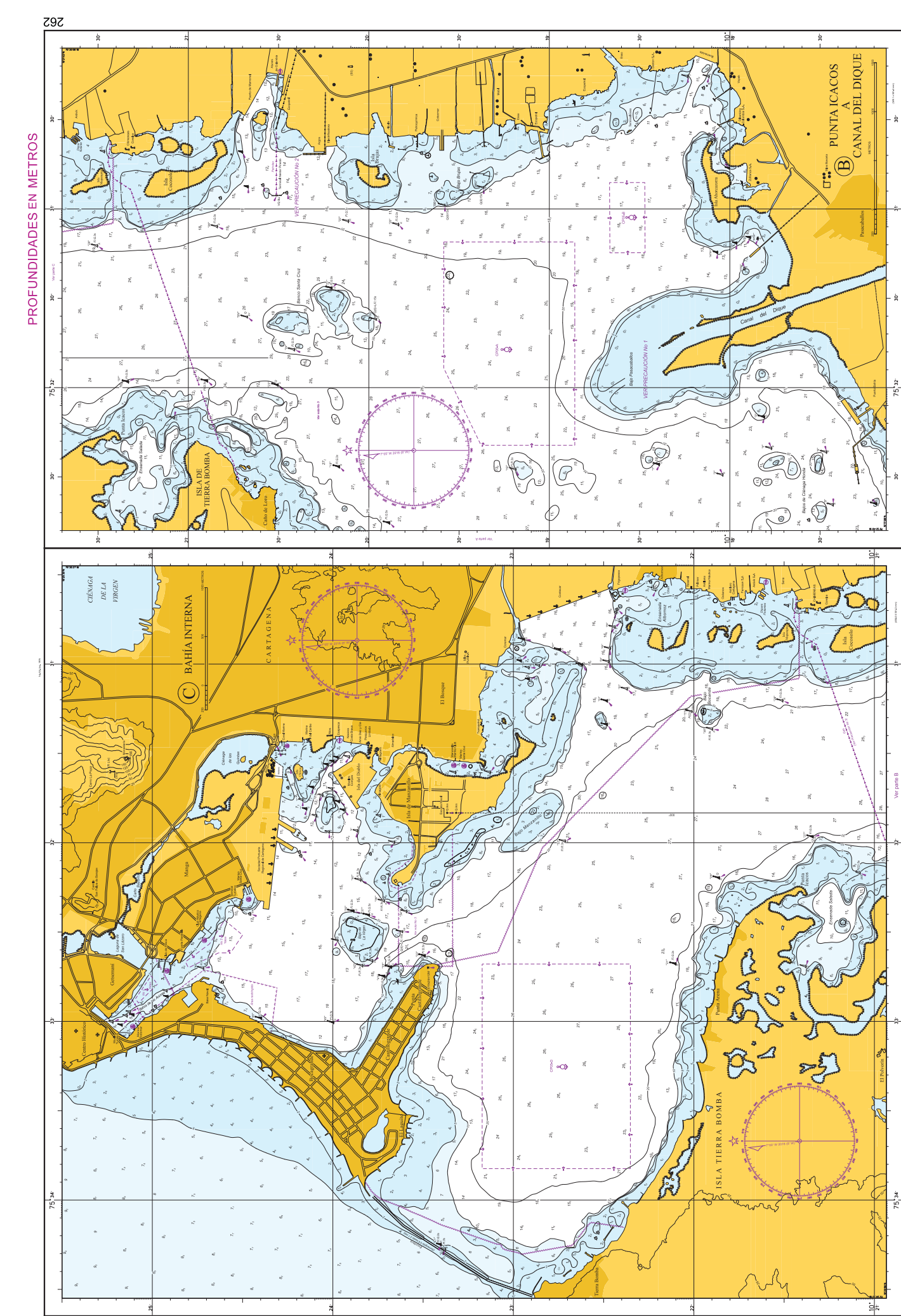

Dlmar

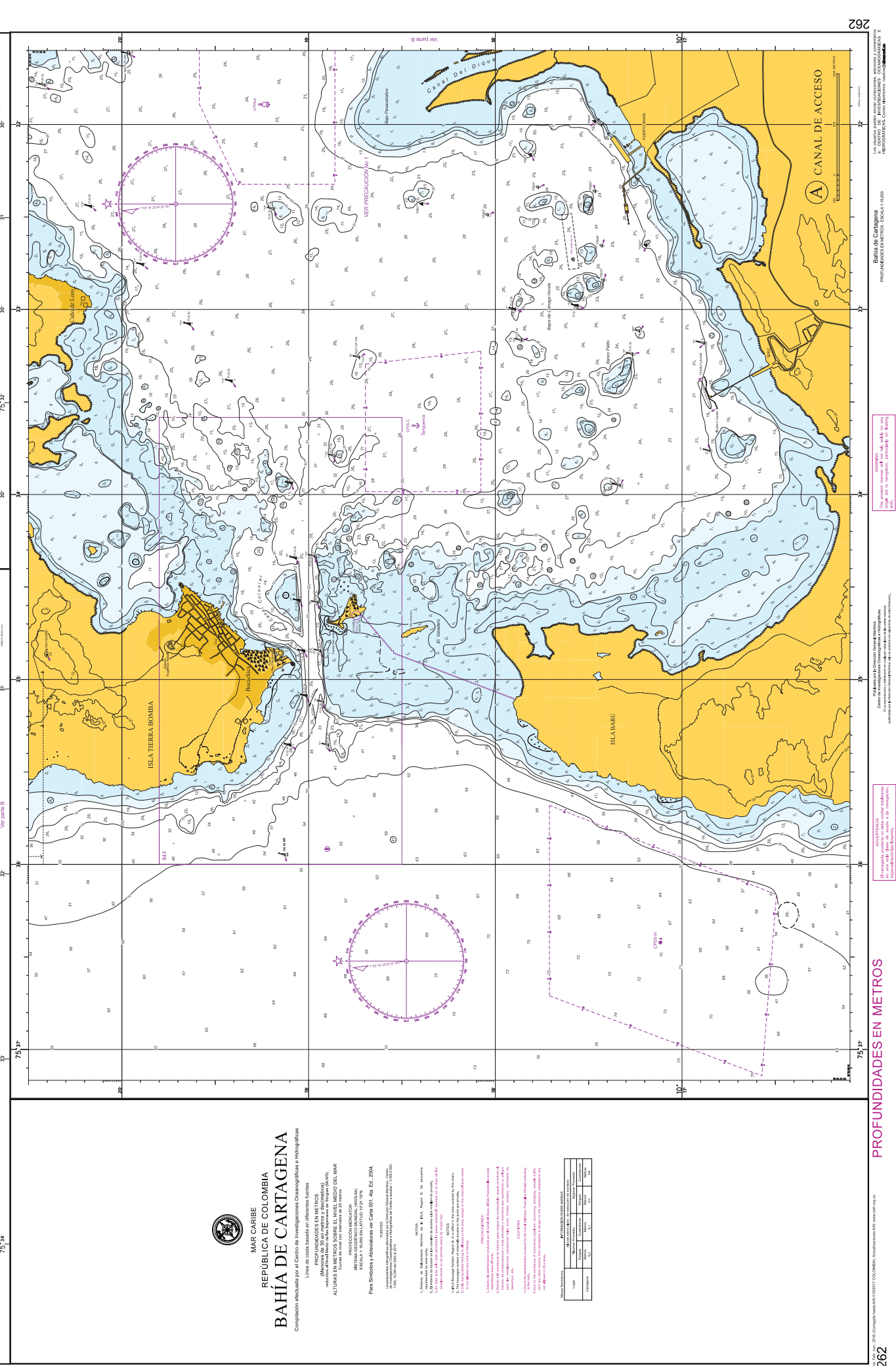

Catálogo de Cartas Náuticas de Colombia dimar -Cloh Pág.e021 


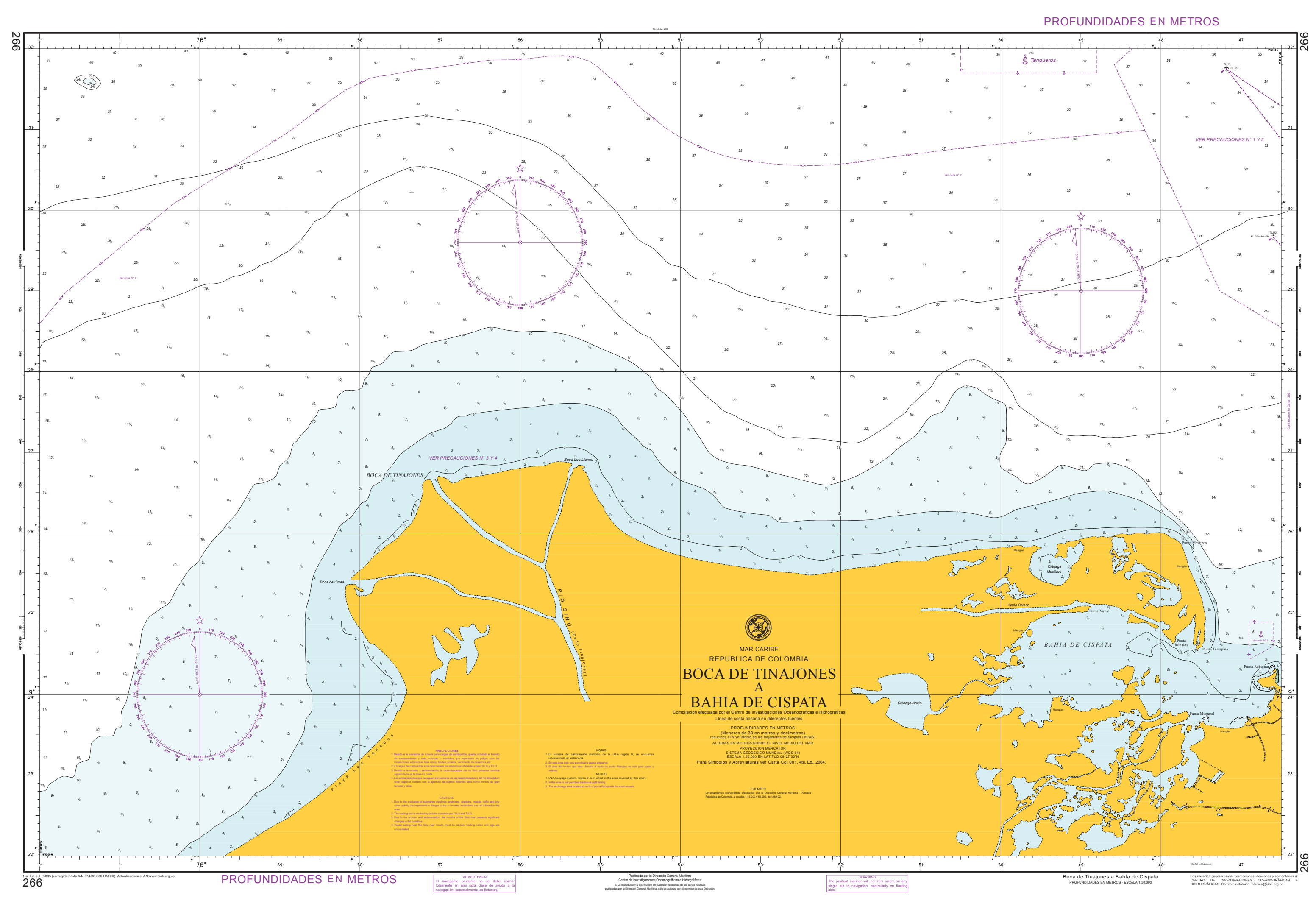




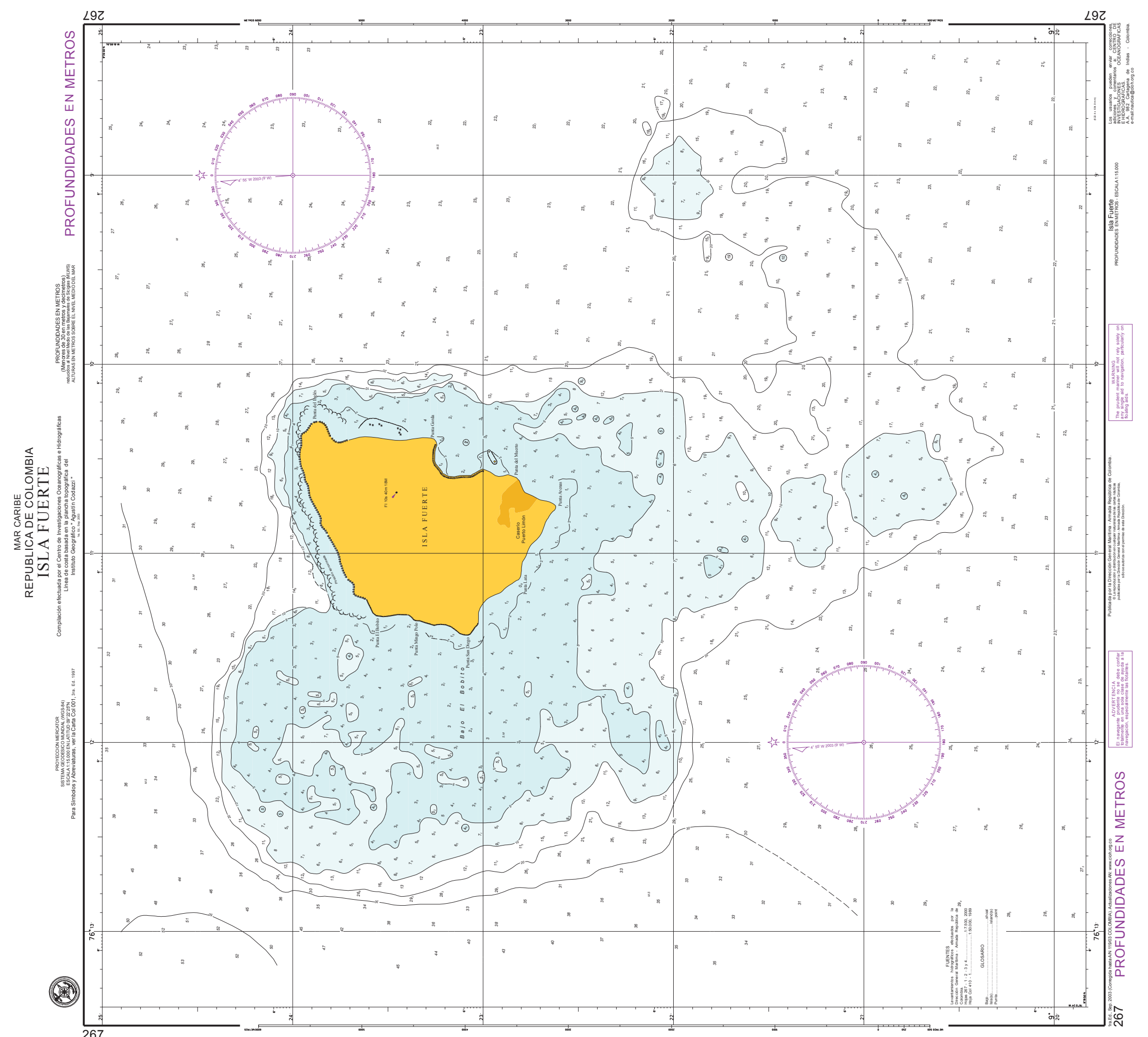




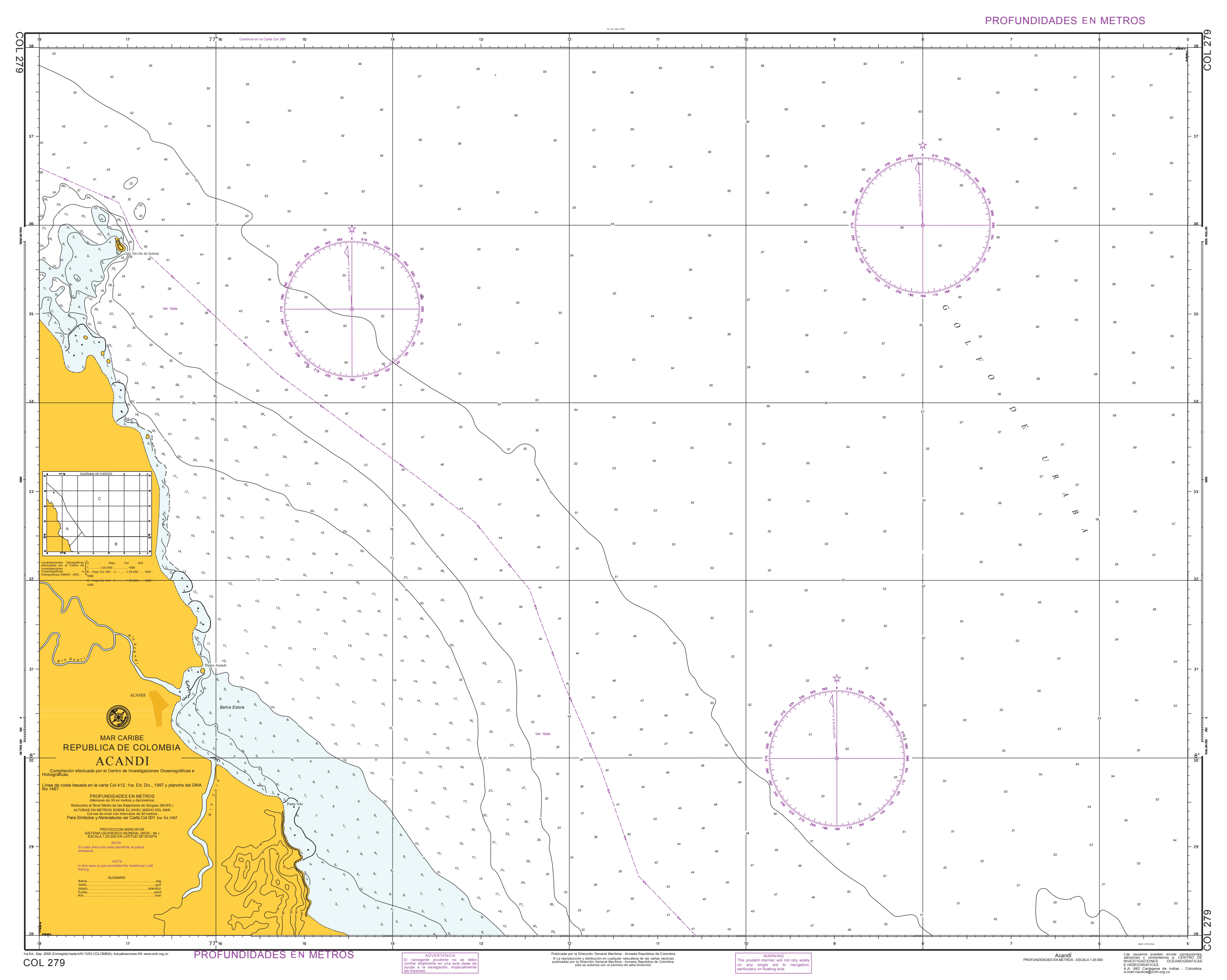

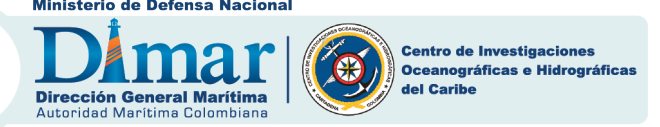


Mar Caribe / Cartas de Puertos/ Carta

280

Cabo Tiburón a IsLa Terrón de AZúcAr

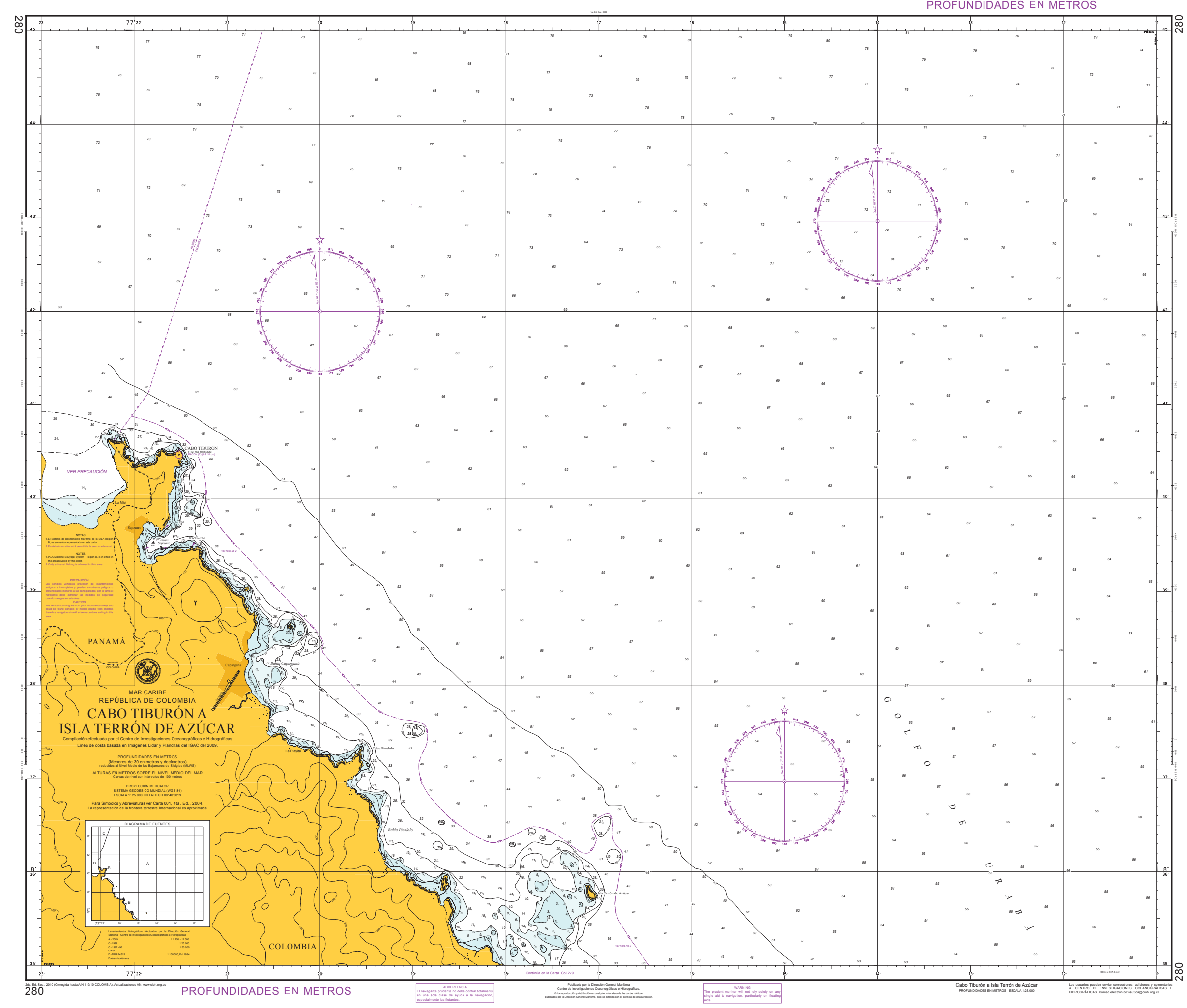

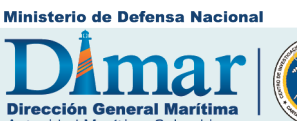

Catálogo de Cartas Náuticas de Colonbia Dimar -CIOH Pág.eoze 
Cartas de canales (canales, muelles, atraque) - (escalas 1:12.500 y mayores)

Tabla F1. Cartas de canales mar Caribe.

\begin{tabular}{|c|c|c|c|c|c|}
\hline No. Carta & Nombre & Escala & Edición & Año & Pág. \\
\hline 880 & Puerto de San Andrés & $1: 7.500$ & 1 & 2016 & F003 \\
\hline 202 & Rada el Cove & $1: 7.500$ & 3 & 2010 & F004 \\
\hline 804 & Bahía de Santa Marta & $1: 10.000$ & 4 & 2015 & F005 \\
\hline 808 & Puerto Brisa & $1: 12.500$ & 1 & 2014 & F006 \\
\hline 833 & Bahía de Cartagena (canal de acceso) & $1: 5.000$ & 5 & 2015 & F007 \\
\hline 885 & Bahía de Santa Catalina & $1: 5.000$ & 1 & 2016 & F008 \\
\hline 848 & Santiago de Tolú & 1:10.000 & 1 & 2013 & F009 \\
\hline 822 & Ensenada Trebal (Puerto Velero) & 1:10.000 & 1 & 2016 & F010 \\
\hline
\end{tabular}

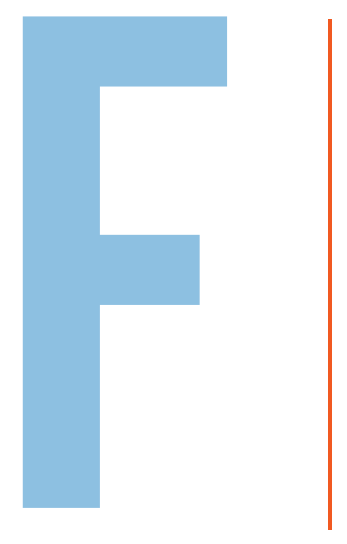




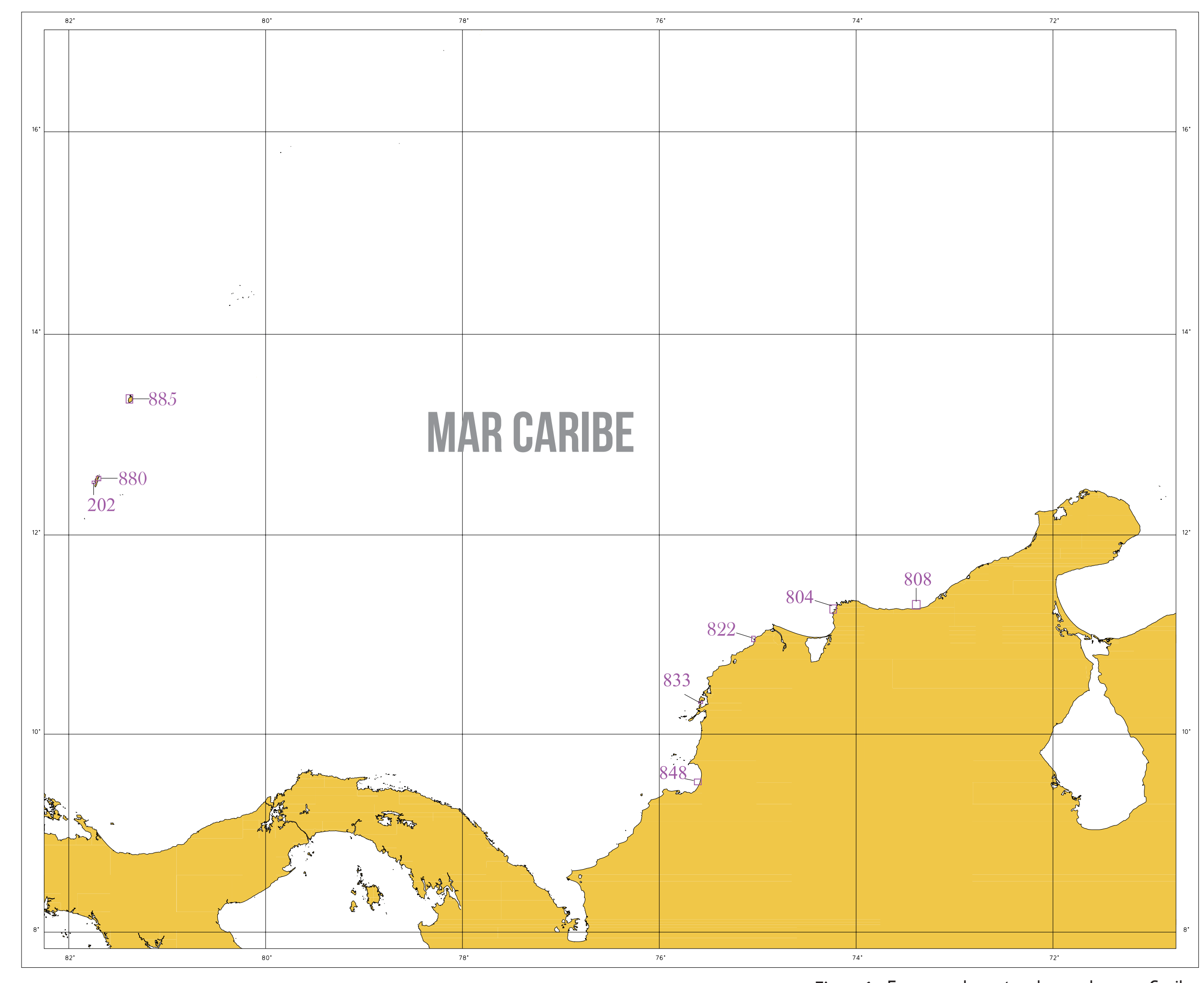




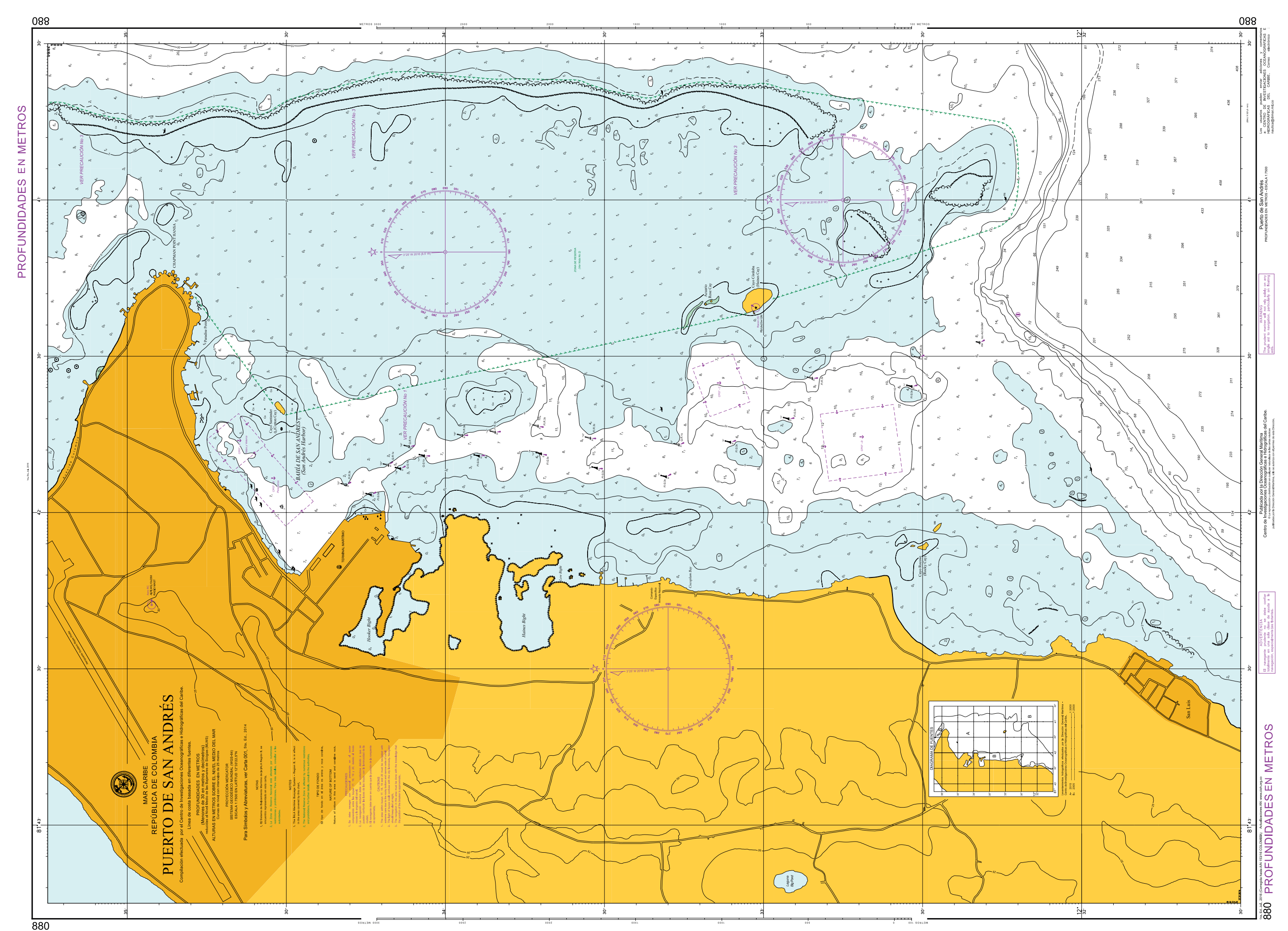




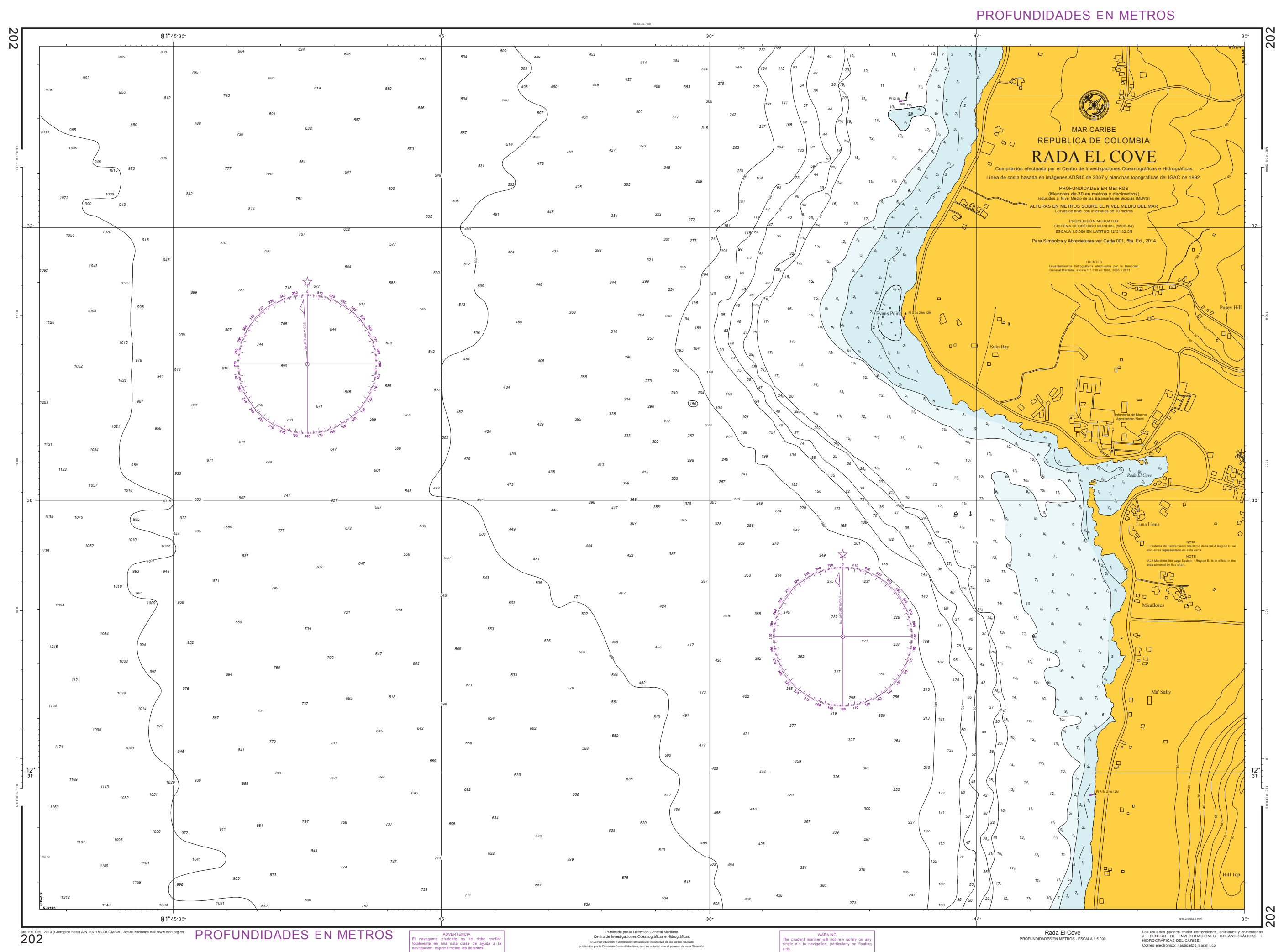




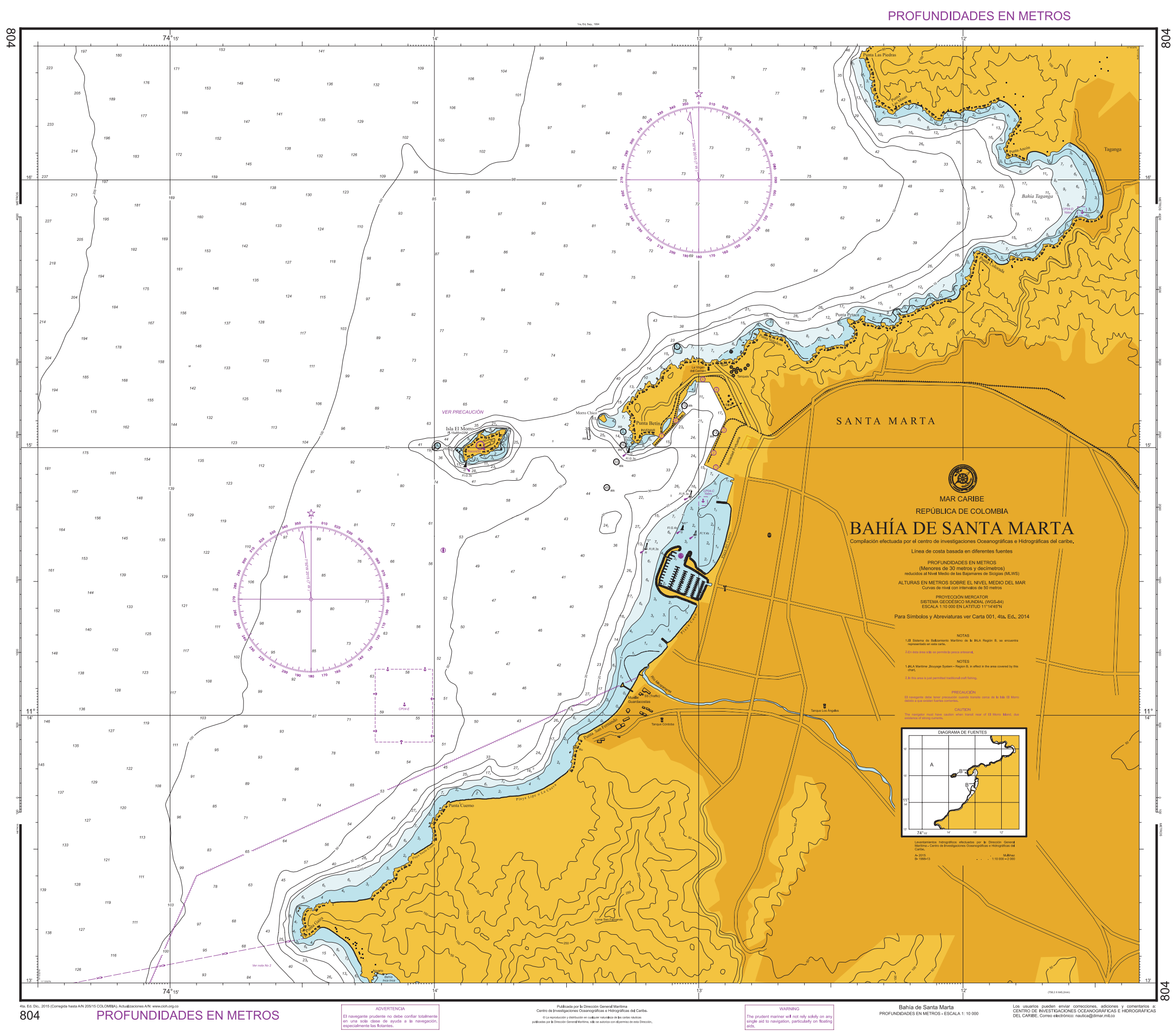

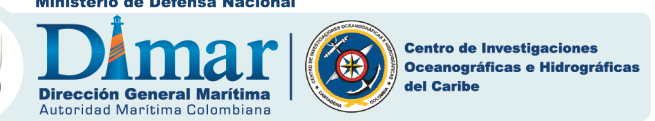




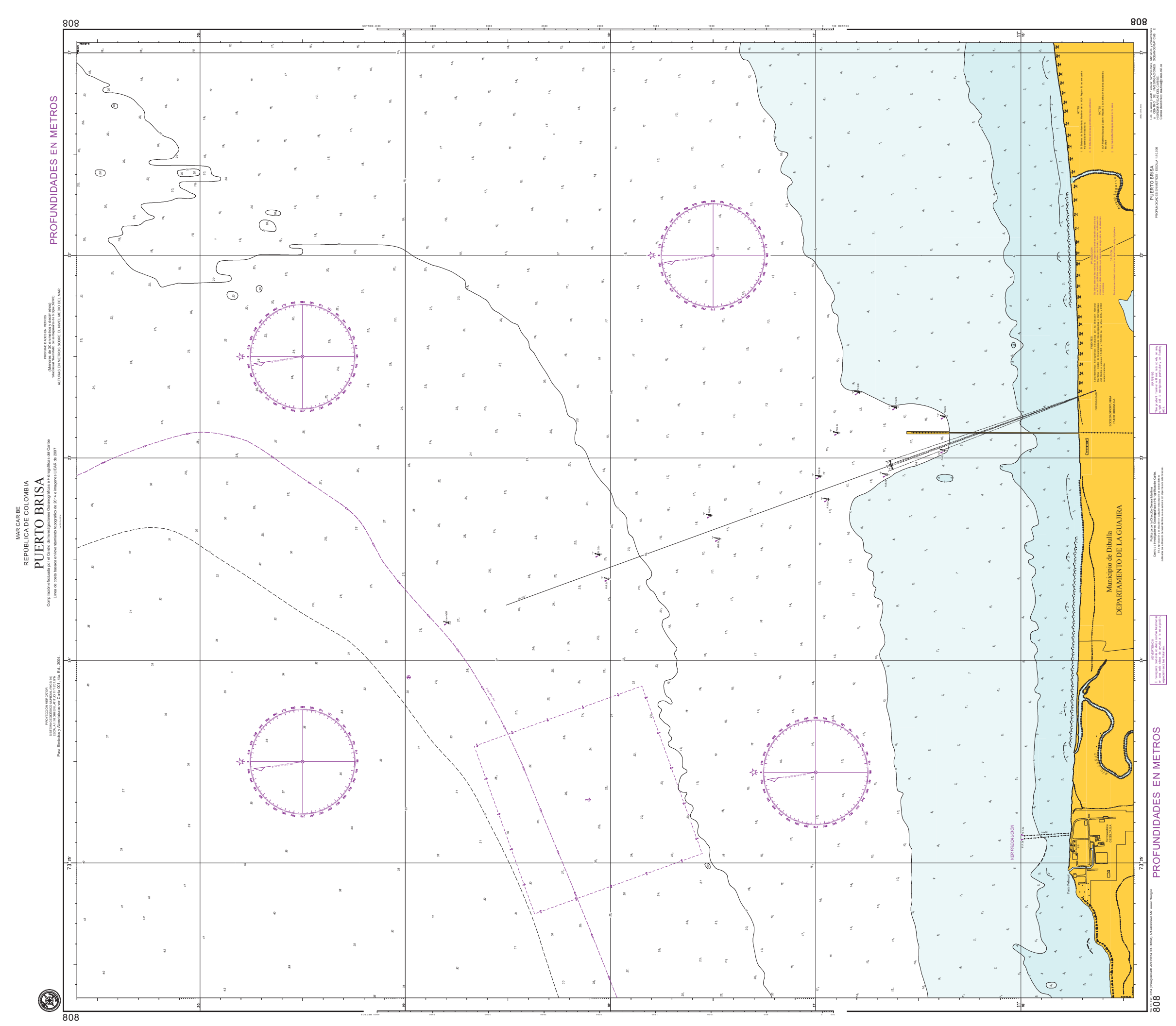




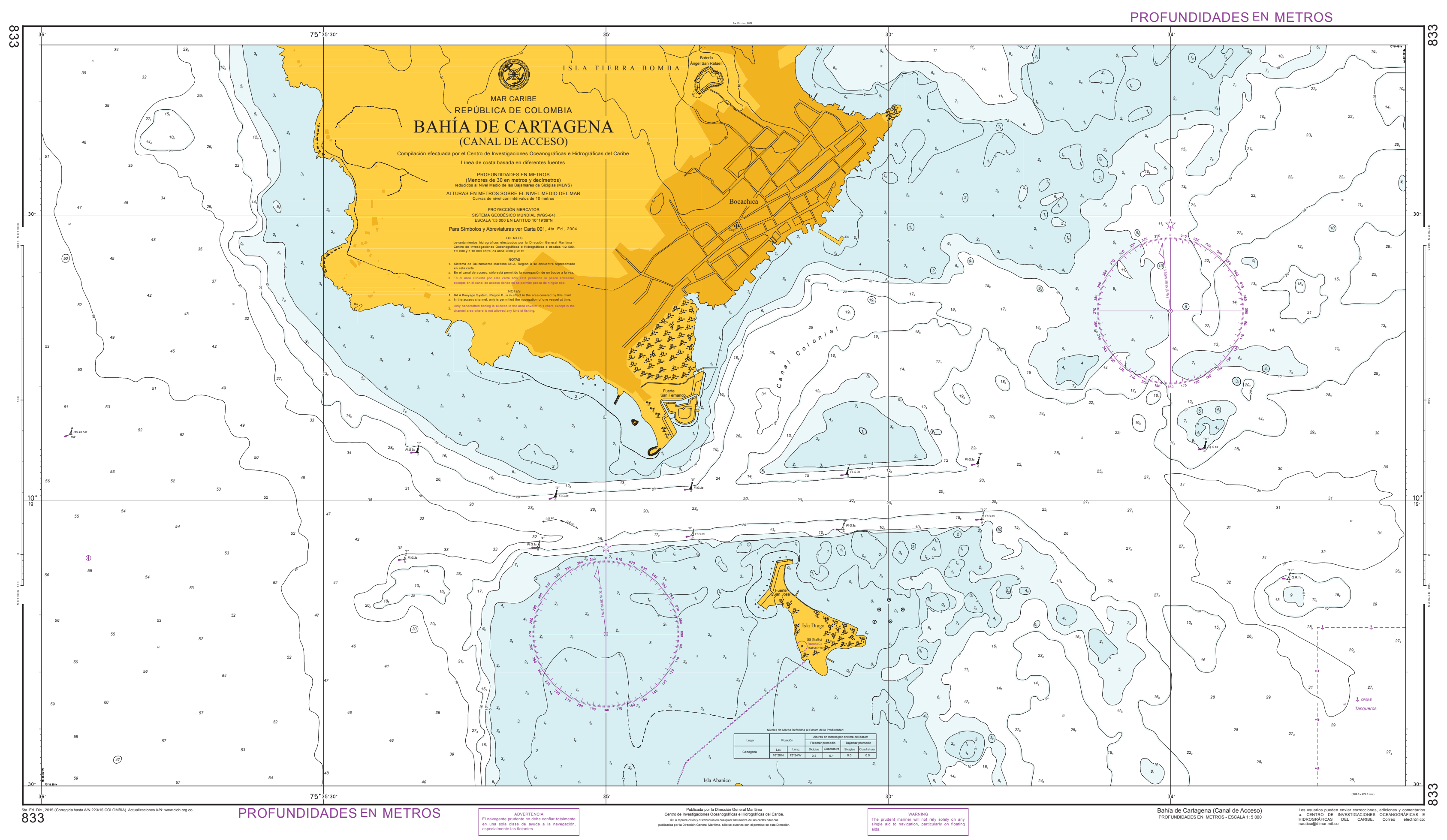

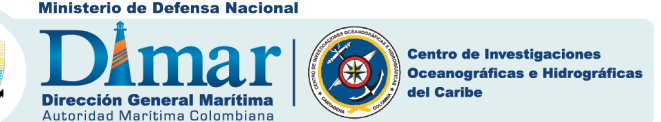




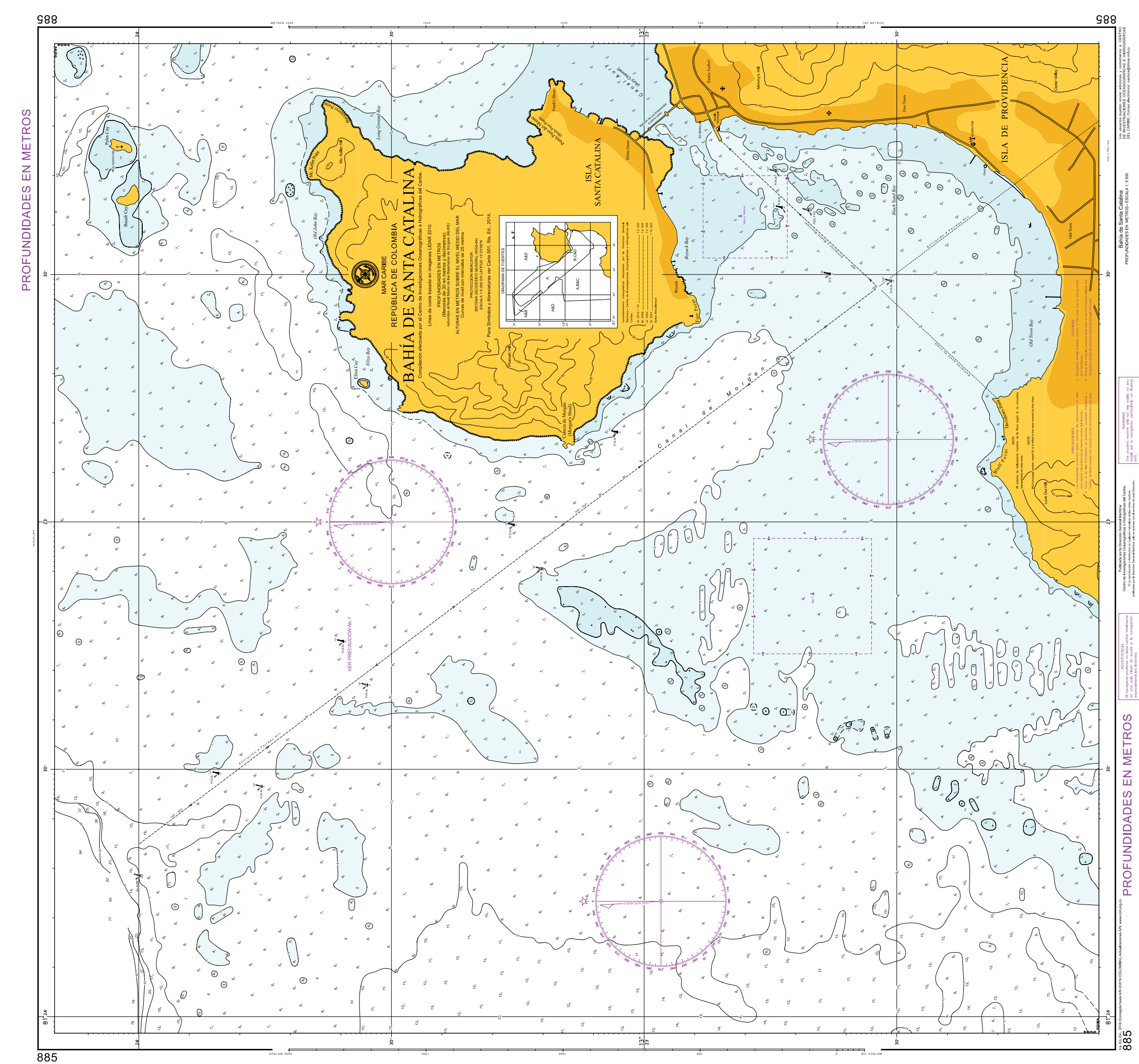




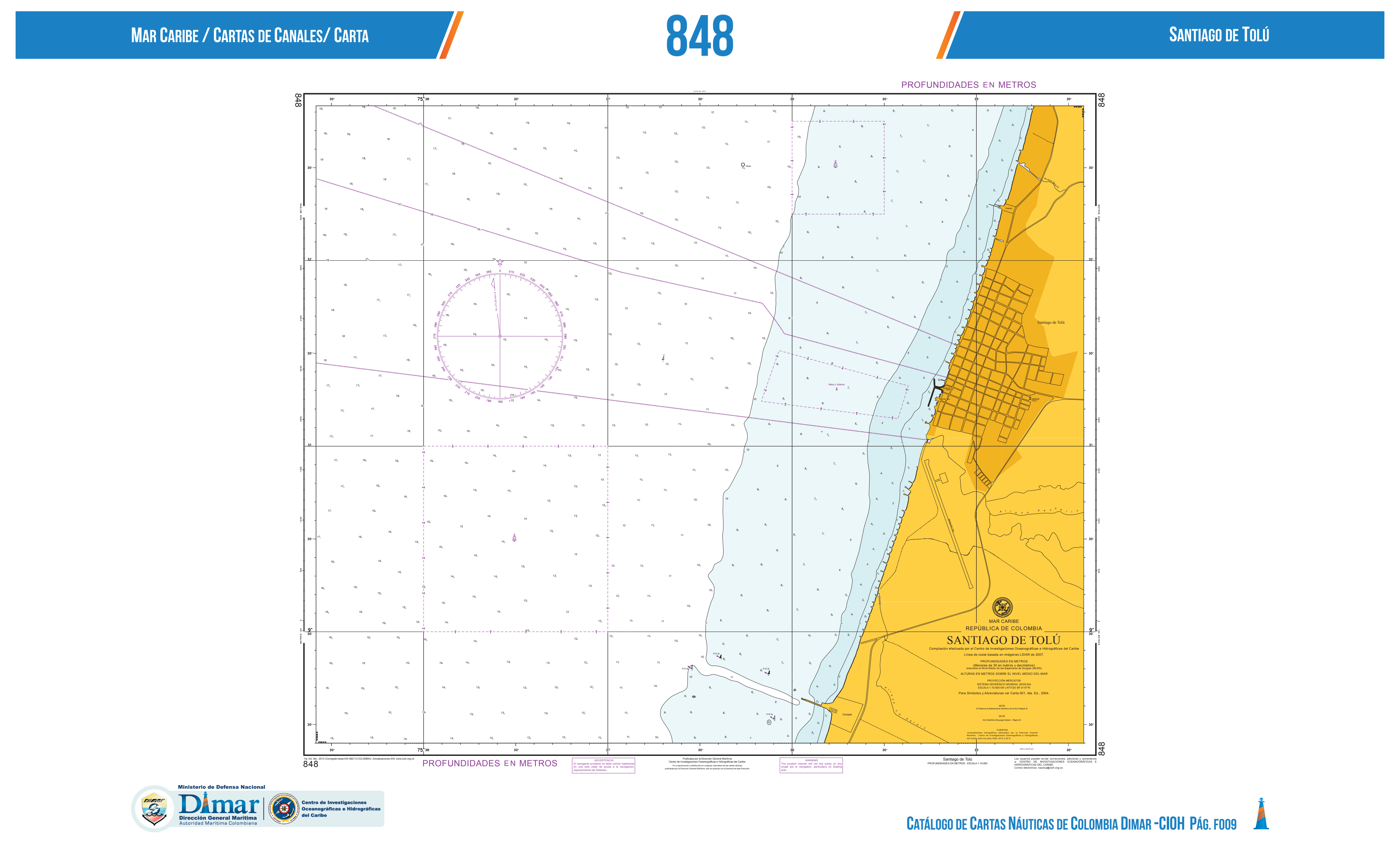




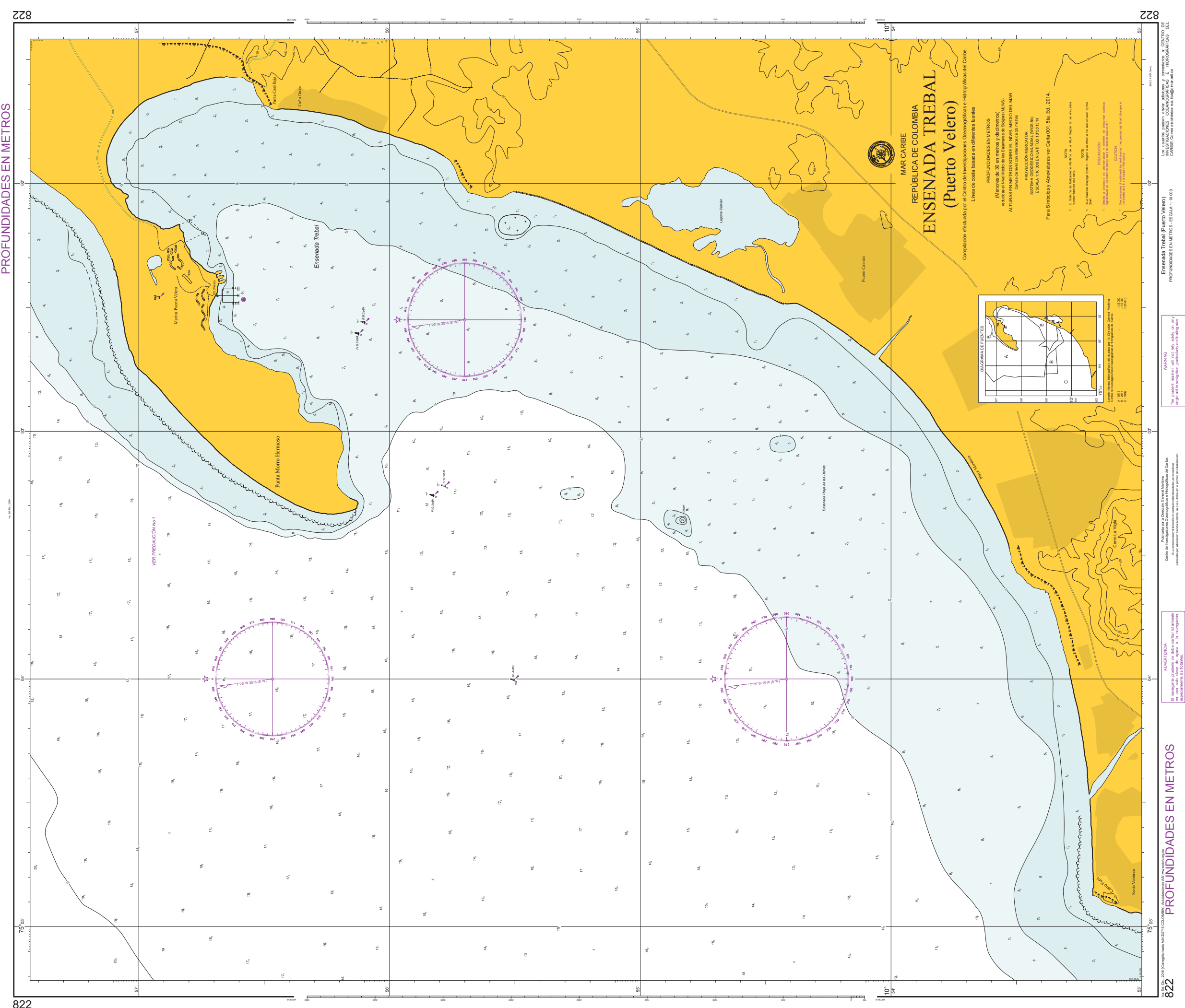




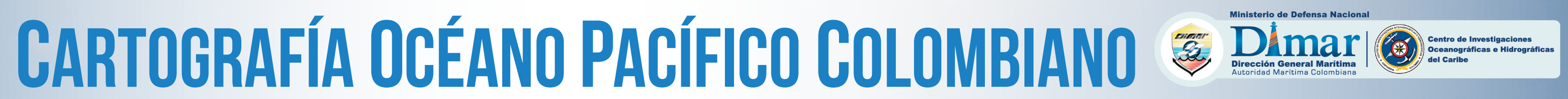

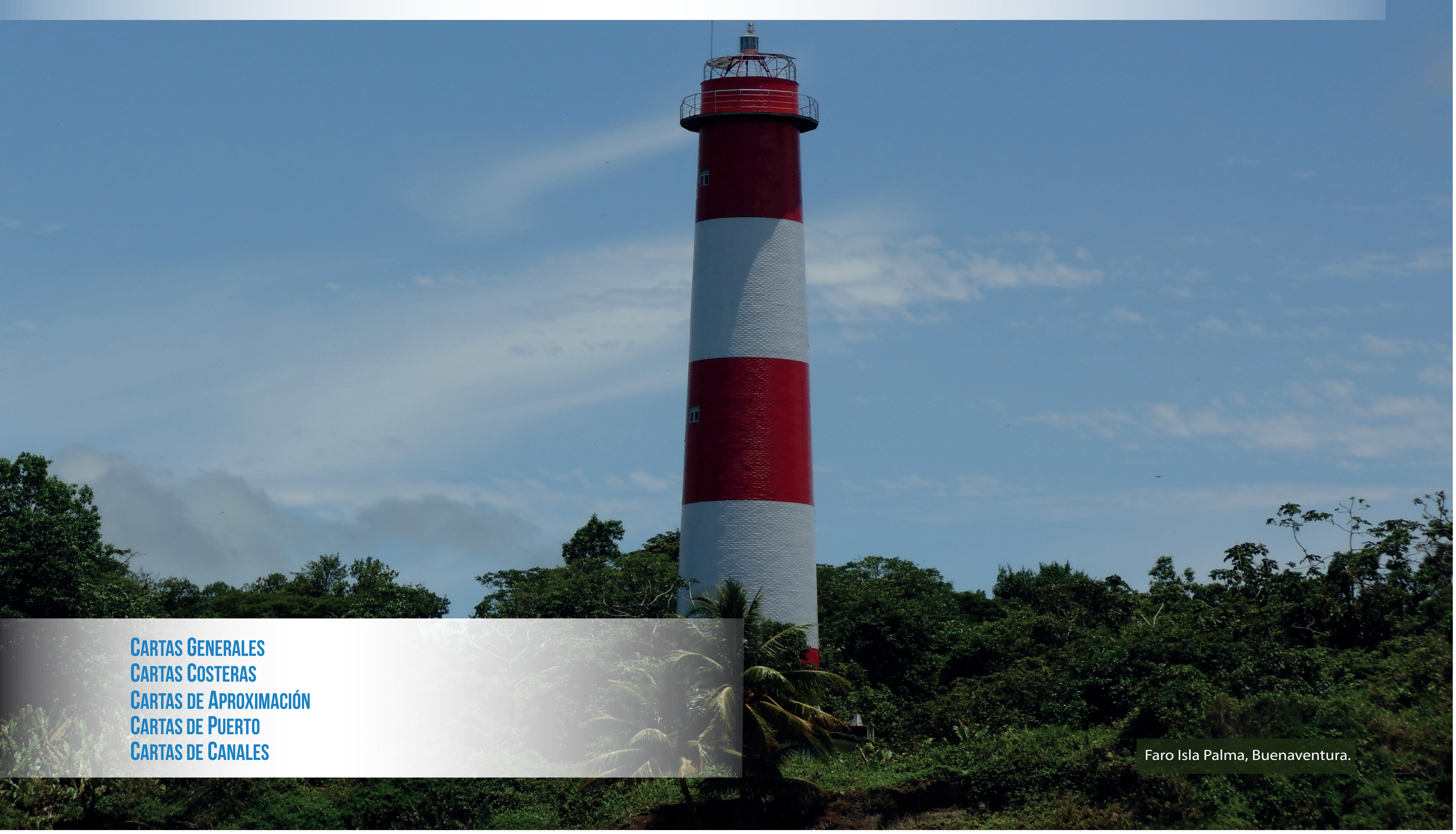


Cartas generales (escalas 1:2.000.000 -1:350.001)

Tabla G1. Cartas generales océano Pacífico.

\begin{tabular}{|l|l|c|c|c|c|}
\hline No. Carta & \multicolumn{1}{|c|}{ Nombre } & Escala & Edición & Año & Pág. \\
\hline 003 INT 6000 & Bahía de Panamá a Cabo San Francisco & $1: 1.200 .000$ & 4 & 2011 & G003 \\
\hline 030 INT 6100 & Canal de Panamá al Golfo de Cupica & $1: 500.000$ & 2 & 2004 & G004 \\
\hline 031 INT 6105 & Golfo de Cupica a Bahía de Buenaventura & $1: 500.000$ & 3 & 2009 & G005 \\
\hline 032 INT 6110 & Bahía de Buenaventura a Bahía Ancón de Sardinas & $1: 500.000$ & 3 & 2009 & G006 \\
\hline
\end{tabular}




\section{/ Cartas Generales / OCÉano PaCífico}

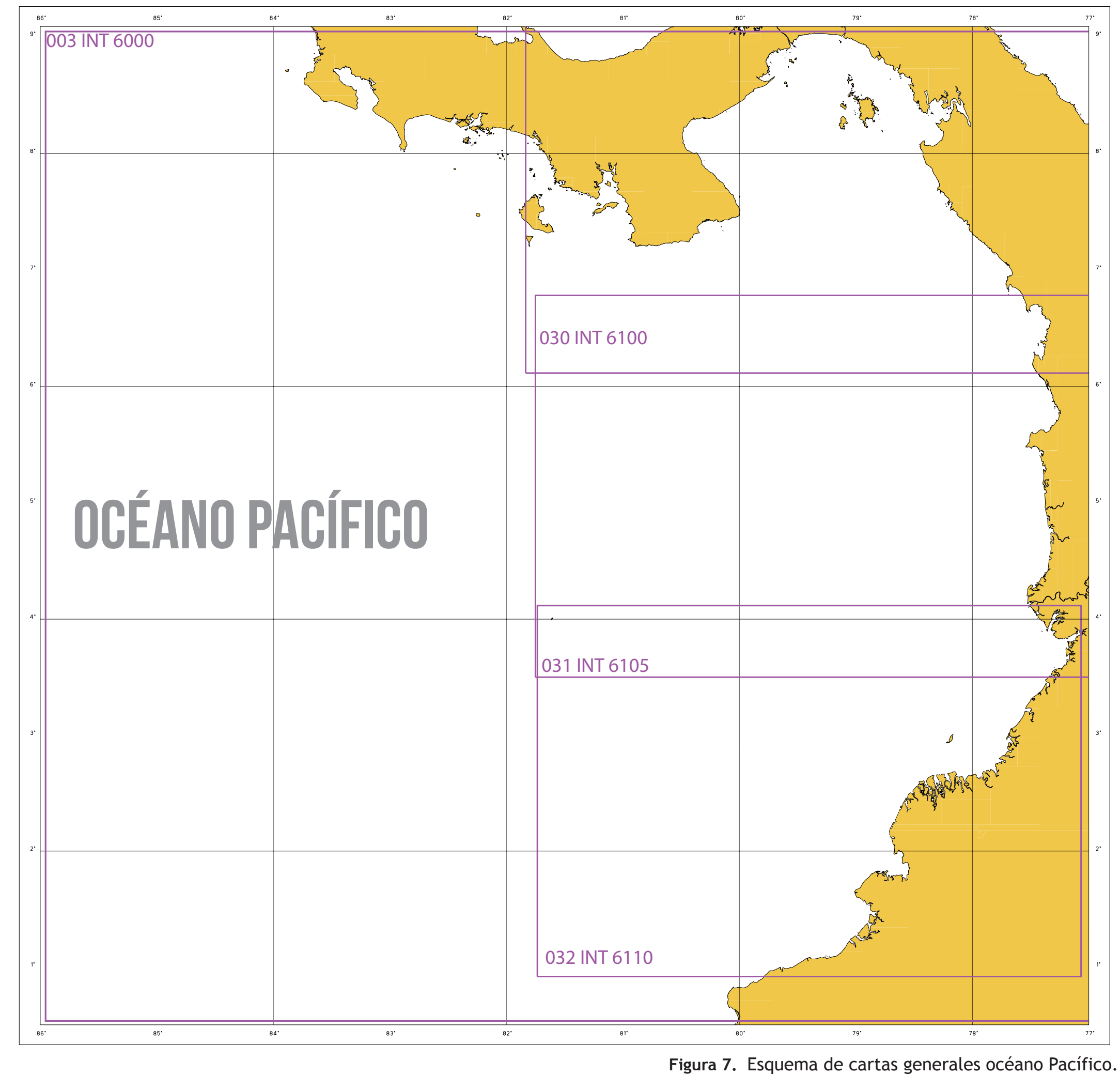

Dlmar 


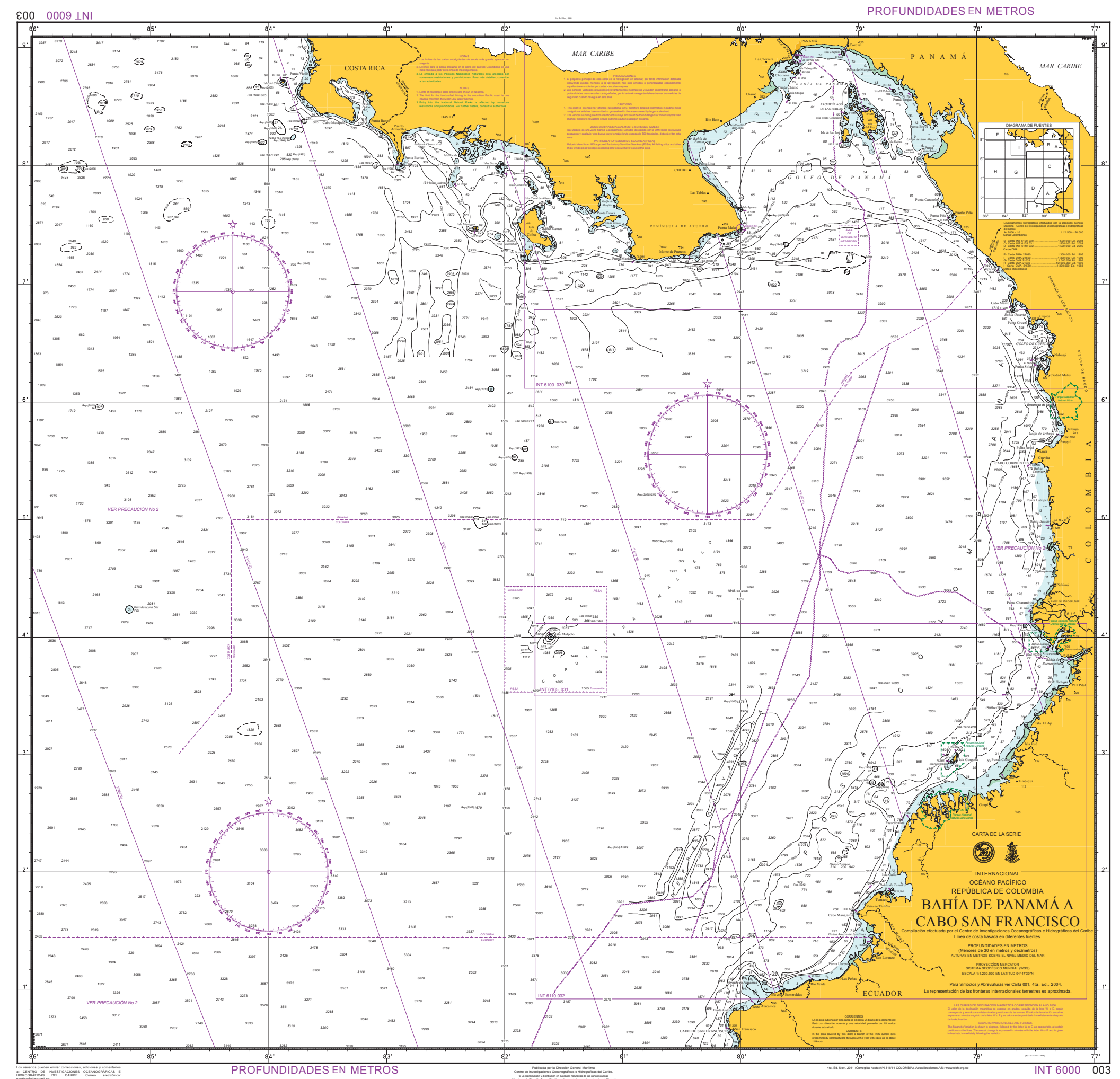




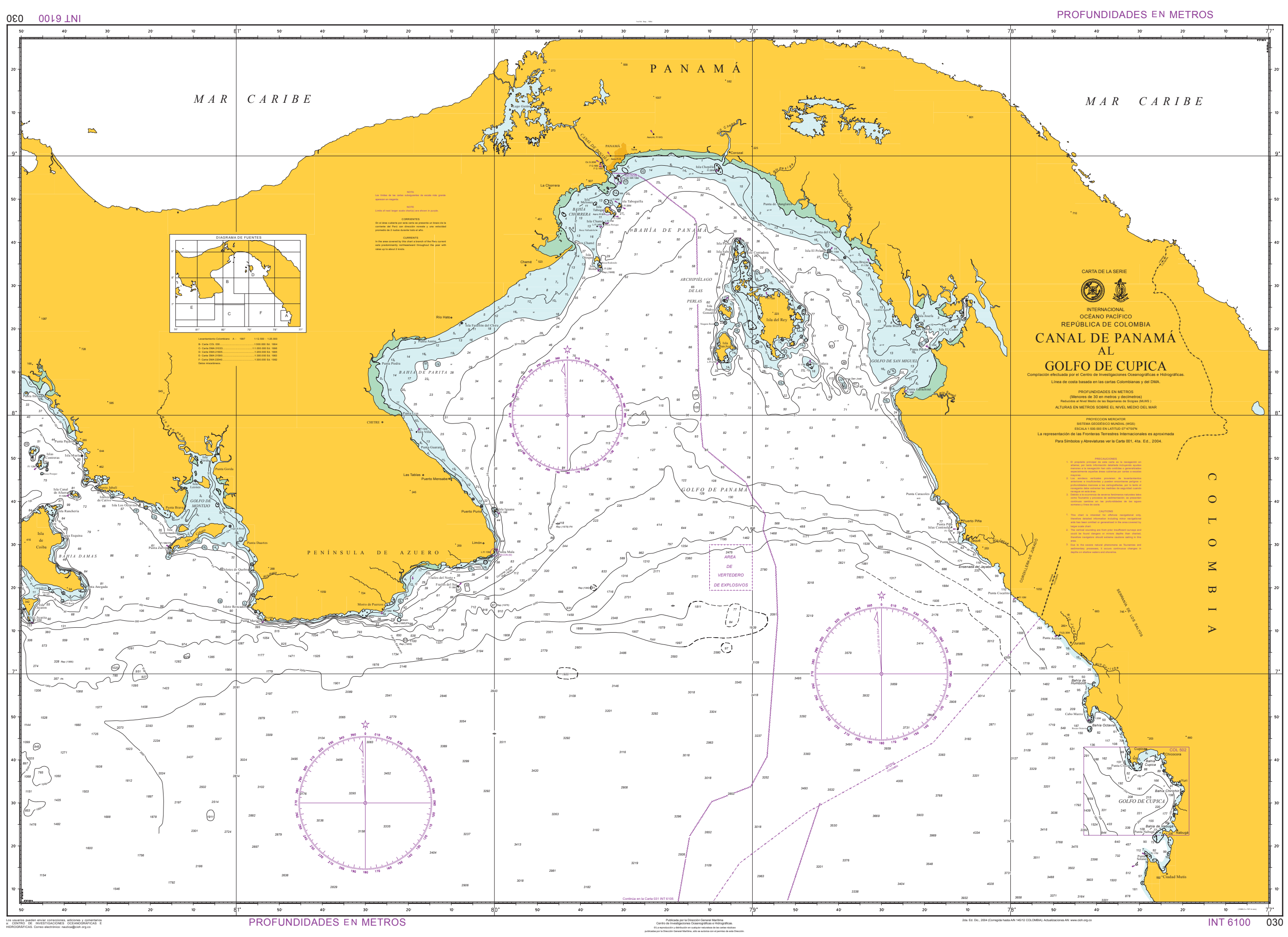




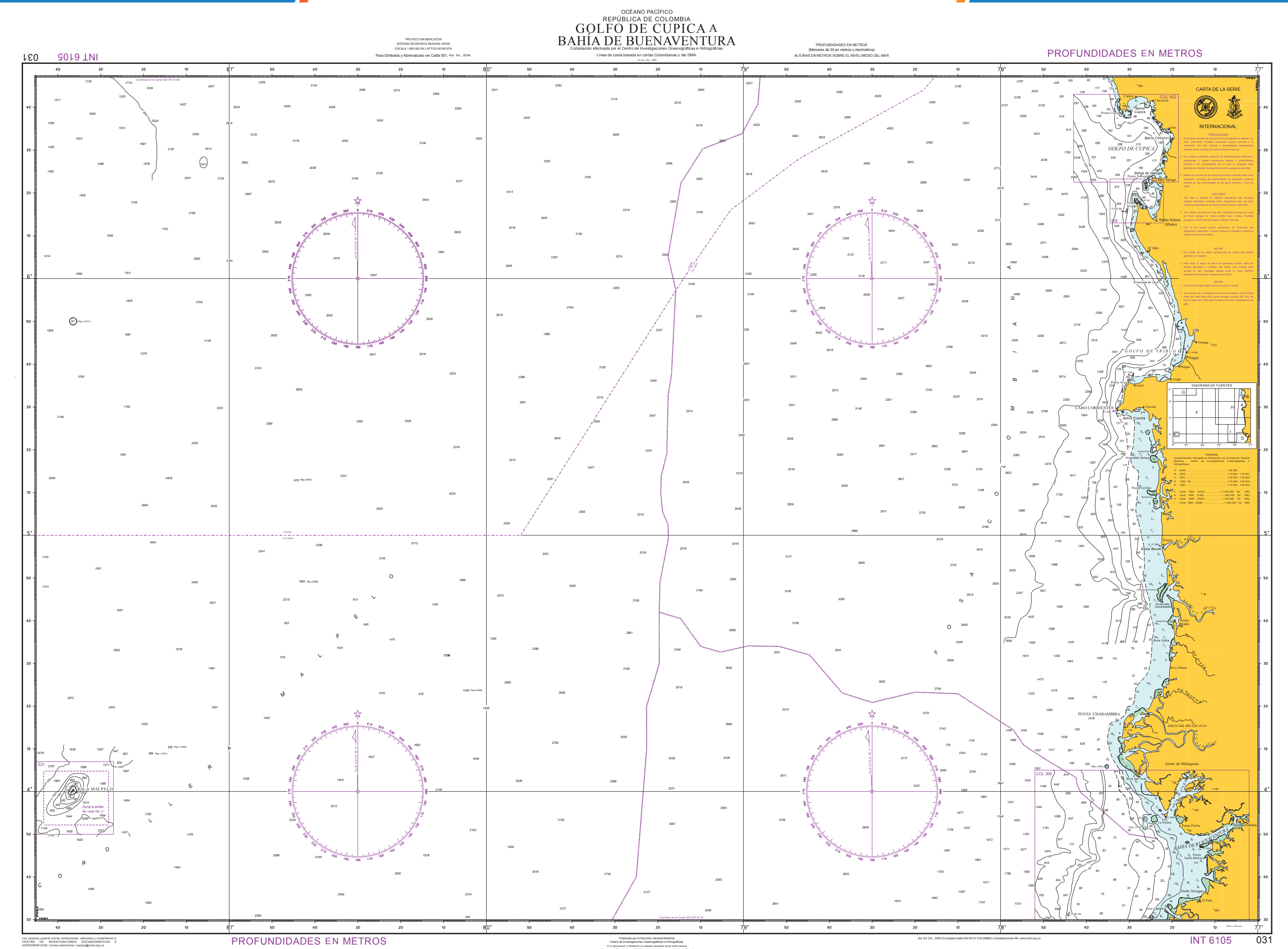




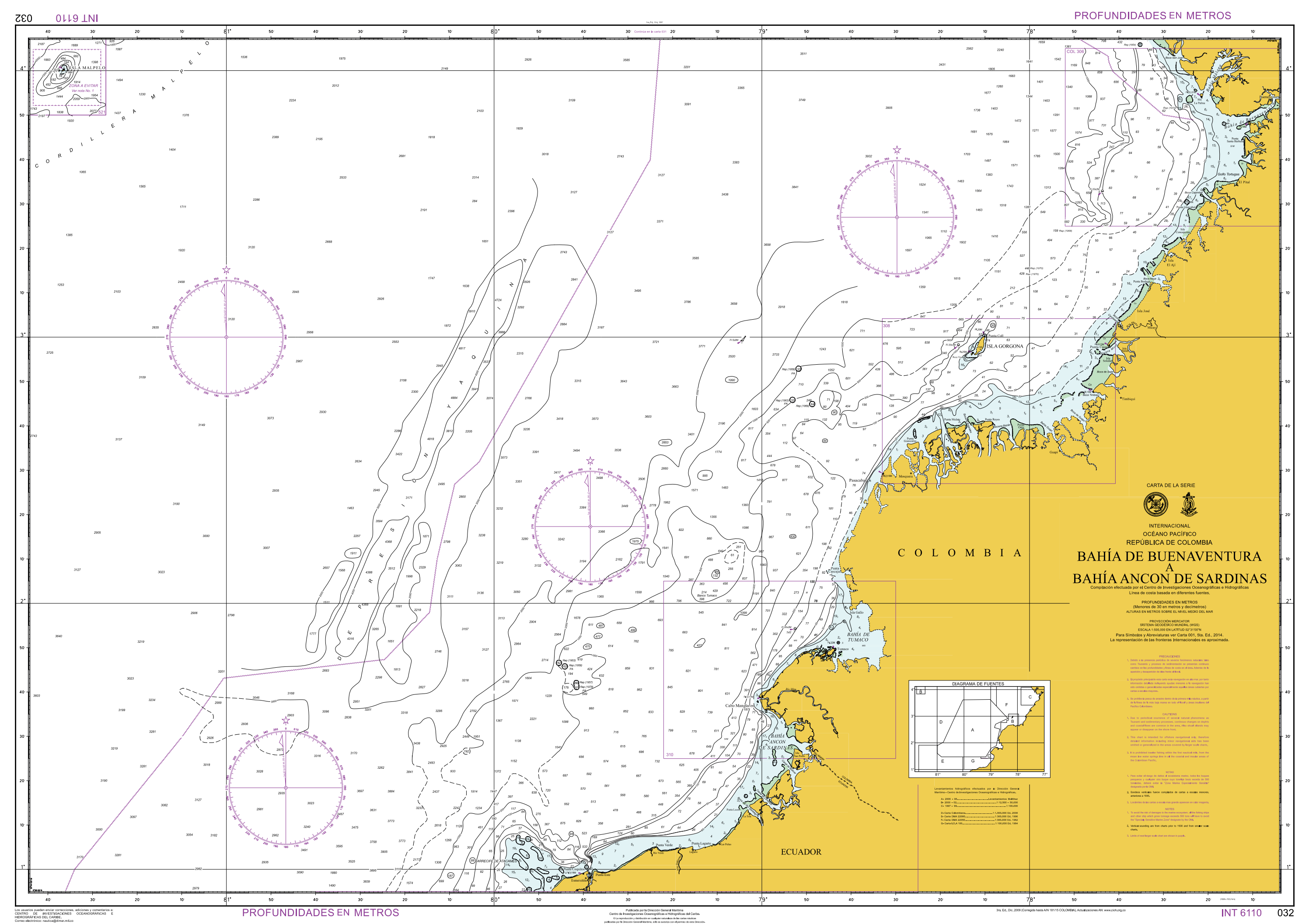


Cartas costeras (escalas 1:350.000 - 1:75.001)

Tabla H1. Cartas costeras océano Pacífico.

\begin{tabular}{|c|c|c|c|c|c|}
\hline No. Carta & Nombre & Escala & Edición & Año & Pág. \\
\hline 302 & Golfo de Tribugá & 1:100.000 & 1 & 2010 & H003 \\
\hline 303 & Nuquí a Punta Catripe & 1:100.000 & 1 & 2010 & HOO4 \\
\hline 306 & Río San Juan a Boca Yurumanguí & 1:100.000 & 1 & 1998 & H005 \\
\hline 308 & Punta Coco a Isla Barrera & $1: 100.000$ & 1 & 2013 & H006 \\
\hline 310 & Punta Isla Cascajal a Río Mataje & $1: 100.000$ & 2 & 2013 & HOO \\
\hline
\end{tabular}

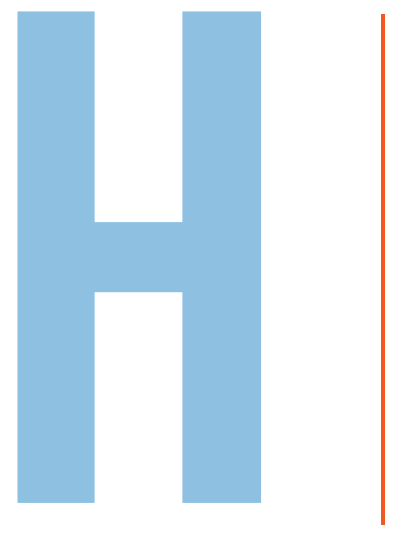




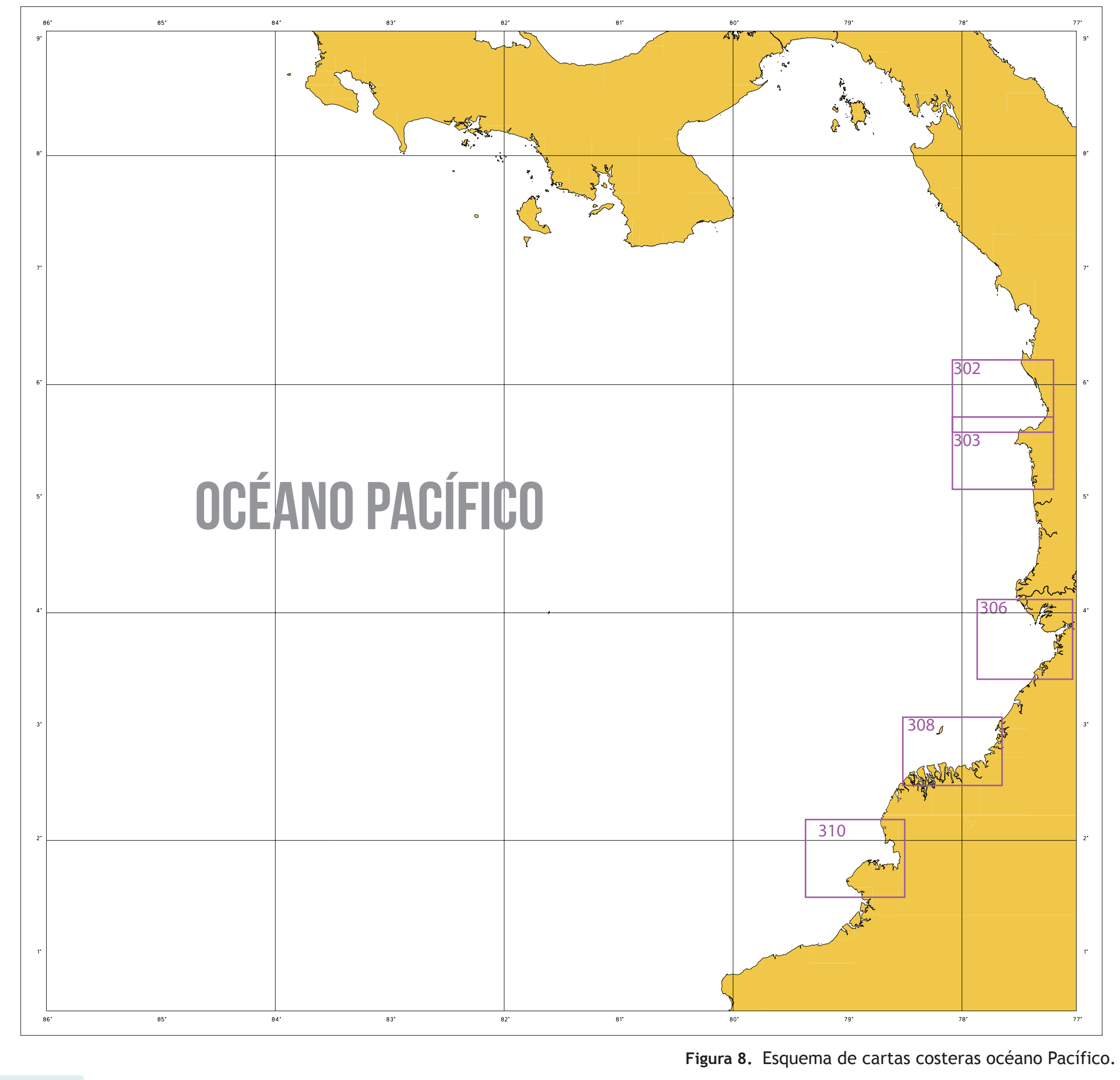




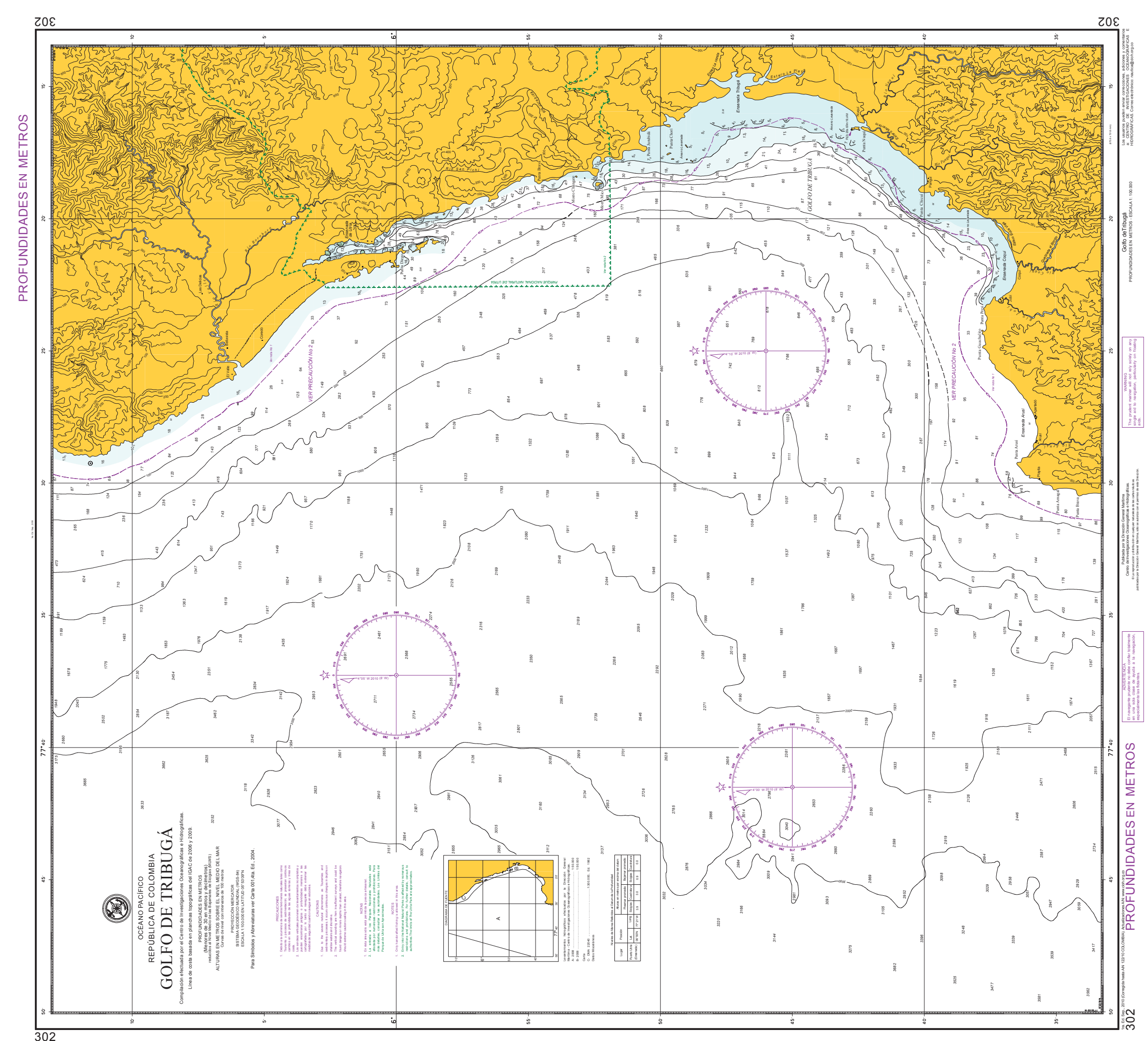




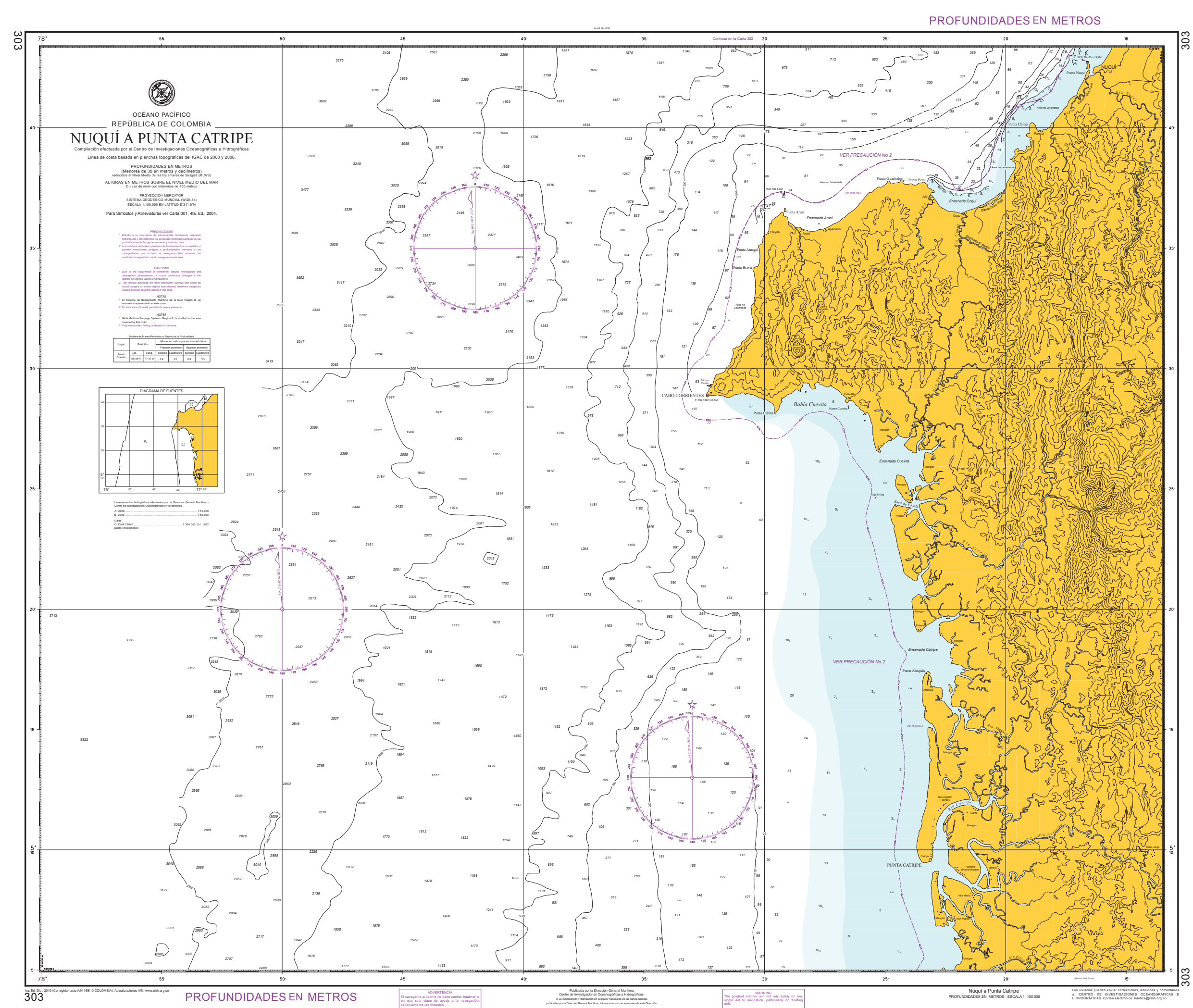

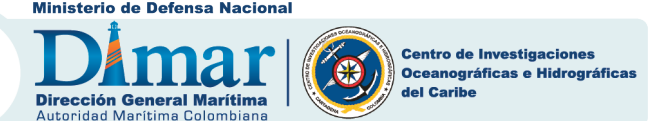




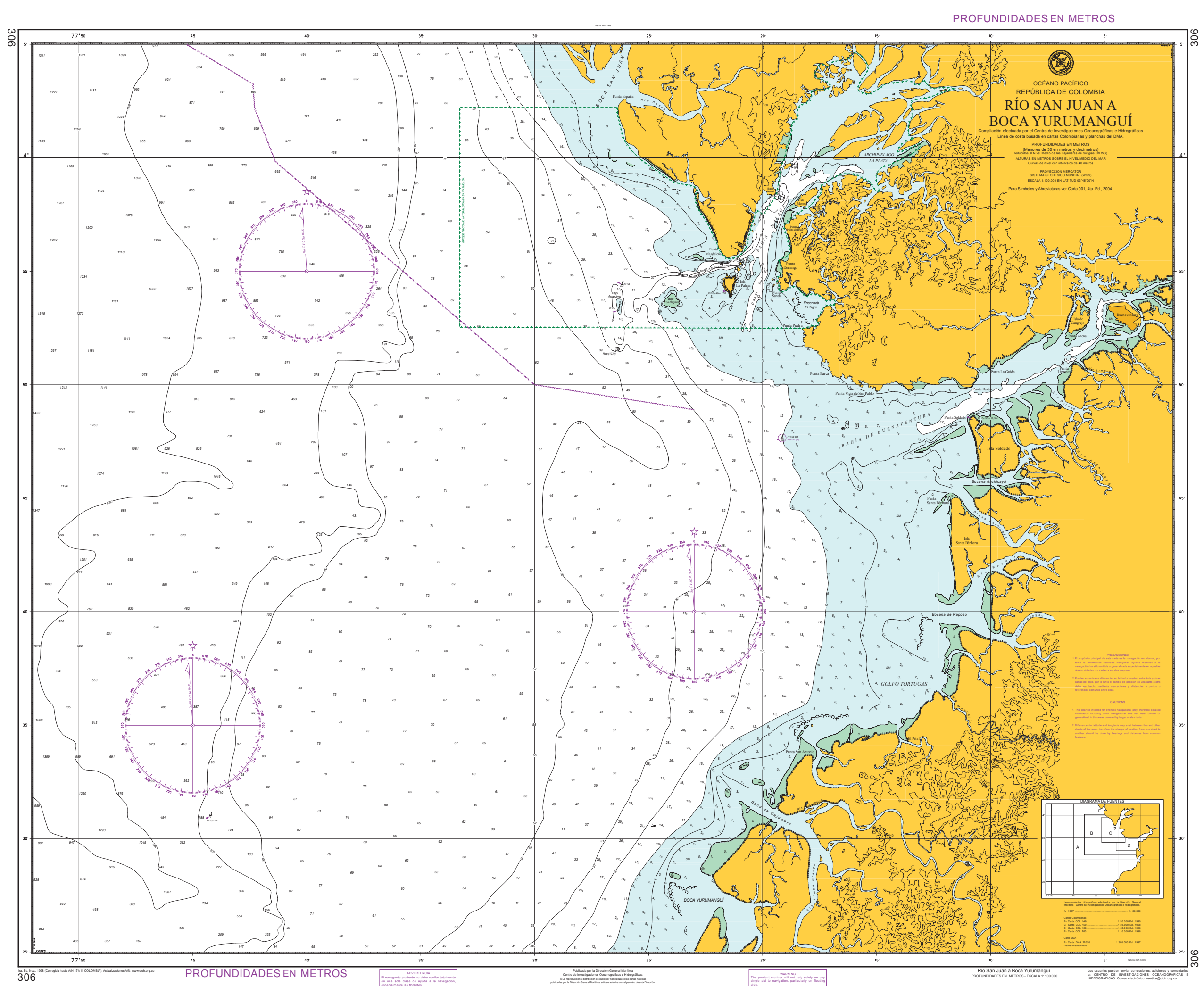

\section{Dlmar (C) $=$}




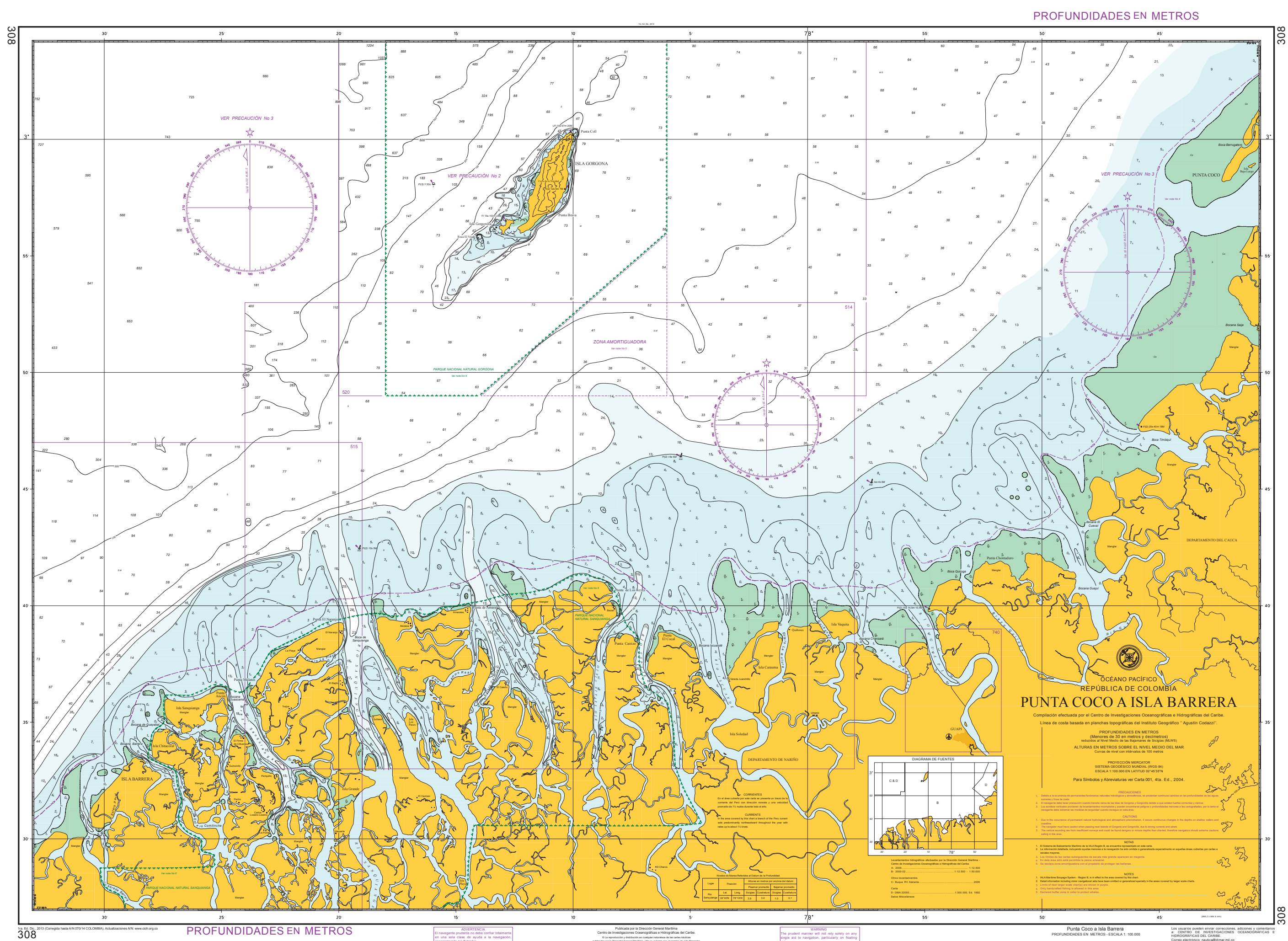

\section{Dimar.}




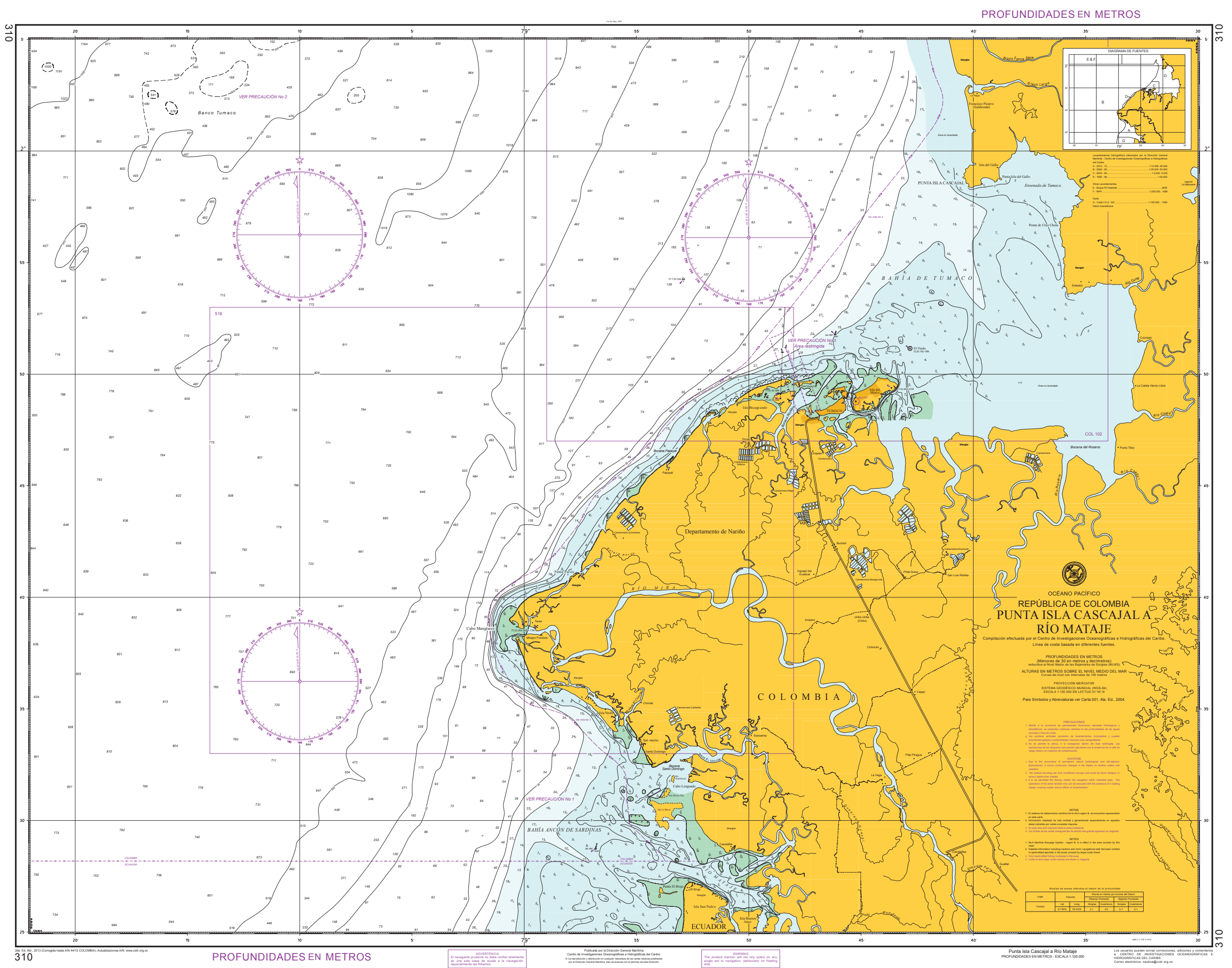

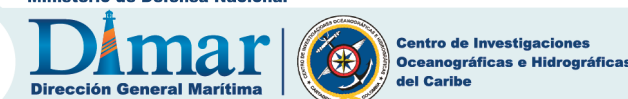


Cartas de aproximación (acceso a puerto, aguas costeras congestionadas o tortuosas) - (escalas 1:75.000-1:30.001) Tabla 11. Cartas de aproximación océano Pacífico.

\begin{tabular}{|l|l|cccc}
\hline No. Carta & \multicolumn{1}{c|}{ Nombre } & Escala & Edición & Año & Pág. \\
\hline 514 & Isla Carauma a Punta Mulatos & $1: 50.000$ & 1 & 2005 & 1003 \\
\hline 515 & Punta Mulatos a Pasacaballos & $1: 50.000$ & 1 & 2005 & 1004 \\
\hline 520 & Isla Gorgona & $1: 50.000$ & 1 & 2003 & 1005 \\
\hline 521 & Isla Malpelo & $1: 50.000$ & 1 & 2005 & 1006 \\
\hline
\end{tabular}


/ Cartas de AproXIMACión / OCÉano PACífico /

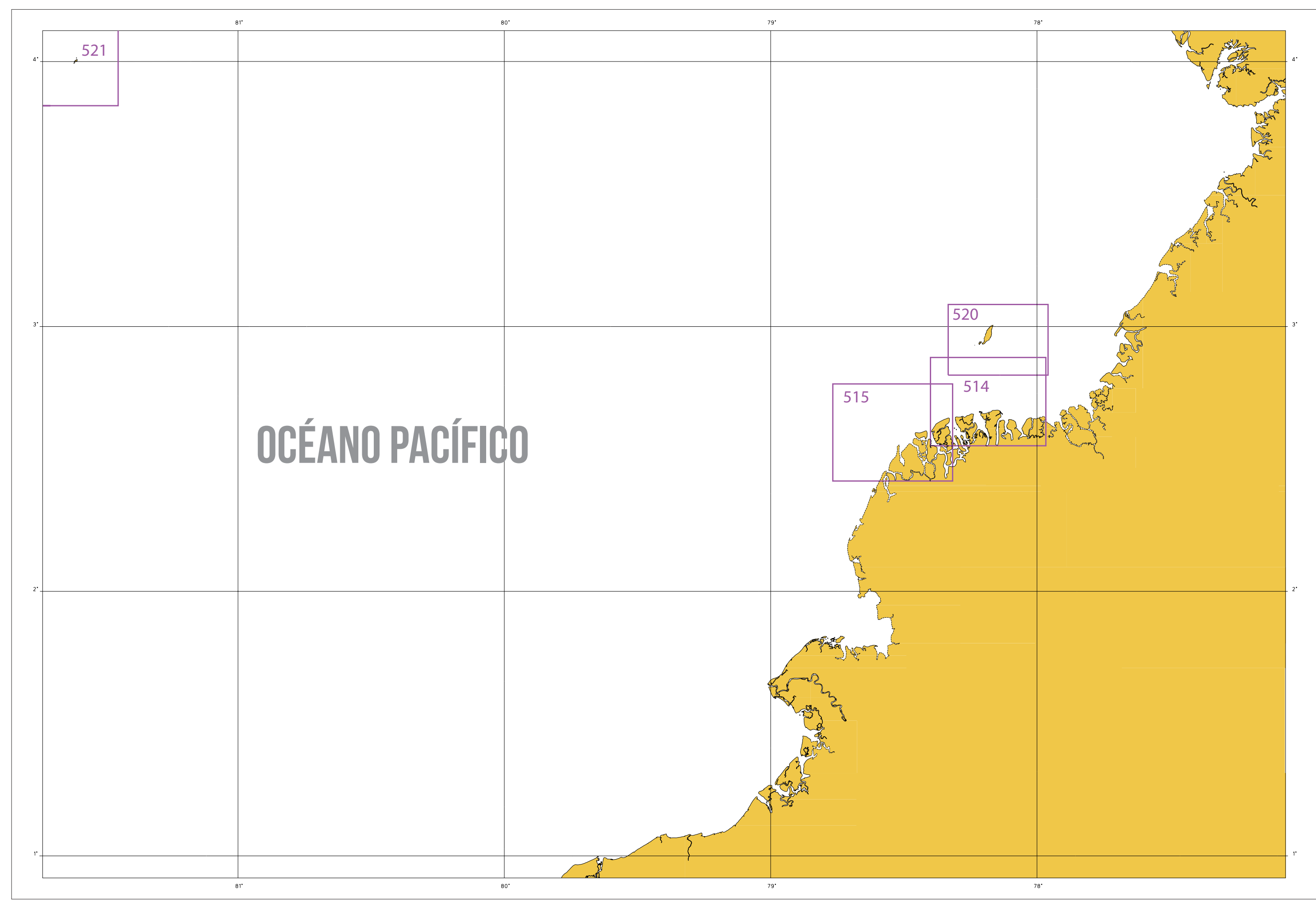

Figura 9. Esquema de cartas de aproximación océano Pacífico. 


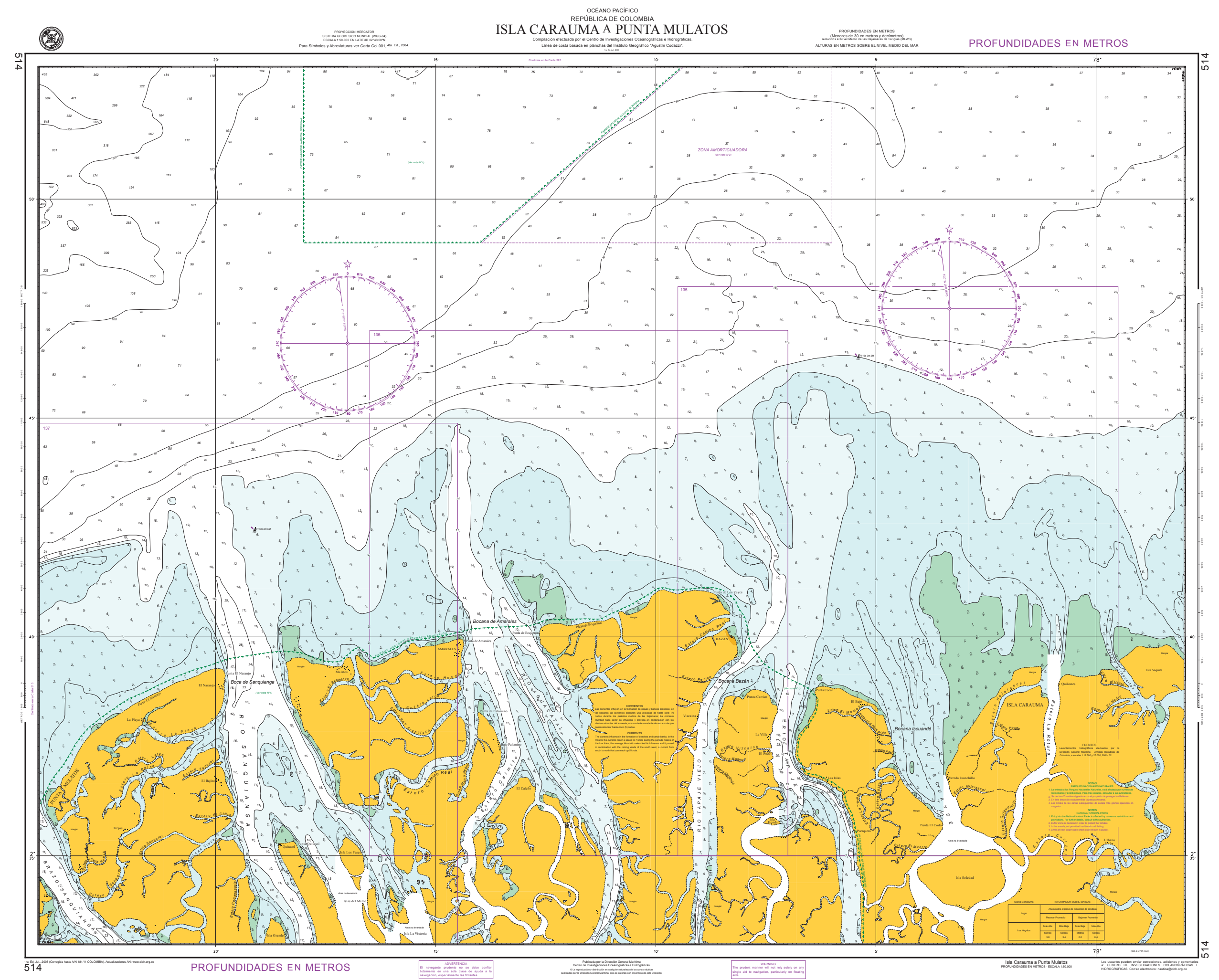

\section{D}




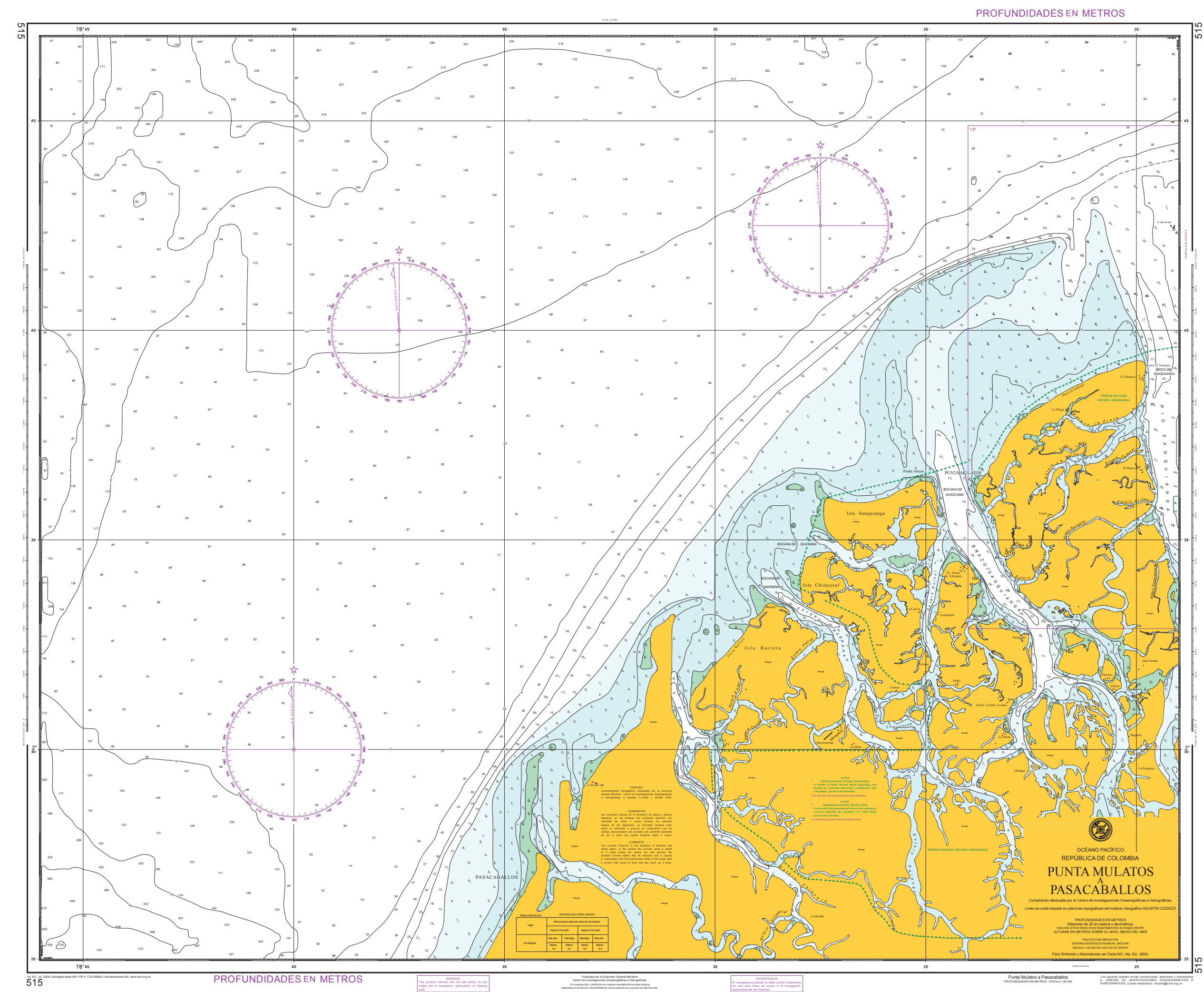




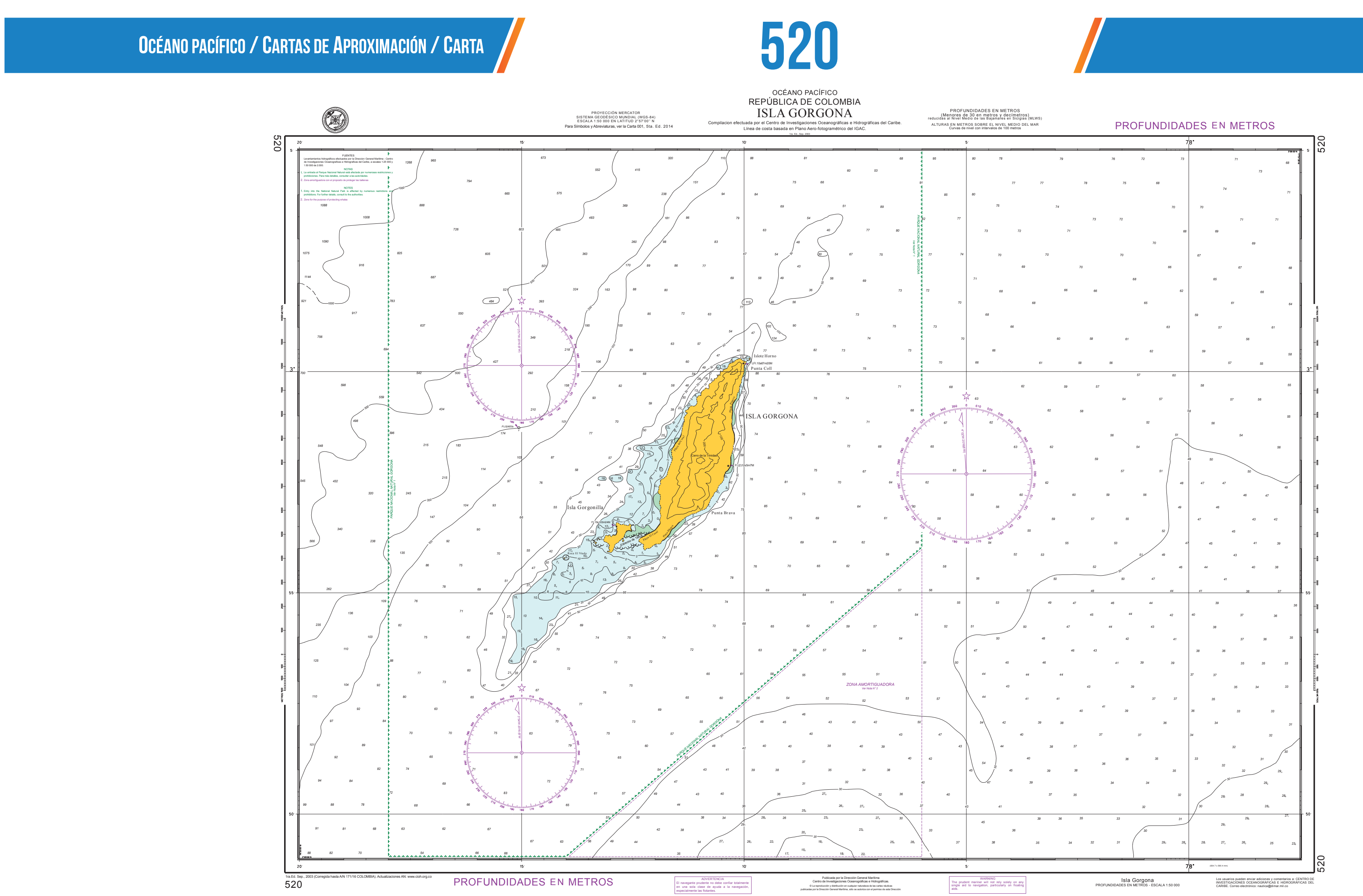

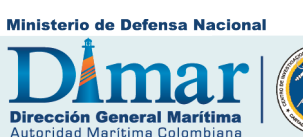
Catáloog de Cartas Naúticas de Colombia Dimar-Cloh Pág. 1005 


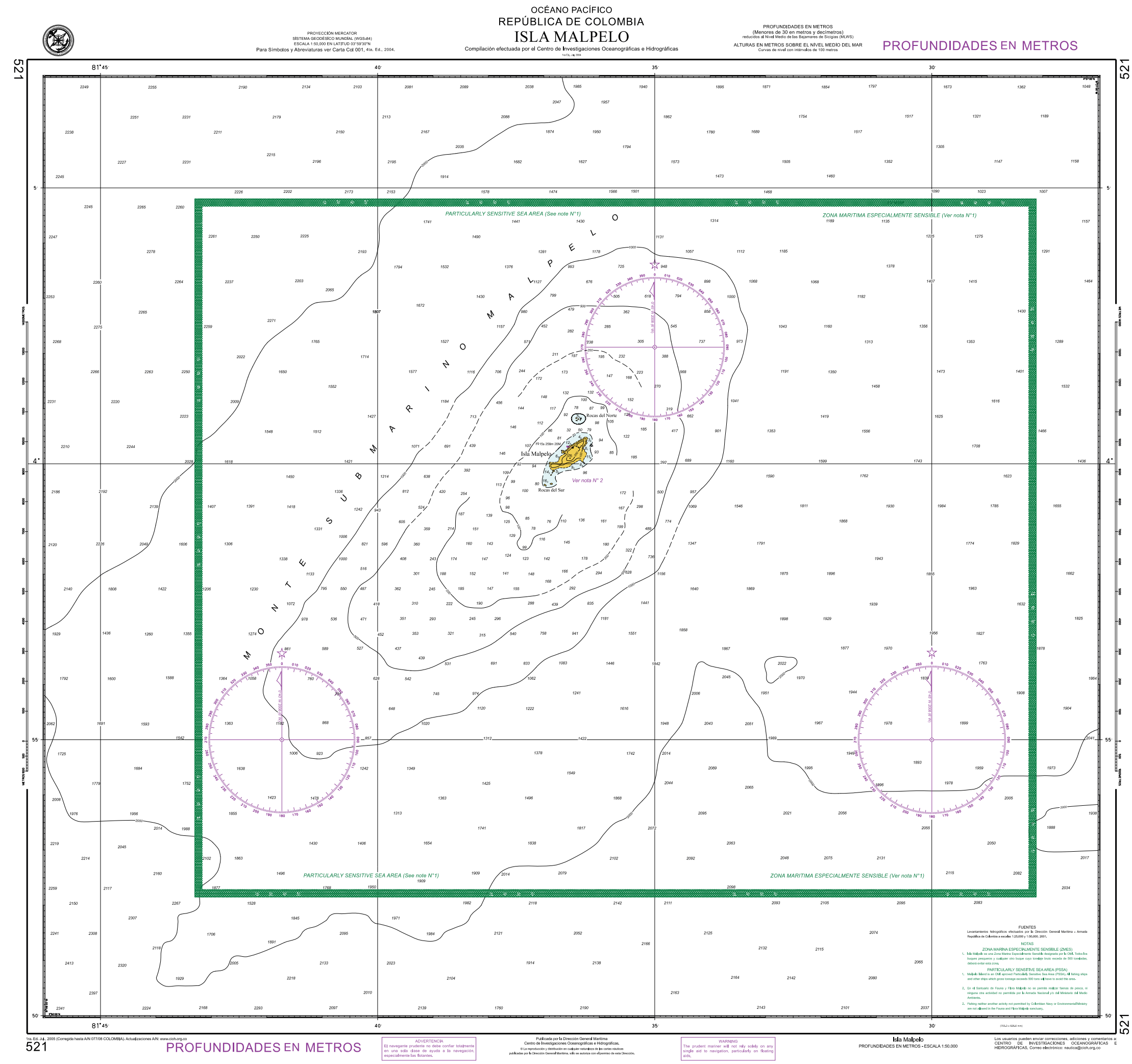


Cartas de puerto (puertos, bahías, fondeaderos, estrechos) - (escalas 1:30.000 -1:12.501)

\begin{tabular}{|c|c|c|c|c|c|}
\hline No. Carta & Nombre & Escala & Edición & Año & Pág. \\
\hline 101 & Aproximación a Tumaco & $1: 25.000$ & 4 & 2009 & J003 \\
\hline 103 & Isla Mono a Juradó & $1: 25.000$ & 1 & 2008 & J004 \\
\hline 107 & Bahías de Cupica y Chirichirí & $1: 30.000$ & 1 & 1998 & J005 \\
\hline 109 & Aproximación a Bahía Solano & $1: 25.000$ & 1 & 2008 & J006 \\
\hline 135 & Bocana Iscuandé & $1: 25.000$ & 1 & 2005 & J007 \\
\hline 136 & Bocana de Amarales & $1: 25.000$ & 1 & 2005 & J008 \\
\hline 137 & Boca de Sanquianga & $1: 25.000$ & 1 & 2006 & J009 \\
\hline 145 & Cabo Manglares & $1: 25.000$ & 1 & 2005 & J010 \\
\hline 150 & Bahía Málaga & $1: 25.000$ & 5 & 2013 & J011 \\
\hline 154 & Bahía de Buenaventura (bahía externa) & $1: 25.000$ & 1 & 2016 & J012 \\
\hline 155 & Bahía de Buenaventura (bahía interna) & $1: 25.000$ & 1 & 2016 & J013 \\
\hline
\end{tabular}




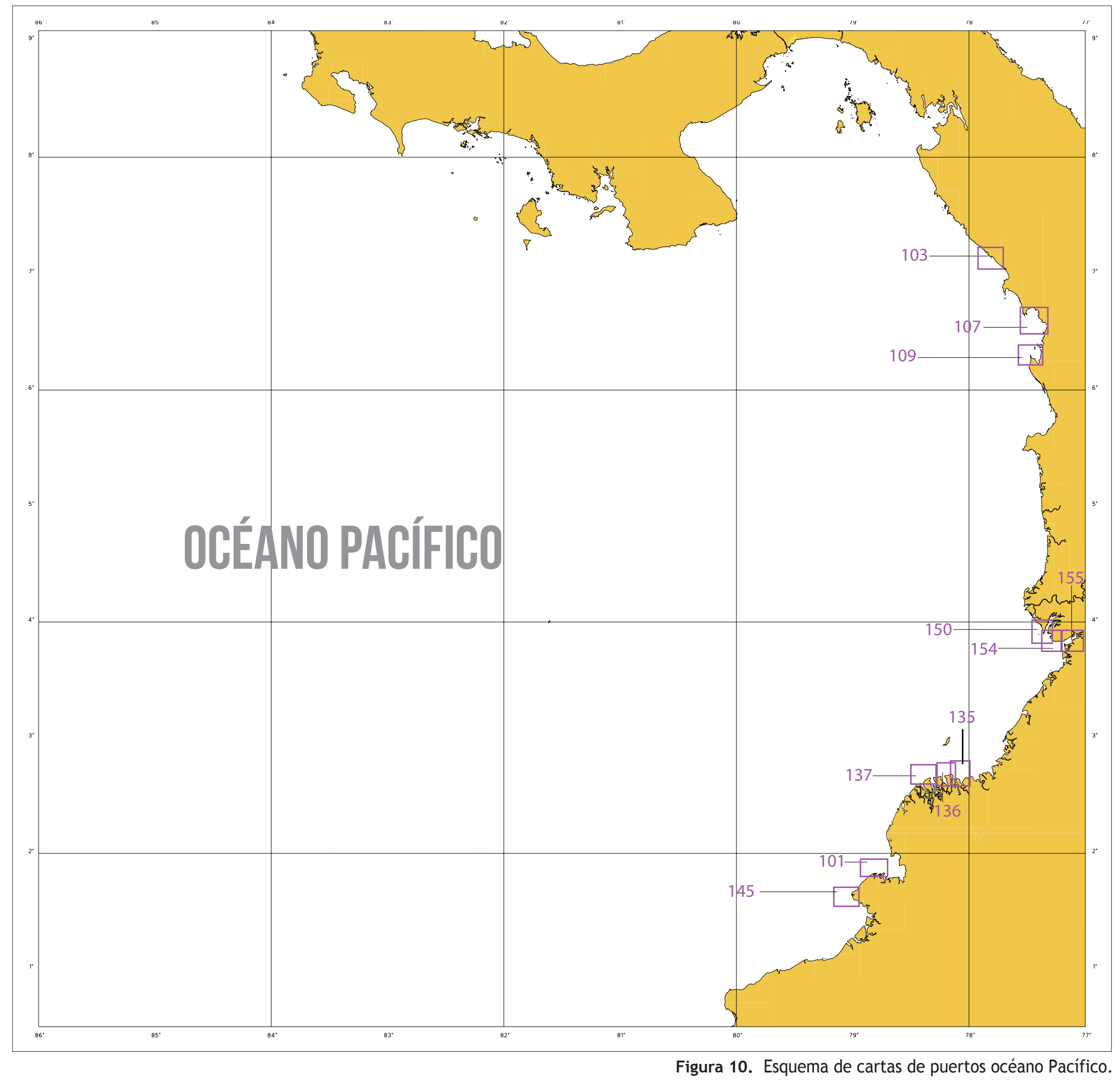




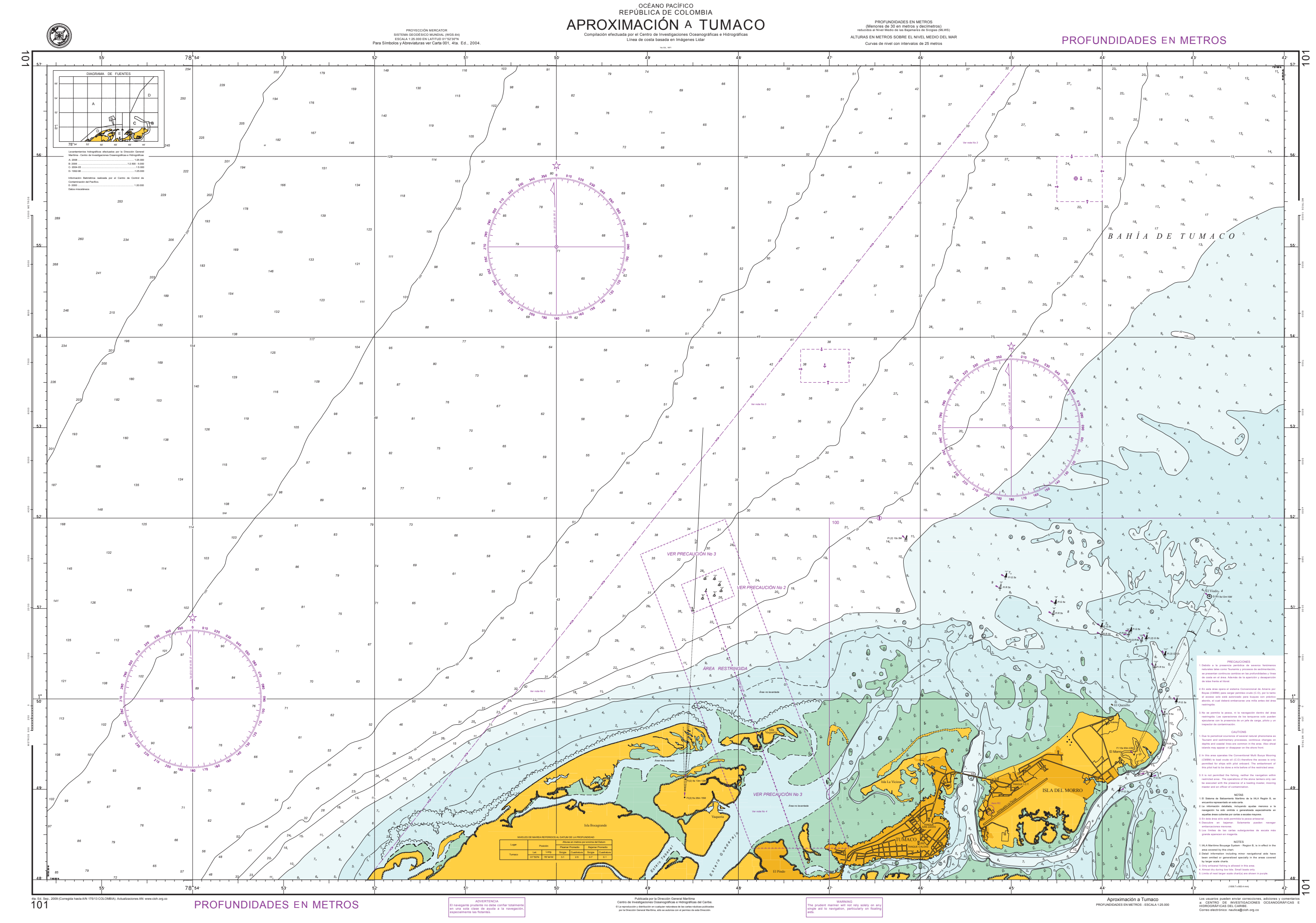

(3) Dlmar (9) =- 


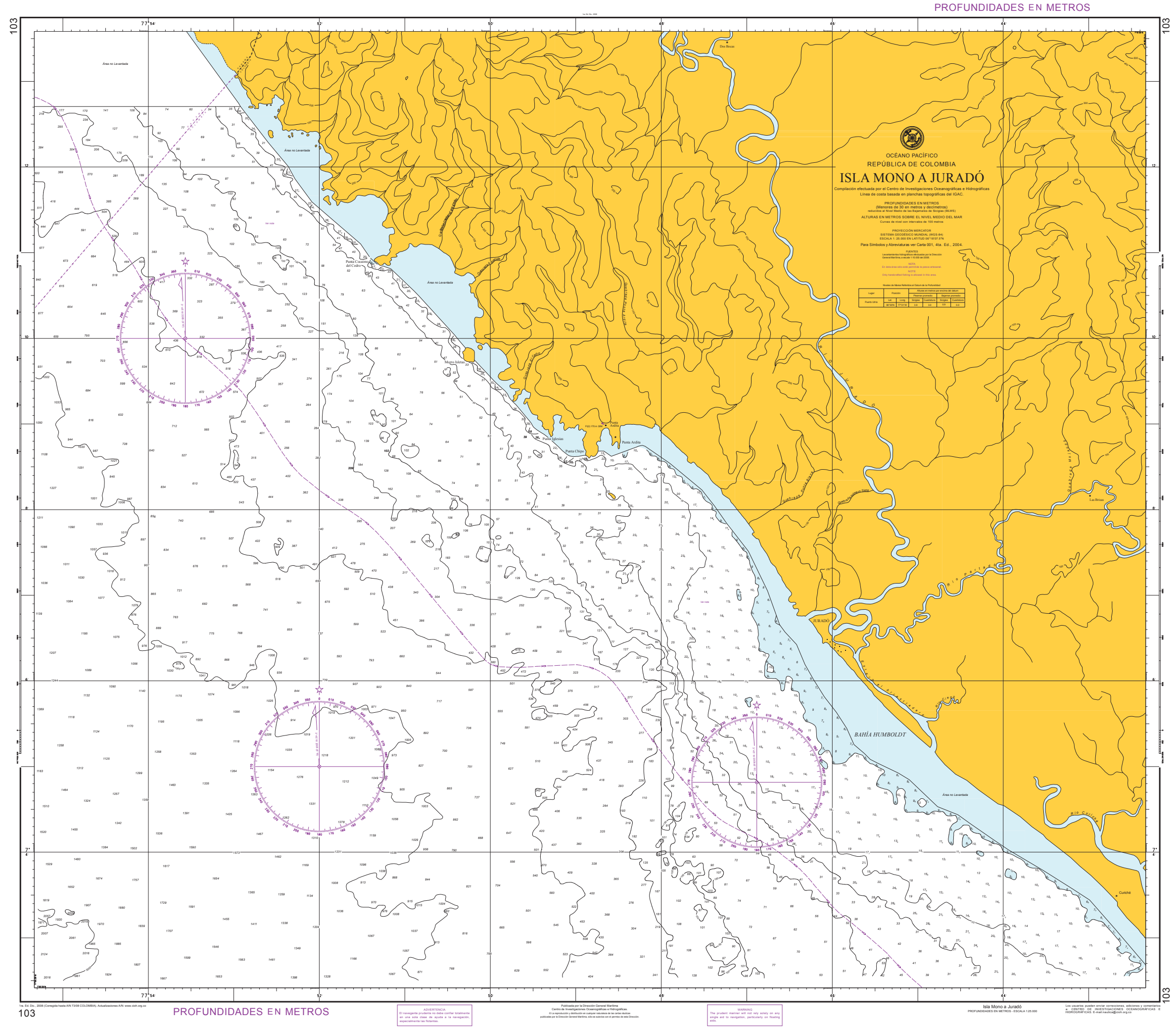




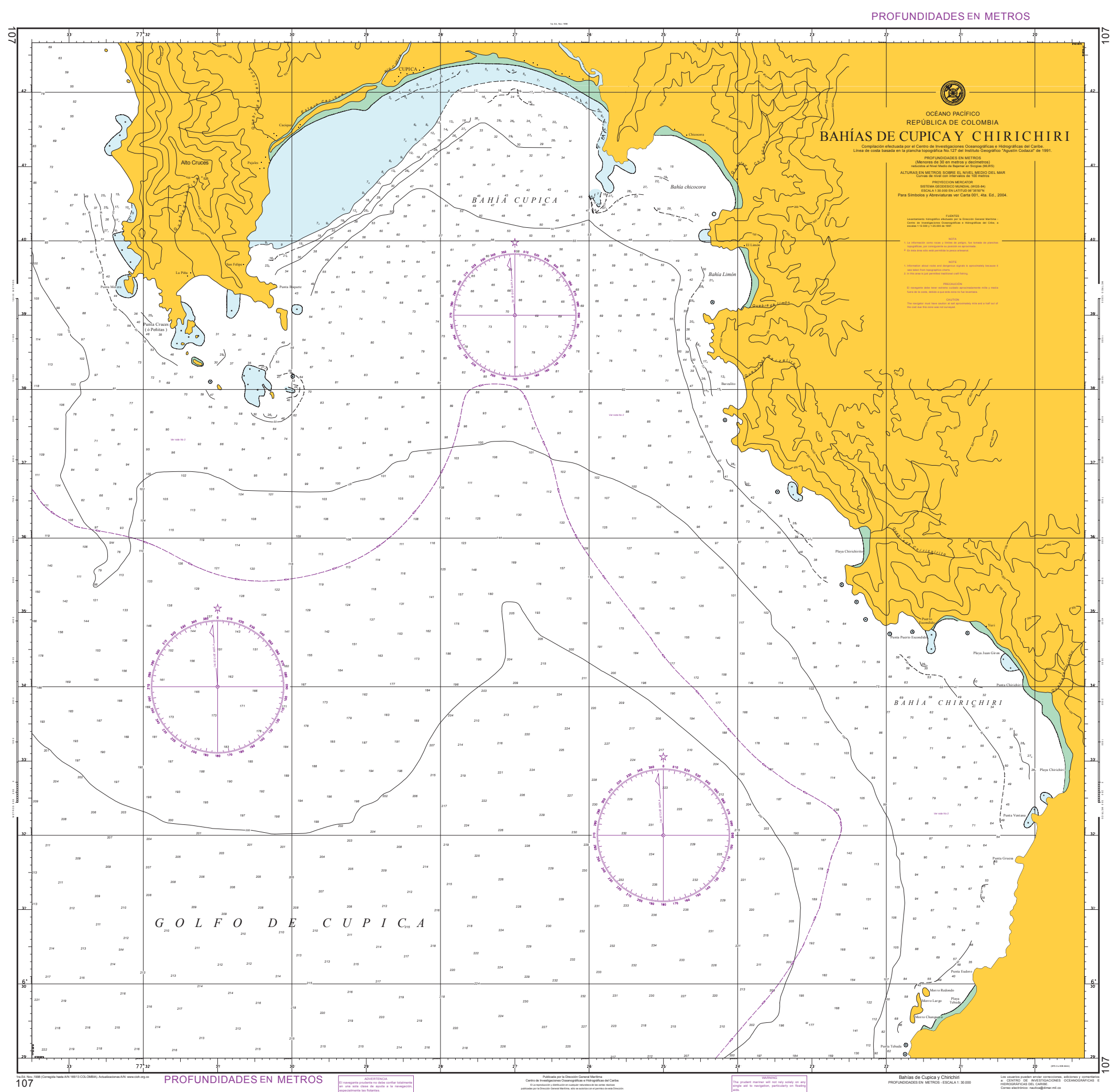




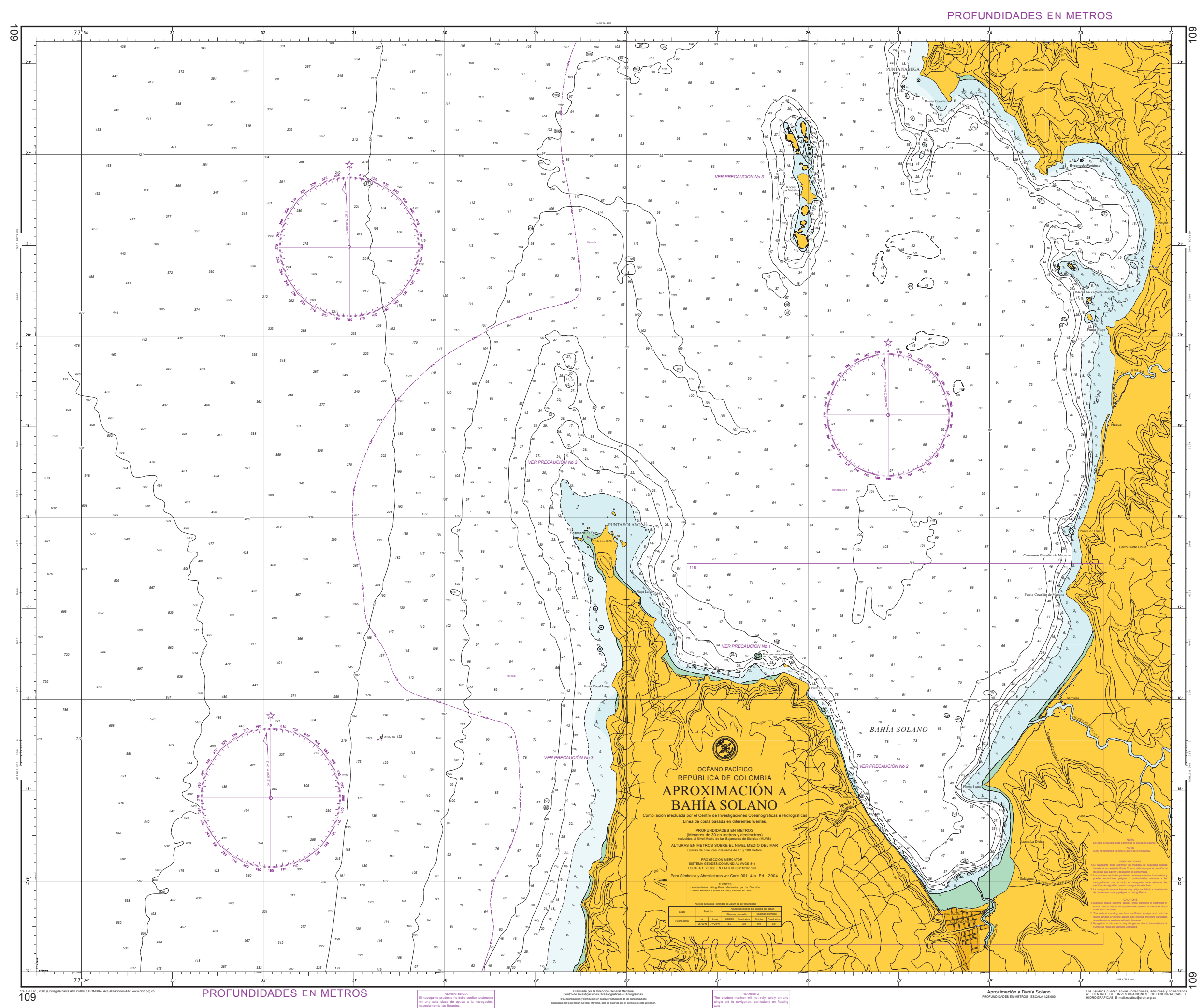

\section{Dimar.}




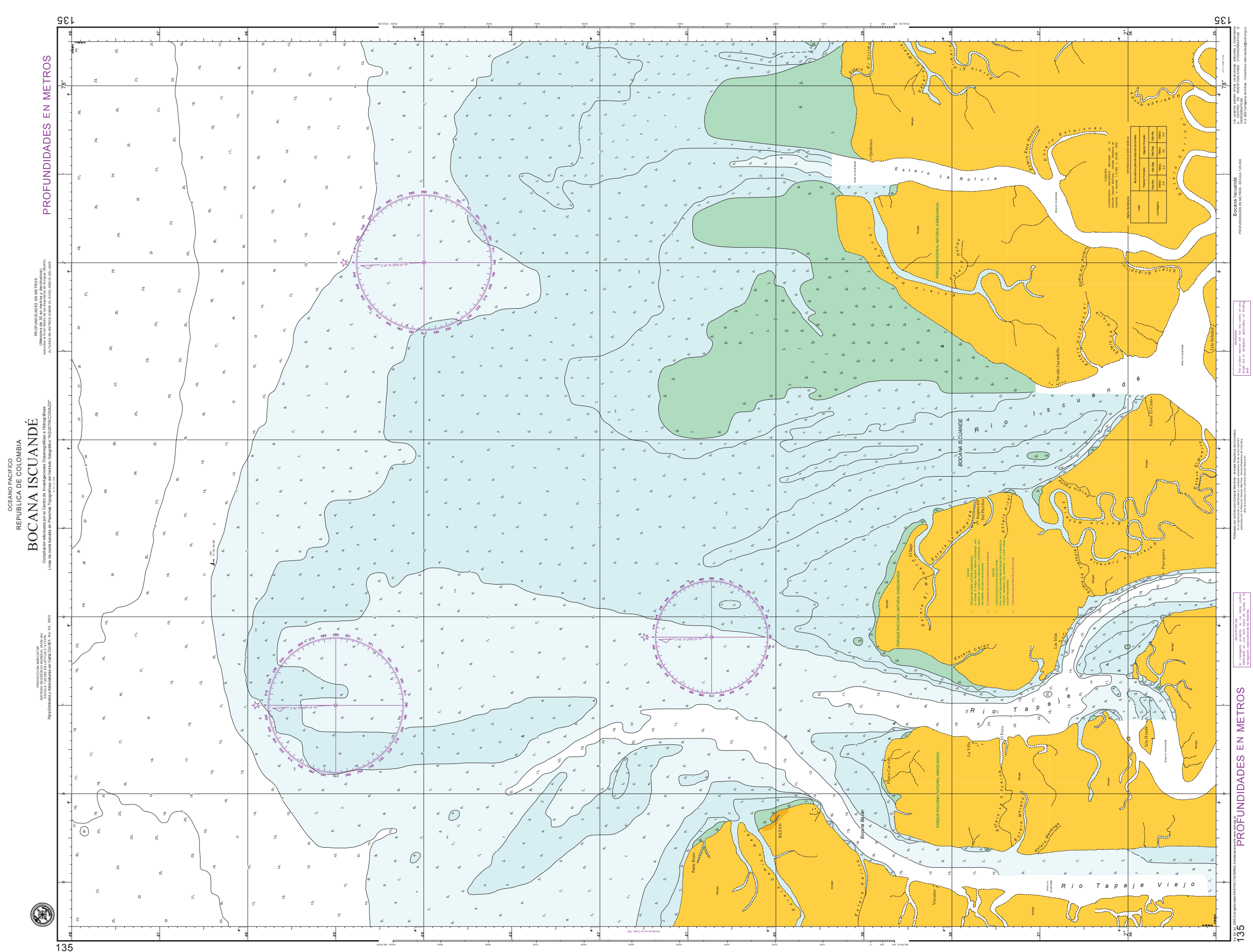




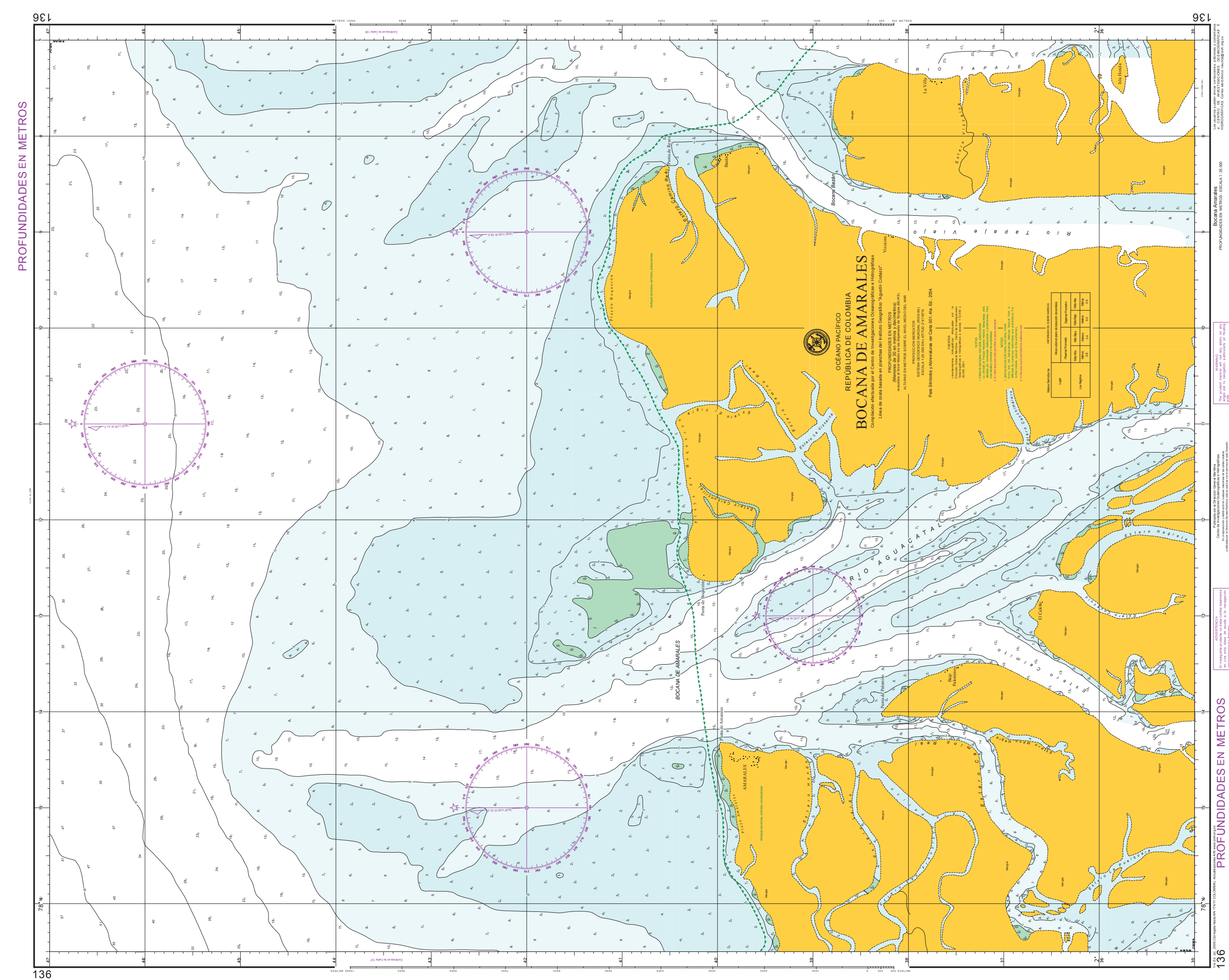

\section{Dlmar (0) =}




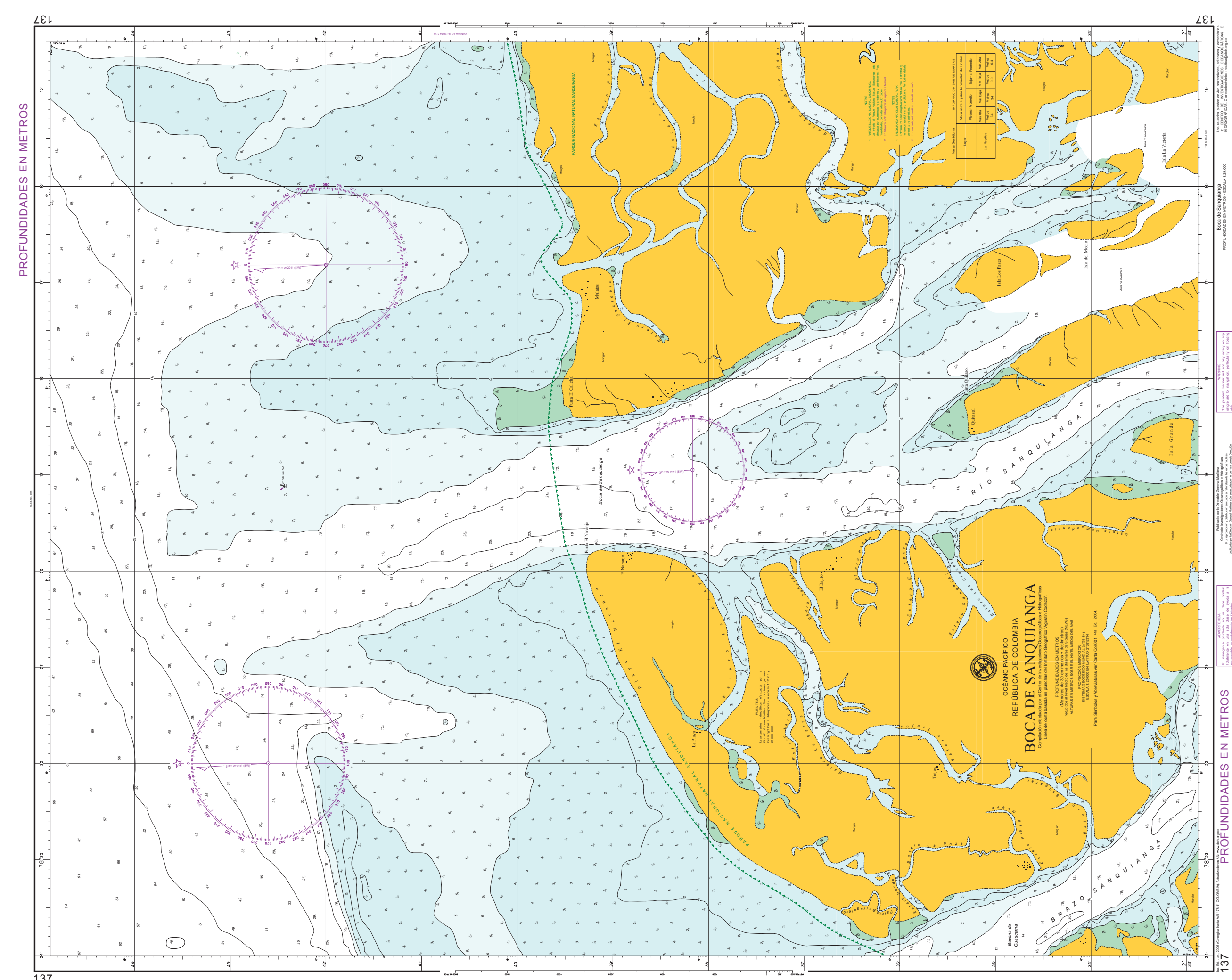




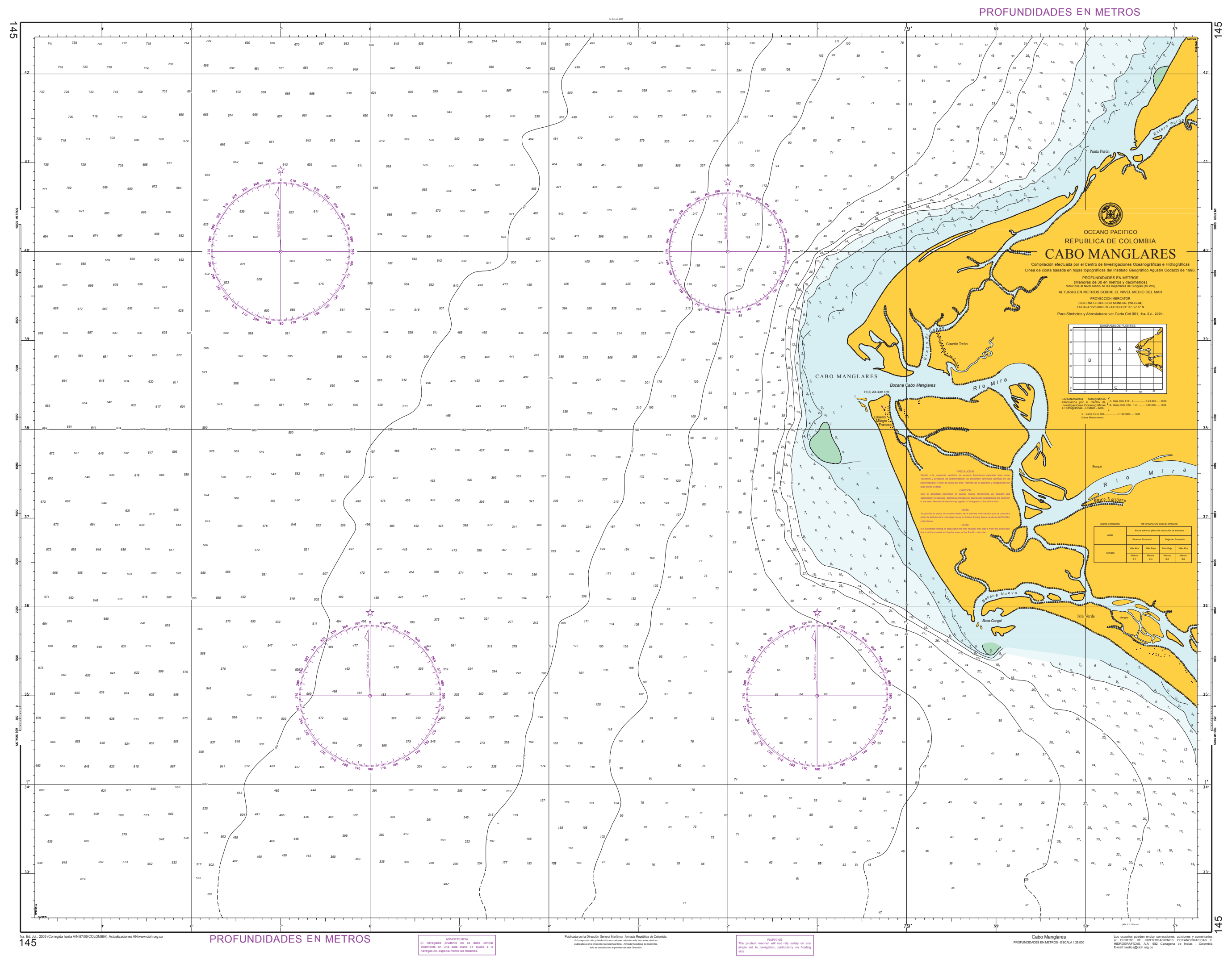




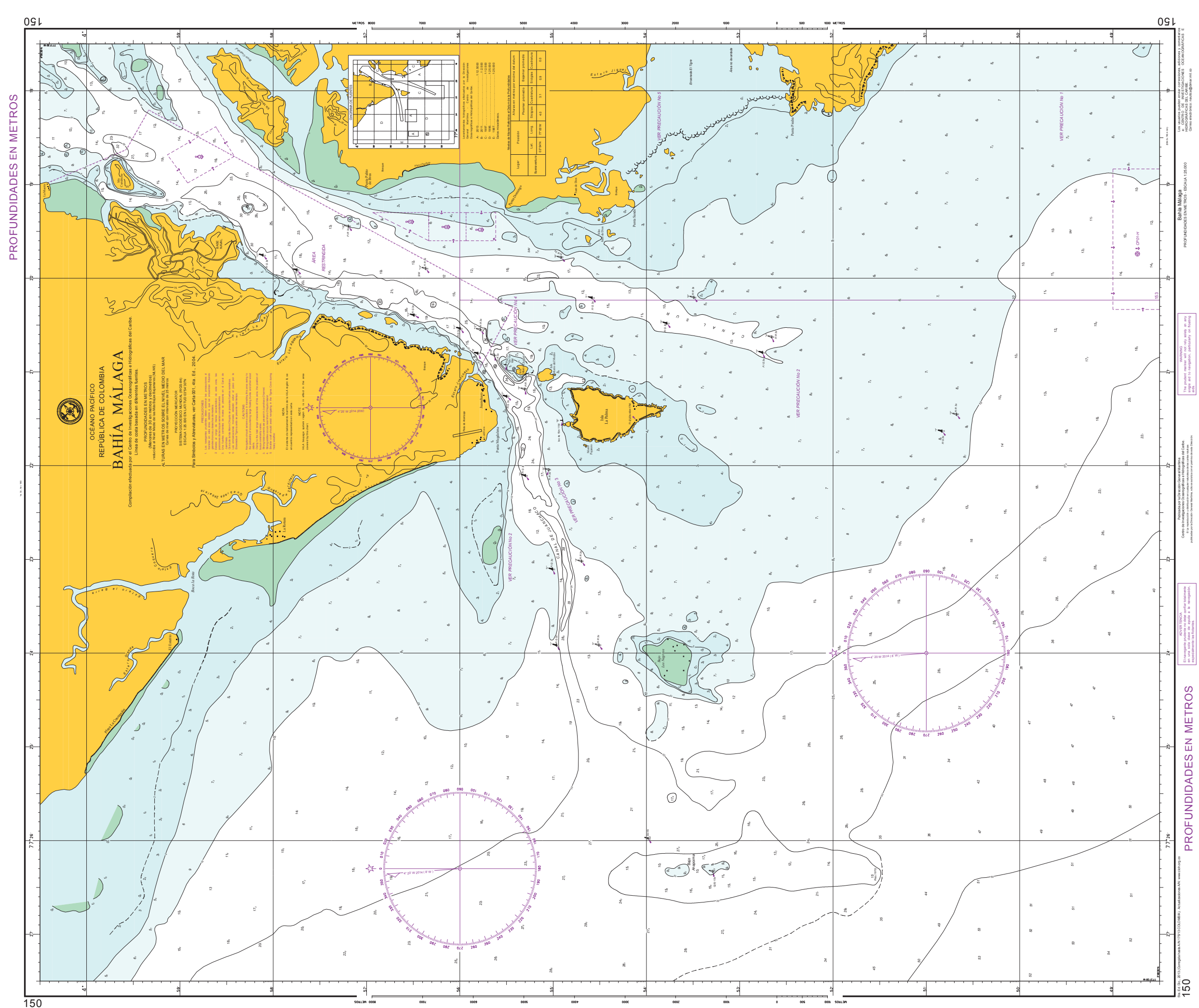




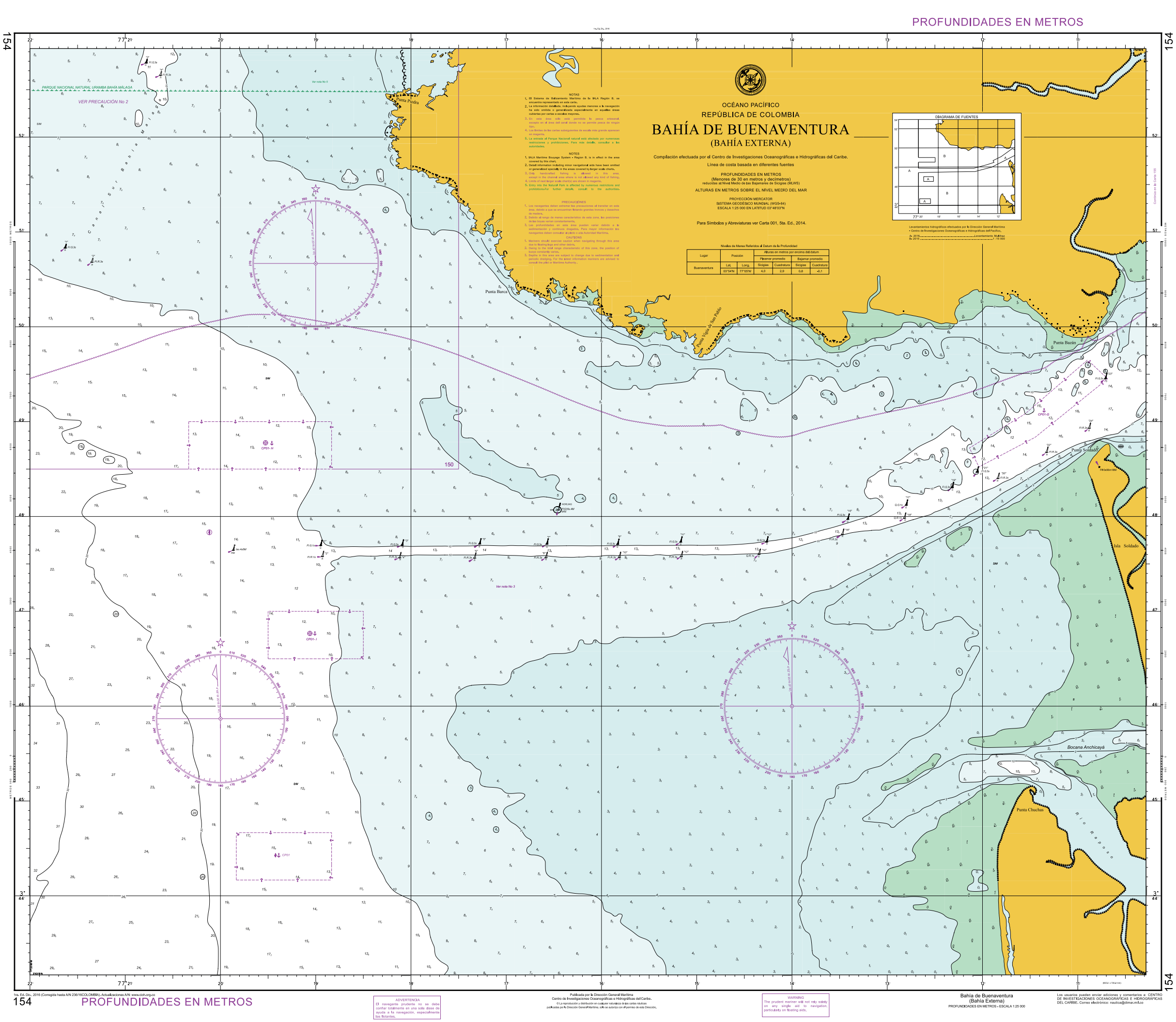




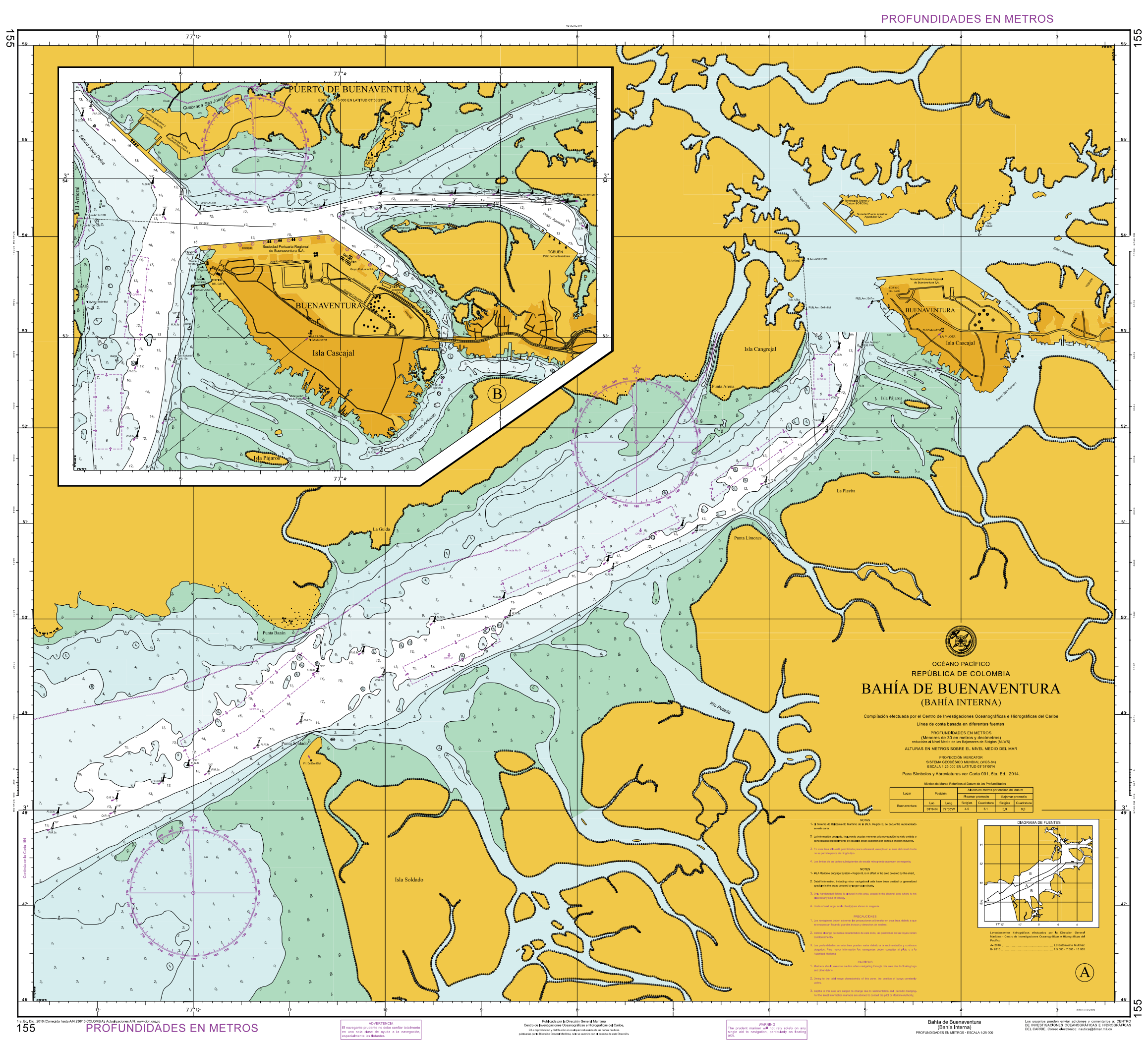


Cartas de canales (canales, muelles, atraque) - (escalas 1:12.500 y mayores) Tabla K1. Cartas de canales océano Pacífico.

\begin{tabular}{|c|c|c|c|c|c|}
\hline No. Carta & Nombre & Escala & Edición & Año & Pág. \\
\hline 770 & Puerto de Tumaco & $1: 10.000$ & 5 & 2016 & K003 \\
\hline 116 & Bahía Interior de Solano & $1: 10.000$ & 2 & 2008 & K004 \\
\hline 740 & Guapi & 1:10.000 & 1 & 2010 & K005 \\
\hline
\end{tabular}

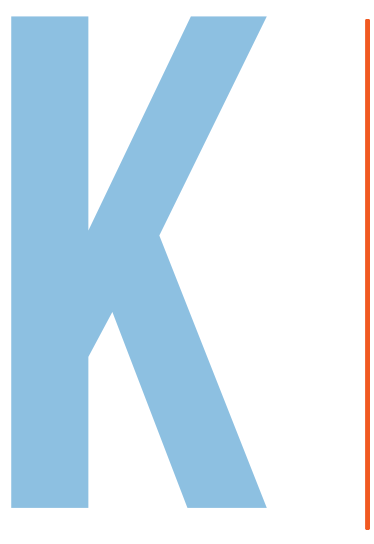




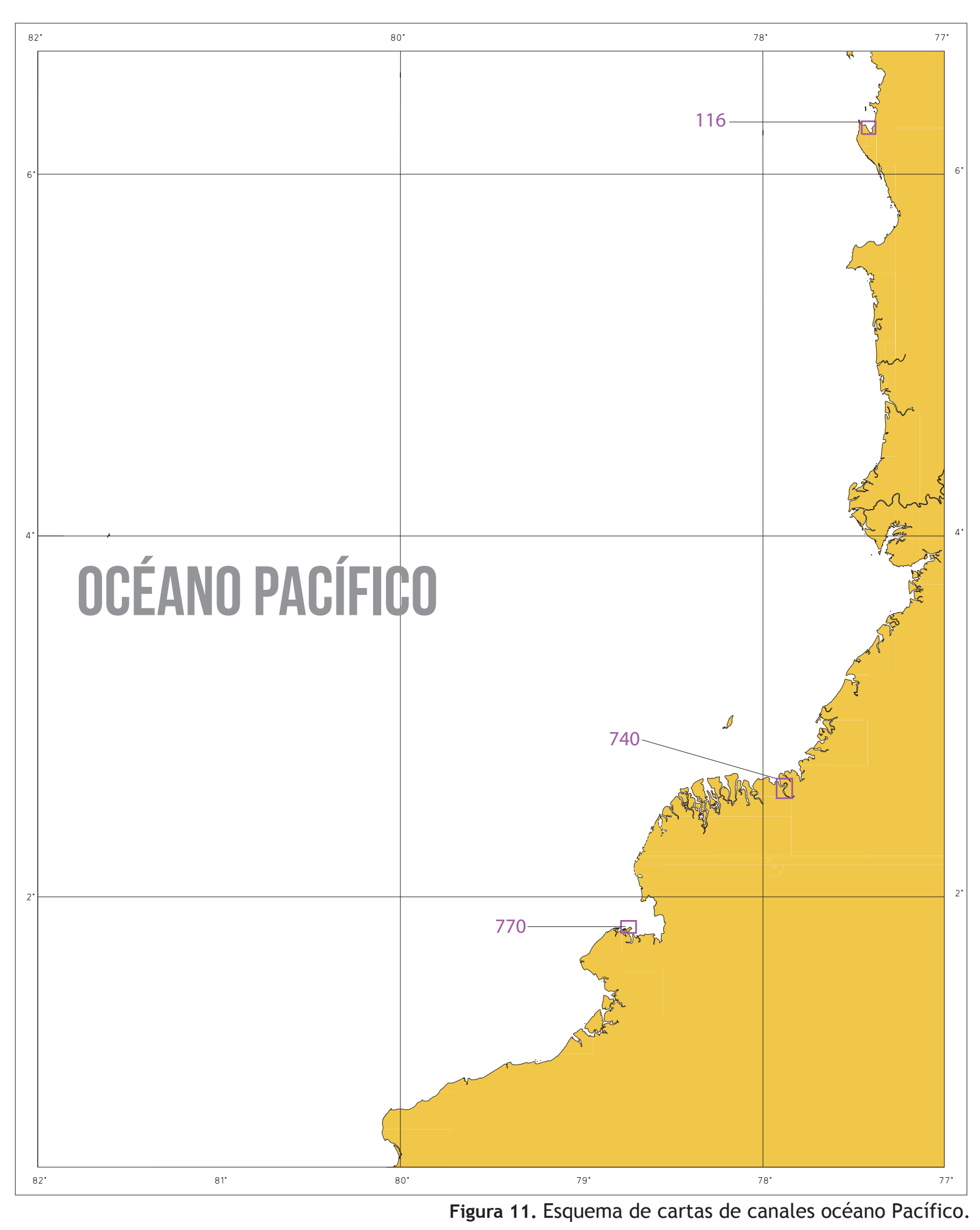




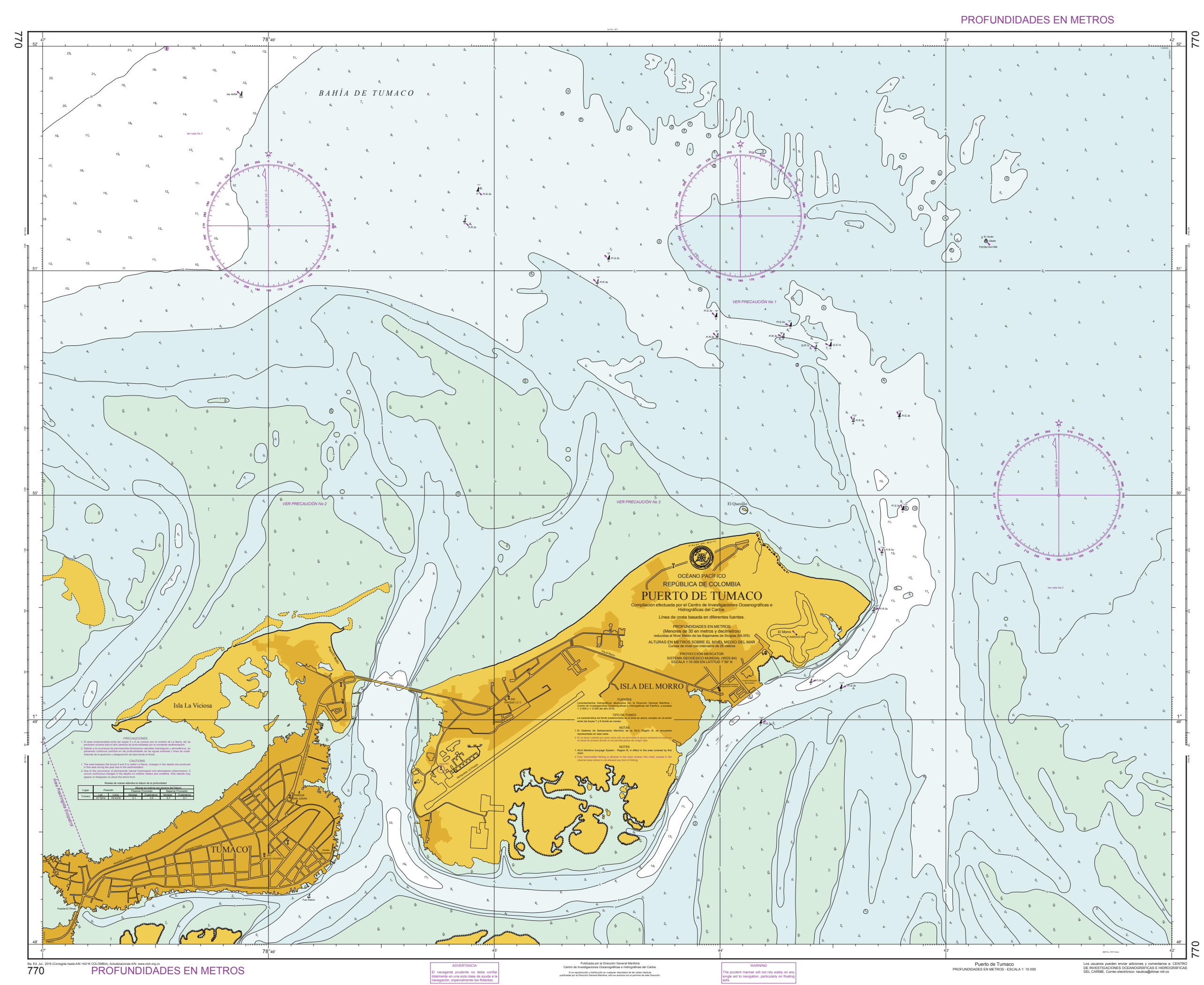




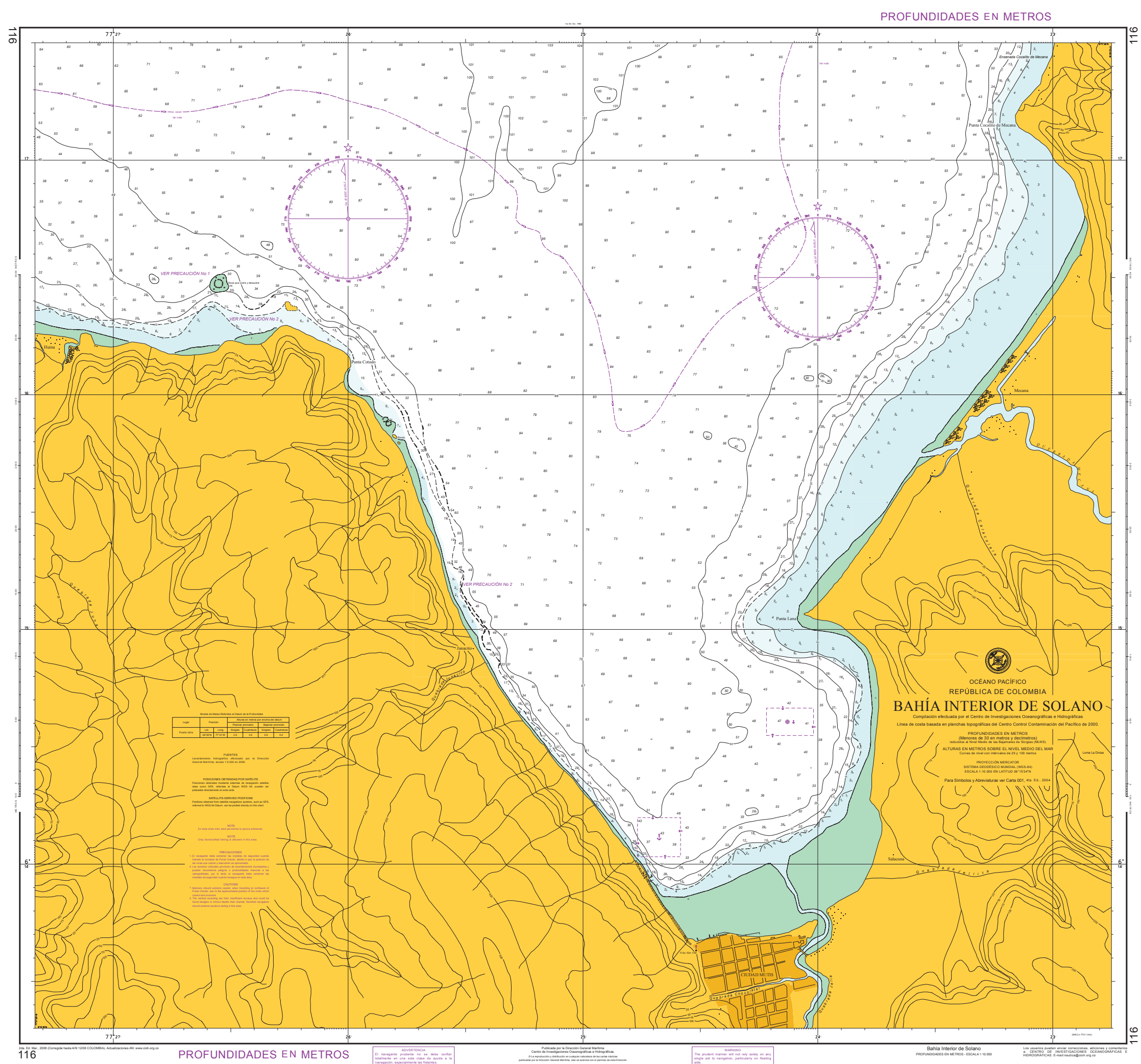




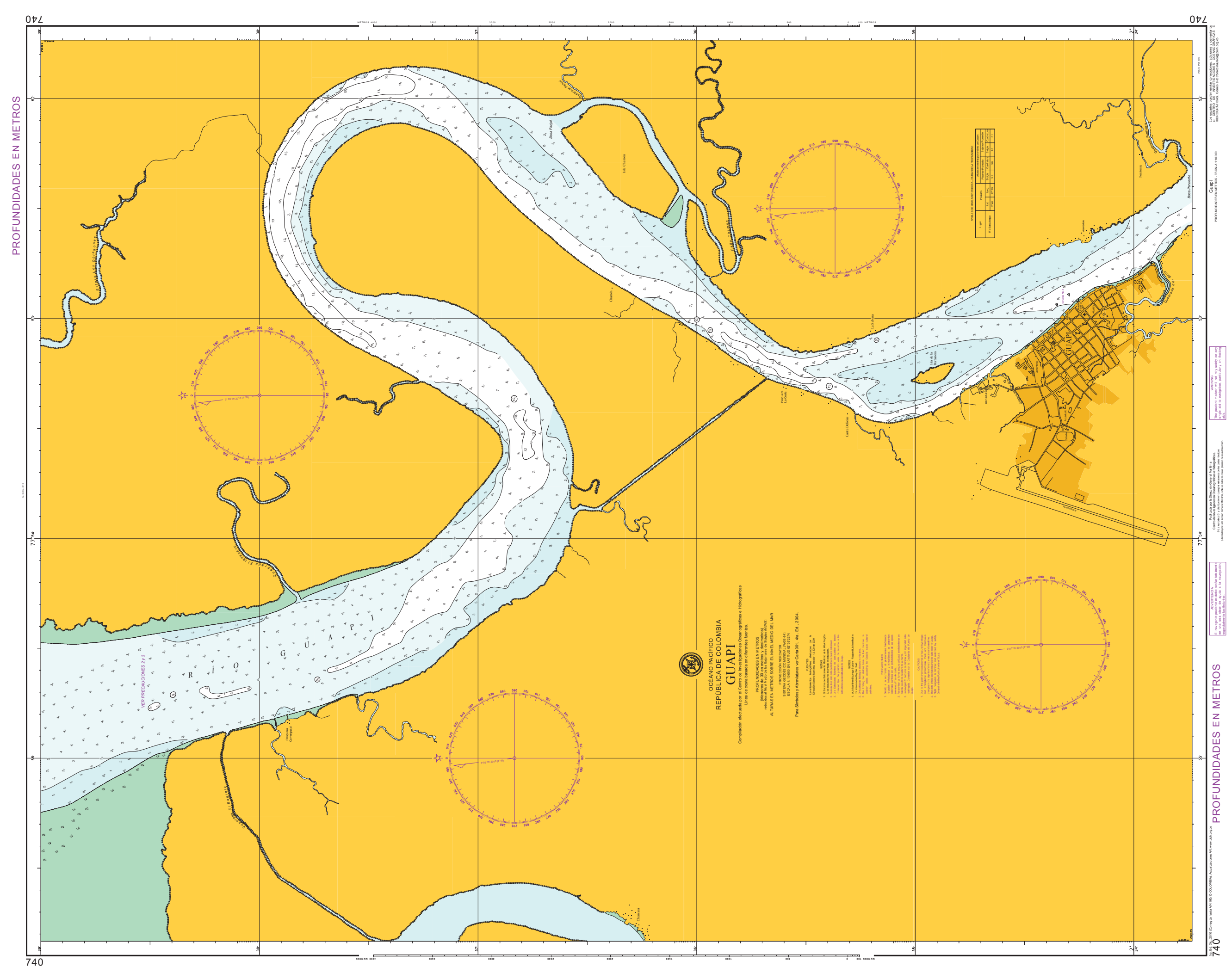

Dlmar (0)= 


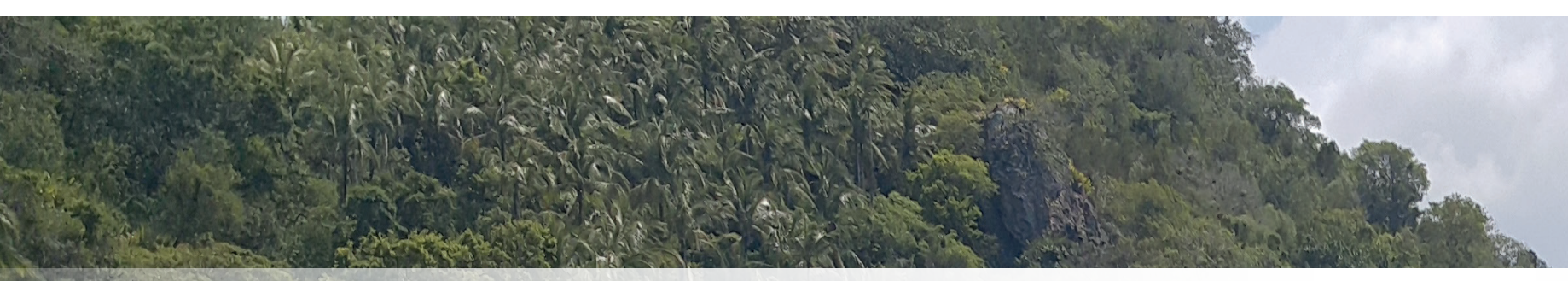

\section{CARTOgrafíA TEMÁTICA}

(3) Dimar (9) $=$

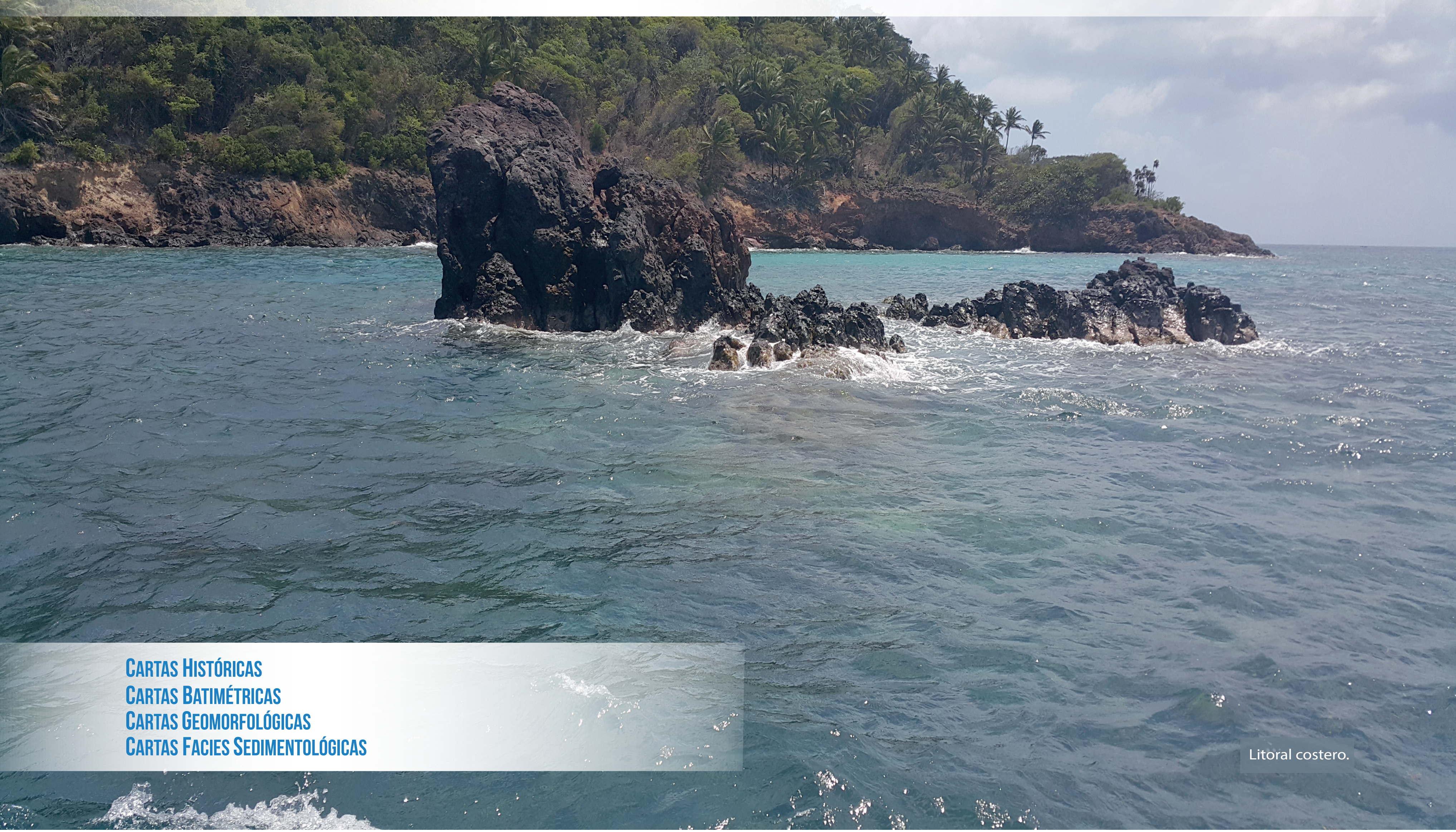




\section{Cartas históricas} Tabla L1. Carta histórica.

\begin{tabular}{c|cccc|c}
\hline No. Carta & Nombre & Edición & Año & Pág. \\
\hline 1010 & Carta Histórica Naval de la Bahía de Cartagena de Indias & 1 & 2000 & L002 \\
\hline
\end{tabular}

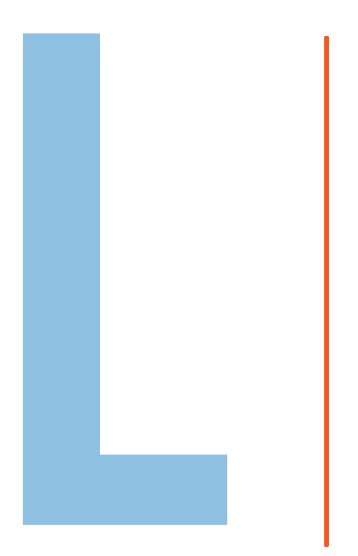




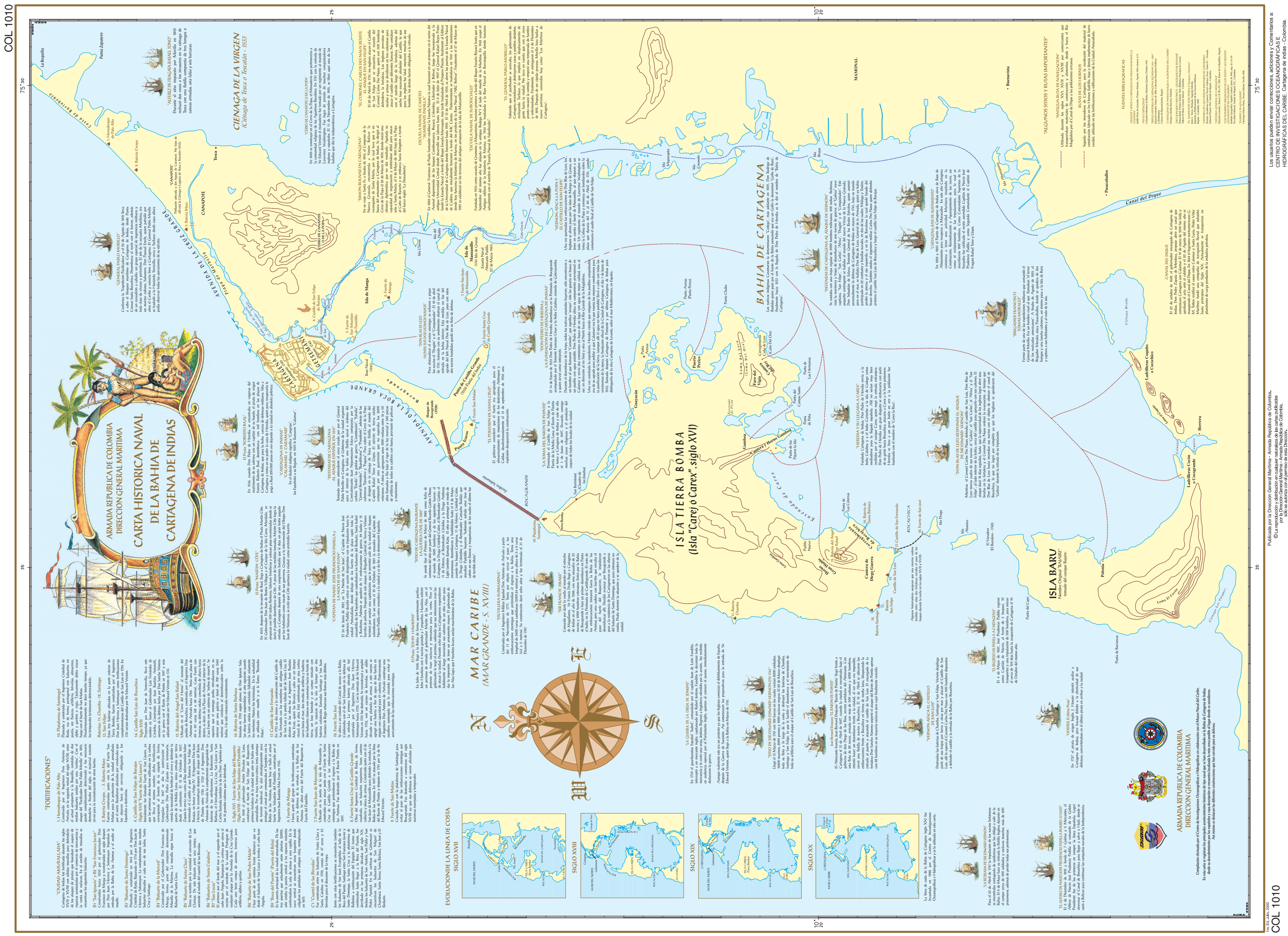

Dlmar (c) $=$ 
Cartas batimétricas (escalas 1:250.000 - 1:1.000.000) Tabla M1. Cartas batimétricas.

\begin{tabular}{|c|c|c|c|c|c|}
\hline No. Carta & Nombre & Escala & Edición & Año & Pág. \\
\hline 1601 & Caribe Suroccidental Sector Oeste & $1: 1.000 .000$ & 1 & 2000 & M002 \\
\hline 1621 & Barranquilla a Riohacha & $1: 250.000$ & 1 & 1998 & M003 \\
\hline 1622 & Abanico del Magdalena & $1: 250.000$ & 1 & 1999 & M004 \\
\hline 1623 & Talud Caribaná Sector Suroeste & $1: 250.000$ & 1 & 1999 & M005 \\
\hline 1624 & Islas de San Andrés y Providencia & $1: 200.000$ & 1 & 1998 & M006 \\
\hline 1625 & Bancos de Quitasueño y Serrana & $1: 250.000$ & 1 & 1999 & M007 \\
\hline 1626 & Banco Serranilla-Bajo Nuevo & $1: 250.000$ & 1 & 1999 & M008 \\
\hline 1649 & Punta Barú a Punta Canoas & $1: 250.000$ & 1 & 1998 & M009 \\
\hline 1701 & Océano Pacífico Colombiano & $1: 1.000 .000$ & 1 & 1999 & M010 \\
\hline
\end{tabular}

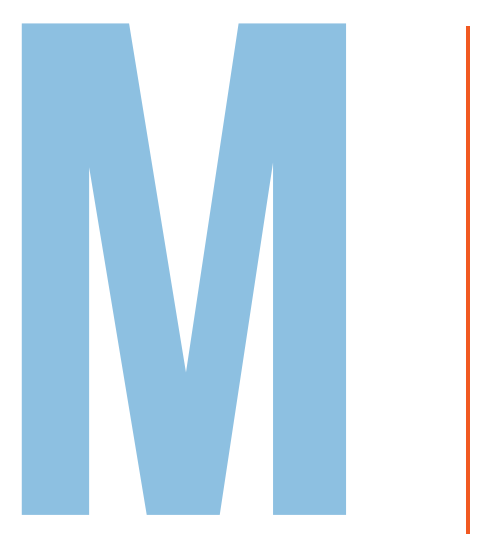




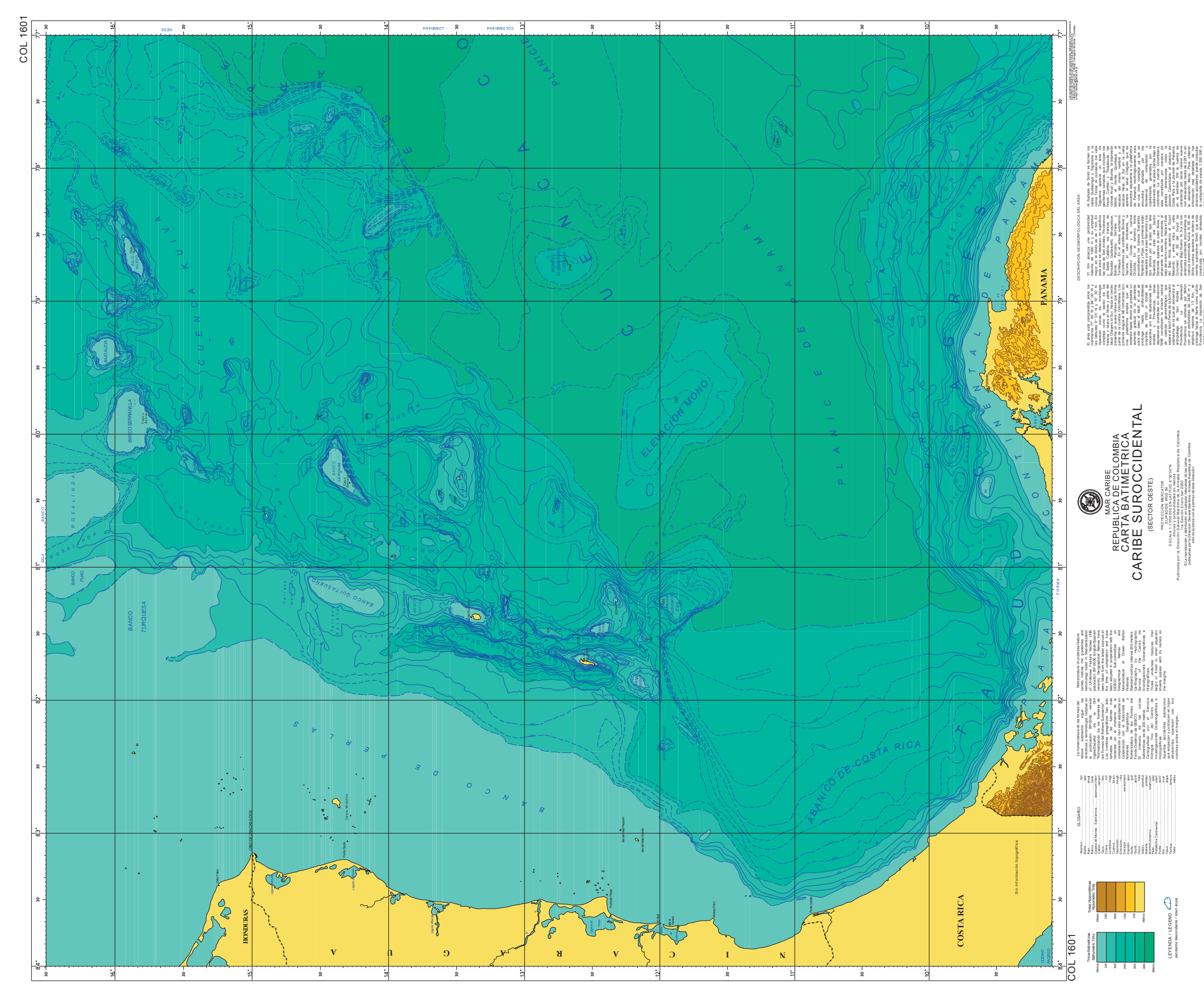




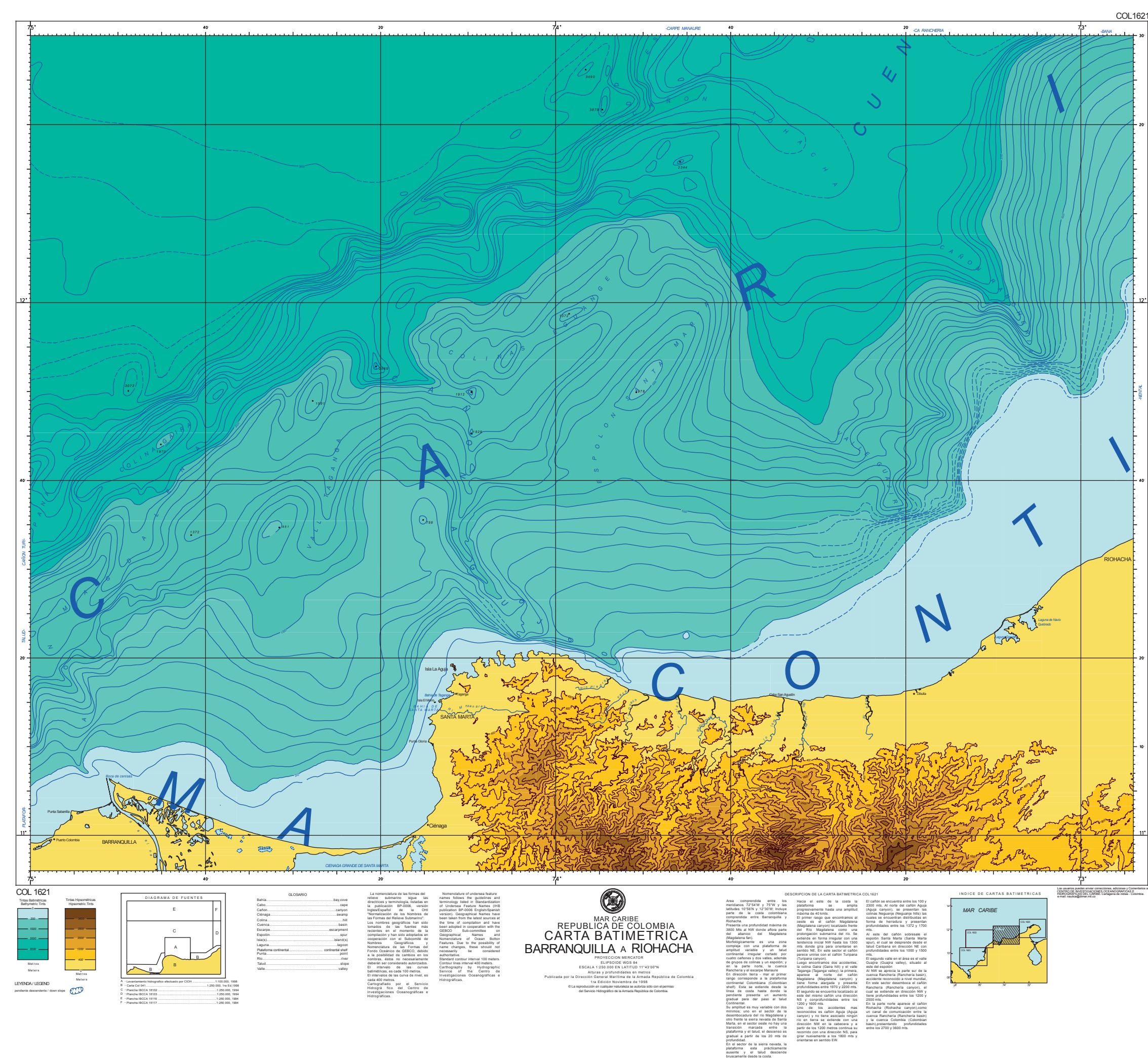




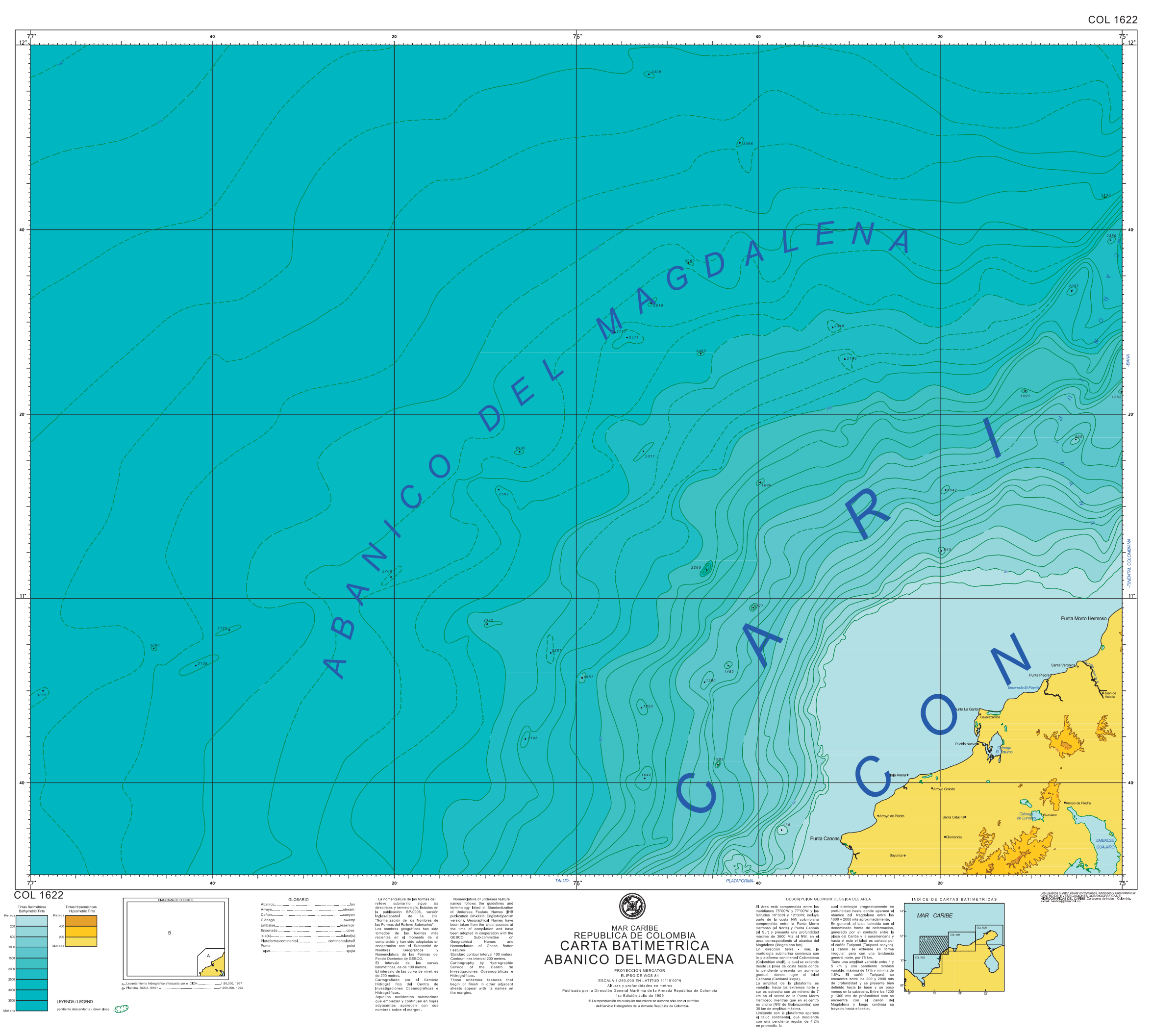




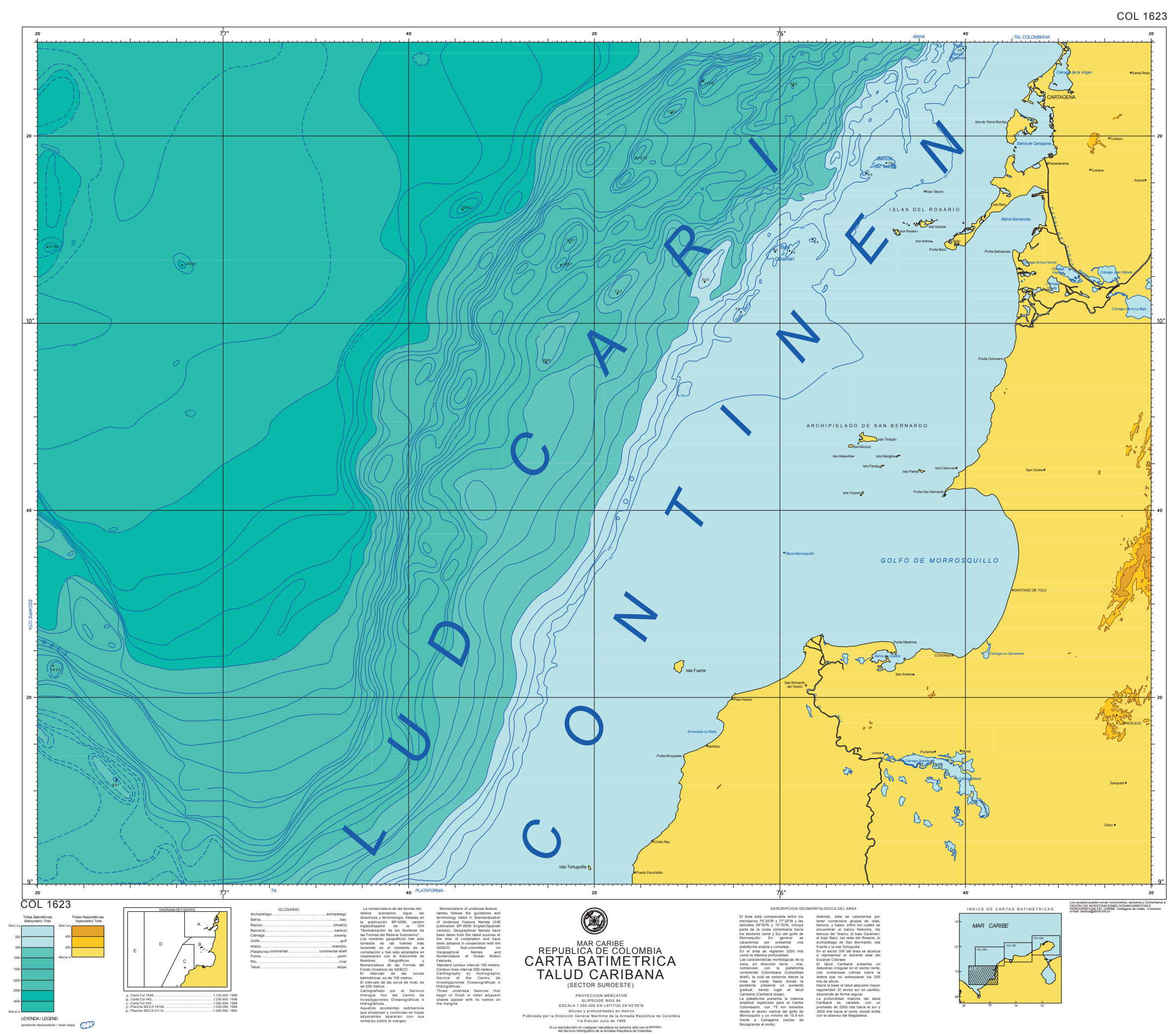



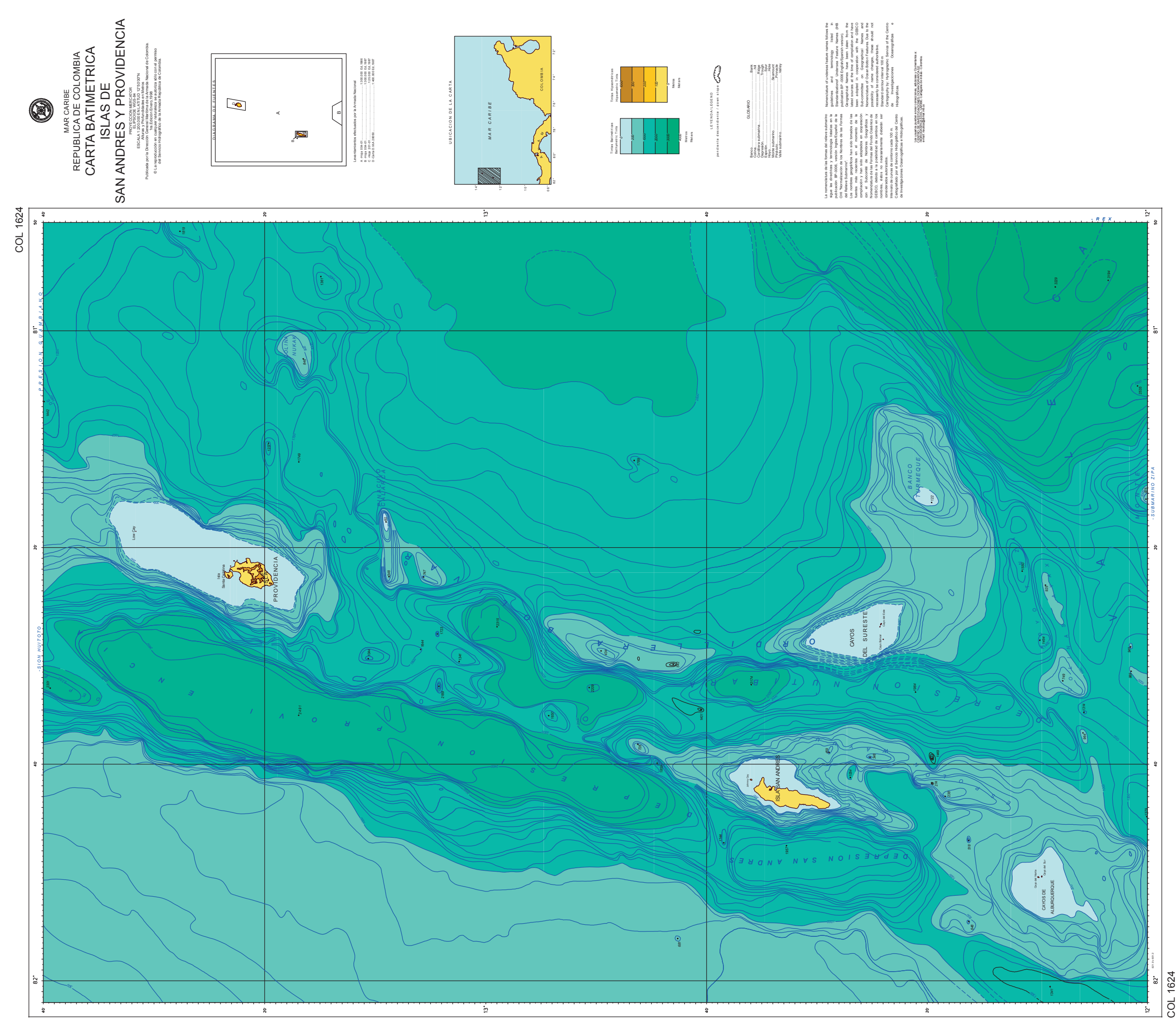


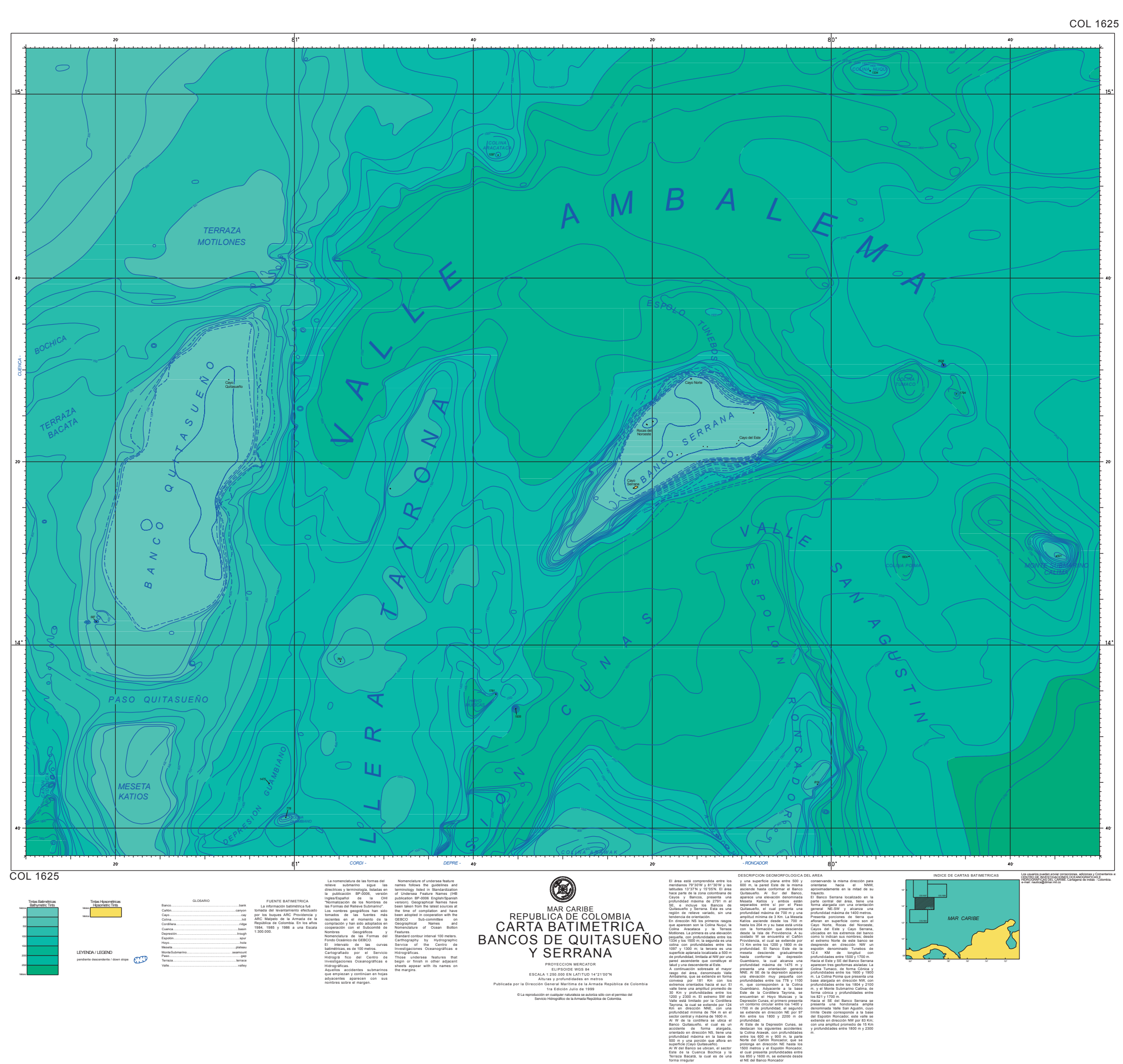




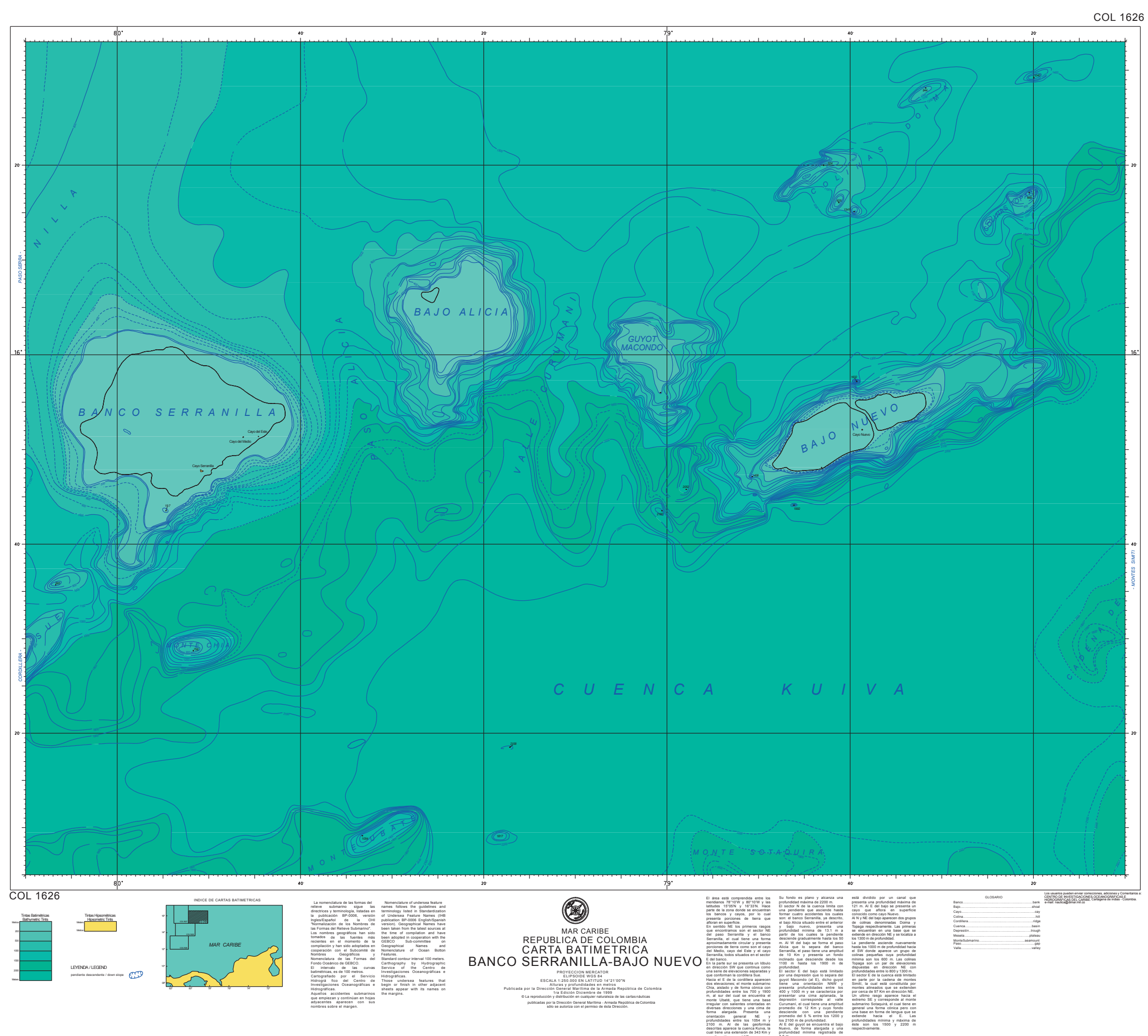




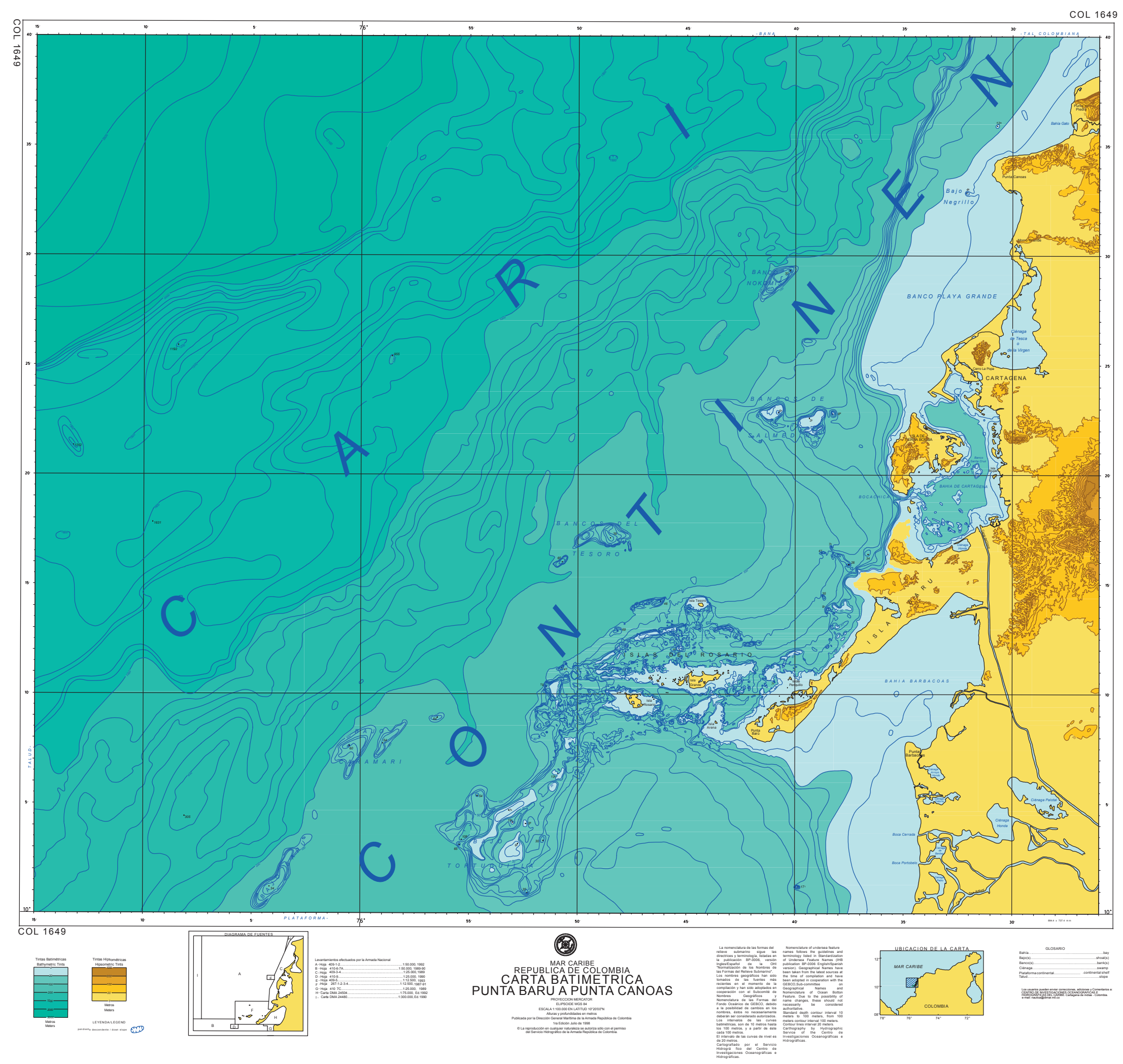




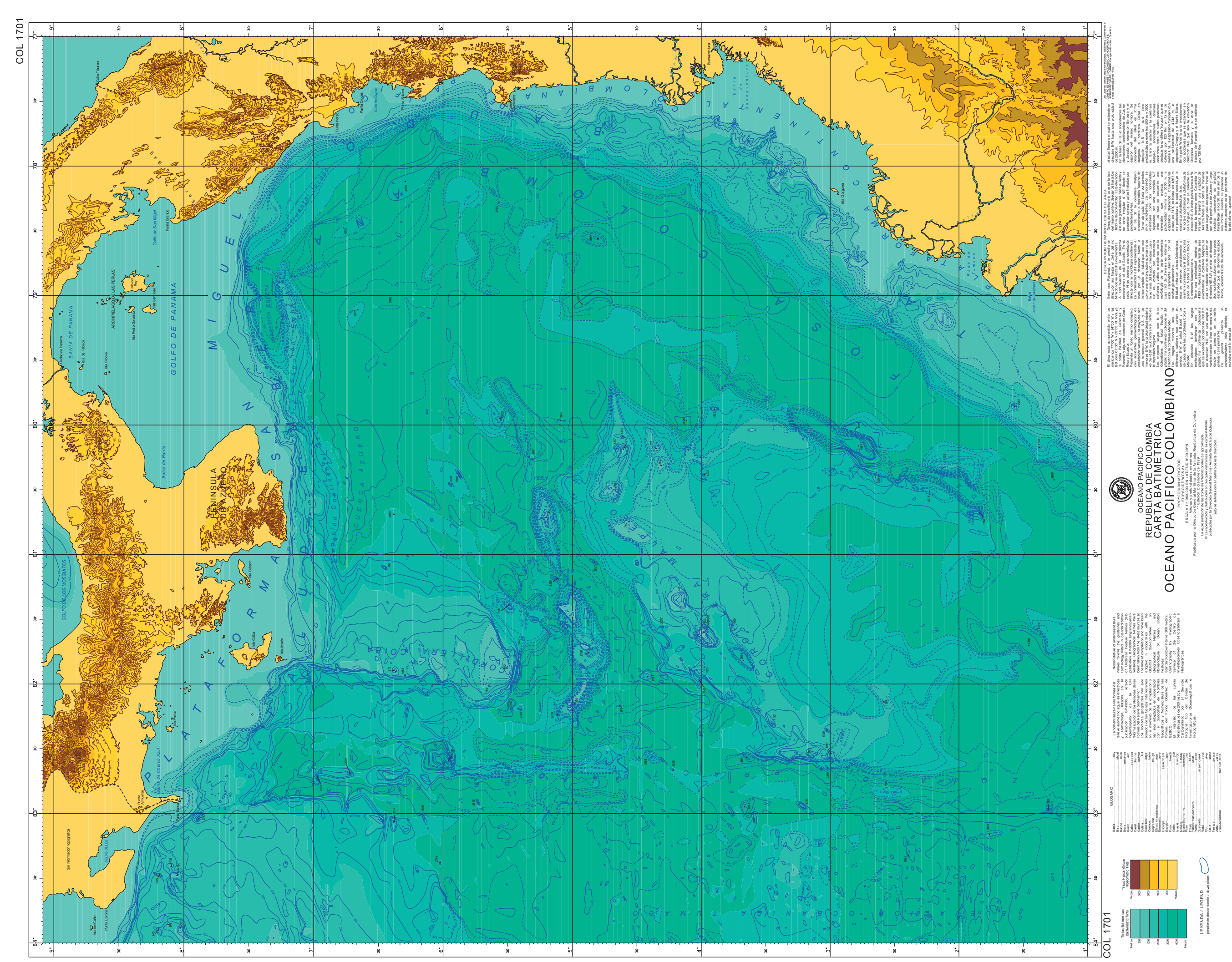


Cartas geomorfológicas (escalas 1:50.000)

Tabla N1. Cartas geomorfológicas.

\begin{tabular}{c|l|c|c|c|c|}
\hline No. Carta & \multicolumn{1}{c|}{ Nombre } & Escala & Edición & Año & Pág. \\
\hline 1416 & Barranquilla-Arroyo Juan de Acosta & $1: 50.000$ & 1 & 1997 & N002 \\
\hline 1417 & Cerro Furú-Galerazamba & $1: 50.000$ & 1 & 1997 & N003 \\
\hline
\end{tabular}

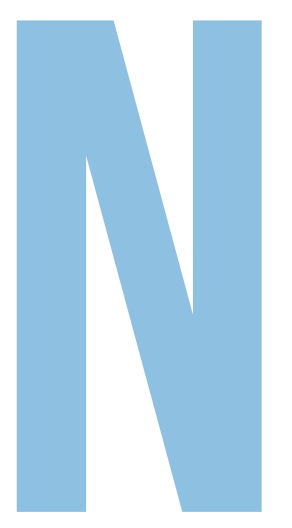




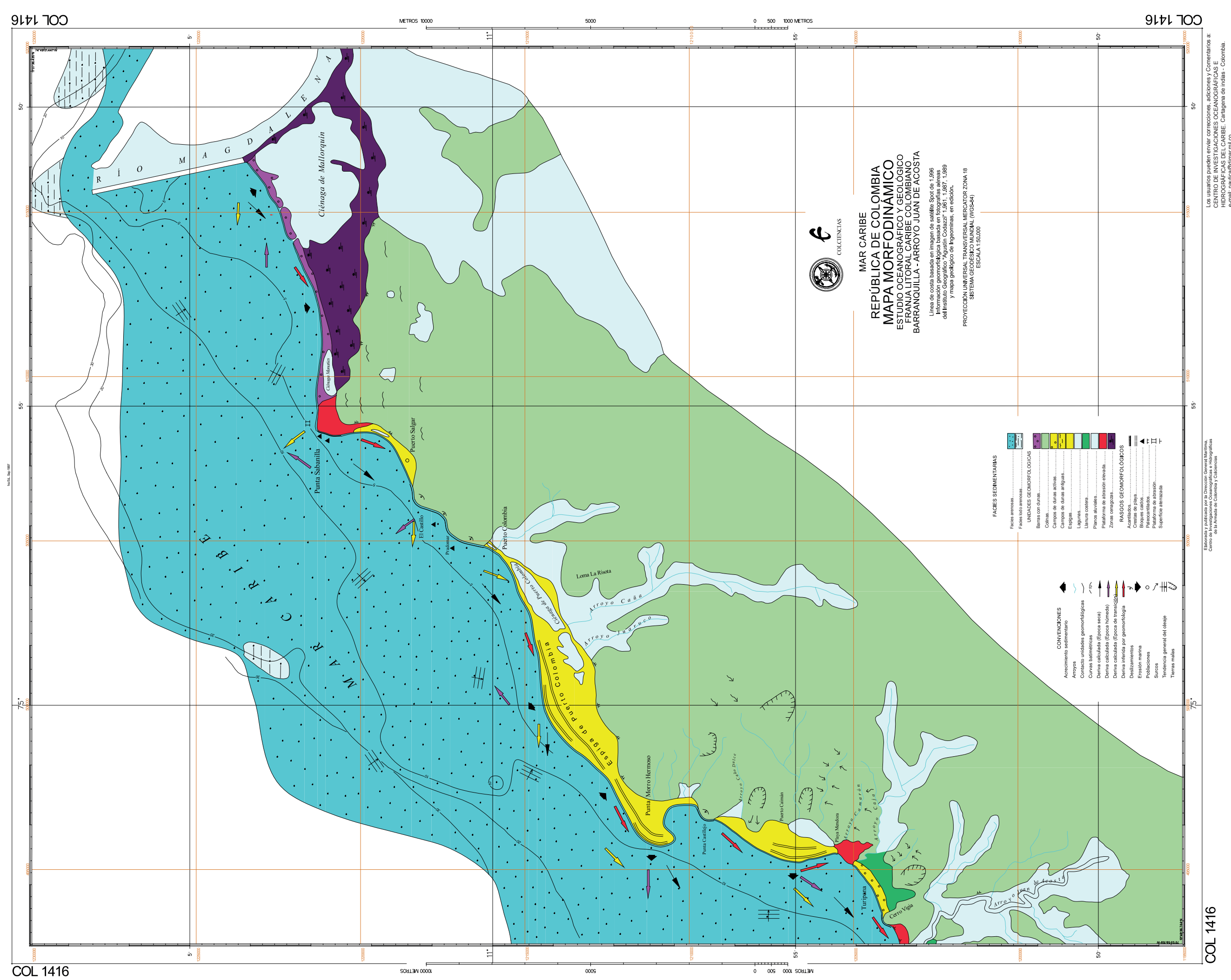




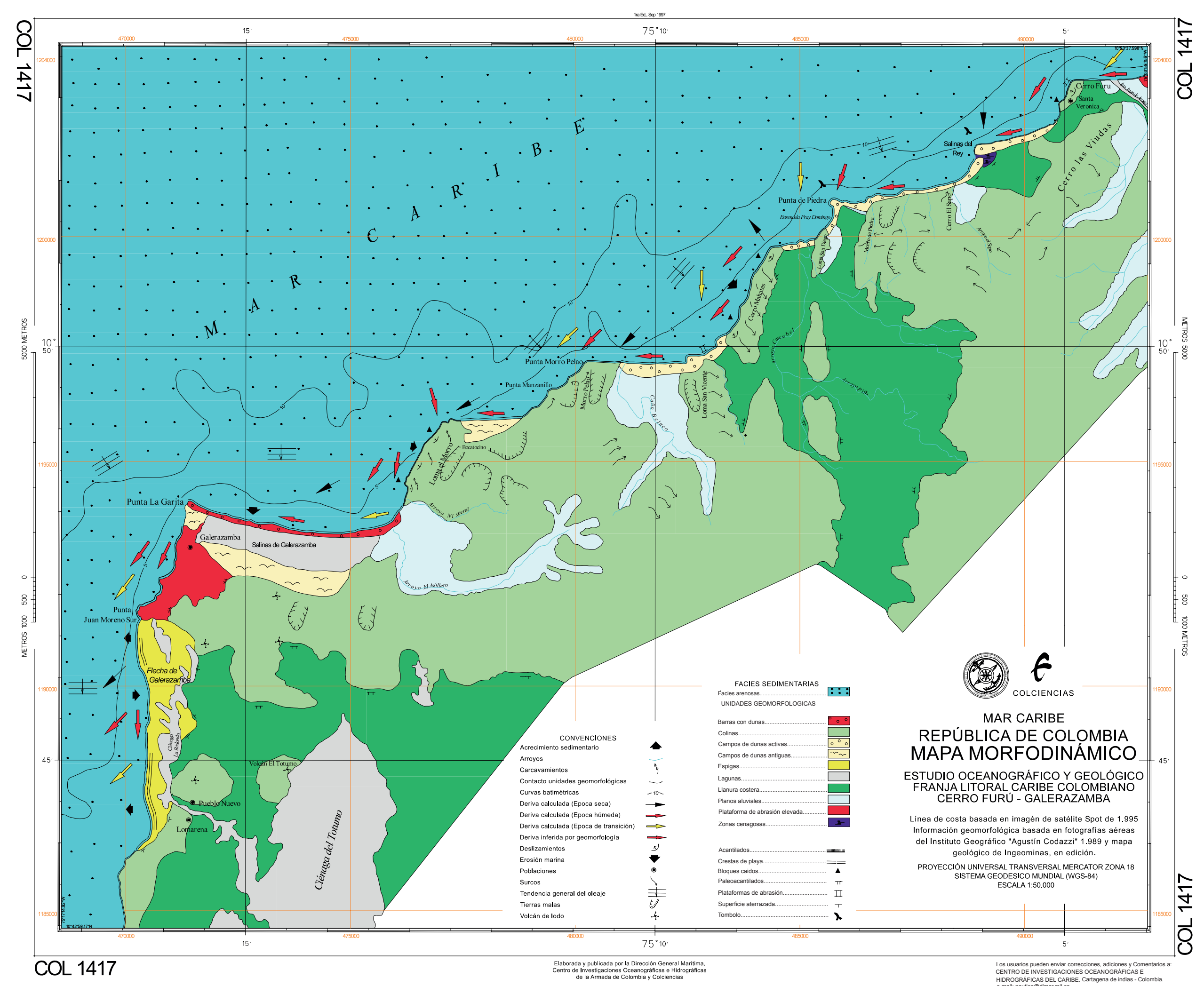

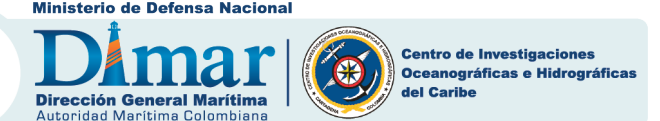


Cartas facies sedimentológicas (escalas 1:300.000)

Tabla 01. Cartas facies sedimentológicas.

\begin{tabular}{c|l|ccc|c|}
\hline No. Carta & \multicolumn{1}{c|}{ Nombre } & Escala & Edición & Año & Pág. \\
\hline 2634 & Dibulla-Castilletes & $1: 300.000$ & 1 & 1999 & 0002 \\
\hline 2728 & Cabo Corrientes a Boca de Cajambre & $1: 300.000$ & 1 & 1999 & 0003 \\
\hline
\end{tabular}


Cartas Temáticas/ Facies Sedimentológicas / CARTA

2634

DIBULLA - CASTILLETES

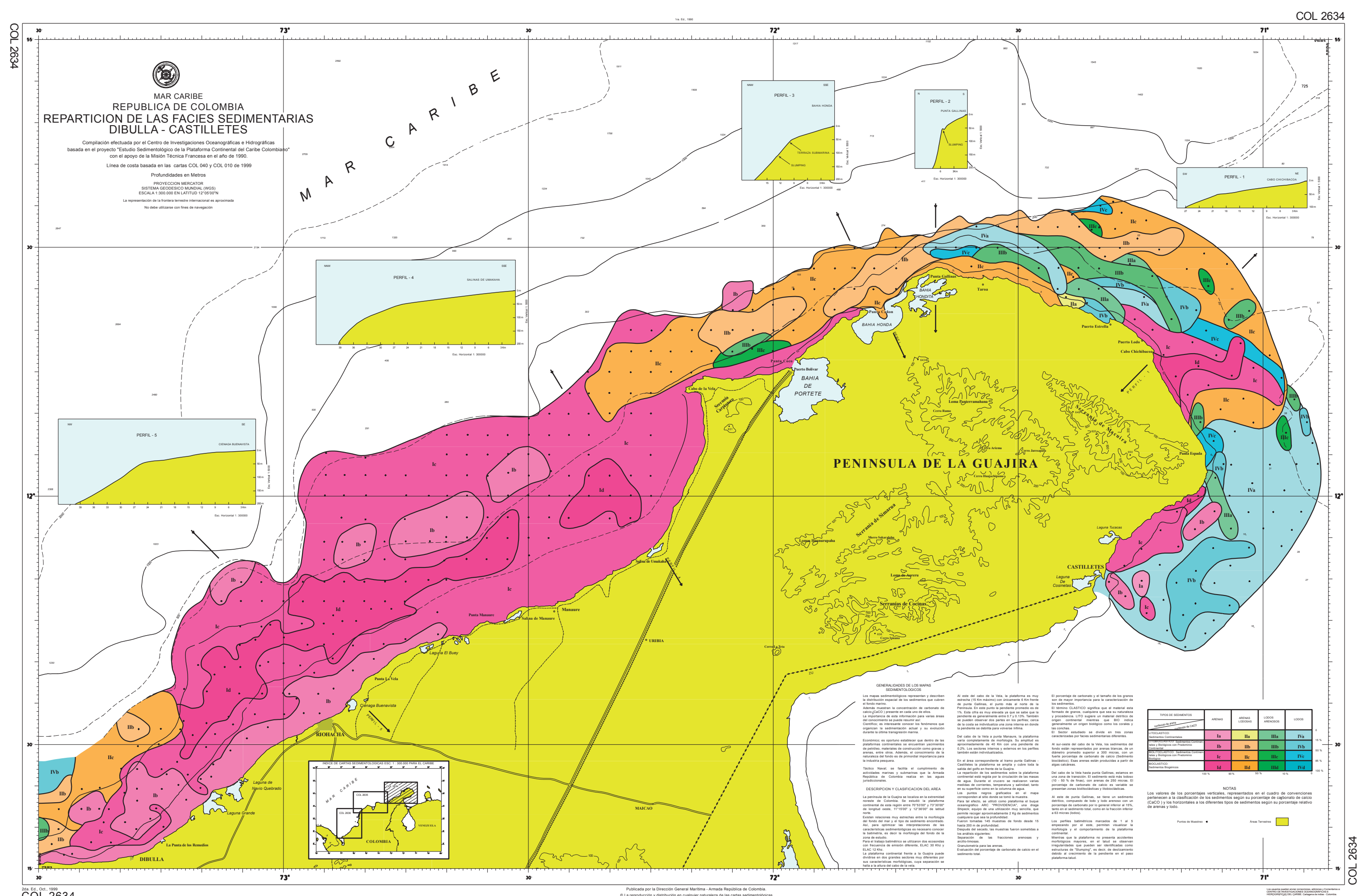

(3) Dimar (6) = 


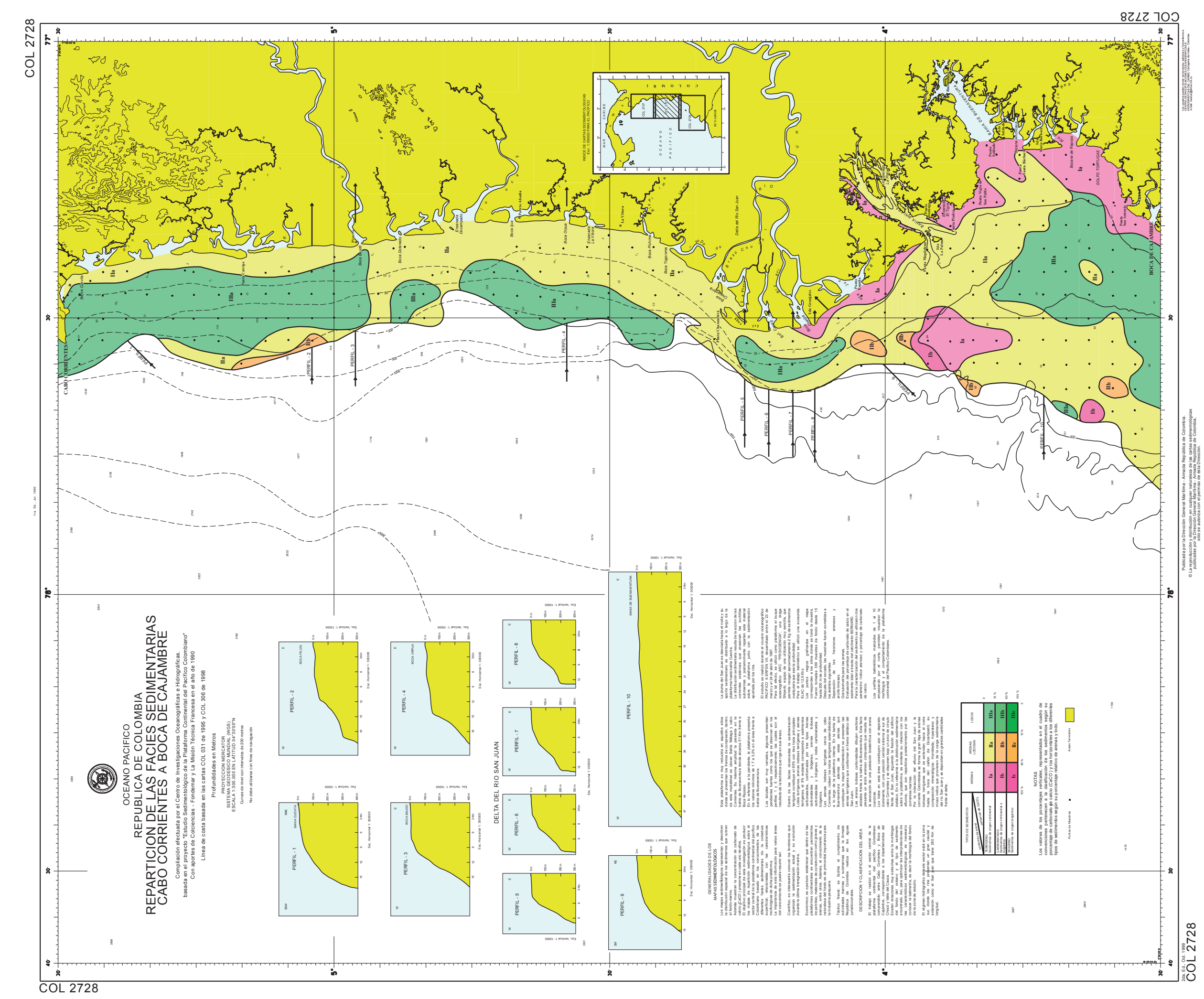




\section{REFERENCIAS BIBLIOGRÁFICAS}

Dimar-ClOH. (2010). Esquema Cartográfico Náutico Nacional.

Dimar-CIOH. (2012). Atlas Cartográfico de los Océanos y Costas de Colombia (4 ed.). Colombia.

OHI. (1996). Diccionario Hidrográfico S-32. Mónaco.

OHI. (2005). Manual de Hidrográfia C-13 (Correcciones a abril de 2010) (1 ed.). Mónaco.

OHI. (2016). Reglamento de la OHI para Cartas Internacionales y Especificaciones Cartográficas de OHI S-4 (4.6.0 ed.). Mónaco.

IMO. (1974). Convenio Internacional para la Seguridad de la Vida Humana en el Mar (SOLAS). Londres. 


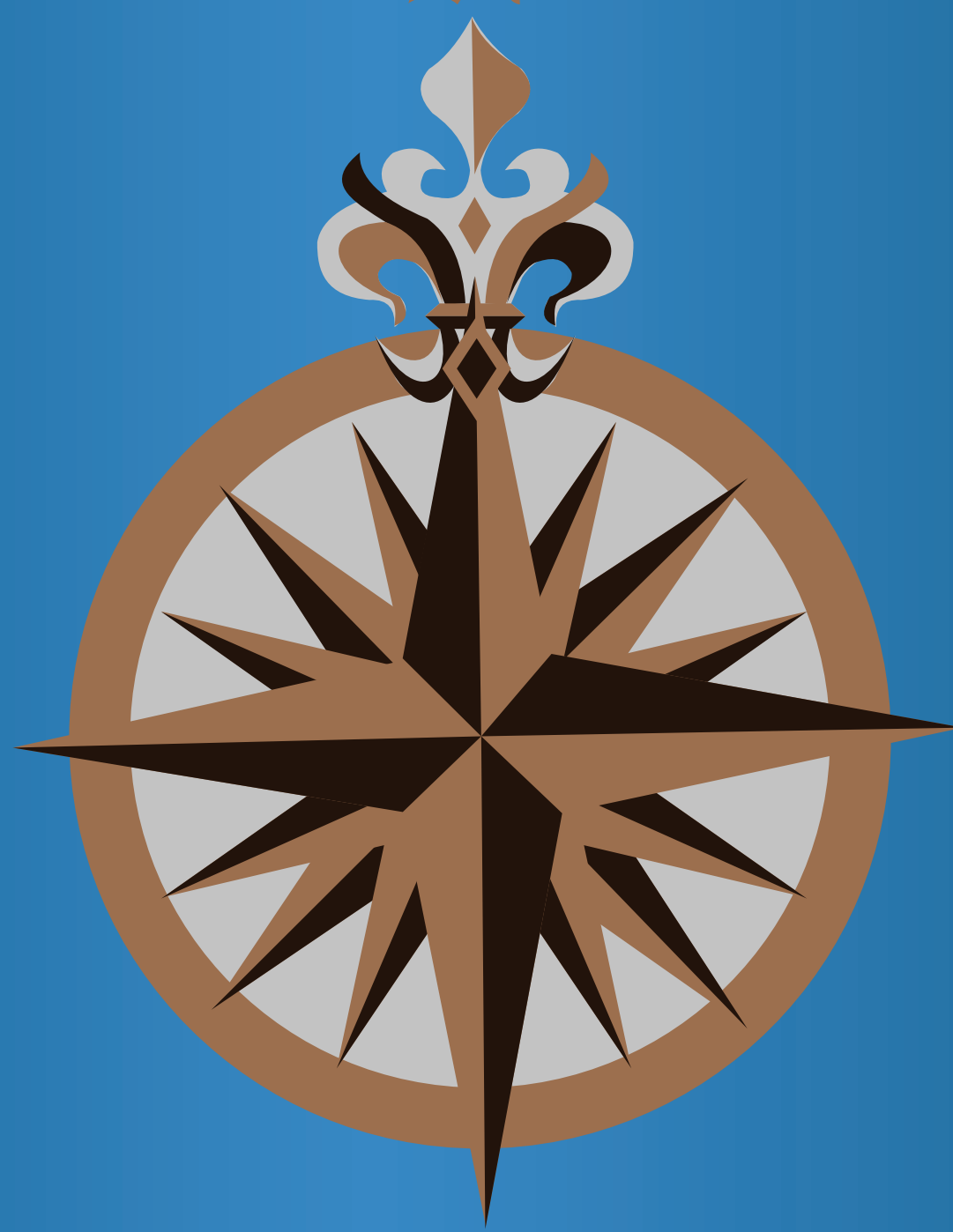

Ministerio de Defensa Nacional

Dirección General Marítima

Centro de Investigaciones Oceanográficas e Hidrográficas del Caribe-ClOH

El Bosque, Isla Manzanillo, Escuela Naval de Cadetes "Almirante Padilla"

Cartagena de Indias, D.T. y C.
Teléfono: +57 (5) 6694465

www.dimar.mil.co

www.cioh.org.co

f 90 (0) 